\title{
TOWARD THE SYNTHESIS OF (-)-TAN-2483B LACTAM ANALOGUES
}

by

\author{
Hedley Stirrat
}

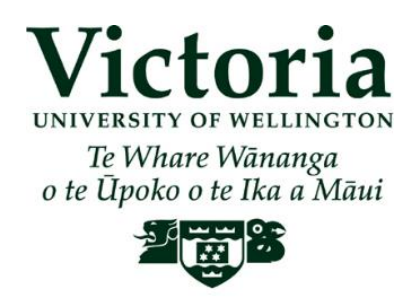

A thesis submitted to the Victoria University of Wellington in partial fulfilment of the requirements for the degree of Master of Drug Discovery and Development

School of Chemical and Physical Sciences

and the

Centre for Biodiscovery 


\begin{abstract}
Natural products continue to be an abundant source of lead compounds for drug discovery and development. (-)-TAN-2483A and (-)-TAN-2483B, isolated from the culture of a filamentous fungus, incorporate an unusual furo[3,4-b]pyran-5-one scaffold. TAN-2483A was initially reported to inhibit the $c$-Src tyrosine kinase enzyme, a potential anticancer target, and parathyroid hormone-induced bone resorption. TAN-2483B, on the other hand, was not isolated in sufficient quantities for biological testing. The synthesis of TAN-2483B is therefore desirable from a drug discovery perspective. Several analogues of TAN-2483B that are functionalised at the propenyl sidechain have previously been synthesised in the Harvey group and have shown promising biological activity. For example, the ( $Z$ )-ethyl ester analogue showed micromolar inhibition of HL-60 cells and Bruton's tyrosine kinase, a protein involved in B-cell maturation that is implicated in certain cancers. The lactone moiety of TAN-2483B and its sidechain analogues, however, appears to be unstable to nucleophilic attack.

The aim of this thesis was to investigate the viability of a synthetic route toward lactam analogues of TAN-2483B. It was proposed that substituting the lactone for a lactam would increase the stability of the compound in nucleophilic media. Moreover, the lactam nitrogen may provide a site for further functionalisation of the compound for future structure-activity relationship studies. Because installation of the $(Z)$-ethyl ester sidechain via Wittig conditions has previously been found to be more facile than installation of the $(E)$-propenyl sidechain found in the natural product, investigations into forming the lactam ring system were carried out on the ethyl ester advanced intermediates. Reductive amination of a ketone intermediate was envisaged to install the amine prior to a palladium-catalysed carbonylation/lactam formation step. The promising bioactivity of the (Z)-ethyl ester analogue was anticipated to be retained in the target lactam analogues.

It was found that the substrates of the proposed reductive amination, the advanced ketone intermediates, were incompatible with the tested conditions, presumably due to base sensitivity. Three by-products from the reductive amination experiments were isolated and tentatively characterised by NMR spectroscopy and HRMS. An alternative route toward lactam analogues of TAN-2483B, via intermediate amines accessed by the substitution of an activated alcohol, was briefly investigated with encouraging results.
\end{abstract}


Further optimisation of the synthetic route toward analogues of TAN-2483B was also achieved. Removal of a purification step enabled the more expedient two-step synthesis of a diol intermediate. The two-step transformation to $(Z)$ - and (E)-ethyl ester intermediates, via sodium periodate-mediated diol cleavage and Wittig olefination, proceeded in the highest yield obtained to date. Investigations into the desilylation of a trimethylsilyl-protected acetylene were also conducted.

Although lactam analogues of TAN-2483B were not obtained in this study, progress was made toward their synthesis. The alternative route toward amines that was briefly explored here appears promising, and work is ongoing in the Harvey group to access lactam (and other) analogues of TAN-2483B, in addition to the natural product itself.<smiles>C/C=C/C1O[C@@H]2C(=C[C@H]1O)C(=O)O[C@H]2C</smiles>

(-)-TAN-2483A<smiles>C/C=C/C1O[C@H]2C(=C[C@H]1O)C(=O)O[C@H]2C</smiles>

$(-)-T A N-2483 B$

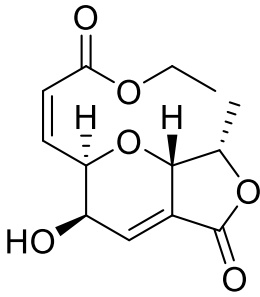

(Z)-ethyl ester analogue<smiles>[R]N1C(=O)C2=C[C@@H](O)[C@@H]3/C=C\C(=O)OC[C@@H]2[C@@H]1O3</smiles>

$\mathrm{R}=\mathrm{H}, \mathrm{Bn},{ }^{n} \mathrm{Pr}$

Lactam and sidechain analogues 


\section{Acknowledgements}

As the second year of my undergraduate degree was drawing to a close, I began emailing my lecturers in the hope of getting some summer work. Joanne Harvey was the only one to reply, and in no time I was set up in the big East End fumehood bumbling my way through a project. I firmly believe that my attraction to organic chemistry (and indeed science itself) would not now exist if it wasn't for the excitement, rigour, and - above all else - enthusiasm that Joanne brings to her work and to her students. Absolutely all of us in the organic synthesis group at VUW are incredibly lucky to have been supervised by you. Thank you.

I would like to thank Paul Teesdale-Spittle for all of his helpful comments. Obviously a huge thanks to the TAN crew: Kalpani, Russell, Jasmin, Jose-Luis, Dan, Chris, Amira, and now Jordan. It's not exactly a trivial synthesis, and any progress I made was predicated on all of your work. Also, thank you Grace for your furopyran report.

Everyone working in the organic synthesis group! My first mentor there was Matt Fisk - for some reason I vividly recall one of the earliest syntheses we did, when our workup resolved into a triphasic solution that just blew our minds. Thank you to everyone who was there when I first started: Kalpani, Jingjing, Hemi, Loic, Sarah B., Thomas, Helena - who were all very kind and welcoming. Thanks to Amira, Sophie, Claire, Ethan and Tao, who have all helped me enormously. Sorry for putting those lids on too tightly. Thank you Jamie and Ash for the laughs. Shout out to the TLC crew: Ethan, Dan, Sarah A., Aleksa. Thanks Jan for your tireless work on the NMR machines. Thanks to the people who proofread parts of my thesis: Sarah, Jordan, Mum, and of course Joanne. To Jordan: it's all you now. I'm looking forward to that paper...

In the first CHEM113 lecture, Suzanne Boniface said that several of us biology students who were only doing this paper out of necessity would end up switching over to a chemistry major. I remember us laughing at that, but she was right. Thank you Suzanne for showing me what chemistry actually is.

Thank you to Mrs. Randal, who was the Deputy Principal of Rongotai College when I was around. You were an inspiration because you showed us that being kind, intelligent and thoughtful was actually cool... Thanks Freya, Rewi and Tui. Special thanks to Gaby: your support over these last few months was so important to me. And finally, thanks Mum and Dad. Hedley, February 2017. 


\section{Declaration and Copyright}

The copyright of this thesis resides with the author. No quotation from it should be published without prior consent and information derived from it should be acknowledged.

The work in this thesis was completed by the author at Victoria University of Wellington, New

Zealand. It has not been submitted, in part or in whole, for any higher degree at this or any other university. 


\section{Table of Contents}

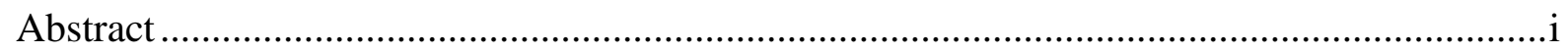

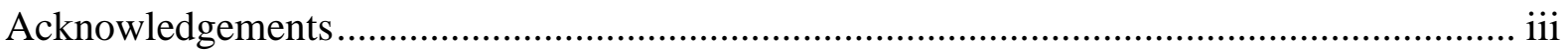

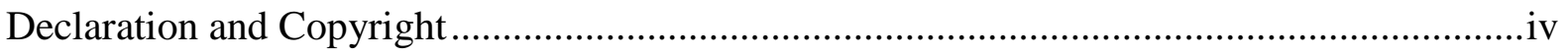

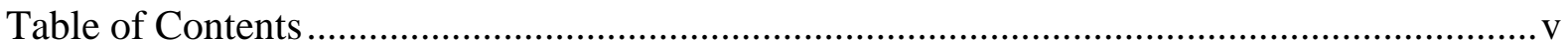

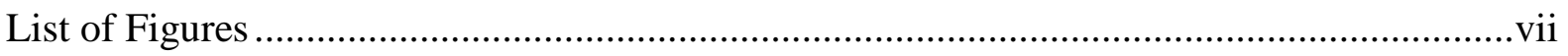

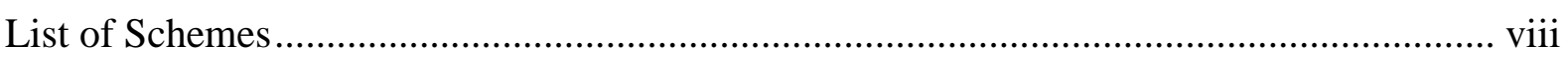

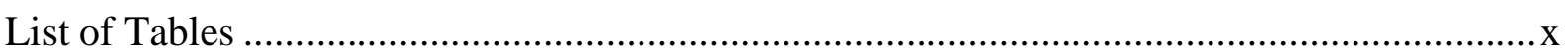

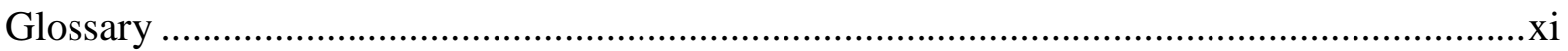

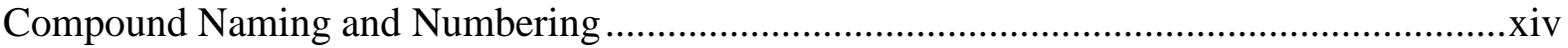

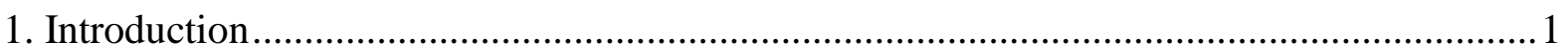

1.1 Natural products incorporating a furo[3,4-b]pyran-5-one scaffold................................ 3

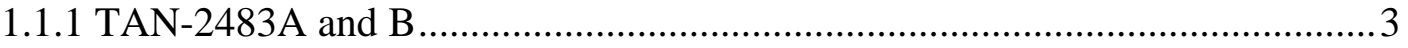

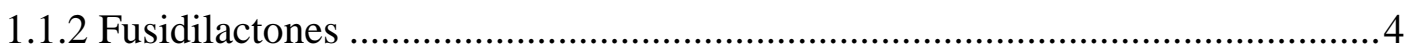

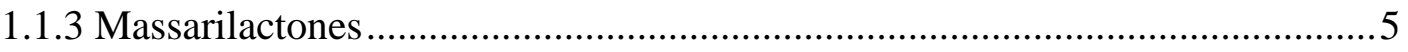

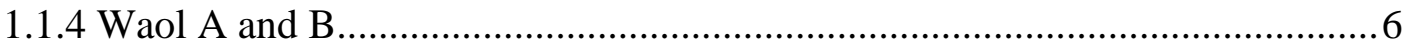

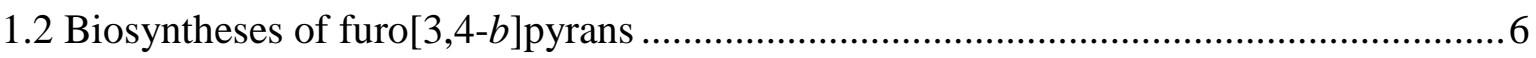

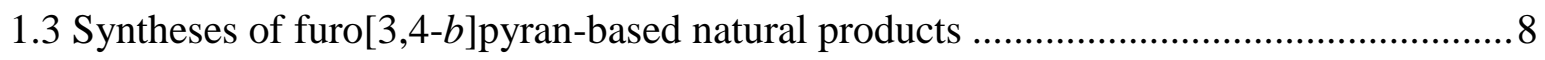

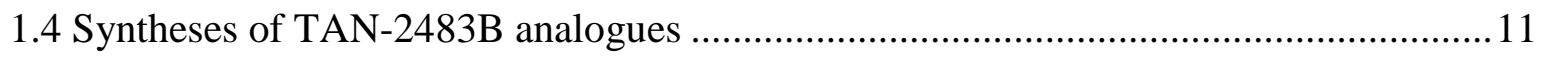

1.4.1 First synthesis of the TAN-2483B ring system........................................... 12

1.4.2 Synthesis of TAN-2483B sidechain analogues.......................................... 14

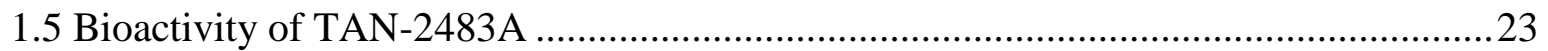

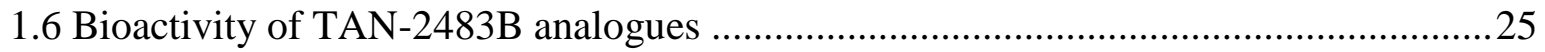

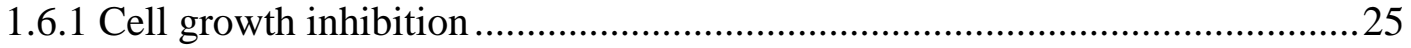

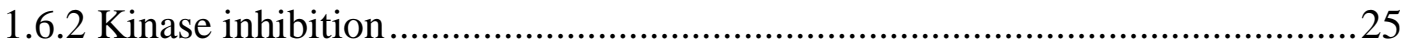

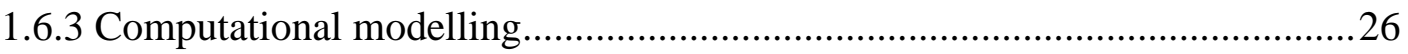

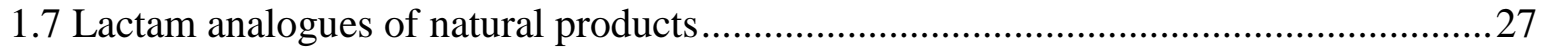


1.9 Proposed synthetic route to TAN-2483B lactam analogues .......................................29

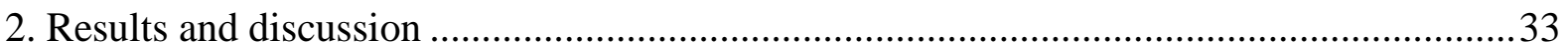

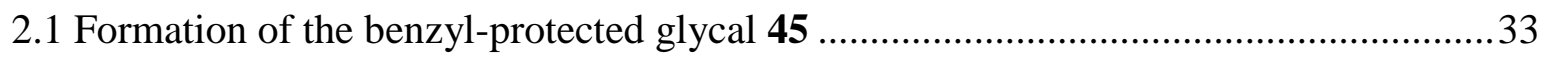

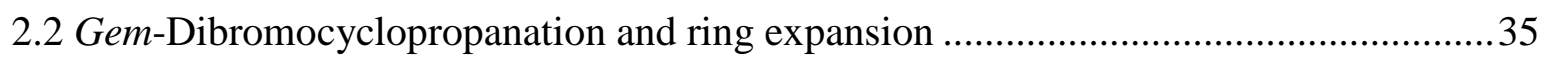

$2.3 C$-Glycosidation via installation of the TMS-protected acetylene ............................... 36

2.4 Desilylation of the TMS-protected acetylene diol 63 .............................................41

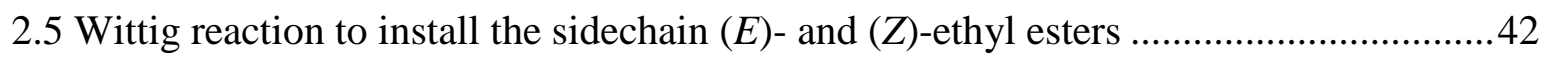

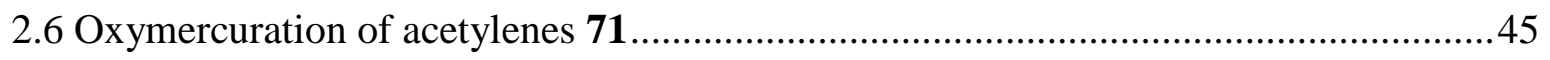

2.7 Reductive amination of the advanced ketone intermediate ...........................................45

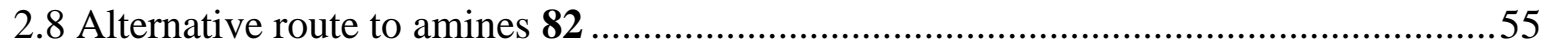

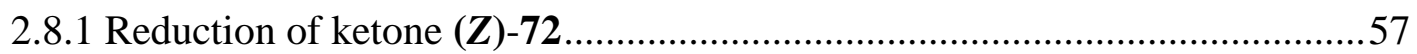

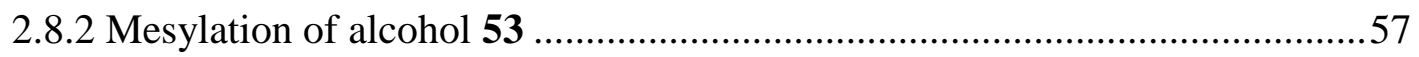

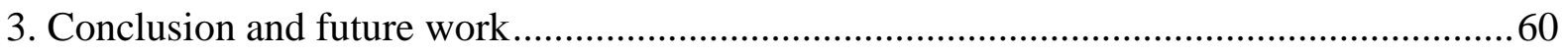

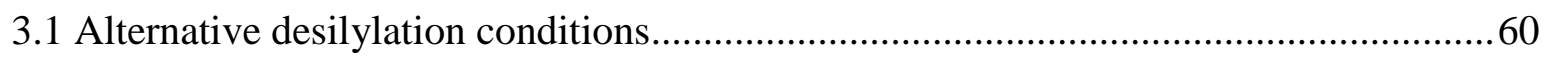

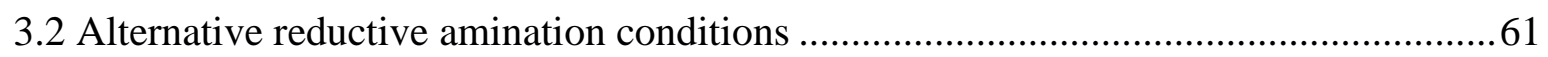

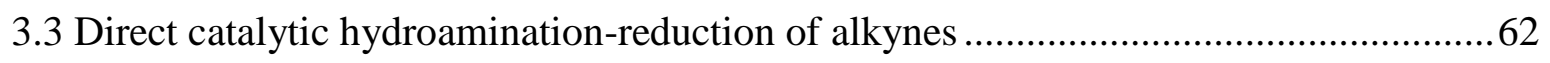

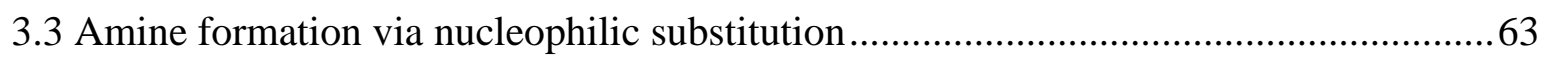

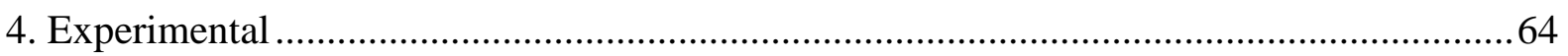

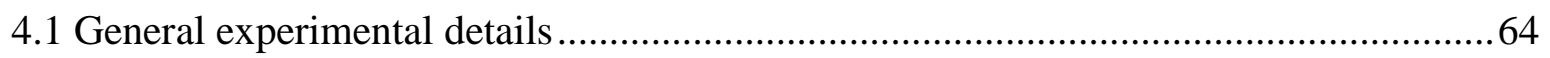

4.2 Description of the experiments and analytical characterisation data ...........................65

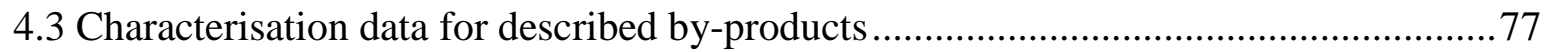

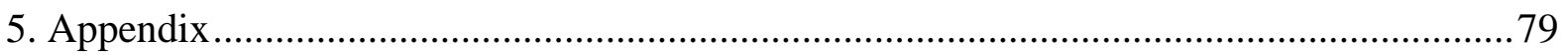

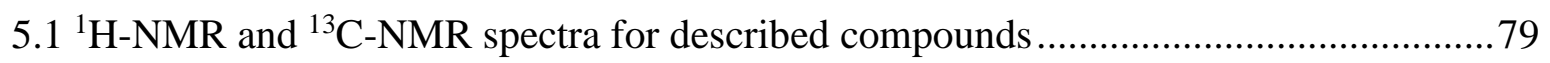

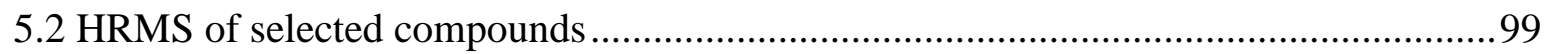

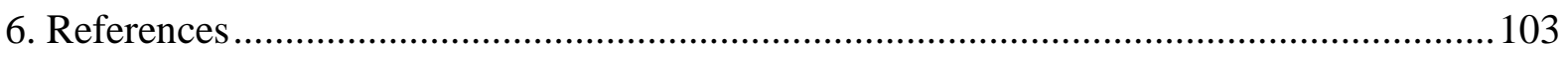




\section{List of Figures}

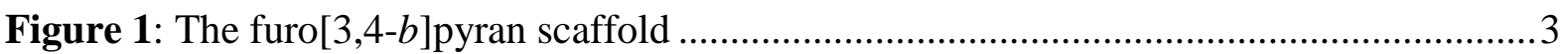

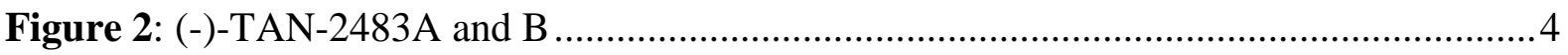

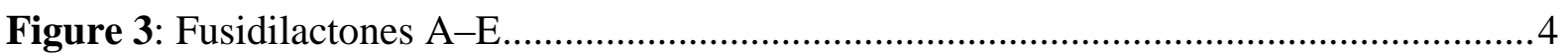

Figure 4: Massarilactones A-H and massarilactone acetonide ............................................5

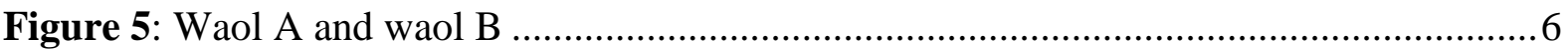

Figure 6: The proposed biogenetic resemblance between massarilactones A, B and D..........8

Figure 7: Natural products bearing biogenetic resemblance to the furopyran core of the

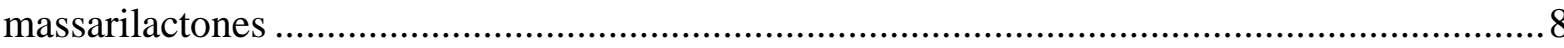

Figure 8: Newman projections of the transitions state in the a) normal Felkin-Ahn model, and

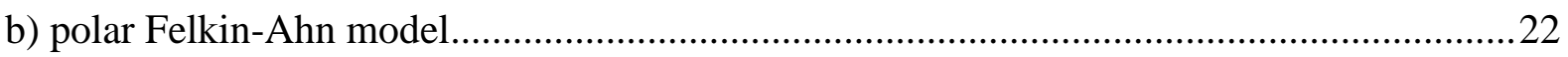

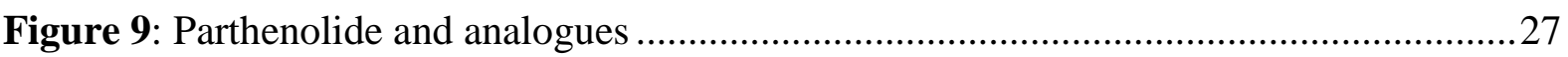

Figure 10: Epothilone natural product and lactam analogue ............................................28

Figure 11: TAN-2483B (left); lactam analogues of TAN-2483B (centre); the proposed targets, the $(E / Z)$-ethyl ester lactam analogues of TAN-2483B (right) ...........................................29

Figure 12: Acetal by-product 88 observed by Somarathne..................................................... 36

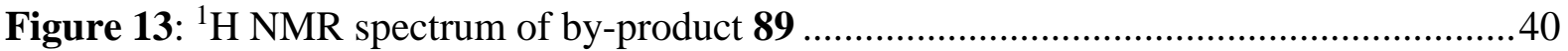

Figure 14: By-products isolated from reductive amination experiments on $(\boldsymbol{Z})$ - and $(\boldsymbol{E})$-72.47

Figure 15: ${ }^{1} \mathrm{H}$ NMR spectra of ketone (E)-72 (top), and by-product (E)-91 (bottom)..........48

Figure 16: ${ }^{1} \mathrm{H}$ NMR spectra of ketone (Z)-72 (top), and by-product ( $\boldsymbol{Z}$ )-91 (bottom) ...........50

Figure 17: ${ }^{1} \mathrm{H}-\mathrm{NMR}$ spectra of by-product 92 (top), and ketone (E)-72 (bottom) ..................51

Figure 18: ${ }^{1} \mathrm{H}-\mathrm{NMR}$ spectra of alcohol 53 (top), and mesylate 94 (bottom) ..........................59

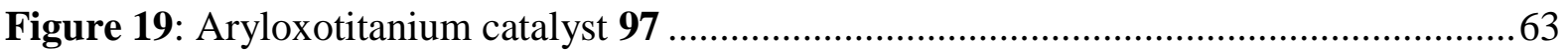




\section{List of Schemes}

Scheme 1: Proposed condensation biosynthesis of TAN-2483A and B ............................... 7

Scheme 2: Snider's retrosynthesis of TAN-2483A and Waol A........................................... 8

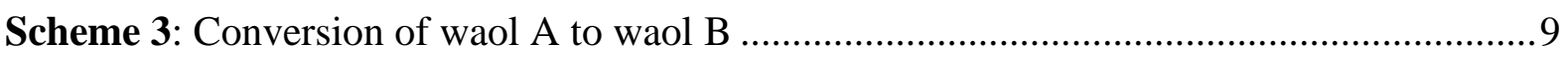

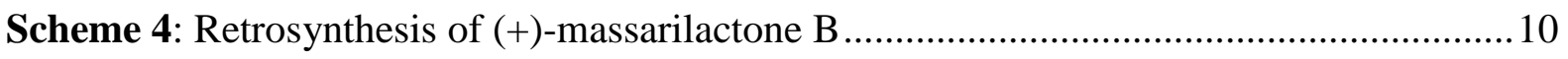

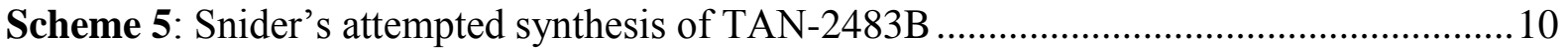

Scheme 6: Final proposed synthetic route to TAN-2483B …................................................. 11

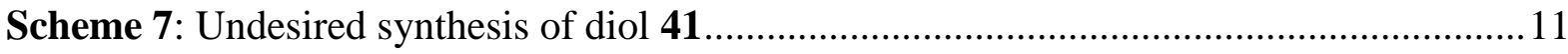

Scheme 8: Cyclopropanation and ring expansion retrosynthesis of TAN-2483B ................. 12

Scheme 9: Gem-Dichlorocyclopropanation and ring expansion ........................................ 13

Scheme 10: Pd-catalysed carbonylation and lactone formation ......................................... 13

Scheme 11: Mechanism of the Pd-catalysed carbonylation .............................................. 14

Scheme 12: Retrosynthetic analysis of TAN-2483B sidechain analogues ............................ 15

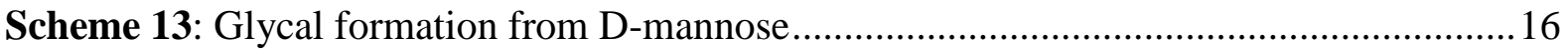

Scheme 14: Formation of methyl glycoside 59 via gem-dihalocyclopropanation and ring expansion

Scheme 15: Formation of acetate 56 via gem-dihalocyclopropanation and ring expansion ... 16

Scheme 16: Modified dibromocyclopropanation and ring expansion.................................. 17

Scheme 17: Stereoselective alkynylation and acetonide deprotection ................................ 18

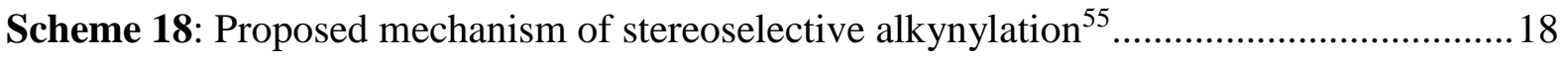

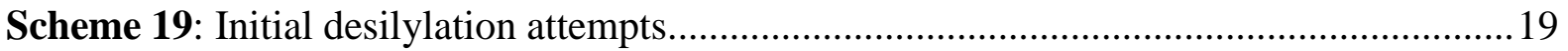

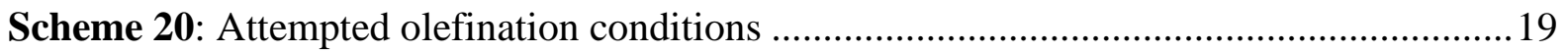

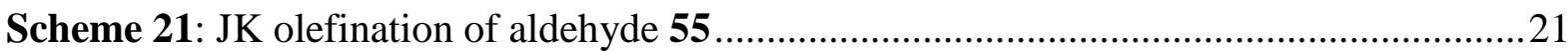

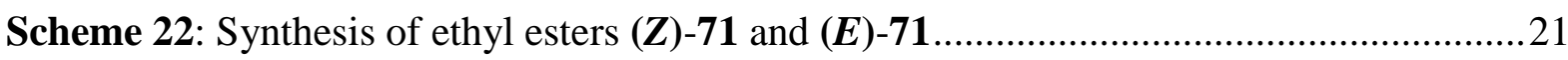

Scheme 23: Final synthetic steps to sidechain analogues of TAN-2483B ............................22

Scheme 24: Polar Felkin-Ahn model for the reduction of ketones 72 .................................23

Scheme 25: Proposed retrosynthesis of lactam analogues of TAN-2483B .........................29

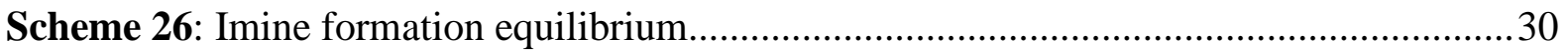

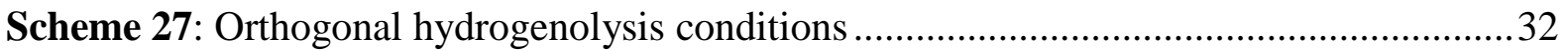

Scheme 28: Final synthetic steps to TAN-2483B ethyl ester lactam analogues ......................32

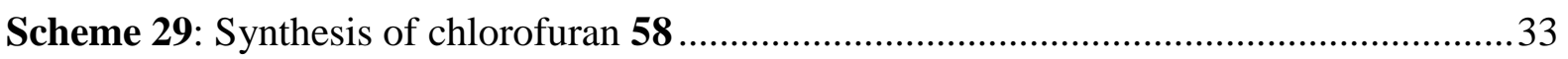

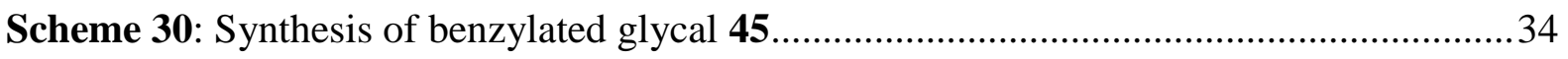


Scheme 31: Proposed mechanism of acid-promoted degradation of glycal 45. .35

Scheme 32: Gem-Dibromocyclopropanation and ring expansion .........................................36

Scheme 33: Deprotection of acetonide 64 using 20 equivalents of TFA ...............................37

Scheme 34: Two-step transformation to the TMS-protected acetylene diol 63 .....................41

Scheme 35: Desilylation of TMS-protected acetylene diol 63 .......................................... 41

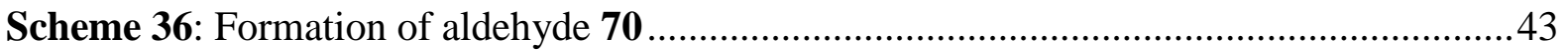

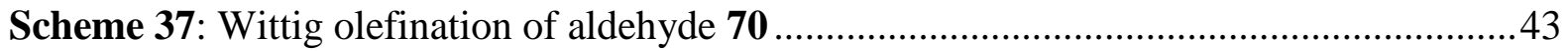

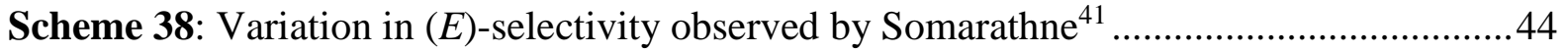

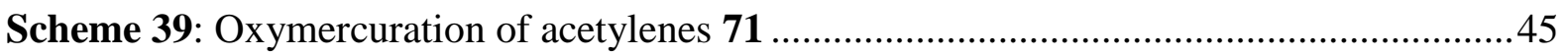

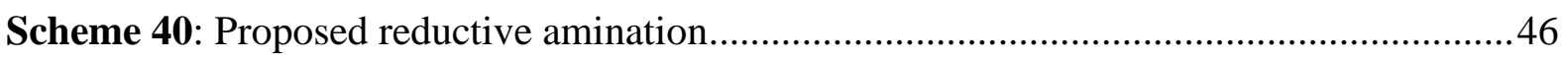

Scheme 41: Proposed mechanism for pyran alkene isomerisation ......................................54

Scheme 42: Proposed mechanism for $(\boldsymbol{Z})-\mathbf{7 2}$ to $(\boldsymbol{E})-\mathbf{7 2}$ isomerisation ................................. 54

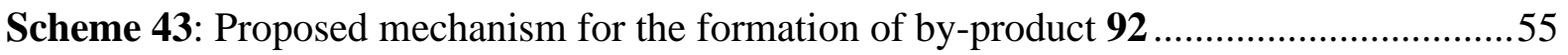

Scheme 44: Retrosynthetic analysis of alternative route toward lactam analogues 81 ..........56

Scheme 45: Retrosynthetic analysis of the proposed proof-of-principle sequence.................57

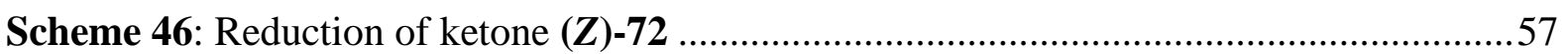

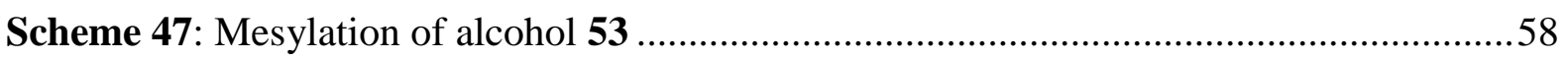

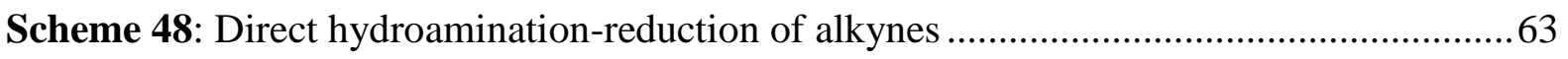




\section{List of Tables}

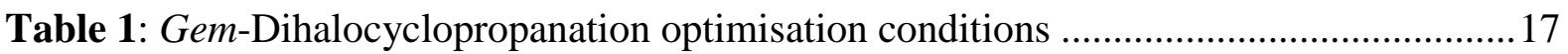

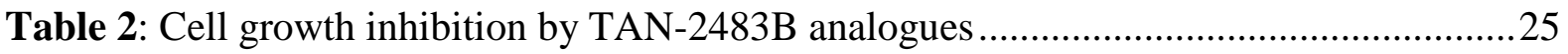

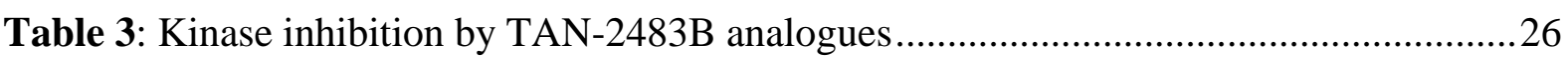

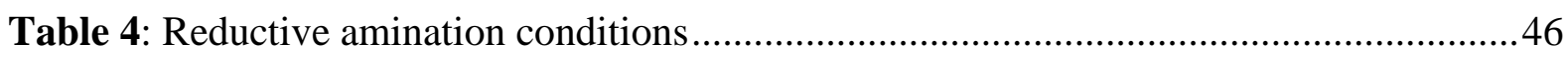




\section{Glossary}

\begin{tabular}{|c|c|}
\hline$\delta$ & chemical shift \\
\hline $1 \mathrm{~A} 9$ & human ovarian carcinoma cell line \\
\hline $\mathrm{AcOH}$ & acetic acid \\
\hline $\mathrm{AgNO}_{3}$ & silver nitrate \\
\hline Ar & aromatic \\
\hline ATP & adenosine triphosphate \\
\hline aq. & aqueous \\
\hline BMX & bone marrow kinase on chromosome $\mathrm{X}$ \\
\hline $\mathrm{Bn}$ & benzyl \\
\hline BTK & Bruton's tyrosine kinase \\
\hline $\mathrm{c}-\mathrm{Src}$ & cellular sarcoma \\
\hline calc. & calculated \\
\hline CBS & Corey-Bakshi-Shibata \\
\hline $\mathrm{CHCl}_{3}$ & chloroform \\
\hline chrom. & chromatography \\
\hline COSY & correlation spectroscopy \\
\hline $\mathrm{d}$ & doublet \\
\hline dd & doublet of doublets \\
\hline ddd & doublet of doublets of doublets \\
\hline DBU & 1,8-Diazabicyclo[5.4.0]undec-7-ene \\
\hline $\mathrm{DCM}$ & dichloromethane \\
\hline DIPEA & $N, N$-diisopropylethylamine \\
\hline DMAP & 4-dimethylaminopyridine \\
\hline $\mathrm{Et}_{3} \mathrm{~N}$ & triethylamine \\
\hline
\end{tabular}


eq. $\quad$ equivalents

HL-60 human leukaemia cancer cell line

HMBC Heteronuclear multiple-bond correlation spectroscopy

HOMO highest occupied molecular orbital

HRMS high-resolution mass spectrometry

HSQC heteronuclear single quantum coherence

HTS high-throughput screening

$\mathrm{Hz} \quad$ hertz

$\mathrm{IC}_{50} \quad$ half maximal inhibitory concentration

$J \quad$ coupling constant

JK Julia-Kocienski

KHMDS potassium bis(trimethylsilyl)amide

LC/MS liquid chromatography/mass spectrometry

LDA lithium diisopropylamide

LHMDS lithium bis(trimethylsilyl)amide

m multiplet

M moles per litre

$\mathrm{m} / \mathrm{z} \quad$ mass to charge ratio

$m$-CPBA $\quad m$-chloroperbenzoic acid

Ms methanesulfonyl (a.k.a. mesyl)

MTT 3-(4,5-dimethylthiazol-2-yl)-2,5-diphenyltetrazolium bromide

n.d. none detected

n.t. not tested

NMR nuclear magnetic resonance

OTf triflate

nOe nuclear Overhauser effect 


\begin{tabular}{|c|c|}
\hline PEA & phenylethylamine \\
\hline $\mathrm{Ph}$ & phenyl \\
\hline Piv & pivaloate \\
\hline PMHS & polymethylhydrosiloxane \\
\hline ppm & parts per million \\
\hline PTH & parathyroid hormone \\
\hline q & quartet \\
\hline qd & quartet of doublets \\
\hline Q-TOF & quadrupole-time of flight \\
\hline r.t. & room temperature \\
\hline $\mathrm{R}_{f}$ & retention factor \\
\hline rotovap & rotary evaporator \\
\hline s & singlet \\
\hline sat. & saturated \\
\hline $\mathrm{t}$ & triplet \\
\hline TBAB & tetra- $N$-butylammonium bromide \\
\hline TBAF & tetra- $N$-butylammonium fluoride \\
\hline TBAI & tetra- $N$-butylammonium iodide \\
\hline TBDPS & tert-butyldiphenylsilyl \\
\hline TEBAC & benzyltriethylammonium chloride \\
\hline TFA & trifluoroacetic acid \\
\hline THF & tetrahydrofuran \\
\hline TLC & thin layer chromatography \\
\hline TMS & trimethylsilyl \\
\hline Ts & p-toluenesulfonyl (a.k.a. tosyl) \\
\hline XantPhos & 4,5-Bis(diphenylphosphino)-9,9-dimethylxanthene \\
\hline
\end{tabular}




\section{Compound Naming and Numbering}

- Compounds incorporating the furo[3,4-b]pyran-5-one ring system were named according to IUPAC recommendations for heterocyclic compounds.

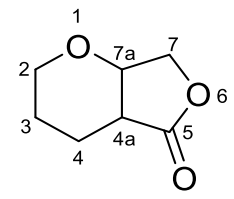

Numbering system used for naming heterocyclic compounds

- In the experimental section, the numbering of $C$-glycosides started from the terminus of the aglycone unit.

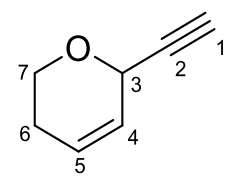

Numbering system used in $C$-glycosides 


\section{Introduction}

Natural products have historically been a rich source of lead compounds for drug development. They are isolated from organisms found in diverse terrestrial and marine environments. As well as being modified by medicinal chemists in the pursuit of higher potency and lower toxicity, natural products have also been utilised in unmodified forms as powerful pharmaceutical agents, most notably in cancer treatment. ${ }^{1,2}$

The production of secondary metabolites by an organism ostensibly comes at a metabolic cost. While some have argued that most natural products do not offer a selective ecological advantage to the organisms that produce them, it is generally believed today that almost all are biologically active or produced for a specific purpose. ${ }^{3}$ The chemical space occupied by natural products is therefore usually more biologically relevant than that of most synthetic or combinatorial compounds, and thus natural products may be more likely to interact with biomolecular targets. ${ }^{4}$

Many natural products, however, have no known biological function, or possess only low potency. In some cases, the selective advantage of a natural product may have been relevant at an earlier evolutionary stage of the organism, but is now no longer useful. Potent bioactivity is rare because high affinity and specificity to a target protein requires a small molecule to adhere to strict structural and conformational limitations, and therefore secondary metabolic pathways may have evolved to optimise the production and retention of a wide range of natural products at a low metabolic cost, producing several chemical cul-de-sacs along the way. ${ }^{5}$ Nevertheless, screening natural products for biological activity will ignore those with no obvious biological function.

Despite the high proportion of natural products possessing promising therapeutic properties, they were not well-suited to drug development programs throughout most of the $20^{\text {th }}$ century. There were several barriers. During initial drug discovery screens, bioassays were conducted on the crude extracts. These consisted of complicated mixtures of natural products that could confound the response of the assay by additive, synergistic or inhibitory effects between compounds. Furthermore, phenotypic responses may not have been observed if compounds were present in low concentrations. The large-scale pharmaceutical manufacture of natural product-based drugs is often challenging. The high expectations of combinatorial chemistry as a drug discovery vehicle also shifted focus away from natural products. Finally, the rise of high-throughput screening (HTS), which is routinely applied in the pharmaceutical industry to 
assay libraries of up to 5 million molecules within a few weeks, was initially deemed to be unsuited to natural product-based drug discovery programs. ${ }^{6,7}$

These novel approaches to drug discovery, however, were not always successful. Screening libraries of synthetic compounds usually consist of molecules with drug- or lead-like properties: those that obey Lipinski's rule of five ${ }^{8}$ and are likely to have favourable absorption, distribution, metabolism, excretion and toxicity characteristics. Although this strategy reduces the likelihood of hit compounds failing in the clinic due to poor bioavailability or possessing otherwise unfavourable physico-chemical properties, it doesn't imply that the components of the library will possess meaningful bioactivity. A recent study found that HTS of natural products had significantly higher hit rates than HTS of traditional synthetic and combinatorial libraries of compounds. ${ }^{9}$

Despite these difficulties, nearly half of all small-molecule pharmaceuticals approved in the US between 2000 and 2010 were derived from natural products, ${ }^{1}$ and they continue to successfully contribute to drug discovery when compared with the disproportionately vast libraries of synthetic compounds employed in HTS and combinatorial chemistry. Additionally, recent technological advances have begun to break down the barriers limiting the use of natural products in modern drug development strategies. Removing molecules that are likely to cause artefacts in bioassays, such as polyphenolic tannins in plant extracts, allows fractions of reduced complexity to be prepared in smaller-scale assays. ${ }^{10}$ Pre-fractionation, whereby partial separation of the crude extracts is conducted prior to HTS, often produces higher hit rates than crude extracts, and can reduce concentration-dependent and synergistic effects that obscure the assay response. ${ }^{11}$ These developments have contributed to a renewed focus on natural productbased drug discovery programs in the pharmaceutical industry. ${ }^{12,13}$

Fungi are well known to be prolific producers of natural products. Several important human therapeutics have been derived from fungal natural products, including antibiotics such as penicillin, cholesterol-lowering drugs such as the statins, and immunosuppressants such as the cyclosporins. While approximately 100,000 fungal species are known, it is thought that over ten times that number exist in nature. ${ }^{14}$ The implications of only a small fraction of existing natural products having been isolated and characterised to date is stimulating further efforts toward fungal natural product-based drug discovery. Hundreds of fungal species have recently undergone genome sequencing, and it is expected that an increased understanding of the 
genetic basis for secondary metabolite production will help to identify and activate hidden natural products in fungal genomes. ${ }^{15}$

Natural products incorporate a wide range of pharmacophores with uncommon structural motifs and varied stereochemical configurations. This structural diversity presents a challenge to synthetic chemists, but also provides exciting opportunities for drug discovery. The furo[3,4$b$ ]pyran $^{\text {a }}$ scaffold (Figure 1) is found in very few natural products. These natural products, which are typically isolated from fungi, incorporate a variety of stereocentres and functional groups. Several groups have been involved in the isolation, structure elucidation, and synthesis of the furo[3,4-b]pyran-based natural products.

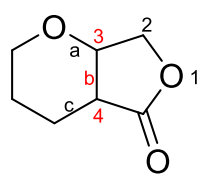

Figure 1: The furo[3,4- $b]$ pyran scaffold

\subsection{Natural products incorporating a furo[3,4- $b]$ pyran-5-one scaffold}

The furo[3,4- $b]$ pyran scaffold is found in only a handful of known natural products, including TAN-2483A and $\mathrm{B},{ }^{16}$ the fusidilactones, ${ }^{17,18}$ the massarilactones, ${ }^{19-22}$ and waol $\mathrm{A}^{23,24}$ and $\mathrm{B} .{ }^{25}$ The biological activity of these natural products is broad, and includes cytotoxic, antibacterial, antifungal and antialgal properties.

\subsubsection{TAN-2483A and B}

In 1998, Hayashi and co-workers from Takeda Chemical Industries in Japan isolated two secondary metabolites from a fermentation broth of filamentous fungus NF 2329.16 Spectroscopic data suggested that (-)-TAN-2483A (1) and (-)-TAN-2483B (2) are epimers incorporating a furo[3,4-b]pyran-5-one scaffold (Figure 2). TAN-2483A was initially reported to inhibit both the $c$-Src (sarcoma) tyrosine kinase enzyme and parathyroid hormone-induced bone resorption. ${ }^{16}$ TAN-2483B was not isolated in sufficient quantities for biological testing. TAN-2483A was first synthesised in $2003,{ }^{24}$ but TAN-2483B has not been synthesised to date.

\footnotetext{
a The nomenclature describes the connection between the pyran and furan rings as formed between C-3 and C-4 of the furan, and bond $b$ of the pyran ring.
} 


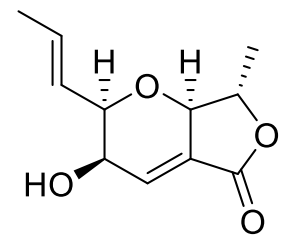

(-)-TAN-2483A (1)

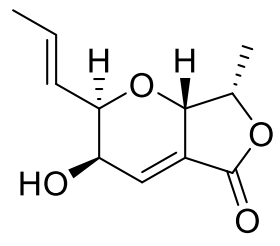

(-)-TAN-2483B (2)

Figure 2: (-)-TAN-2483A and B

\subsubsection{Fusidilactones}

In 2002, Krohn and co-workers isolated fusidilactones A, B, and C from cultures of the fungal endophyte Fusidium sp (Figure 3). ${ }^{17}$ The crude diethyl ether extracts showed good antifungal activity against Eurotium repens and Fusarium oxysporum, and weak antibacterial activity against Escherichia coli and Bacillus megaterium. The same group later isolated fusidilactones $\mathrm{D}$ and $\mathrm{E}$ from the same species, which differ from fusidilactones A and B only in the extent of hydroxylation of the sidechain, and confirmed the absolute and relative stereochemical configurations of the compounds by a solid state CD/TDDFT (circular dichroism/timedependent density functional theory) approach. ${ }^{18}$ Fusidilactone A has recently been isolated from the fermentation culture of the fungus Pseudallescheria boydii. ${ }^{26}$

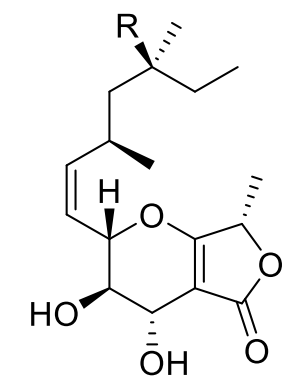

$\mathrm{R}=\mathrm{H},(+)$-fusidilactone $\mathrm{A}(\mathbf{3})$ $\mathrm{R}=\mathrm{OH},(+)$-fusidilactone $\mathrm{D}(\mathbf{6})$

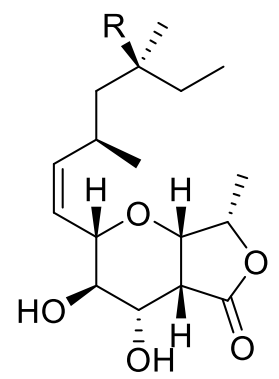

$\mathrm{R}=\mathrm{OH},(+)$-fusidilactone $\mathrm{B}(\mathbf{4})$ $\mathrm{R}=\mathrm{H},(+)$-fusidilactone $\mathrm{E}(7)$

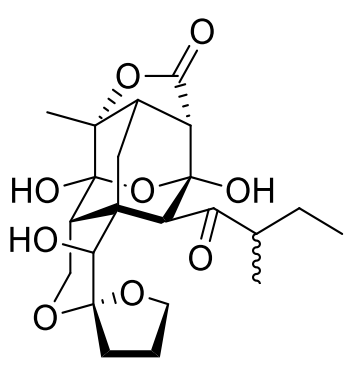

(+)-fusidilactone C (5)

Figure 3: Fusidilactones A-E

Fusidilactones A, B, D and E contain a furopyran scaffold, whereas fusidilactone C exhibits an ususual oxoadamantane skeleton and a spiroketal component. Hsung and co-workers explored a ketal-tethered intramolecular Diels-Alder cycloaddition (IMDA) toward the synthesis of the spiroketal core of fusidilactone $\mathrm{C} .{ }^{27}$ The novel and facile cycloaddition was highly endoselective, which was further enhanced by use of Lewis acids or protic solvents. ${ }^{28}$ Unfortunately, 
exo-selectivity is desired for the synthesis of fusidilactone C. Snider and co-workers synthesised the fusidilactone B ring system in 2003, confirming the correct stereochemical assignments by ${ }^{1} \mathrm{H}$ and ${ }^{13} \mathrm{C}$ NMR spectroscopic comparisons with the natural product (see section 1.3$){ }^{29}$

\subsubsection{Massarilactones}

Massarilactones B, D and H incorporate a furopyran scaffold (Figure 4). In 2001, Gloer and co-workers isolated massarilactones $\mathrm{A}$ and $\mathrm{B}$ from cultures of the freshwater aquatic fungus Massarina tunicata. ${ }^{19}$ Both showed antibacterial activity against Bacillus subtilis, while massarilactone B was also active against Staphylococcus aureus. Krohn and co-workers later discovered massarilactones $\mathrm{C}$ and $\mathrm{D}$ from the endophytic fungus Coniothyrium sp, but despite the crude extract of all six isolates showing antifungal, antibacterial and antialgal activities, the purified substances were inactive against the gram-positive bacterium Bacillus megaterium, the fungus Microbotryum violaceum, and the green alga Chlorella fusca.$^{20}$ Further work by the same group uncovered massarilactones $\mathrm{E}, \mathrm{F}$ and $\mathrm{G}$ and the acetonide 16, also isolated from Coniothyrium $s p .^{21}$ Massarilactone $\mathrm{H}$ was later isolated from the marine fungus Phoma herbarum. $^{22}$

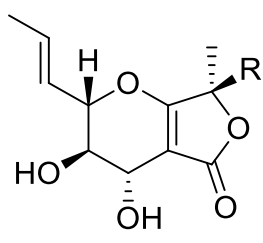

$\mathrm{R}=\mathrm{H},(+)$-massarilactone $\mathrm{B}(\mathbf{8})$

$\mathrm{R}=\mathrm{OH},(+)$-massarilactone $\mathrm{D}(\mathbf{9})$<smiles>C=C1OC(=O)[C@@]23CO[C@H](CC(=O)[C@@H]2O)C[C@@]13C</smiles>

(+)-massarilactone E (13) (+)-massarilactone F (14)

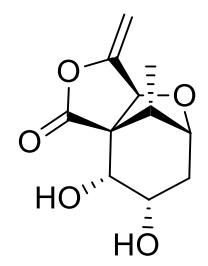

(+)-massarilactone A (11)

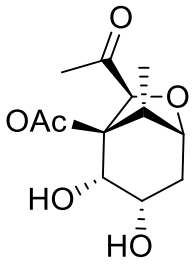

(+)-massarilactone $\mathrm{C}(\mathbf{1 2})$
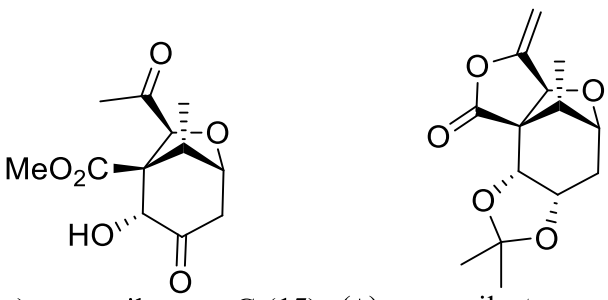

Figure 4: Massarilactones $\mathrm{A}-\mathrm{H}$ and massarilactone acetonide

Other work has shown the massarilactones to be present in many different fungal species. Massarilactone B has been isolated from the plant pathogenic fungus Pestalotiopsis scirpina. ${ }^{30}$ Massarilactones D and E were isolated from fungal endosymbiont Paraphaeosphaeria sp., 
found in the gut of Pantala flavescens larvae. ${ }^{31}$ Finally, massarilactones $\mathrm{C}$ and $\mathrm{G}$ have been isolated from the solid-substrate fermentation cultures of the ascomycete fungus Trichocladium opacum, found in China. ${ }^{32,33}$ Snider and co-workers first synthesised massarilactone B in 2003 via an aldol strategy (see section 1.3$){ }^{24,29}$

\subsubsection{Waol A and B}

Mizoue and co-workers in 1995 isolated $\delta$-lactone FD-211 from the fermentation broth of the fungus Myceliophthora lutea. ${ }^{23}$ When the same group subsequently isolated a closely related compound from the same strain, termed waol B, FD-211 was renamed to waol A. ${ }^{25}$ Both showed activity against a range of tumour cell lines, including adriamycin-resistant HL-60 cells. Soon after, the synthesis of a key intermediate of the proposed waol A structure was reported. ${ }^{34}$ However, spectroscopic properties of waol A that were inconsistent with the proposed structure prompted the Snider group to investigate further. Spectroscopic comparison of waol A with TAN-2483A, whose structure was previously assigned crystallographically, suggested that waol A may be the vinylogue of TAN-2483A. The correct structures of waol A and B were confirmed by their total synthesis (Figure 5). ${ }^{24,29}$ Waol B is the ring-opened methyl ester analogue of waol A.

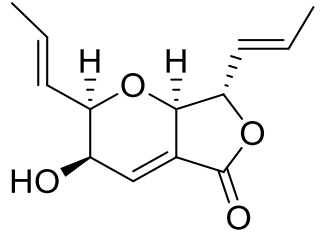

$( \pm)$-waol A (17) (FD-211)

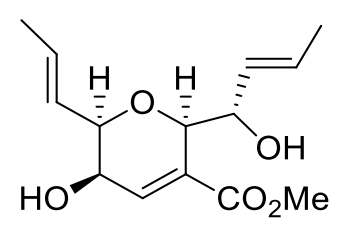

( \pm -waol B (18)

Figure 5: Waol A and waol B

\subsection{Biosyntheses of furo[3,4- $b]$ pyrans}

In organic chemistry, bioinspired syntheses are those which mimic a series of transformations hypothesised or proven to be carried out in the biosynthesis of a natural product. Biosynthetic hypotheses can provide a framework for developing a synthetic route toward a target compound, and if successful, the resulting biomimetic synthesis can lend weight to the original biosynthetic proposal. Conversely, a failed biomimetic synthesis may imply that the 
biosynthetic hypothesis needs revisiting. Identifying a common biosynthetic precursor can enable ready access to a group of related natural products, and can help reveal links between natural products that appear to share biogenetic resemblance. Several complex natural products have been accessed using a bioinspired synthetic strategy. ${ }^{35}$

The Snider group proposed a biosynthetic approach to both TAN-2483A and TAN-2483B (Scheme 1). The condensation of an aldehyde such as 19 with the natural product $\gamma$ methyltetronic acid ${ }^{36}(\mathbf{2 0})$ could produce intermediate 21 as an epimeric mixture. Reduction of 21 would produce TAN-2483A and TAN-2483B. However, initial attempts at performing this biomimetic route on a number of representative aldehydes with tetronic acid were unsuccessful. Failure to construct the pyran ring does not, however, discount the possibility that $\mathbf{2 1}$ is a common precursor to both TAN-2483A and B. More work is required to elucidate possible biosynthetic pathways toward these natural products.

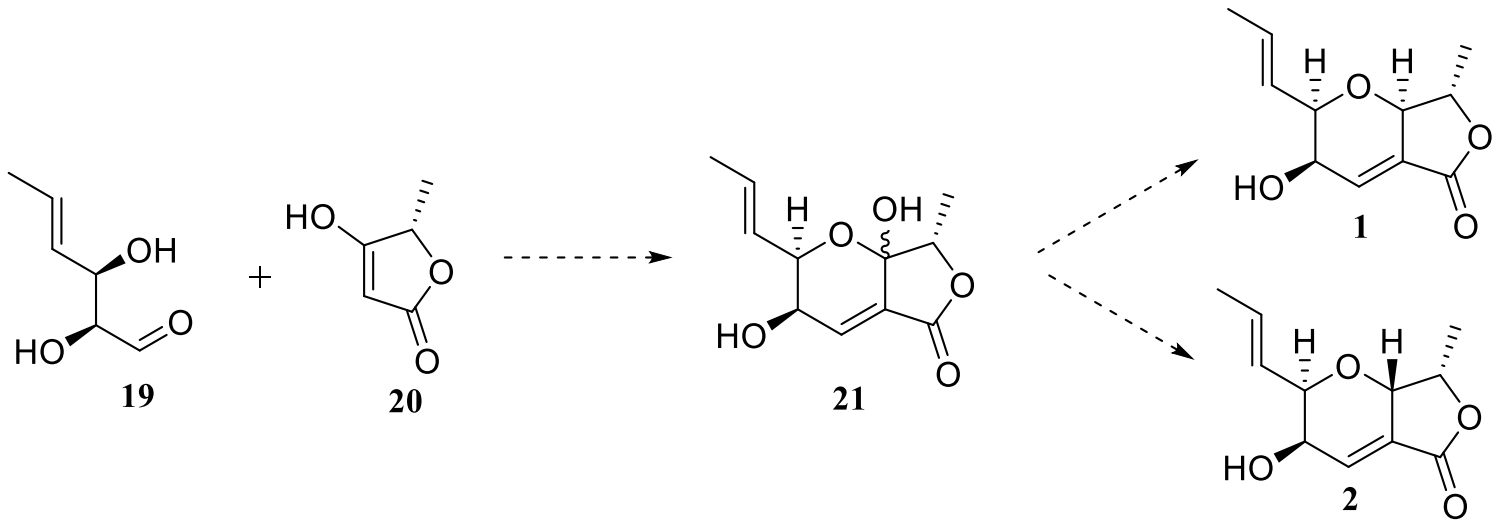

Scheme 1: Proposed condensation biosynthesis of TAN-2483A and B

The Gloer group have suggested that massarilactones A (11), B (8) and D (9) appear to be derived from the same polyketide precursor. ${ }^{19}$ The incorporation of a three carbon unit is proposed to account for carbons labelled here as 7, 7a and 8 (Figure 6). ${ }^{37}$ Many other fungal metabolites bear biogenetic resemblance to the furopyran core of the massarilactones, including rosigenin (22, also isolated from $M$. tunicata), the curvupallides (e.g. 23), and the spirostaphylotrichines (e.g. 24) (Figure 7) ${ }^{38-40}$ Studies on spirostaphylotrichine biosynthesis which may be extended to other members of this class of compounds - suggest that they are formed by the condensation of a polyketide chain with an unidentified $\mathrm{C}_{4}$ unit, possibly aspartic acid or an intermediate from the citric acid cycle. ${ }^{38}$ 
<smiles>C=C1OC(=O)C23COC(C[C@H](O)[C@@H]2O)C13</smiles>

(+)-massarilactone A (11)<smiles>[R][C@]12OC(=O)C3=C(O[C@H](/C=C/C)[C@@H](O)[C@@H]3O)[C@@]1(C)O2</smiles>

$\mathrm{R}=\mathrm{H},(+)$-massarilactone $\mathrm{B}(\mathbf{8})$

$\mathrm{R}=\mathrm{OH},(+)$-massarilactone D (9)

Figure 6: The proposed biogenetic resemblance between massarilactones A, B and D

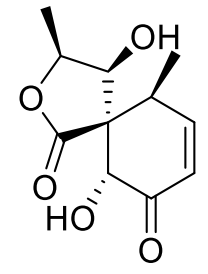

rosigenin (22)<smiles>C=C1C2=C(C(=O)N1OC)[C@@H](O)[C@@H](O)[C@@H](/C=C/C=C/C)O2</smiles>

curvupallide A (23)<smiles>C=C1C[C@]2(C/C(=C\CC)C=CC(=O)[C@@H]2O)C(=O)N1OC</smiles>

spirostaphylotrichine A (24)

Figure 7: Natural products bearing biogenetic resemblance to the furopyran core of the massarilactones

\subsection{Syntheses of furo[3,4- $b]$ pyran-based natural products}

In 2003 the Snider group published the first total syntheses of TAN-2483A, massarilactone B, and waol A and B. ${ }^{29}$ The retrosynthetic route to TAN-2483A (1) and waol A (17) is shown in Scheme 2.<smiles>[R]C1OC(=O)C2=C[C@H](O)[C@@H](/C=C/C)O[C@H]21</smiles>

$\mathrm{R}=\mathrm{Me}, \mathrm{TAN}-2483 \mathrm{~A}(\mathbf{1})$

$\mathrm{R}=1 E$-propenyl, waol A (17)<smiles>[R][C@H]1OC(=O)C[C@H]1O</smiles><smiles>[R][C@H]1O[C@H](/C=C/C)[C@H](C)O[C@H]1C</smiles>

29<smiles>[R]C1OC(=O)[C@H]([C@H](O)/C=C/C=C/C)[C@@H]1O</smiles><smiles>C=CC</smiles><smiles>C=CC</smiles><smiles>[R]C1OC(=O)[C@H]2[C@@H]1O[C@H](/C=C/C)[C@H](I)[C@@H]2O</smiles>

28

Scheme 2: Snider's retrosynthesis of TAN-2483A and Waol A ${ }^{29}$ 
Aldol reaction of aldehyde $\mathbf{2 5}$ and lactone $\mathbf{2 6}$ produced a mixture of $\beta$-hydroxy lactone 27 and its undesired C-4 epimer. The C-4 epimers were separated by column chromatography on $20 \%$ silver nitrate on silica gel. The stereochemical configuration at C-4 is important because the iodoetherification occurring in the next step is directed by the alcohol at that position: formation of the iodinium ion occurs on the opposite face of the alkene. Subsequent nucleophilic attack to form the pyran $\mathbf{2 8}$ then results in the propenyl substituent at C-2 adopting the correct stereochemical configuration to that present in the natural product (i.e. $2 R$ ). Furthermore, the configuration of the C-4 alcohol is conserved during epoxide formation and subsequent epoxide opening from C-4 to C-3, so that the desired $3 R$ configuration is obtained. Iodoetherification of 27 using bis(sym-collidine)- $\mathrm{AgPF}_{6}$ and iodine produced the desired iodoalcohol 28. Treatment of $\mathbf{2 8}$ with triethylamine afforded epoxide $\mathbf{2 9}$, which reacted further to produce TAN-2483A.

The vinylogue of TAN-2483A - waol A - was similarly prepared using the appropriate lactone with the $1 E$-propenyl substituent in the initial aldol reaction without complication. Lactone hydrolysis of waol A followed by reaction with diazomethane produced waol B in a $38 \%$ yield, with a $47 \%$ yield of by-product $\mathbf{3 0}$ formed via the conjugate addition of methoxide at the C-4 position (Scheme 3).<smiles>C/C=C/C1O[C@H]2C(=C[C@H]1O)C(=O)O[C@H]2/C=C/C</smiles>

(土)-waol A (17)

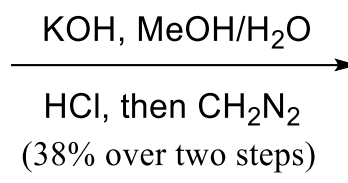

( \pm )-waol B (18)<smiles>C/C=C/[C@@H]1OC(=O)[C@@H]2[C@@H](O)[C@H](O)[C@@H](/C=C/C)O[C@@H]12</smiles>

30

Scheme 3: Conversion of waol A to waol $\mathrm{B}^{29}$

Massarilactone B (8) was synthesised via a longer route involving an aldol reaction of aldehyde $\mathbf{2 5}$ and the diastereoisomer of lactone 26, i.e. lactone $\mathbf{3 1}$ (Scheme 4). Iodoetherification of intermediate $\mathbf{3 2}$ was followed by radical substitution of the iodide in $\mathbf{3 3}$ by a hydroxy group. Finally, oxidation-elimination of intermediate $\mathbf{3 4}$ produced massarilactone B. 
<smiles>C=C=CC1OC(=O)C2=C1O[C@H](/C=C/C)[C@H](O)[C@H]2O</smiles>

$(+)$-massarilactone B (8)

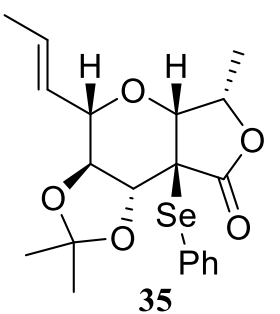

35

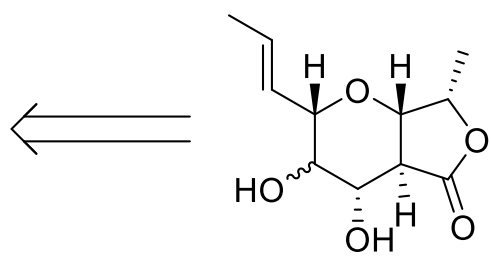

34

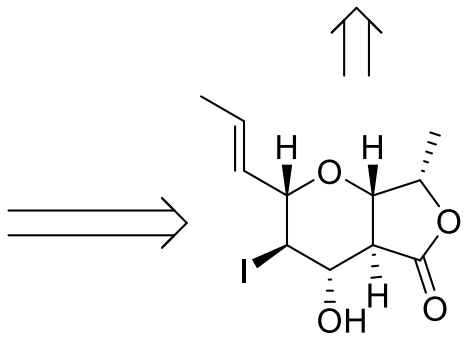

33

Scheme 4: Retrosynthesis of (+)-massarilactone $B^{29}$

The same group explored similar methodology toward the synthesis of TAN-2483B. The previously discussed lactone $\mathbf{3 1}$ was considered a potential precursor and reacted with aldehyde $\mathbf{2 5}$ to form a separable diastereomeric mixture of $\mathbf{3 2}$ and $\mathbf{3 6}$ (Scheme 5). Iodoetherification of 32 produced the iodoalcohol 33, with the expected C-2, C-3 and C-4 configurations due to the directing effects of the $\mathrm{C}-4$ alcohol (as discussed above). Treatment of $\mathbf{3 3}$ with DBU produced the TAN-2483B C-2/C-3 diastereoisomer 37.

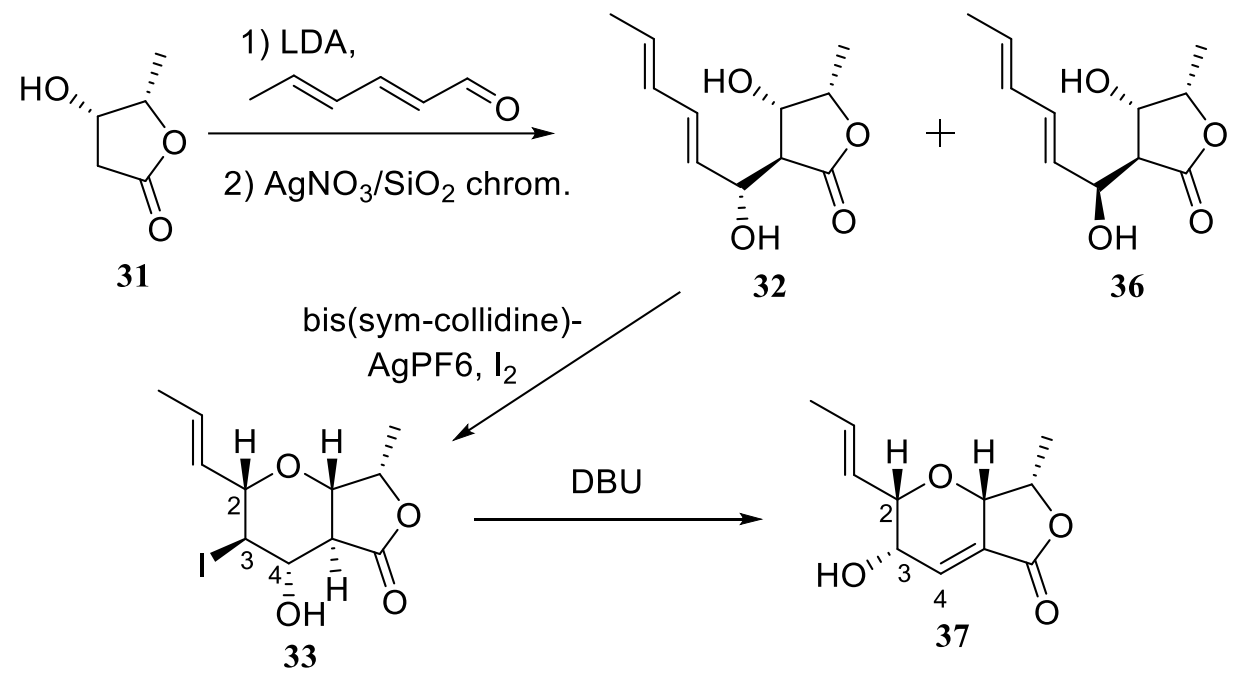

Scheme 5: Snider's attempted synthesis of TAN-2483B ${ }^{29}$ 
It is unclear why the iodoetherification of dienol $\mathbf{3 6}$ was not reported, since we may expect that it possesses the correct stereochemistry to produce the corresponding iodoalcohol for the synthesis of TAN-2483B. Instead, Snider and co-workers reported a final attempted route to TAN-2483B. They envisaged that directed epoxidation of dienol 36 with $m$-CPBA would produce mainly threo alcohol 38. Cyclisation of the presumed intermediate $\mathbf{3 8}$ should yield furopyran 39. Epoxidation followed by a base-catalysed dehydration would complete the synthesis of TAN-2483B (Scheme 6).

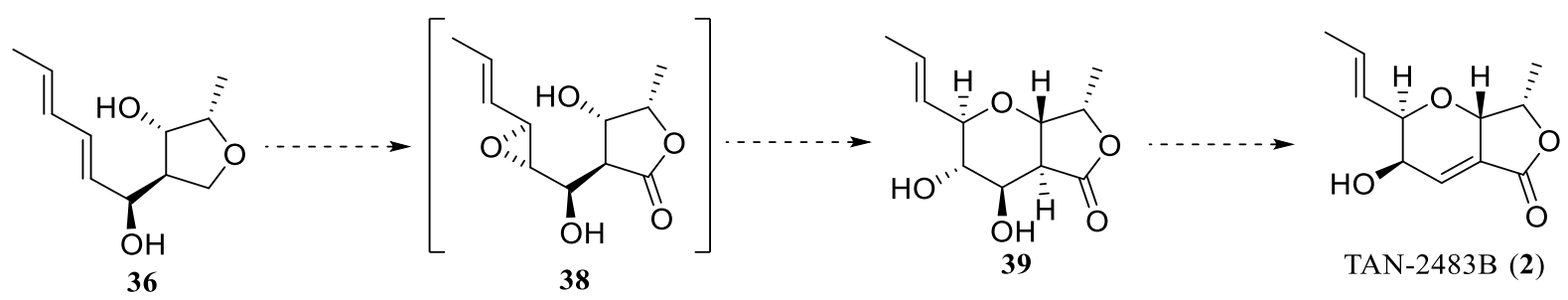

Scheme 6: Final proposed synthetic route to TAN-2483B

Instead, epoxidation of $\mathbf{3 6}$ produced a mixture of terminal epoxides $\mathbf{4 0}$ and diol $\mathbf{4 1}$ (Scheme 7). The authors suggested that the lactone alcohol helps to direct epoxidation of the terminal double bond.<smiles>C/C=C/C=C/[C@H](O)[C@H]1CO[C@H](C)[C@H]1O</smiles>

36

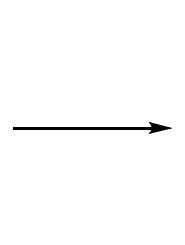<smiles>CC1CC1/C=C\[C@H](O)[C@H]1C(=O)O[C@H](C)[C@H]1O</smiles>

40<smiles>C/C=C/[C@H]1O[C@H]2[C@@H](C)OC(=O)[C@@H]2[C@H](O)[C@@H]1O</smiles>

41

Scheme 7: Undesired synthesis of diol $\mathbf{4 1}^{29}$

\subsection{Syntheses of TAN-2483B analogues}

The total synthesis of TAN-2483B has not yet been achieved. However, the Harvey group at Victoria University of Wellington has produced a number of analogues of TAN-2483B. ${ }^{41}$ The synthetic strategy uses D-mannose as the chiral starting material, and incorporates a gemdihalocyclopropanation/ring expansion sequence and a palladium-catalysed lactone formation step. 


\subsubsection{First synthesis of the TAN-2483B ring system}

In 2011, Harvey and Hewitt published the first synthesis of the TAN-2483B ring system via a D-mannose-derived cyclopropane. ${ }^{42}$ As TAN-2483B incorporates diverse stereochemistry and several oxygen groups, readily available D-mannose provided a suitable chiral scaffold. Retrosynthetic analysis suggested that TAN-2483B (2) could be accessed from furopyran $\mathbf{4 2}$, which in turn could be derived from haloalkenes 43 or 44 via a palladium-catalysed carbonylation and lactone formation step (Scheme 8). Haloalkenes $\mathbf{4 3}$ or $\mathbf{4 4}$ could be prepared by gem-dihalocyclopropanation and subsequent ring expansion of glycal $\mathbf{4 5}$. The formation of 45 follows a four-step procedure developed by Theodorakis and co-workers. ${ }^{43}$ Synthesis of the simplified furopyran $\mathbf{4 6}$ was conducted as a proof-of-principle.<smiles>C/C=C/C1O[C@]2(C)C(=CC1O)C(=O)O[C@H]2C</smiles>

$(-)-T A N-2483 B(2)$

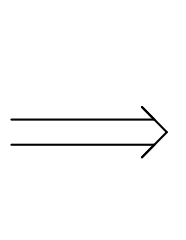

$\mathrm{OH}$

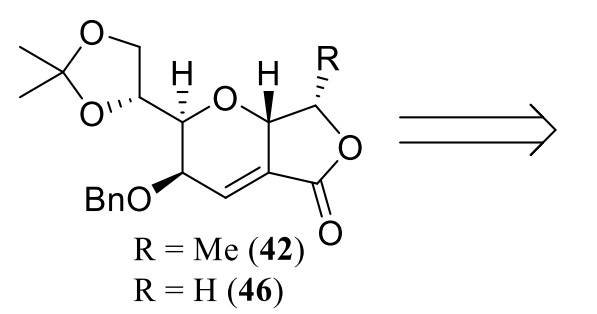<smiles>[X]C1=C[C@@H](O)[C@H]([C@H]2COC(C)(C)O2)O[C@H]1O</smiles>
$\mathrm{X}=\mathrm{Cl}(\mathbf{4 3})$ $\mathrm{X}=\mathrm{Br}(\mathbf{4 4})$<smiles>CCC1O[C@H](O)[C@H](O)C(O)[C@@H]1O</smiles>

D-mannose
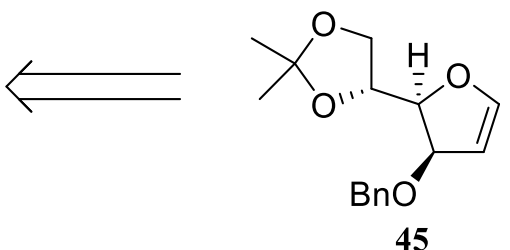

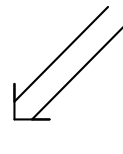

Scheme 8: Cyclopropanation and ring expansion retrosynthesis of TAN-2483B

Initial attempts to generate the dibromocyclopronane intermediate through the in situ formation of dibromocarbene produced complex mixtures. On the other hand, using chloroform to generate the dichlorocarbene that undergoes addition to glycal $\mathbf{4 5}$ under Makosza conditions ${ }^{44}$ led to the more facile formation of the dichlorocyclopropane 47 (Scheme 9). ${ }^{42}$ Ring expansion was achieved using silver acetate in acetic acid to produce acetate $\mathbf{4 8}$ in good yield over two steps. While the dichlorocyclopropane 47 was isolable, avoiding chromatographic purification by using a one-pot, two-step sequence produced better yields. 


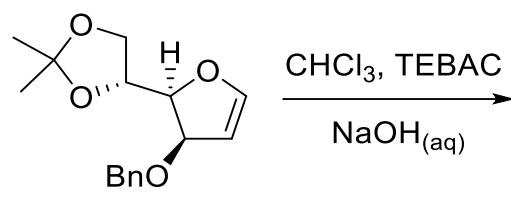

45

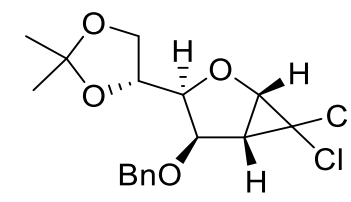

47

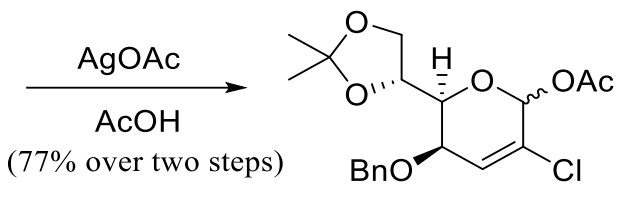

48

Scheme 9: Gem-Dichlorocyclopropanation and ring expansion ${ }^{42}$

The formation of the furanone ring system was carried out using a palladium-catalysed carbonylation/lactonisation of $\mathbf{4 9}$ under an atmosphere of carbon monoxide (Scheme 10). Stereochemical assignments of lactone $\mathbf{4 6}$ were based on nOe correlations, and suggested that only one of the diastereoisomers of $\mathbf{4 9}$ reacted.<smiles>CC1(C)OC[C@H]([C@H]2O[C@H](CO)C(Cl)=C[C@H]2O)O1</smiles>

49

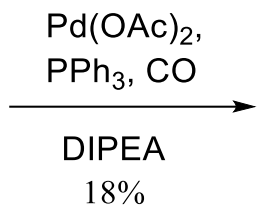

$18 \%$

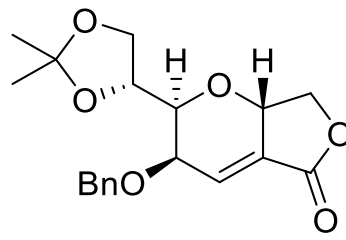

46

Scheme 10: Pd-catalysed carbonylation and lactone formation ${ }^{42}$

The low yield of the carbonylation sequence may be partly due to the poor reactivity of chloroalkenes in carbonylation reactions. This reaction was first described by Heck in 1974 and involves the carbonylation of aryl and vinyl halides with carbon monoxide under basic conditions in the presence of a nucleophile. ${ }^{45,46}$ Applications of the reaction have continued to broaden, and it has become an important process in the chemical industry. ${ }^{47}$ The active palladium catalyst is generated in situ from a stable $\mathrm{Pd}^{2+}$ precursor. The first step in the catalytic cycle is oxidative addition of the aryl or vinyl halide to the palladium catalyst via insertion of palladium into the R-X bond (Scheme 11). ${ }^{48}$ The next step is the insertion of carbon monoxide into the Pd-R bond (carbonylation). Finally, reductive elimination of the carbonylated species and HX is triggered by nucleophilic attack, regenerating the $\operatorname{Pd}^{0}(\mathrm{~L})_{n}$ catalyst. Consideration of many factors is necessary when determining the reactivity of a particular substrate and nucleophile combination. 


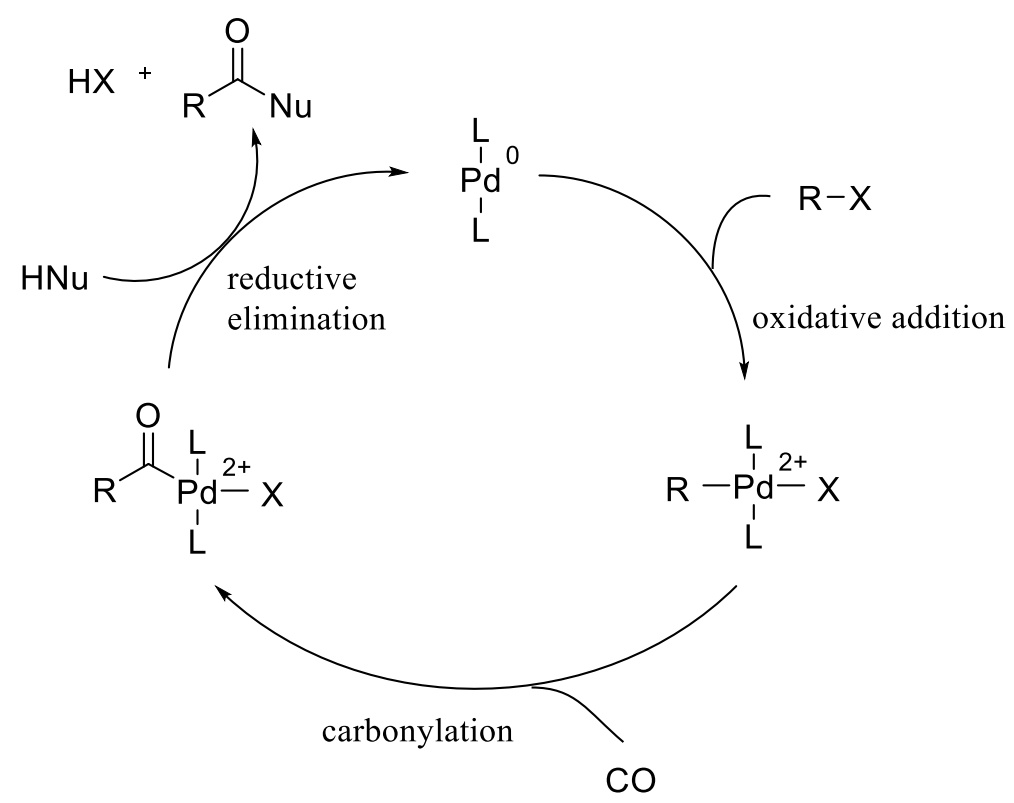

Scheme 11: Mechanism of the Pd-catalysed carbonylation

The nature of the rate-determining step may depend on the catalyst, the nucleophile and/or the identity of the halide. Halide reactivity typically increases with size and decreases with electronegativity, so that $\mathrm{I}>\mathrm{Br} \gg \mathrm{Cl}^{47}$ Since oxidative addition involves insertion of palladium into the R-X bond, the ease of oxidative addition is dependent on the strength and size of the R-X bond. Therefore, the rate-determining step with aryl iodides and bromides is often the carbonylation step, because oxidative addition of these species tends to be facile. On the other hand, oxidative addition is more likely to be the rate-determining step with aryl chlorides, which indeed often require more electron-donating ligands on the catalyst. ${ }^{49}$

While this model system delivered the desired furopyran core, the limitations of the chloroalkene in the palladium-catalysed carbonylation reinvigorated efforts to proceed via the corresponding bromoalkene, which should be more reactive under Heck conditions.

\subsubsection{Synthesis of TAN-2483B sidechain analogues}

Dr. Kalpani Somarathne developed the D-mannose-based synthetic strategy further during her synthesis of TAN-2483B sidechain analogues. ${ }^{41}$ Attempts at synthesising the ring system via dichlorocyclopropane and Vilsmeier-Haack-derived intermediates were unsuccessful, largely due to the poor reactivity of the chloroalkene in the carbonylation reaction. Thus the dibromocyclopropanation route was explored in more detail (Scheme 12). Sidechain analogues 
50, 51 and 52 were accessed from alcohols 53 via the palladium-catalysed carbonylation, and subsequent work in the same group by Jasmin Riesterer produced the long-chain heptadecanoyl ester sidechain analogue 54. ${ }^{41,53}$ Alcohol $\mathbf{5 3}$ was accessed from aldehyde $\mathbf{5 5}$ through the oxymercuration and stereoselective reduction of the TMS-deprotected alkyne, and Wittig olefination of the aldehyde to append the sidechains: the $(E)$ - and $(Z)$-ethyl esters (51 and 52), (E)-hydroxypropenyl (50) and (E)-heptadecanoyl ester (54). Aldehyde 55 was produced from acetate 56 by acetonide deprotection and oxidative diol cleavage, and stereoselective alkynylation at the anomeric centre. Acetate $\mathbf{5 6}$ was accessed via the gemdibromocyclopropanation and ring expansion of glycal 45, which in turn was produced from D-mannose in a four-step procedure described by Theodorakis and co-workers. ${ }^{43}$
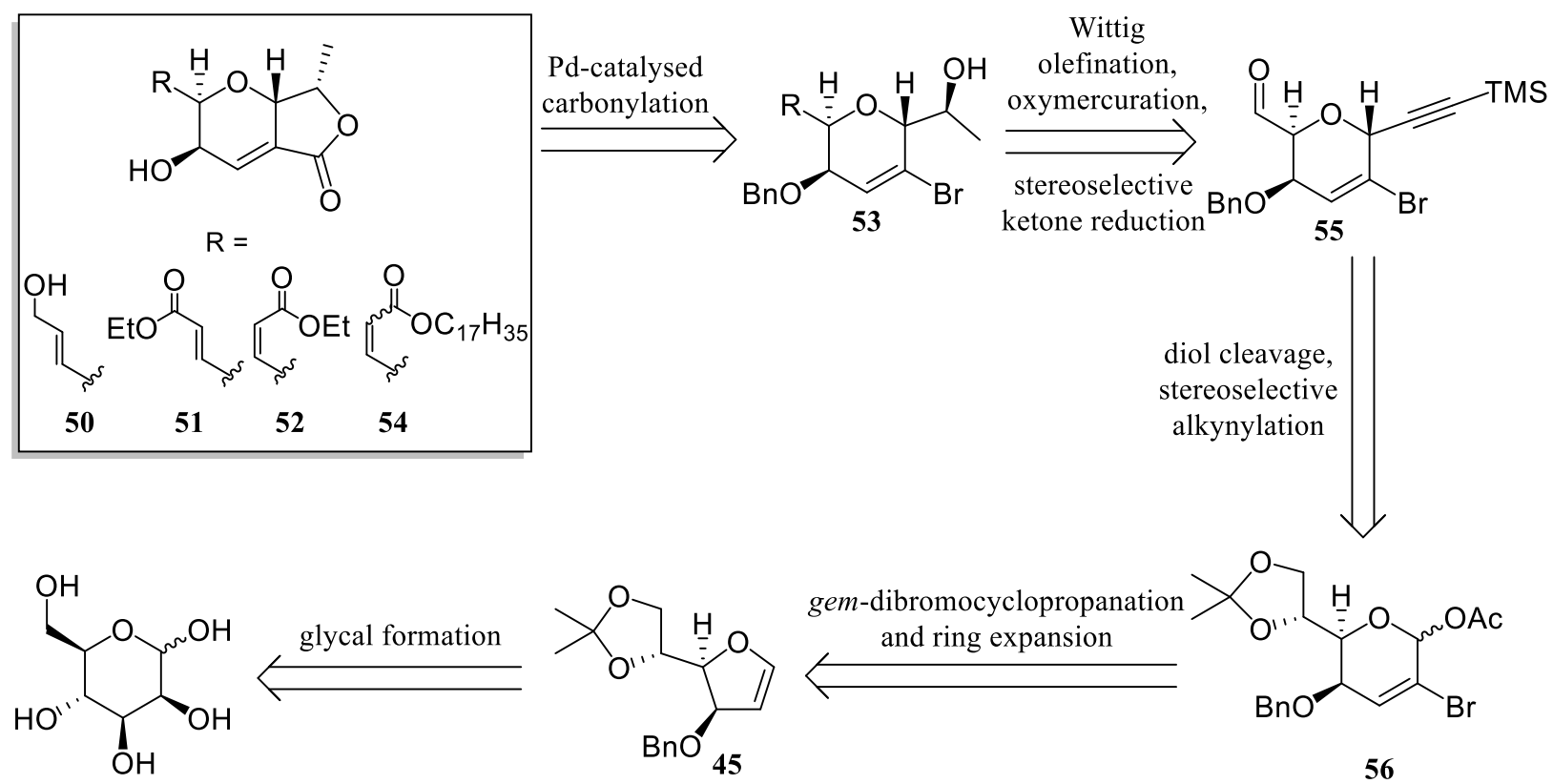

Scheme 12: Retrosynthetic analysis of TAN-2483B sidechain analogues ${ }^{41,53}$

The first major transformation was the formation of glycal $\mathbf{4 5}$ from D-mannose (Scheme 13). Catalytic $\mathrm{I}_{2}$ was used to form the bisacetonide furanol $\mathbf{5 7}$ from D-mannose dissolved in acetone. Treatment of 57 with $p$-toluenesulfonyl chloride (tosyl chloride), triethylamine and 4dimethylaminopyridine produced chlorofuran 58, which was added to a solution of the naphthalene radical anion ${ }^{50}$ formed in situ from freshly-cut sodium in tetrahydrofuran. Two single-electron-transfer steps produced the intermediate glycal alcohol, which was immediately protected using benzyl bromide and sodium hydride to form $\mathbf{4 5} .^{43}$ 


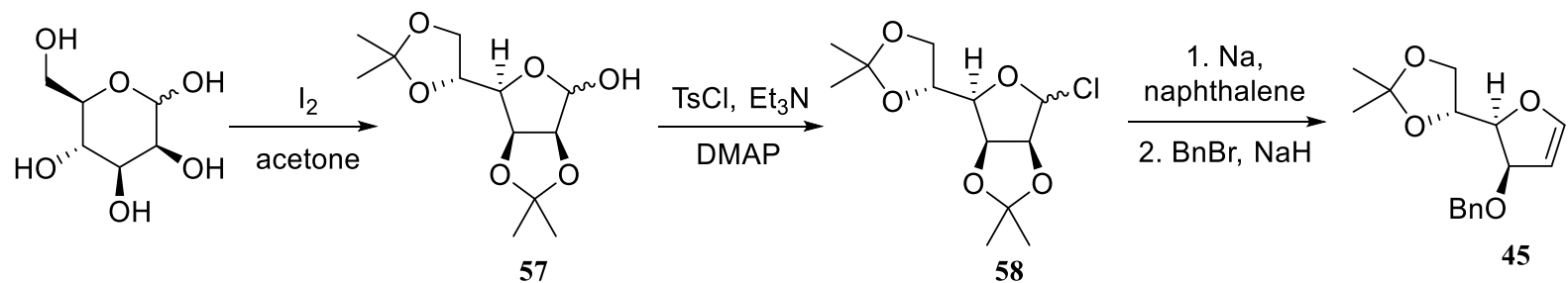

Scheme 13: Glycal formation from D-mannose ${ }^{43}$

As described in Hewitt's $\mathrm{PhD}$ thesis ${ }^{51}$ and subsequent publication, ${ }^{42}$ the gemdibromocyclopropanation step was extremely challenging under many typical conditions. However, Galin and co-workers had previously demonstrated that using potassium carbonate as a weak base in conjunction with TBAB as a phase-transfer catalyst allows for the moderately facile formation and in situ ring opening of dihalocyclopropanes. ${ }^{52}$ Somarathne applied this methodology to glycal $\mathbf{4 5}$ which afforded the ring-opened methyl glycoside $\mathbf{5 9}$ (Scheme 14). ${ }^{41}$

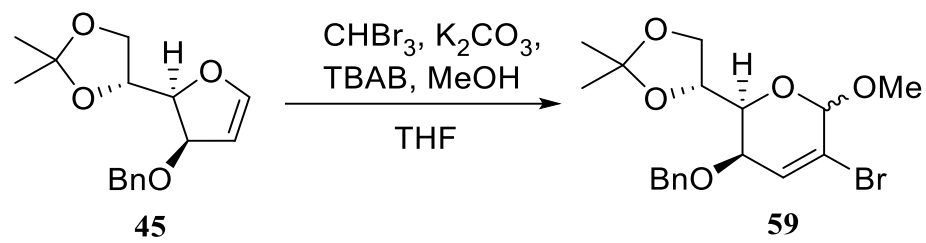

Scheme 14: Formation of methyl glycoside 59 via gem-dihalocyclopropanation and ring expansion ${ }^{41}$

Recognising that the subsequent transformation to the $C$-glycoside acetylene $\mathbf{5 5}$ would be more facile with a better leaving group at the anomeric centre, the reaction was then attempted with sodium acetate as the nucleophile, rather than methanol. The expected acetate $\mathbf{5 6}$ was obtained in a $21 \%$ yield, along with two by-products 60 and $\mathbf{6 1}$ (Scheme 15). ${ }^{41}$

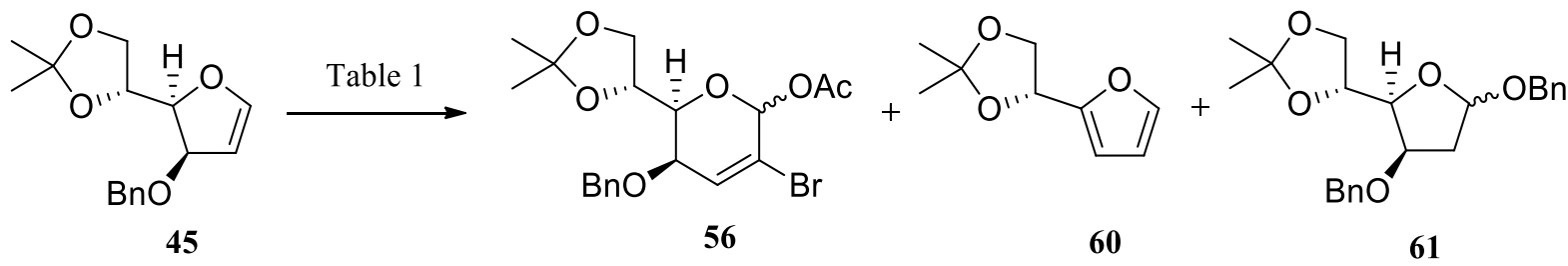

Scheme 15: Formation of acetate 56 via gem-dihalocyclopropanation and ring expansion ${ }^{41}$ 
Heating the reaction mixture in neat bromoform at $85-90^{\circ} \mathrm{C}$ for two days, and adding 18 -crown6 to increase the basicity and solubility of potassium carbonate, resulted in a yield of $47 \%$ with less evidence of by-product formation (Table 1).

\begin{tabular}{|c|c|c|c|c|c|c|}
\hline Entry & Reagents & Nucleophile & Solvent & Conditions & Product & Yield \\
\hline 1 & $\begin{array}{l}\mathrm{CHBr}_{3}, \mathrm{~K}_{2} \mathrm{CO}_{3}, \\
\mathrm{TBAB}\end{array}$ & $\mathrm{MeOH}$ & THF & $\begin{array}{l}\text { Reflux, } 24 \\
\text { hours }\end{array}$ & 59 & $18 \%$ \\
\hline 2 & $\begin{array}{l}\mathrm{CHBr}_{3}, \mathrm{~K}_{2} \mathrm{CO}_{3}, \\
\mathrm{TBAB}\end{array}$ & $\mathrm{NaOAc}$ & THF & $\begin{array}{l}\text { Reflux, } 24 \\
\text { hours }\end{array}$ & 56 & $21 \%$ \\
\hline 3 & $\begin{array}{l}\mathrm{CHBr}_{3}, \mathrm{~K}_{2} \mathrm{CO}_{3}, \\
\text { TBAB, 18-crown-6 }\end{array}$ & $\mathrm{NaOAc}$ & neat $\mathrm{CHBr}_{3}$ & $\begin{array}{l}85-90^{\circ} \mathrm{C}, 2 \\
\text { days }\end{array}$ & 56 & $47 \%$ \\
\hline
\end{tabular}

Table 1: Gem-Dihalocyclopropanation optimisation conditions ${ }^{41}$

Later, Jasmin Riesterer ${ }^{53}$ and José Luis Pinedo Rivera ${ }^{54}$ explored modifications to the procedure. By using an excess of freshly distilled bromoform, stirring the reaction at room temperature to create a uniform dispersion before heating, and adding fresh quantities of bromoform after each day of heating, the acetate $\mathbf{5 6}$ was reliably obtained in moderate to good yields (Scheme 16).<smiles>CC1(C)OC[C@H](C2OC=C[C@@H]2O)O1</smiles>

45

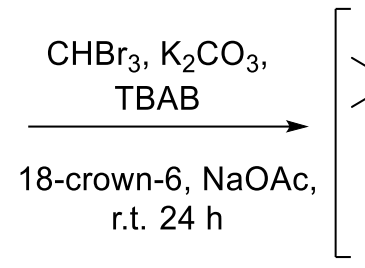

Scheme 16: Modified dibromocyclopropanation and ring expansion

The next transformation produces the TMS-protected acetylene diol $\mathbf{6 3}$. Treatment of $\mathbf{5 6}$ with bis-trimethylsilylacetylene promoted by tin tetrachloride yielded a mixture of the desired diol 63 and the acetonide-protected 64 (Scheme 17). The stereoselectivity of this alkynylation reaction is important because the configuration at the $\mathrm{C}-1$ position defines the difference between TAN-2483A and B. The alkynylation conditions produce only the $\alpha$-glycoside, which is required for accessing TAN-2483B. The stereoselectivity is thought to be due to the orbitals 
of the oxonium ion overlapping best with the acetylene orbitals in an $\alpha$-pseudo-axial orientation (Scheme 18). ${ }^{55}$ Any acetonide $\mathbf{6 4}$ isolated from the alkynylation was converted to the desired diol 63 using trifluoroacetic acid in acetonitrile.
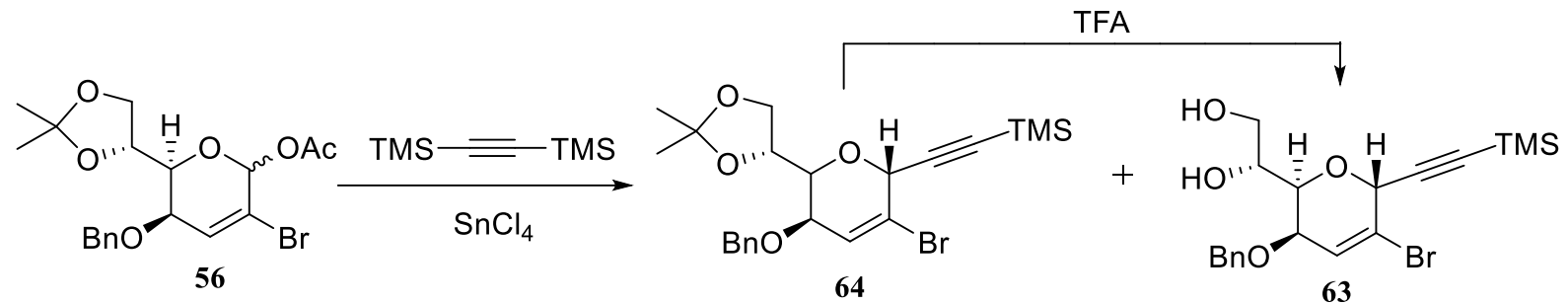

Scheme 17: Stereoselective alkynylation and acetonide deprotection

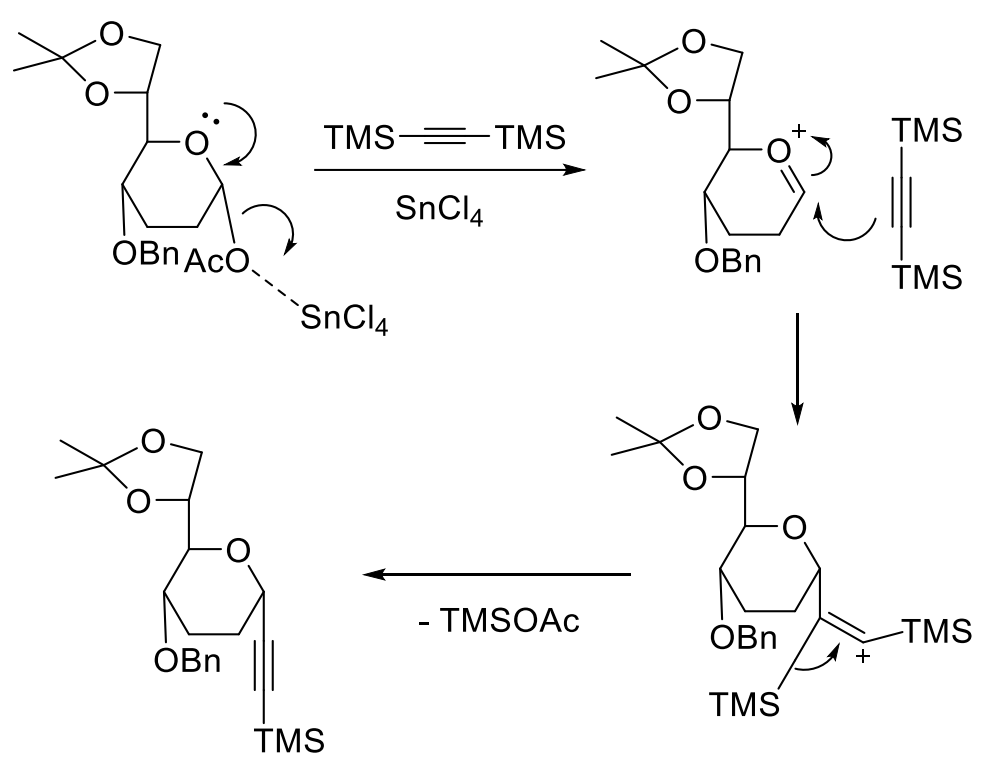

Scheme 18: Proposed mechanism of stereoselective alkynylation ${ }^{55}$

The desilylation of TMS-protected acetylenes is typically conducted with a weak base in a protic solvent. ${ }^{56}$ This reaction was first investigated on the analogous chloroalkene acetonide 65 (Scheme 19). ${ }^{41}$ It was found that, while the reaction conditions appeared to produce the terminal acetylene, prolonged concentration at $40^{\circ} \mathrm{C}$ caused degradation to an unknown byproduct, possibly via the formation of an allene. Similar degradation to an allene following desilylation of an acetylene had previously been reported by Hagenah and co-workers. ${ }^{57}$ It was rationalised that prolonged evaporation during workup could be avoided by using a co-solvent with a lower boiling point, and so dichloromethane was investigated as a primary solvent with 
methanol as a $20 \%(\mathrm{v} / \mathrm{v})$ co-solvent. This procedure, using 5 equivalents of potassium carbonate, with careful evaporation of the solvent during workup at room temperature, yielded the desired deprotected acetylene $\mathbf{6 6}$ in moderate to good yields. When this reaction was carried out on the chloroalkene ethyl ester variant of the acetylene, migration of the internal alkene to the 1,2-position was evident; fortunately, this migration was not detected on the bromoalkene variants that were ultimately used to produce the TAN-2483B sidechain analogues. ${ }^{41}$

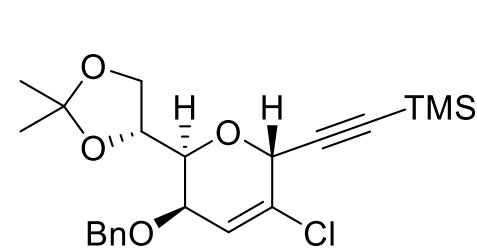

65

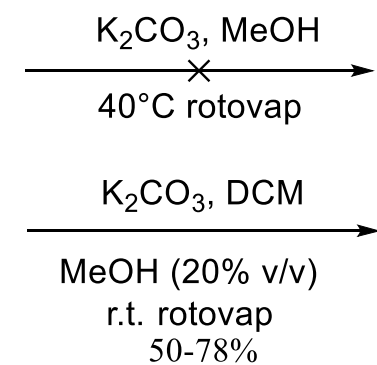

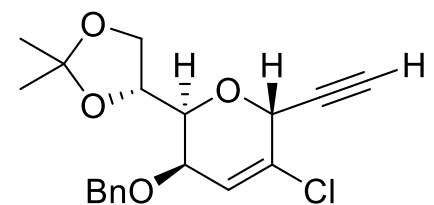

66

Scheme 19: Initial desilylation attempts ${ }^{41}$

Prior to the installation of sidechain analogues under Wittig conditions, attempts were made to install the (1E)-propenyl sidechain found in the natural product TAN-2483B. Because the JuliaKocienski (JK) olefination has high selectivity for $(E)$-alkenes, ${ }^{58} \mathrm{JK}$ conditions were tested on aldehyde $67 .{ }^{41}$ Unfortunately, the desired alkene $\mathbf{6 8}$ was not obtained. Similar degradation occurred when Wittig homologation was trialled with ethyltriphenylphosphonium iodide (Scheme 20). ${ }^{41}$<smiles>CS(C)(=O)(C#C[C@H]1OC(C=O)[C@@H](O)C=C1Cl)OCc1ccccc1</smiles>

67<smiles>CC#C[C@H]1O[C@H](C=O)[C@@H](OBr)C=C1Cl</smiles>

67
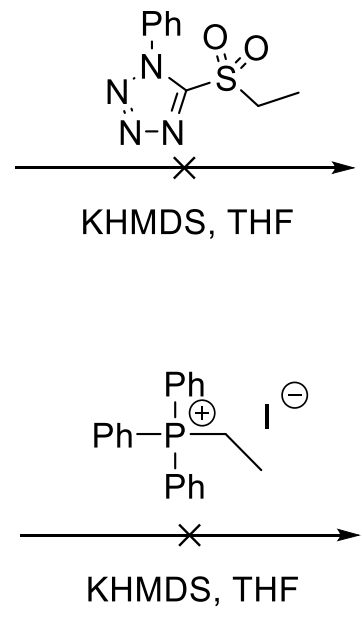

KHMDS, THF<smiles>C/C=C/[C@H]1O[C@H](C#CC#N)[C@H](O)C=C1Cl</smiles>

68<smiles>C/C=C/[C@H]1O[C@H](C#CC#N)[C@H](O)C=C1Cl</smiles>

68

Scheme 20: Attempted olefination conditions ${ }^{41}$ 
It was proposed that the acidic $\alpha$-proton of the aldehyde could be deprotonated by KHMDS or the sulfone anion, or the ylide under Wittig conditions, leading to rearrangement and degradation of the starting material, possibly via elimination of benzyl alcohol. Consequently, it was reasoned that milder conditions without the use of a strong base would be required for sidechain installation. Stabilised Wittig reagents generally do not require external bases to be used, are not themselves highly basic and are typically selective for $(E)$-alkenes. Thus, the stabilised Wittig reagent ethyl (triphenylphosphoranylidene)acetate was initially investigated as a means toward an $(E)$-ethyl ester sidechain analogue of TAN-2483B. A number of solvents were trialled, but the $(E)$-selectivity was generally poor; dimethylformamide was the most selective, with a 3:1 (E:Z) ratio. Nevertheless, successful installation of several sidechain analogues was achieved under Wittig conditions. Ethyl (triphenylphosphoranylidene)acetate was used to form the $(E)$ - and (Z)-ethyl esters $\mathbf{5 1}$ and 52; (triphenylphosphoranylidene)acetaldehyde was used to form the aldehyde precursor to 10hydroxyTAN-2483B 50; and the Bestmann ylide (triphenylphosphoranylidene)ketene ${ }^{59}$ was used with heptadecanol to form the (E)-heptadecanoyl ester analogue 54 (see Scheme 12). ${ }^{53}$

Progress toward more reliable installation of the (1E)-propenyl sidechain via the JK reaction was recently made in the Harvey group by Christopher Orme. ${ }^{60}$ Changing solvent from the originally investigated tetrahydrofuran to dimethylformamide allowed for the conversion of aldehyde 55 to alkene $\mathbf{6 9}$ in a 39\% yield (see Scheme 21). It was proposed that dimethylformamide, as a more polar aprotic solvent, may better stabilise the intermediate formed following attack of the sulfone anion on the aldehyde.

On a $10-20 \mathrm{mg}$ scale, the reaction was found to proceed best at $-35^{\circ} \mathrm{C}$ for 24 hours. However, scaling up to over $100 \mathrm{mg}$ with the same conditions consistently yielded below $10 \%$ of the alkene. As described above, it was expected that degradation of the starting material occurred via deprotonation of the acidic $\alpha$-proton of the aldehyde in the presence of the strong base used in the JK reaction. In order to mitigate this potential side reactivity, the reaction mixture was diluted to $0.05 \mathrm{M}$ in dimethylformamide at a larger scale (significantly lower than the concentrations typical of JK olefinations, $0.5-1 \mathrm{M}$ ), reacted at $35^{\circ} \mathrm{C}$ for 4 hours, and then warmed to room temperature to react for a further 24 hours. The alkene $\mathbf{6 9}$ was obtained in a $35 \%$ yield (Scheme 21). ${ }^{60}$ 
<smiles>CC#C[C@H]1O[C@H](C=O)[C@@H](OCc2ccccc2)C=C1Br</smiles>

55

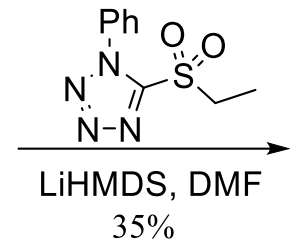

$35 \%$<smiles>C/C=C/[C@H]1O[C@H](C#CC#N)C(Br)=C[C@H]1OC(C)C</smiles>

69

Scheme 21: JK olefination of aldehyde $\mathbf{5 5}^{60}$

Synthesis of the natural product from alkene 69 is currently under investigation in the Harvey group. If installation of the (1E)-propenyl sidechain undergoes further optimisation, this route may also afford analogues of TAN-2483B that differ in areas other than the sidechain, which would help to develop a better structure-activity relationship (SAR) understanding.

The final synthetic route toward sidechain analogues of TAN-2483B proceeded via desilylation of the bromoalkene diol 63, using the successful conditions described above for the acetonide (viz.Scheme 19). The deprotected acetylene was formed in excellent yields, but was anticipated to degrade if subjected to column chromatography and was thus used without further purification. The crude acetylene was treated with sodium periodate to afford aldehyde 70, the substrate for Wittig olefination, in excellent yields. To access the ethyl ester sidechain analogues of TAN-2483B, the crude aldehyde was then treated with ethyl (triphenylphosphoranylidene)acetate to yield a 4:1 mixture of the ethyl esters $(\boldsymbol{Z})-\mathbf{7 1}$ and $(\boldsymbol{E})$ 71 in a $48 \%$ yield over three steps (Scheme 22). ${ }^{41}$

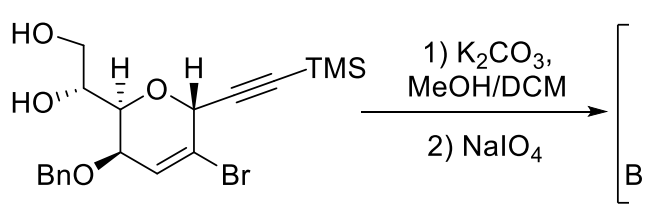

63

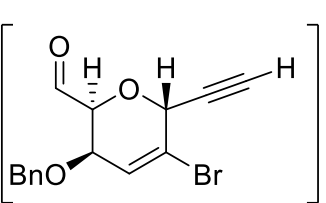

70

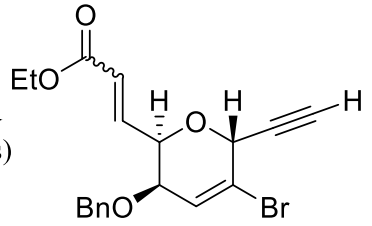

$4: 1$

$(Z)-71:(E)-71$

Scheme 22: Synthesis of ethyl esters $(\boldsymbol{Z})-\mathbf{7 1}$ and $(\boldsymbol{E})-\mathbf{7 1}^{41}$

The final four steps in the reaction sequence are conserved among the syntheses of the $(E)$ - and (Z)-ethyl ester analogues 51 and 52, 10-hydroxy-TAN 50 and the (E)-heptadecanoyl ester analogue 54. Advanced ketone intermediates $\mathbf{7 2}$ were formed via oxymercuration of the 
deprotected acetylene intermediates (e.g. $(\boldsymbol{E})-\mathbf{7 1}$ and (Z)-71) with Markovnikov selectivity (Scheme 23).<smiles></smiles>

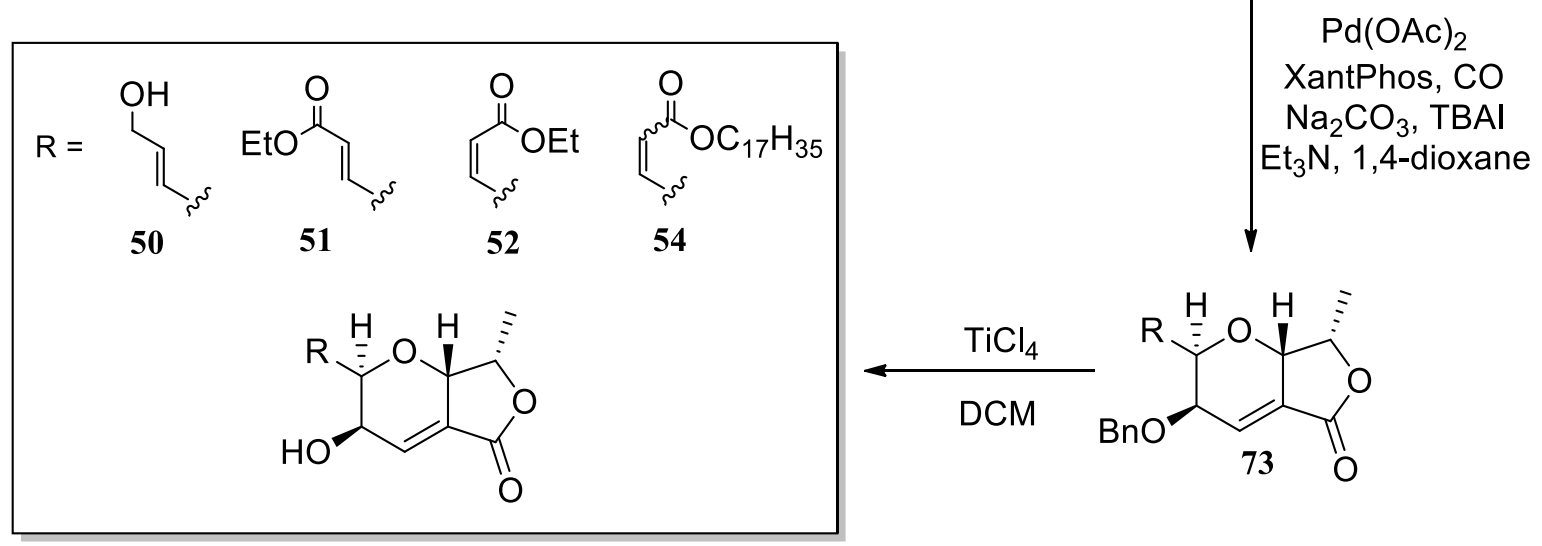

Scheme 23: Final synthetic steps to sidechain analogues of TAN-2483B

Oxymercuration reactions are typically carried out on alkene substrates to generate the corresponding acetoxymercury alcohol. Alkyne substrates afford enols, which undergo rapid tautomerisation to the more stable ketones. ${ }^{61}$ Treatment of the ketones $\mathbf{7 2}$ with sodium borohydride generated alcohols $\mathbf{5 3}$ with high stereoselectivity for the desired isomer. This was attributed to the effect described by the polar Felkin-Ahn model ${ }^{62}$ used to explain stereoselectivity of nucleophilic addition to a carbonyl group with an adjacent stereogenic centre (Figure 8).

a)

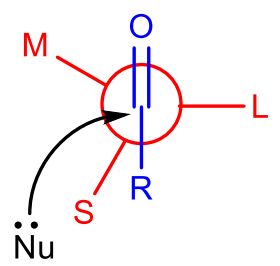

$\mathbf{S}=$ small, $\mathbf{M}=$ medium, $\mathbf{L}=$ large b)

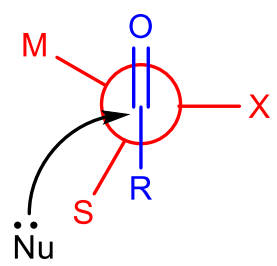

$\mathbf{X}=$ most electronegative substituent

Figure 8: Newman projections of the transitions state in the a) normal Felkin-Ahn model, and b) polar Felkin-Ahn model 
In the normal Felkin-Ahn model, the carbonyl $\mathrm{C}=\mathrm{O}$ bond is oriented perpendicular to the largest $\alpha$-substituent in the reactive conformation (Figure 8-a). Nucleophilic attack occurs along the Bürgi-Dunitz ${ }^{63}$ trajectory closest to the smallest substituent. The polar Felkin-Ahn model is applicable in substrates with an electronegative $\alpha$-substituent. In this case, a similar conformation is observed whereby the carbonyl $\mathrm{C}=\mathrm{O}$ bond is oriented perpendicular to the electronegative $\alpha$-substituent (Figure 8-b). This conformation is thought to be favoured due to the stabilising effect of hyperconjugation between the HOMO orbital of the nucleophile (i.e. the newly-forming bond) and the $\sigma^{*}$ orbital of the $\mathrm{C}-\mathrm{X}$ bond.

When applied to the reduction of ketones 72, the pyran ring oxygen is considered the electronegative $\alpha$-substituent (Scheme 24). The path of the incoming hydride nucleophile passes closest to the smallest substituent, the pseudoanomeric proton. The configuration of the newly-formed chiral centre was confirmed by hydrogenation of a later intermediate (73) and by nOe correlations. ${ }^{41}$

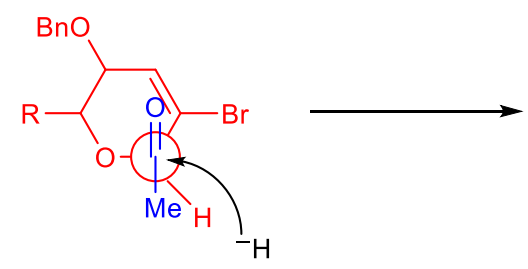

71

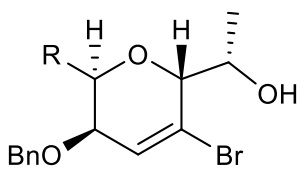

53

Scheme 24: Polar Felkin-Ahn model for the reduction of ketones $\mathbf{7 2}$

Finally, the palladium-catalysed carbonylation was carried out on alcohols $\mathbf{5 3}$ as described above to produce furopyrans 73 . The removal of the benzyl protecting group was carried out with titanium tetrachloride in dichloromethane to afford sidechain analogues 50, 51, 52 and 54 (see Scheme 12).

\subsection{Bioactivity of TAN-2483A}

Initial bioassays of TAN-2483A revealed two primary activities: (1) inhibition of the $c$-Src tyrosine kinase (a known anticancer target) and (2) inhibition of parathyroid hormone-induced bone resorption of a mouse femur. ${ }^{16}$ Therefore, analogues of TAN-2483A and TAN-2483B 
have potential relevance in human therapeutics, including in cancer therapy and osteoporosis treatment.

Kinases are enzymes which catalyse the transfer of phosphate groups from adenoside triphosphate (ATP) to specific molecular substrates. ${ }^{64}$ This process, known as phosphorylation, usually results in a functional change in the substrate. Protein kinases, comprising some 500 enzymes, phosphorylate specific amino acid residues, often on other kinase enzymes, which results in signalling cascades modulating cell metabolism, transcription, and other processes. ${ }^{65}$ Mutations and disregulation of protein kinases are often associated with disease, and as such, protein kinases have become important drug targets ${ }^{64}$ - highlighted by the success of imatinib in treating chronic myeloid leukaemia through inhibition of the BCR-ABL protein resulting from gene mutation and fusion. ${ }^{2,66}$ The $c$-Src tyrosine kinase plays an important role in cell division, motility, and survival, and is often overexpressed in certain cancers. ${ }^{67,68}$ Elevated levels of the $c$-Src enzyme, which is inhibited by TAN-2483A, are associated with cancer progression by its activation of other signalling proteins. ${ }^{69}$ The development of selective kinase inhibitors is often difficult, ${ }^{70}$ though recent work has shown that rational design of selective $c$ Src inhibitors may be expedited by adding functionality proposed to interact with the phosphate-binding loop of $c$-Src. ${ }^{71}$

TAN-2483A also inhibits parathyroid hormone (PTH)-induced bone resorption, which involves the breaking down of bone and resorption into the blood stream. Bone is in equilibrium with bone formation, such that, in a healthy individual, about $10 \%$ of a human's bone is replaced each year. ${ }^{72}$ This equilibrium is mediated by osteoblasts (controlling bone formation) and osteoclasts (controlling bone resorption). ${ }^{73}$ If the balance between bone formation and resorption is disrupted - which may be caused by heightened levels of osteoclasts - pathogenic bone loss, like osteoporosis, can occur. Osteoclast-mediated bone resorption results in the release of $\mathrm{Ca}^{2+}$ ions into the blood. Low levels of $\mathrm{Ca}^{2+}$ stimulate the release of PTH, which acts to increase the formation and activity of osteoclasts indirectly via the modulation of osteoblasts. ${ }^{74}$ TAN-2483A was reported to inhibit the PTH-induced bone resorption of a mouse femur. ${ }^{16}$ It is unclear whether TAN-2483A directly affects PTH; the inhibition of bone resorption may instead be the result of a downstream effect of the inhibition of $c$-Src tyrosine kinase, as $c$-Src will alter cell growth, which may in turn affect the release of PTH and thus alter bone resorption activity. 


\subsection{Bioactivity of TAN-2483B analogues}

The bioactivities of the TAN-2483B analogues 10-hydroxy 50, $(E)$-ethyl ester $\mathbf{5 1}$ and (Z)-ethyl ester 52 were tested in a cell growth inhibition assay and a kinase inhibition assay. ${ }^{75}$ Due to the promising inhibitory activity of the (Z)-ethyl ester analogue $\mathbf{5 2}$ against a range of related tyrosine kinases, $\mathbf{5 2}$ has emerged as the primary lead compound for future development and SAR studies.

\subsubsection{Cell growth inhibition}

Inhibition of cell growth by analogues 50, 51 and $\mathbf{5 2}$ was tested using MTT cell proliferation assays with the HL-60 (human promyelocytic leukemia) and 1A9 (human ovarian cancer) cell lines. The HL-60 genome contains an amplified c-Myc proto-oncogene, and thus HL-60 cell lines are commonly used to model human myeloid cell differentiation. ${ }^{76}$ The $1 \mathrm{~A} 9$ cell line is a copy of the A2780 human ovarian carcinoma cell line. The $\mathrm{IC}_{50}$ values of both the (Z)-ethyl ester and the $(E)$-ethyl ester analogues were in the low micromolar range against both cells lines, while the 10-hydroxy analogue displayed an $\mathrm{IC}_{50}$ of $42 \mu \mathrm{M}$ against HL-60 and was not tested against 1A9 (Table 2).

\begin{tabular}{llc}
\hline Analogue & $\mathbf{I C}_{\mathbf{5 0}}(\boldsymbol{\mu M})$ & \\
\hline & HL-60 & $\mathbf{1 A 9}$ \\
\cline { 2 - 3 }$(Z)$-ethyl ester $\mathbf{5 2}$ & 3.6 & 9.0 \\
$(E)$-ethyl ester $\mathbf{5 1}$ & 2.4 & 3.4 \\
10-hydroxy $\mathbf{5 0}$ & 42 & n.t. \\
\hline
\end{tabular}

Table 2: Cell growth inhibition by TAN-2483B analogues

\subsubsection{Kinase inhibition}

Selected analogues were tested in a kinase inhibition assay by Life Technologies. The inhibitory activity of TAN-2483A on the $c$-Src kinase was not observed in the TAN-2483B sidechain analogues to any significant extent (Table 3). Inhibition of Bruton's tyrosine kinase (BTK), bone marrow kinase on chromosome X (BMX) and resting lymphocyte kinase (TXK1), 
however, was observed among all of the analogues tested, most notably the (Z)-ethyl ester $\mathbf{5 2}$. These three enzymes are members of the related family of Tec non-receptor tyrosine kinases, which also include tyrosine kinase expressed in hepatocellular carcinoma (TEC) and interleukin-2-inducible T-cell kinase (ITK). ${ }^{77}$ BTK plays an important role in B-cell receptor signalling and regulates cell proliferation and survival in several B-cell malignancies. ${ }^{78}$ Smallmolecule BTK inhibitors have shown promising anti-tumour activity in pre-clinical and, recently, clinical trials. ${ }^{79}$ Ibrutinib, a potent selective inhibitor of BTK, was approved by the US Food and Drug Administration in 2013 for the treatment of relapsed mantle cell lymphoma. At a $10 \mu \mathrm{M}$ concentration of $\mathbf{5 2}$, activity of the BTK kinase was inhibited by $83 \%$. BMX has approximately $70 \%$ sequence homology to BTK, and has roles in inflammation and signalling pathways. ${ }^{80}$ Considering the strong inhibition of BTK, it was therefore unsurprising that BMX activity was inhibited by $67-80 \%$ at a $10 \mu \mathrm{M}$ concentration of analogues $\mathbf{5 0}-\mathbf{5 2}$.

Serine/threonine kinases 5' AMP-activated protein kinase (AMPK), polo-like kinase 1 (PLK1), NUAK2 and mitogen-activated protein kinase (MAPK14) were also inhibited to various extents. The (Z)-ethyl ester $\mathbf{5 2}$ again displayed the highest inhibition at a $10 \mu \mathrm{M}$ concentration.

\begin{tabular}{lcclllllll}
\hline Analogue & \multicolumn{1}{c}{ Percent inhibition at 10 $\boldsymbol{\mu M}$} \\
\hline & SRC & BTK & $\begin{array}{l}\text { AMPK } \\
\text { A2/B1/G1 }\end{array}$ & PLK1 & BMX & NUAK2 & $\begin{array}{l}\text { MAPK } \\
\mathbf{1 4}\end{array}$ & TXK1 \\
\cline { 2 - 9 }$(Z)$-ethyl ester 52 & -38 & 83 & 81 & 81 & 80 & 76 & 74 & 71 \\
$($ E)-ethyl ester 51 & 13 & 73 & 48 & 18 & 75 & 12 & 40 & 25 \\
10-hydroxy 50 & 10 & 55 & 25 & 12 & 67 & 3 & 24 & 16 \\
\hline
\end{tabular}

Table 3: Kinase inhibition by TAN-2483B analogues

\subsubsection{Computational modelling}

Understanding the potential binding mode of TAN-2483B-related furopyrans for specific protein kinases may be facilitated by computational modelling studies. Work is currently underway in the Harvey group by $\mathrm{PhD}$ candidate Jordan McCone to devise a kinase model to investigate the binding of TAN-2483B analogues to the BTK enzyme. The results obtained from this study are intended to direct the focus of future medicinal chemistry to optimise the structure of analogues for potency and selectivity. 


\subsection{Lactam analogues of natural products}

Lactam analogues of therapeutically-relevant natural products are well-established targets in medicinal chemistry. ${ }^{81-85}$ These elaborations are usually intended to add to an understanding of SARs, and in some cases increase stability. Sterner and co-workers synthesised ${ }^{81}$ lactam analogues of the lactone-containing natural product galiellalactone, an inhibitor of the transcription factor STAT3 in prostate cancer cells. ${ }^{86}$ It was anticipated that the analogues would show enhanced metabolic stability, and better selectivity because unsaturated lactams are less reactive as Michael acceptors than unsaturated lactones. However, bioassay results were not disclosed. More recently, the Zhang group synthesised a desmethyl lactam analogue of the lactone-containing cytotoxic natural product parthenolide (74), in addition to a further variant (75) (Figure 9). ${ }^{82}$ Unfortunately, the lactam analogue (76) exhibited greatly reduced cytotoxicity $\left(\mathrm{IC}_{50}>50 \mu \mathrm{M}\right)$ against the six cancer lines tested.

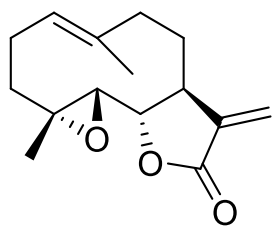

parthenolide (74)

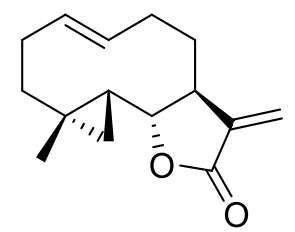

75

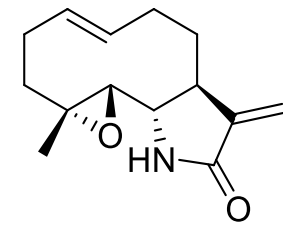

76

Figure 9: Parthenolide and analogues

Another notable synthesis of lactam analogues was conducted by Borzilleri and co-workers, where several macrolactam analogues of the epothilone macrolides were prepared (Figure 10). ${ }^{83}$ The epothilones (e.g. 77) are cytotoxic natural products that operate via a similar mode of action to the chemotherapeutic agent paclitaxel (Taxol), by inducing tubulin polymerisation and stabilisation of microtubules. ${ }^{87}$ In contrast to paclitaxel, however, the epothilones retain high potency against P-glycoprotein-expressing multiple drug resistant cells. ${ }^{8}$ While most of the synthesised lactam analogues (e.g. 78) had significantly decreased tubulin-polymerising and cytotoxic properties, the lactam BMS-247550 (Ixabepilone, 79) was comparable to paclitaxel in both assays. Furthermore, Ixabepilone was found to be superior to epothilones A$\mathrm{F}$ in preclinical anti-tumour models. The enhanced stability of the lactam moiety toward metabolic cleavage was proposed to partly account for these results. Ixabepilone was approved by the US Food and Drug Administration in 2007 for the treatment of certain cancers that have not responded to conventional chemotherapeutic agents. 
<smiles>[R]C(=O)C[C@@H](O)[C@H](C[C@@H]1O[C@H]1CCCC[C@@H](C)[C@@H](O)[C@@H](C)C(=O)C(C)C)C(C)=Cc1csc(C)n1</smiles>

$\mathrm{R}=\mathrm{O}$, epothilone $\mathrm{A}(\mathbf{7 7})$

$\mathrm{R}=\mathrm{NH}$, example macrolactam analogue (78)

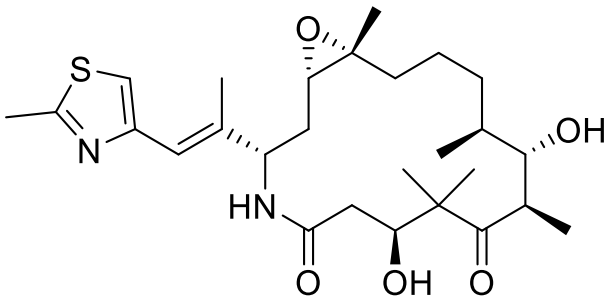

Ixabepilone (79)

Figure 10: Epothilone natural product and lactam analogue

\subsection{Project aims}

The main research aim of the project presented in this thesis was to investigate synthetic routes toward the formation of lactam analogues of TAN-2483B (80, Figure 11). Attempts to install the amine via a reductive amination were proposed to be carried out on advanced ketone intermediates containing the $(E)$ - and $(Z)$-ethyl ester sidechain, because their installation via Wittig conditions was more facile than the Julia-Kocienski conditions used to install the $1 E$ propenyl sidechain found in the natural product. Furthermore, the (Z)-ethyl ester analogue 52 is currently the main lead compound for future development, based on kinase inhibition results.

The analogues of TAN-2483B synthesised in the Harvey group appeared to degrade in nucleophilic media. Hydrolysis of the lactone moiety in TAN-2483B sidechain analogues could be compared to that observed in waol A, the vinylogue of TAN-2483B. Base-mediated methanolysis of waol A produces its ring-opened methyl ester variant, waol B. ${ }^{29} \mathrm{We}$ proposed that lactam analogues will be more stable in nucleophilic media than the corresponding lactones. Enhanced stability of the lactam moiety is expected because of its reduced electrophilicity (and steric hindrance created by substituents on the nitrogen may further impede nucleophilic attack). Reductive amination of an advanced intermediate ketone to install the amine prior to lactam formation was envisaged to provide such a site for further functionalisation at the nitrogen centre. These elaborations of TAN-2483B are expected to produce new compounds for enhancing the understanding of the SARs (81, Figure 11).

Functionalisation of the lactam nitrogen was envisaged to proceed via a reductive amination using benzylamine, $N$-propylamine or ammonium acetate, which would generate the benzylsubstituted amine, the $N$-propyl-substituted amine or the primary amine, respectively. Lactam analogues obtained during the course of this thesis were intended to direct the choice of future 
amine substituents through SAR results. Furthermore, to expedite the synthesis of further analogues in future projects, optimisation of the synthetic route toward such analogues - and the natural product itself - is desirable. This thesis therefore outlines efforts toward the synthesis of lactam analogues of TAN-2483B.

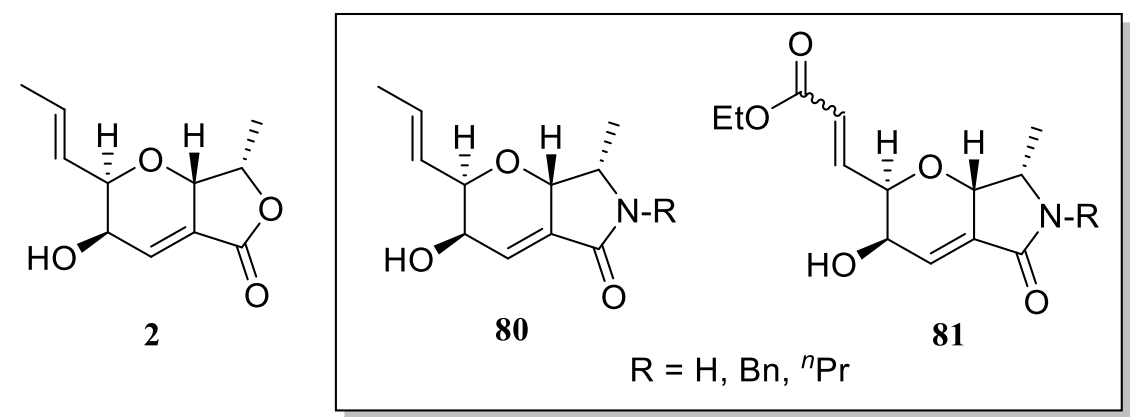

Figure 11: TAN-2483B (left); lactam analogues of TAN-2483B (centre); the proposed targets, the (E/Z)-ethyl ester lactam analogues of TAN-2483B (right)

\subsection{Proposed synthetic route to TAN-2483B lactam analogues}

The proposed synthetic route toward TAN-2483B lactam analogues $\mathbf{8 1}$ diverges from that previously used for sidechain analogues only toward the end of the synthesis. As a result of previous work in the Harvey group, many of the early steps in the reaction sequence have been optimised to some extent. ${ }^{41,42,53,54,60}$ The synthetic route diverges at the advanced ketone intermediate (72, Scheme 25).<smiles>[R]N[C@H](C)[C@H]1O[C@H](/C=C/C(=O)OCC)[C@@H](OBr)C=C1Br</smiles>
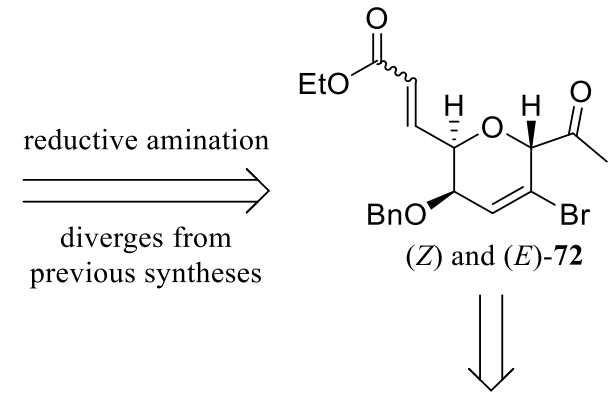<smiles>OCC1O[C@H](O)C(O)C(O)[C@@H]1O</smiles><smiles>CC#CC1(C)OCC(C2OC=CC2[Se]Br)O1</smiles><smiles>CC#CC1(C)OCC(C2OC(OC(C)=O)C(Br)=CC2Br)O1</smiles><smiles>C=C</smiles><smiles>CC(C)(C)C#CC1=CC(OCc2ccccc2)C(Br)OC1C=O</smiles>

Scheme 25: Proposed retrosynthesis of lactam analogues of TAN-2483B 
For the formation of lactam analogues, stereoselective reductive amination of $(\boldsymbol{Z})$ - and $(\boldsymbol{E})-\mathbf{7 2}$ is required to produce amines $\mathbf{8 2}$. Reductive amination is a powerful reaction widely used in chemical synthesis, ${ }^{89}$ and stereoselective transformations have become commonly accessible. ${ }^{90,91}$ A common problem found in the synthesis of primary amines via reductive amination is the formation of secondary and tertiary amine by-products. Careful optimisation of reaction conditions, however, can mitigate this side reactivity. For example, Timmer and coworkers recently reported on the protecting group-free synthesis of primary amines from aldehydes with no or minimal formation of the secondary and tertiary by-products. ${ }^{92}$

The reaction usually proceeds via sequential imine formation and reduction in one pot, where the formation of the imine is an equilibrium step that can be pushed toward imine formation with the extraction of water from the reaction (Scheme 26).

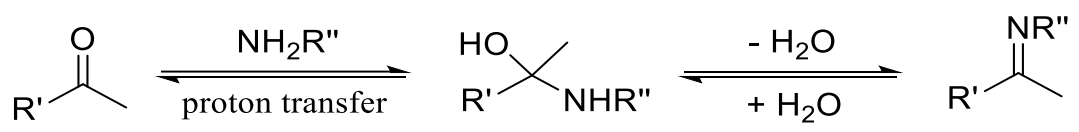

Scheme 26: Imine formation equilibrium

The choice of amine reagent determines the substitution of the amine product. Primary amines may be accessed from ammonia (commonly added in the form of ammonium acetate or ammonium chloride), whereas secondary amines may be accessed from a primary amine reagent. Initial investigations into the reductive amination were intended to be carried out using benzylamine, $N$-propylamine and ammonium acetate.

The reducing agents are often required to be more reactive toward protonated imines than their ketone or aldehyde precursors, otherwise reduction to the alcohol can dominate. Furthermore, such reductants must tolerate the mildly acidic conditions that are usually required, as hydride reduction is expected to be more facile on a protonated iminium species than the corresponding neutral imine. Sodium cyanoborohydride or sodium triacetoxyborohydride are typically used as selective reducing agents for reductive aminations. ${ }^{93}$ Sodium cyanoborohydride is attractive because at pH 6-8 it preferentially reduces imines over carbonyl species and is stable in aqueous solutions. ${ }^{94}$ On the other hand, it is both highly toxic and flammable, and in strongly acidic conditions can release hydrogen cyanide gas. ${ }^{95}$ Furthermore, a large excess of amine may be required, particularly for less basic amines or those with more steric hindrance. ${ }^{94,96}$ A common alternative to sodium cyanoborohydride is sodium triacetoxyborohydride, which is a milder 
reductant as the steric and electron-withdrawing effects of $(\mathrm{OAc})_{3}$ stabilise the B-H bond. ${ }^{97}$ This reductant is less stable in aqueous media and often performs poorly in methanol, but is highly compatible with dimethylformamide, tetrahydrofuran, 1,2-dichloroethane and acetonitrile..$^{93,95,98}$ Tetramethylammonium triacetoxyborohydride is less commonly used in reductive aminations, but is used in the Evans-Saksena stereoselective reduction of $\beta$-hydroxy ketones. $^{99}$ It has, however, been demonstrated to promote the stereoselective reductive amination of several ketoepoxides with the nucleophile benzylamine in 1,2-dichloroethane. ${ }^{100}$ The immediate availability of tetramethylammonium triacetoxyborohydride, and its relative non-toxicity, motivated its use in the initial reductive amination attempts.

Because the formation of the imine from the ketone is reversible, dehydrating agents are often employed to push the equilibrium toward the imine. Anhydrous magnesium sulfate or $3 \AA$ molecular sieves are commonly used, though not necessary. ${ }^{96}$

Considering that reduction of ketones $\mathbf{7 2}$ with sodium borohydride was stereoselective via substrate control, ${ }^{41}$ it was envisaged that the reductive amination of the same substrate could be similarly stereoselective. Asymmetric reductive aminations, however, are also possible. The $(R)$ - or $(S)$-phenylethylamine (PEA) auxiliary has been used with a number of catalysts in the stereoselective reductive amination of prochiral ketones followed by hydrogenolysis of the auxiliary. ${ }^{101}$ At this late stage of the synthesis, however, finding reaction conditions orthogonal to the existing functionality present in substrate $\mathbf{7 2}$ (and related compounds) may be challenging. For example, hydrogenolysis conditions that are typically used with PEA will probably reduce the alkenes present. Gudmundsson and co-workers investigated alternative hydrogenolysis conditions when earlier attempts using conventional catalysts led to loss of the chlorine and decomposition of the tetrahydrocarbazole moiety (Scheme 27). ${ }^{102}$ During scaleup, debenzylation of $\mathbf{8 3}$ catalysed by 2-3 equivalents of boron trichloride in dichloromethane produced amine $\mathbf{8 4}$ in good to excellent yields. However, such a strategy involving extra steps should be avoided if possible; hence, the achiral variant was initially pursued to investigate its facility and the degree of substrate-controlled selectivity. 
<smiles>COc1ccc([C@H](C)N[C@H]2CCCc3c2[nH]c2ccc(Cl)cc32)cc1</smiles>

83
1) $\mathrm{BCl}_{3}, \mathrm{DCM}, 0^{\circ} \mathrm{C}$<smiles>O=C(O)c1ccccn1</smiles>

$(80-92 \%)$<smiles>N[C@H]1CCCc2c1[nH]c1ccc(Cl)cc21</smiles>

84

Scheme 27: Orthogonal hydrogenolysis conditions ${ }^{102}$

The palladium-catalysed carbonylation/lactam formation of amines $\mathbf{8 2}$ was expected to proceed without additional complication to produce lactams 85 (Scheme 28). Indeed, the increased nucleophilicity of the nitrogen compared to the analogous oxygen nucleophile may result in a more facile reaction. It should be noted, however, that increasing the size of substituents on the nitrogen may impede the final nucleophilic attack/reductive elimination step of the carbonylation ring-closure. Debenzylation of 85 to yield TAN-2483B ethyl ester lactam analogues $\mathbf{8 1}$ was envisaged to be carried out using titanium tetrachloride in dichloromethane, consistent with the previous syntheses of sidechain analogues. ${ }^{41}$<smiles>CCOC(=O)/C=C/C1O[C@H](C(C)=O)C(Br)=CC1OC(=O)c1ccccc1</smiles>

72

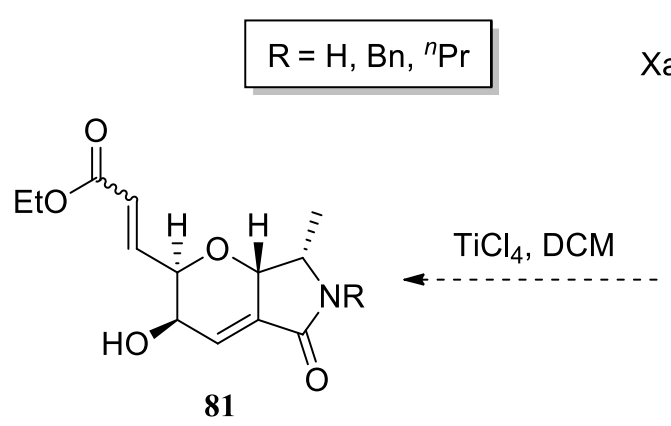<smiles>[R]N[C@H](C)[C@H]1O[C@H](/C=C/C(=O)OCC)[C@@H](OC(=O)c2ccccc2)C=C1Br</smiles>

82

Scheme 28: Final synthetic steps to TAN-2483B ethyl ester lactam analogues 


\section{Results and discussion}

\subsection{Formation of the benzyl-protected glycal $\mathbf{4 5}$}

The formation of benzyl-protected glycal $\mathbf{4 5}$ follows a four-step literature procedure from Dmannose. ${ }^{43}$ Catalytic $I_{2}$ was used to form the bisacetonide 57 from D-mannose dissolved in acetone. Following a series of seven recrystallisations, the purified product was isolated as colourless crystals in an $82 \%$ yield (Scheme 29 ).

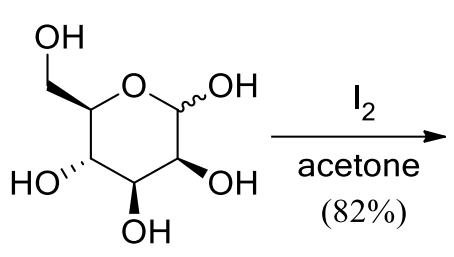

D-mannose

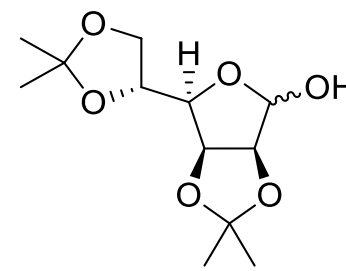

57

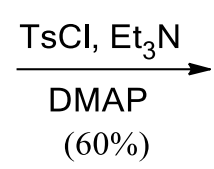

$(60 \%)$

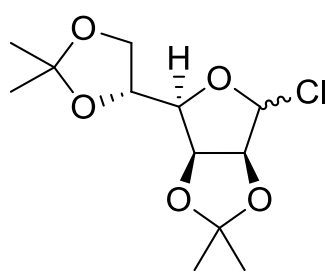

58

Scheme 29: Synthesis of chlorofuran 58

The chlorofuran $\mathbf{5 8}$ was accessed by sequentially treating furanol $\mathbf{5 7}$ in dichloromethane with DMAP, tosyl chloride and trimethylamine. In this reaction, the furanol is converted into the tosylated intermediate, which is then substituted in situ by chloride. While previous members of the Harvey group reported yields between 60 to $70 \%, 53,54$ early attempts at the chlorodehydroxylation produced disappointing yields between 16 to 38\%. Furthermore, multiple column chromatographic purification steps were required to isolate the pure product, and significant quantities of starting material and tosyl chloride were recovered. Loading the crude product onto a column for silica gel purification is problematic if significant quantities of tosyl chloride are present, because it tends to crystallise along the walls of the column. A TLC plate spotted with the crude reaction mixture also revealed a UV-active spot significantly less polar than the product $\left(\mathrm{R}_{f} \approx 0.89\right.$ v.s. $\mathrm{R}_{f} \approx 0.40$ in $1: 1$ petroleum ether:ethyl acetate). It was postulated that this may be the tosylated intermediate, which would indicate that the reaction had not gone to completion.

In an attempt to increase the reaction yield, attention was turned to purifying the reagents. Triethylamine was freshly distilled over calcium hydride. Subsequently, increased reaction yields of 54\% and 58\% were obtained. Tosyl chloride, which is known to degrade into $p$ toluenesulfonic acid and hydrogen chloride, was then purified via a reported procedure. ${ }^{103}$ 
Thus, the reagent, an off-white solid, was dissolved in chloroform, diluted with petroleum ether to precipitate impurities, and filtered; the filtrate was then clarified with charcoal and concentrated. Purified tosyl chloride was isolated as white crystals. The most notable difference in the ${ }^{1} \mathrm{H}-\mathrm{NMR}$ spectra of the crude and purified samples was a significant concentration of water in the crude tosyl chloride. Dry conditions are desirable for the reaction because displacement of the tosyl group by water would reduce the amount of product able to be formed via the tosylated intermediate. When the reaction was repeated using both distilled trimethylamine and purified, dry tosyl chloride, chlorofuran $\mathbf{5 8}$ was obtained in an increased yield of $60 \%$.

The glycal 45 was obtained following a two-step procedure in which elimination leads to an intermediate alcohol that is immediately protected with a benzyl group. Naphthalene was dissolved in tetrahydrofuran and treated with sodium to produce the naphthalene radical anion, which was apparent by the deep green colour of the solution. Chlorofuran $\mathbf{5 8}$ in tetrahydrofuran was added to the reaction mixture via cannula. Two single-electron transfer steps ${ }^{50}$ result in the elimination of acetone and chloride to produce the intermediate alcohol $\mathbf{8 6}$. Alcohol 86 is known to be unstable - it has been proposed that this is due to self-oligomerisation ${ }^{43}-$ so the hydroxyl group was immediately protected by treating the crude material with benzyl bromide, sodium hydride and TBAI, to yield the benzylated glycal 45 (Scheme 30).

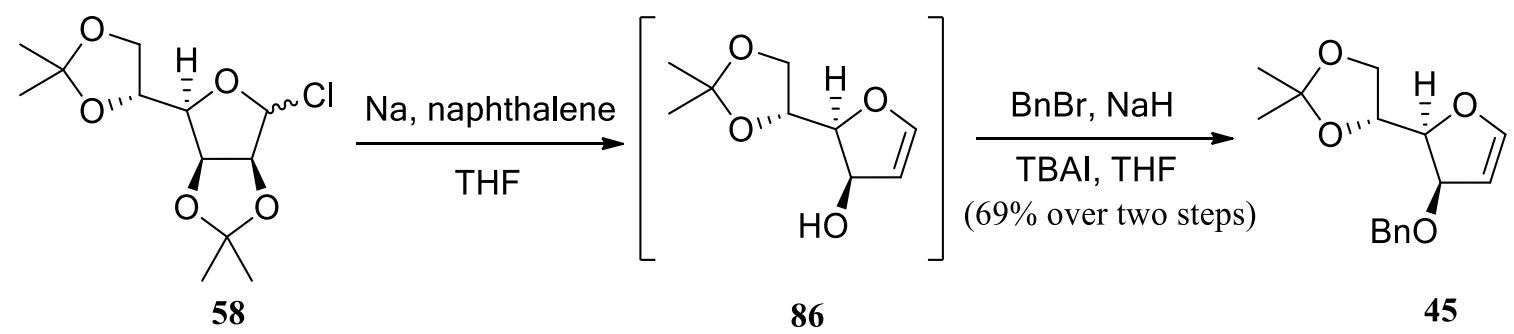

Scheme 30: Synthesis of benzylated glycal 45

Purification of the crude material was problematic because of the large excess of naphthalene required (8 equivalents). A reaction with 10 grams of chloride $\mathbf{5 8}$ used approximately 40 grams of naphthalene, and the large amount of solvent required to solubilise the crude material for loading onto the column lowered the chromatographic resolution. Attempts to remove the naphthalene using reverse-phase column chromatography were unsuccessful. 
Previous purification methods employed a gradient elution system starting from pure hexanes to remove the naphthalene, followed by $20: 1$ to $9: 1$ petroleum ether:ethyl acetate. Here, the glycal was purified using a simplified gradient elution system (9:1 to 5:1 petroleum ether:ethyl acetate) as it was found to be unnecessary to first remove the naphthalene with pure petroleum ether. Dry-loading the crude product onto silica gel was explored as a way to avoid using excess solvent to load the column. On a 10-gram scale, the crude material was required to be split into three separate dry-loaded columns due to practical limitations in column size. This protocol yielded $69 \%$ of the pure glycal over two steps, higher than previous attempts without dryloading which yielded between 50 to $60 \%$.

It is also notable that glycal $\mathbf{4 5}$ appears to be unstable in acidic media (Scheme 31 ). The aromatic degradation product 87 was previously isolated in the Harvey group, ${ }^{41}$ and was indeed observed in this study. In order to obtain NMR spectra of $\mathbf{4 5}$, the deuterated chloroform solvent must first be neutralised by passing it through a potassium carbonate plug. The acid sensitivity of $\mathbf{4 5}$ also requires purification by column chromatography to be conducted quickly to avoid degradation due to the slight acidity of silica gel. It is recommended that neutralisation of silica gel with $1 \%$ triethylamine prior to chromatographic separation be conducted in the future. Ultimately, the glycal $\mathbf{4 5}$ was obtained in a 34\% yield over four steps from D-mannose.

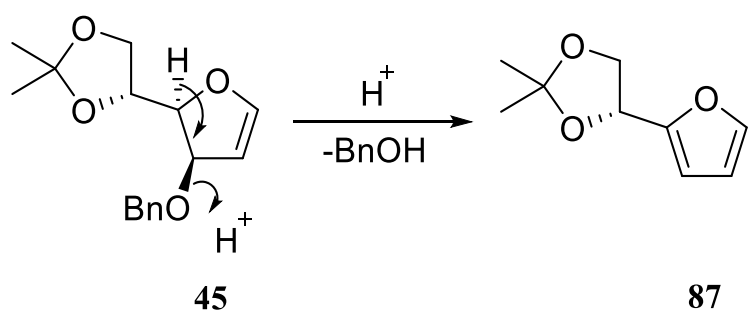

Scheme 31: Proposed mechanism of acid-promoted degradation of glycal 45

\subsection{Gem-Dibromocyclopropanation and ring expansion}

The acetate 56 was obtained from glycal $\mathbf{4 5}$ following the procedure initially described by Galin $^{52}$ and modified in the Harvey group ${ }^{41,53,54}$ (Scheme 32). Distillation of bromoform prior to use was necessary to remove the $1-3 \%(\mathrm{v} / \mathrm{v})$ ethanol stabiliser present in commercial bromoform, otherwise nucleophilic attack of ethanol on glycal 45 leads to the known byproduct $\mathbf{8 8}$ (Figure 12). ${ }^{41}$ 


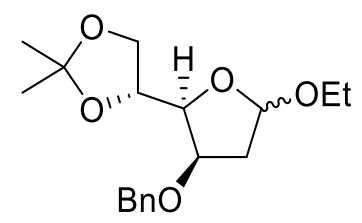

88

Figure 12: Acetal by-product 88 observed by Somarathne ${ }^{41}$

Glycal 45 in a large excess of freshly distilled bromoform was treated with potassium carbonate, sodium acetate, 18 -crown-6 and tetra- $N$-butylammonium bromide (TBAB) and stirred under nitrogen at room temperature to create a uniform dispersion. 18-crown-6 was used to chelate potassium in order to enhance the solubility and hence basicity of potassium carbonate. Potassium carbonate was required to generate the dibromocarbene species from bromoform, and TBAB was used as a phase-transfer catalyst. The reaction mixture was heated to $82^{\circ} \mathrm{C}$ and reacted for 3 days, while further portions of bromoform were added after each day of heating. The acetate 56 was obtained as a mixture of $\alpha$ - and $\beta$-anomers in a $61 \%$ yield (Scheme 32).<smiles>CC1(C)OC[C@H](C2OC=C[C@@H]2O)[C@@H]1Br</smiles>

45

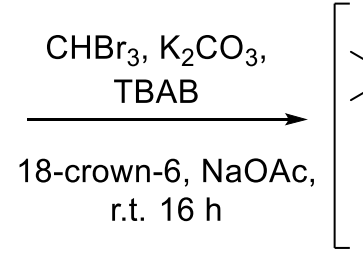
r.t. $16 \mathrm{~h}$ L<smiles>CC1(C)OC[C@H](CO[C@H]2O[C@H](Br)[C@H](Br)[C@H]2Br)[C@@H]1Br</smiles>

62

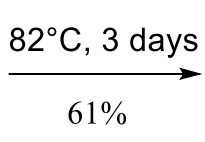<smiles>CC(=O)O[C@H]1O[C@H]([C@@H]2COC(C)(C)O2)[C@H](O)C=C1Br</smiles>

56

Scheme 32: Gem-Dibromocyclopropanation and ring expansion

Two successive iterations of purification via column chromatography allowed a portion of $\boldsymbol{\alpha}$ 56 to be obtained in a pure form. It was therefore possible to characterise the resonances of the ${ }^{1} \mathrm{H}$ - and ${ }^{13} \mathrm{C}-\mathrm{NMR}$ spectra of $\boldsymbol{\alpha - 5 6}$, and in doing so distinguish the resonances of $\boldsymbol{\alpha}$ - and $\boldsymbol{\beta}-\mathbf{5 6}$ in the remaining mixture to enable full characterisation of $\boldsymbol{\beta}-\mathbf{5 6}$ (see section 4.2).

\subsection{C-Glycosidation via installation of the TMS-protected acetylene}

A stereoselective alkynylation reaction was used to install a two-carbon fragment at the anomeric centre. In initial attempts, acetate $\mathbf{5 6}$ was treated with bis(trimethylsilyl)acetylene, 
cooled to $-78^{\circ} \mathrm{C}$, treated with tin tetrachloride, and then the mixture was warmed to room temperature and left to react for 1-2 hours. These conditions, which were employed by previous members of the Harvey group, yielded a mixture of the expected acetonide-protected acetylene 64 and the acetonide-deprotected diol 63 in varying ratios (see Scheme 17). Because diol 63 is desired for the next step, any acetonide 64 isolated following purification by column chromatography was then treated with trifluoroacetic acid in acetonitrile to produce the diol. Somarathne found that treating the acetonide with 60 equivalents of trifluoroacetic acid at $0^{\circ} \mathrm{C}$, and then warming to room temperature and reacting for 1 hour, yielded the diol in near quantitative yield. ${ }^{41}$ To determine whether such a large excess of trifluoroacetic acid was necessary, this project investigated whether the reaction would proceed with fewer equivalents. While the reaction was initially sluggish, a 74\% yield of diol 63 was obtained upon treating the acetonide with 20 equivalents of trifluoroacetic acid at $0^{\circ} \mathrm{C}$, warming to room temperature and reacting for a prolonged period of 16 hours (Scheme 33). This result indicated that there may be a trade-off between using a large excess of trifluoroacetic acid, and reacting for a prolonged period of time.

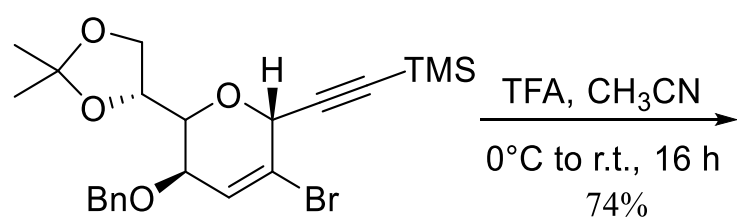

64

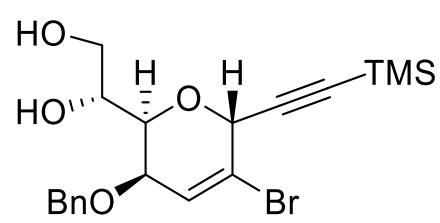

63

Scheme 33: Deprotection of acetonide 64 using 20 equivalents of TFA

Instead of following the proposed synthetic route, it would be more efficient to produce the desired diol product 63 without the need to isolate, purify and react any remaining acetonide. This project therefore investigated whether adding trifluoroacetic acid to the crude reaction mixture after the alkynylation was completed could yield solely the diol product. For the initial attempt, the acetate was dissolved in dichloromethane, treated with bis(trimethylsilyl)acetylene, cooled to $-78^{\circ} \mathrm{C}$ and treated with tin tetrachloride (using the standard equivalents used in previous work). Following the reaction progress by TLC, after one hour most of the starting material was consumed, and the acetonide and diol products were present in approximately a 2:1 ratio. Trifluoroacetic acid (11 equivalents) ${ }^{\mathrm{b}}$ was added, and the

\footnotetext{
${ }^{\mathrm{b}} 11$ equivalents of trifluoroacetic acid is in relation to the amount of acetate starting material $\mathbf{5 6 .}$
} 
mixture was left to react for one hour, whereupon a further 11 equivalents of trifluoroacetic acid were added. The reaction mixture was warmed to room temperature and reacted for one more hour. Following workup and purification steps, the diol was obtained in a poor yield of $29 \%$.

The one-pot, two-step procedure was attempted a second time. The acetate was again dissolved in dichloromethane, treated with bis(trimethylsilyl)acetylene, cooled to $-84^{\circ} \mathrm{C}$ and treated with tin tetrachloride. Instead of remaining at a low temperature, the reaction mixture was allowed to warm to approximately $0^{\circ} \mathrm{C}$ and reacted for two hours. Trifluoroacetic acid (10 equivalents) was added, and the mixture was left to react for a further two hours. Following workup and purification steps, the diol was obtained in a $45 \%$ yield over two steps.

Deprotection of the acetonide produces acetone, and under dry conditions the source of oxygen and hydrogen is not apparent. The one-pot procedure was carried out a third time using dichloromethane that was not sourced from the solvent purifier (and thus was expected to contain trace amounts of water), and glassware that was not flame-dried. Again, the acetate was dissolved in dichloromethane, treated with bis(trimethylsilyl)acetylene, cooled to $-78^{\circ} \mathrm{C}$ and treated with tin tetrachloride. The reaction mixture was then allowed to slowly warm to room temperature. After reacting for two and a half hours, the reaction mixture was cooled to $0^{\circ} \mathrm{C}$ and treated with trifluoroacetic acid (10 equivalents), warmed to room temperature and reacted for a further two hours. Following workup and purification steps, the diol was obtained in a $31 \%$ yield over two steps. This result was not competitive with either the two-reaction sequence or the one-pot procedure conducted with dry equipment and solvent. It therefore remains unclear whether dry solvents and flame-dried glassware affects the ratio of diol to acetonide produced, although the higher yields obtained using dry conditions are consistent with previous experience in the Harvey group. It is likely that adventitious moisture or water present in trifluoroacetic acid or tin tetrachloride is required for the deprotection of the acetonide. The required oxygen and hydrogen may also be derived from the glassware; this could be investigated in the future by running comparable reactions in silanised vs. unsilanised glassware.

The one-pot, two-step procedure was attempted a fourth time under similar (dry) conditions to that used in the second attempt. The reaction mixture was kept at $0^{\circ} \mathrm{C}$ and was sluggish, so was left to react overnight. The diol was eventually obtained in a $42 \%$ yield. 
A significant amount of by-product was isolated from reaction attempts three and four. Purification of the crude reaction mixture by column chromatography yielded a slightly less polar compound in about $15 \%$ of the mass of the isolated diol. An initial analysis of the ${ }^{1} \mathrm{H}$ NMR spectrum of the by-product suggested that the pyran ring protons $\mathrm{H}-1, \mathrm{H}-3, \mathrm{H}-4$ and $\mathrm{H}-$ 5 were all present, in addition to $\mathrm{H}-6$ and the $\mathrm{CH}_{2}$ group at $\mathrm{C}-7$. However, the absence of the characteristic trimethylsilyl $\mathrm{CH}_{3}$ and acetate $\mathrm{CH}_{3}$ proton singlets at approximately $0.18 \mathrm{ppm}$ and $2.16 \mathrm{ppm}$ respectively indicated that the anomeric acetate group in the starting material had been removed, but not substituted with the desired trimethylsilyl-protected acetylene. The ${ }^{13} \mathrm{C}$ NMR spectrum showed only twelve resonances, and was consistent with the conservation of the pyran ring system, the benzyl-protected alcohol at C-4 and the two-carbon diol sidechain. It was initially postulated that the anomeric acetate had been substituted with a chlorine atom sourced from tin tetrachloride. However, the pseudo-anomeric carbon C-1 (which was assigned by HSQC analysis) was observed at $93.7 \mathrm{ppm}$. This chemical shift was reasonably close to that observed for the acetate 56 (90.6 ppm), but was unexpectedly downfield for a chloridesubstituted species. The analogous carbon in the diol 63 appears at 69.9 ppm. Furthermore, HRMS of the compound showed peaks of near-equal abundance at a mass to charge ratio $(\mathrm{m} / \mathrm{z})$ of 344.0480 and 346.0460. The mass separation and abundance of the observed peaks were therefore indicative of a bromine-containing, but not chlorine-containing compound.

It was then realised that a bicyclic product had formed, presumably via nucleophilic attack of the primary alcohol on the oxonium ion. This bicyclic by-product is consistent with the conservation of all of the proton resonances in the ${ }^{1} \mathrm{H}$ NMR spectrum (albeit with small chemical shift changes), and with the ${ }^{13} \mathrm{C}$ NMR spectrum containing only twelve resonances. The chemical shift of C-1 was consistent with an acetal, and close to that observed for the acetal $\mathrm{C}-1$ in acetate 56. The peaks in the mass spectrum were proposed to correspond to the ammonium adducts of compound $89\left(\mathrm{C}_{14} \mathrm{H}_{15} \mathrm{BrO}_{4} \mathrm{NH}_{4}{ }^{+}\left[\mathrm{M}+\mathrm{NH}_{4}{ }^{+}\right]\right.$calc. 344.0492, found $344.0480, \Delta 3.49 \mathrm{ppm})$. The ${ }^{1} \mathrm{H}$ NMR spectrum of the by-product is shown in Figure 13. 


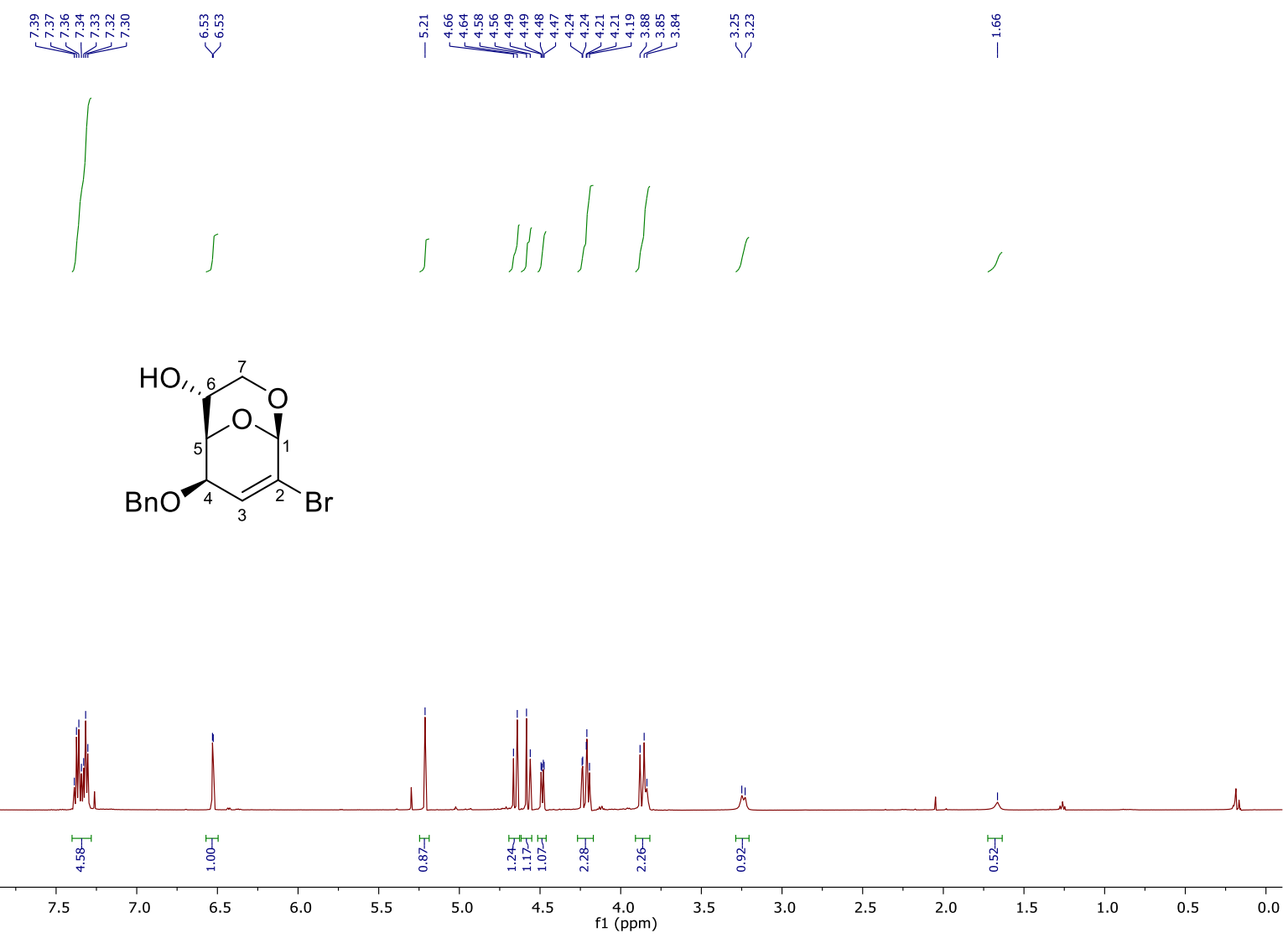

Figure 13: ${ }^{1} \mathrm{H}$ NMR spectrum of by-product 89

The one-pot, two-step sequence to the diol $\mathbf{6 3}$ investigated in this study produced relatively low yields (29-45\%). Although this procedure was able to save both time and expense by removing the steps required to isolate, purify and react the acetonide, the obtained yields were disappointing. It was reasoned that higher yields may be obtainable if the first reaction step (installation of the trimethylsilyl-protected acetylene) was quenched, worked up, and then subjected to the acetonide-deprotection conditions without prior column purification. This approach may be seen as a compromise between the one-pot, two-step method investigated here, and the two-step sequence taken previously.

To this end, the acetate $\mathbf{5 6}$ was dissolved in dry dichloromethane, treated with bis(trimethylsilyl)acetylene, cooled to $-78^{\circ} \mathrm{C}$ and treated with tin tetrachloride. After reacting at $-78^{\circ} \mathrm{C}$ for two hours, the reaction mixture was then warmed to room temperature and left to react for a further two hours. The reaction mixture was then quenched and worked up to yield a crude mixture of the acetonide 64 and the diol 63. The crude material was then dissolved in acetonitrile, cooled to $0^{\circ} \mathrm{C}$, treated with trifluoroacetic acid, allowed to warm to room 
temperature and left to react overnight. Following workup and column chromatography, the diol 63 was obtained in a pleasing $62 \%$ yield over two steps, in addition to $8 \%$ of the acetonide 64 (Scheme 34).

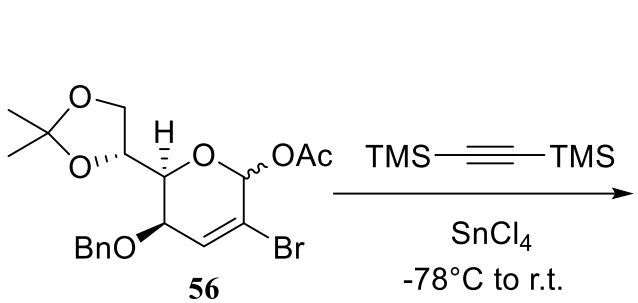

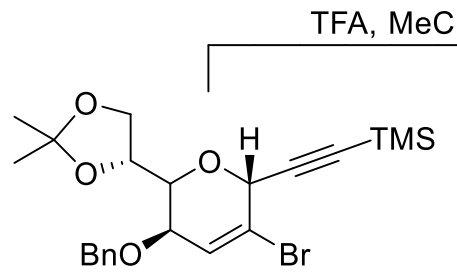

64<smiles>CS(C)(=O)(F)C#C[C@H]1O[C@H]([C@H](O)CO)[C@@H](OBr)C=C1Br</smiles>

63

$62 \%$ over two steps

\subsection{Desilylation of the TMS-protected acetylene diol $\mathbf{6 3}$}

Desilylation of the TMS-protected acetylene can be conducted on the diol $\mathbf{6 3}$, or subsequent to installation of the $(Z)$ - and $(E)$-ethyl ester sidechains via diol cleavage and Wittig olefination. Steric hindrance created by the TMS group could enhance $(E)$-selectivity of the Wittig olefination - and the (Z)-ethyl ester is desired here - so desilylation was carried out on diol $\mathbf{6 3}$.

The TMS-protected acetylene diol 63 was treated with potassium carbonate and methanol (20\% $\mathrm{v} / \mathrm{v}$ ) in dichloromethane to obtain the acetylene 90 in a $91 \%$ crude yield (Scheme 35).

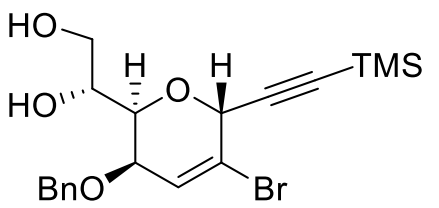

63

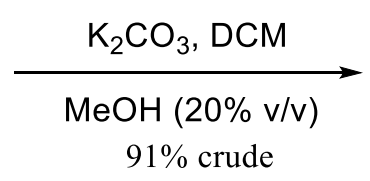

$91 \%$ crude

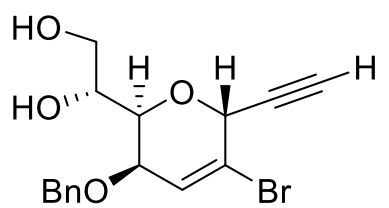

90

Scheme 35: Desilylation of TMS-protected acetylene diol 63

As discussed in section 1.4.2, the deprotection of trimethylsilyl acetylenes is routinely achieved using potassium carbonate in a protic solvent such as methanol. Theoretically, only a catalytic amount of base is required. For example, it was reported that 0.2 equivalents of potassium carbonate in a 1:1 mixture of wet tetrahydrofuran and methanol are sufficient to deprotect several trimethylsilyl-protected acetylenes within 2 hours. ${ }^{104}$ Caddick and co-workers also 
reported the selective deprotection of a TMS-protected acetylene over a TBDPS-protected acetylene with 0.12 equivalents of potassium carbonate. ${ }^{56}$ However, 5 equivalents of potassium carbonate were previously used in the Harvey group for the deprotection of silyl acetylenes. ${ }^{41,53,54}$ To test the necessity of such a large excess of base, the desilylation was carried out using 3 equivalents of potassium carbonate. Reaction progress was monitored by TLC, analysis of which suggested complete conversion of starting material after 2 hours with little by-product formation on a $91 \mathrm{mg}$ scale. However, only $44 \%$ yield was obtained following purification by column chromatography.

It is notable in this case that the product of the reaction, acetylene 90, is usually not purified because of concerns with possible degradation on a silica column. ${ }^{41}$ In this instance, however, purification by column chromatography was attempted in order to obtain a pure product for spectral characterisation. Furthermore, a highly pure acetylene is desirable at this stage, because the next step in the reaction sequence - the sodium periodate-mediated diol cleavage - yields the aldehyde, which is unable to be purified by column chromatography. A second desilylation attempt was conducted with 3.5 equivalents of potassium carbonate; however, the reaction was sluggish, and took 9 hours before most of the starting material was consumed (as monitored by TLC). Following purification by column chromatography, a low yield of $25 \%$ of the product was obtained.

On the other hand, when the reaction was carried out without purification by column chromatography - using 3 equivalents of potassium carbonate - a $67 \%$ crude yield was obtained. In total, the desilylation of $\mathbf{6 3}$ was attempted seven times. Crude yields varied considerably from $27 \%$ to $91 \%$. The most successful conditions in this study were those used by Somarathne, i.e. with 5 equivalents of potassium carbonate. While the necessity of such an excess of catalytic base is unclear, future syntheses would do well to conserve these reaction conditions.

\subsection{Wittig reaction to install the sidechain $(E)$ - and $(Z)$-ethyl esters}

Wittig olefination to form $(\boldsymbol{Z})$ - and $(\boldsymbol{E})$-71 was conducted on aldehyde 70, which in turn was formed by the sodium periodate-mediated cleavage of diol 90. Diol 90 was dissolved in tetrahydrofuran and a $\mathrm{pH} 7$ sodium phosphate buffer, and treated with sodium periodate. After reacting for 1.5 hours, the aldehyde was reliably obtained with near full mass recovery (Scheme 36). Purification via column chromatography was not attempted. 
<smiles>C#C[C@H]1O[C@H]([C@H](O)CO)[C@@H](OBr)C=C1Br</smiles>

90

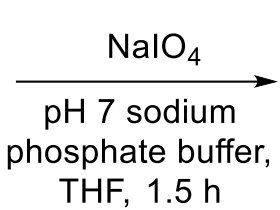

THF, $1.5 \mathrm{~h}$<smiles>C#C[C@H]1O[C@H](C=O)[C@@H](O[GaH2])C=C1Br</smiles>

70

quantitative crude yield

Scheme 36: Formation of aldehyde 70

Installation of the (Z)- and (E)-ethyl ester sidechains using the Wittig reagent ethyl (triphenylphosphoranylidene)acetate proved to be a reliable and facile transformation. Unsurprisingly, the best yield of $80 \%$ was obtained from the aldehyde substrate $\mathbf{7 0}$ that had been formed from a purified diol 90 (Scheme 37).

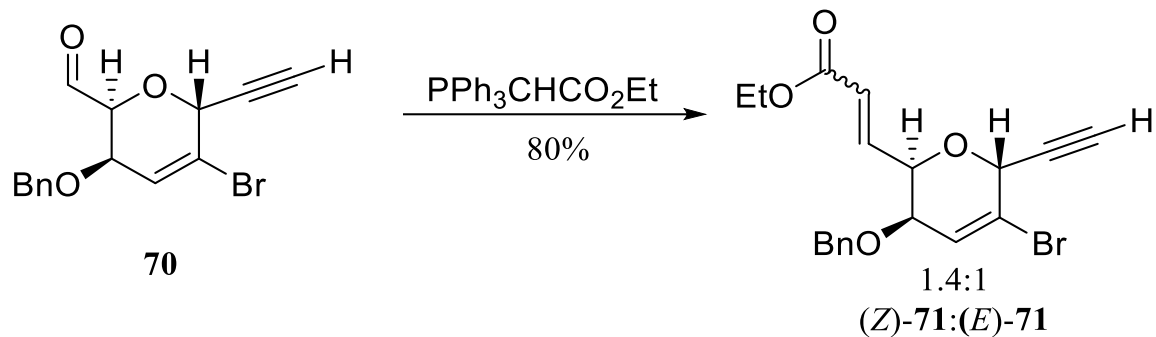

Scheme 37: Wittig olefination of aldehyde 70

The transformation from purified 90 yielded a 1.4:1 ratio of $(Z)-$ and $(\boldsymbol{E})-\mathbf{7 1}$ in a $66 \%$ yield over two steps, the highest reported to date. When the two-step sequence was carried out from unpurified acetylene 90, however, the total yield over two steps varied from 35 to $46 \%$. It is possible that the discrepancy of the observed yields is simply due to the fact that the actual amount of pure acetylene $\mathbf{9 0}$ in the crude sample before the reaction is lower than $100 \%$. However, these results do not necessarily imply that the best method is to purify intermediate acetylene 90, because as discussed in section 2.4, significant loss of product appears to occur during column chromatography. Indeed, the combined yield of $(\boldsymbol{Z})$ - and $(\boldsymbol{E})-\mathbf{7 1}$ over three steps from TMS-protected acetylene diol 63 was $29 \%$ when the intermediate acetylene 90 underwent purification by column chromatography; on the other hand, Somarathne reported a highest yield of $48 \%$ over three steps without purification of the intermediate $90 .{ }^{41}$ In this study, the combined yields of $(\boldsymbol{Z})$ - and $(\boldsymbol{E})-\mathbf{7 1}$ over three steps without purification of intermediate $\mathbf{9 0}$ ranged from $26 \%$ to $46 \%$. 
The approximate $(Z):(E)$ ratios ranged from 1:1 to 2.3:1. (E)-Selectivity was therefore higher in this study than that observed by Somarathne, who reported a 4:1 (Z):(E) ratio. Stabilised Wittig reagents such as ethyl (triphenylphosphoranylidene)acetate are generally expected to show greater $(E)$-selectivity than unstabilised Wittig reagents. However, the greatest $(E)$ selectivity obtained during Somarathne's initial olefination attempts of model aldehyde 67 was only a 3:1 $(E):(Z)$ ratio (in dimethylformamide). Conducting the reaction in tetrahydrofuran, on the other hand, gave a 1:1 ratio. Tetrahydrofuran was chosen by Somarathne as the solvent for the olefination of aldehyde $\mathbf{7 0}$ because it produced the highest yields. The enhanced $(Z)$ selectivity of the olefination of aldehyde $\mathbf{7 0}$ over aldehyde $\mathbf{6 7}$ in tetrahydrofuran may be partly due to the removal of steric hindrance created by the TMS group, although the trans-orientation of the aldehyde and the alkyne detracts from this hypothesis (Scheme 38).<smiles>CC#C[C@H]1O[C@H](C=O)[C@@H](O)C=C1Cl</smiles>

67<smiles>C#C[C@H]1OC(C=O)[C@@H](O)C=C1Br</smiles>

70
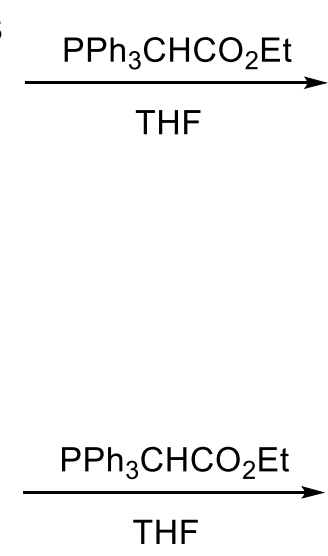

THF

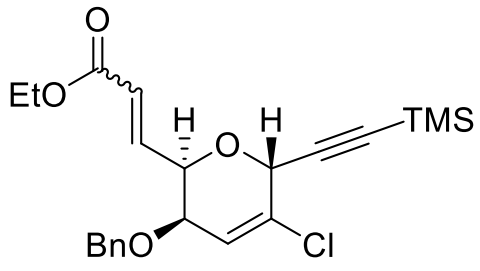

1:1(Z)-91:(E)-91

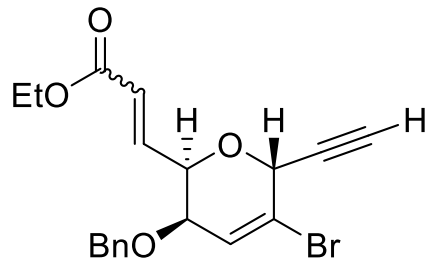

$4: 1(Z)-71:(E)-71$

Scheme 38: Variation in $(E)$-selectivity observed by Somarathne ${ }^{41}$

It is unclear why variable ratios and higher $(E)$-selectivity were observed here compared to Somarathne's work. This increased $(E)$-selectivity is undesired because the current main lead compound is the (Z)-ethyl ester analogue 52; it is assumed that the lactam analogue of $\mathbf{5 2}$ would possess higher inhibitory potency than the lactam analogue of the $(E)$-ethyl ester analogue $\mathbf{5 1}$ by analogy with the equivalent lactones. Nevertheless, sufficient quantities of both $(\boldsymbol{Z})$ - and $(\boldsymbol{E})$-71 were obtained for the purposes of this project, and were easily separated via silica gel column chromatography. Work is currently underway in the Harvey group to investigate $(Z)$ selective olefination conditions such as the Still-Gennari ${ }^{105}$ reaction. 


\subsection{Oxymercuration of acetylenes $\mathbf{7 1}$}

Installation of the ketone was achieved by treating a mixture of acetylenes $(\boldsymbol{Z})$ - and $(\boldsymbol{E})-\mathbf{7 1}$ with mercury (II) sulfate and aqueous sulfuric acid in tetrahydrofuran (Scheme 39). The reaction was also conducted on separate quantities of the pure $(Z)$ - and $(E)$-isomers.<smiles>C#C[C@H]1O[C@H](/C=C/C(=O)OCC)[C@@H](O)C=C1Br</smiles>

71

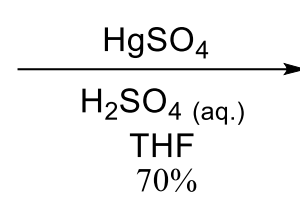

$70 \%$

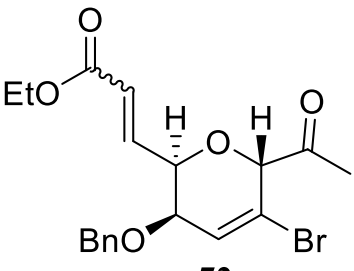

72

Scheme 39: Oxymercuration of acetylenes 71

$(Z)-71$ was found to be a better substrate for the oxymercuration than $(\boldsymbol{E})-\mathbf{7 1}$. While $(\boldsymbol{Z})-\mathbf{7 2}$ was reliably formed in yields around 70\%, the formation of $(\boldsymbol{E})-\mathbf{7 2}$ was less consistent, with yields of $16 \%, 31 \%$ and $69 \%$. The relative lower reactivity of $(\boldsymbol{E})-\mathbf{7 1}$ was observed to a lesser extent by Somarathne, who obtained yields of $70 \%$ for $(\boldsymbol{Z})-\mathbf{7 2}$ and $61 \%$ for $(\boldsymbol{E})-\mathbf{7 2} .^{41}$ These results may partially be a consequence of typically carrying out the reaction on smaller quantities of (E)-71 than $(Z)-71$.

In addition to conducting the reaction on pure samples of $(\boldsymbol{Z})$ - and $(\boldsymbol{E})-\mathbf{7 1}$, the oxymercuration was also carried out on a mixture of the above isomers. The product ketones $(\boldsymbol{Z})$ - and $(\boldsymbol{E})-\mathbf{7 2}$ were still easily separated and purified by column chromatography, and good yields were obtained using this method. Therefore, there appears to be no adverse effect on the outcome of the reaction by using a mixture of $(\boldsymbol{Z})$ - and $(\boldsymbol{E})-\mathbf{7 1}$; in fact, doing so allows for the more expedient synthesis of $(\boldsymbol{Z})$ - and $(\boldsymbol{E})-\mathbf{7 2}$ requiring only the one reaction and purification sequence.

\subsection{Reductive amination of the advanced ketone intermediate}

In total, six reductive aminations were attempted on $(\boldsymbol{Z})$ - and $(\boldsymbol{E}) \mathbf{- 7 2}$ (Scheme 40). The experiments were generally carried out on a small scale, $c a$. 5-10 mg of starting material. Three amine nucleophiles were tested: $N$-propylamine, benzylamine and ammonium acetate. Two available reductants were tested: tetramethylammonium triacetoxyborohydride and sodium 
cyanoborohydride. Tetrahydrofuran was used as the solvent. Magnesium sulfate was used as a dehydrating agent to push the imine-ketone equilibrium toward the imine, and acetic acid $(0.1$ $\mathrm{M}$ in tetrahydrofuran) was used as a buffer (Table 4).
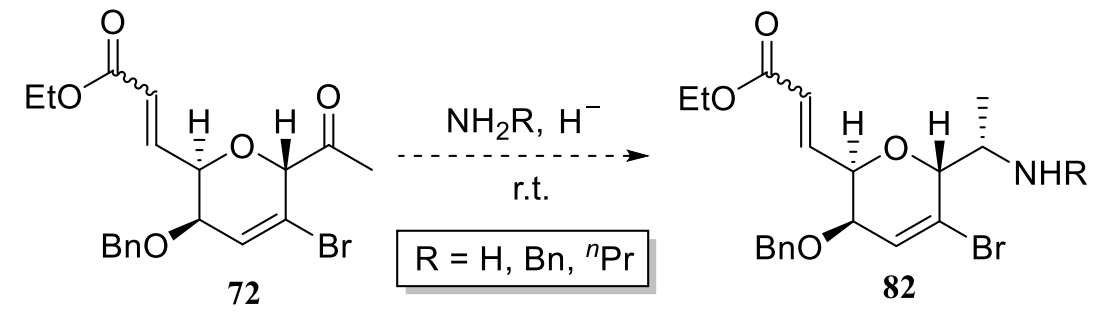

Scheme 40: Proposed reductive amination

\begin{tabular}{ccccccc}
\hline Entry & Substrate & Nucleophile & Reductant & Additive & Duration & Product \\
\hline 1 & $(\boldsymbol{Z})-\mathbf{7 2}$ & ${ }^{n} \mathrm{Pr}$ & $\mathrm{NMe}_{4} \mathrm{BH}(\mathrm{OAc})_{3}$ & - & $2.5 \mathrm{~h}$ & n.d. \\
2 & $(\boldsymbol{Z})-\mathbf{7 2}$ & ${ }^{n} \mathrm{Pr}$ & $\mathrm{NMe}_{4} \mathrm{BH}(\mathrm{OAc})_{3}$ & $\mathrm{MgSO}_{4}, \mathrm{AcOH}$ & $16 \mathrm{~h}$ & $(\boldsymbol{E}) /(\boldsymbol{Z})-91$ \\
3 & $(\boldsymbol{E})-\mathbf{7 2}$ & ${ }^{n} \mathrm{Pr}$ & $\mathrm{NMe}_{4} \mathrm{BH}(\mathrm{OAc})_{3}$ & $\mathrm{MgSO}_{4}, \mathrm{AcOH}$ & $48 \mathrm{~h}$ & $(\boldsymbol{E})-\mathbf{9 1 , 9 2}$ \\
4 & $(\boldsymbol{Z})-\mathbf{7 2}$ & $\mathrm{NH}_{2} \mathrm{Bn}$ & $\mathrm{NaCNBH}_{3}$ & $\mathrm{MgSO}_{4}, \mathrm{AcOH}$ & $5.5 \mathrm{~h}$ & $(\boldsymbol{E})-91$ \\
5 & $(\boldsymbol{Z})-\mathbf{7 2}$ & $\mathrm{NH}_{2} \mathrm{Bn}$ & $\mathrm{NaCNBH}_{3}$ & $\mathrm{MgSO}_{4}, \mathrm{AcOH}$ & $20 \mathrm{~h}$ & $(\boldsymbol{E})-91$ \\
6 & $(\boldsymbol{Z})-\mathbf{7 2}$ & $\mathrm{NH}_{4} \mathrm{OAc}$ & $\mathrm{NaCNBH}_{3}$ & $\mathrm{MgSO}_{4}$ & $48 \mathrm{~h}$ & n.d.
\end{tabular}

Table 4: Reductive amination conditions

The proposed structures of three by-products isolated from the reductive amination experiments are presented in Figure 14. The first experiment was conducted on $(\boldsymbol{Z}) \mathbf{- 7 2}$ with $\mathrm{N}$ propylamine as the nucleophile, and tetramethylammonium triacetoxyborohydride as the reductant (Entry 1, Table 4). Reaction progress was monitored by TLC (9:1 petroleum ether:ethyl acetate). After 2.5 hours, the development of a less polar spot $\left(\mathrm{R}_{f} \approx 0.47\right)$ compared to the starting material $\left(\mathrm{R}_{f} \approx 0.31\right)$ was observed. Notwithstanding, it was expected that the amine product would be more polar than the starting material. As the majority of the starting material had been consumed, the reaction mixture was quenched, extracted, dried and concentrated. A ${ }^{1} \mathrm{H}-\mathrm{NMR}$ spectrum was obtained of the crude reaction mixture which showed no evidence of resonances in the regions expected for the $N$-propyl protons. Furthermore, the HRMS spectrum of the crude material lacked the isotope pattern typical of bromine in the main peaks. Further characterisation of the crude reaction mixture was therefore not attempted. 


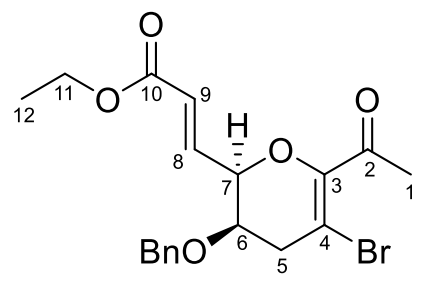

(E)-91

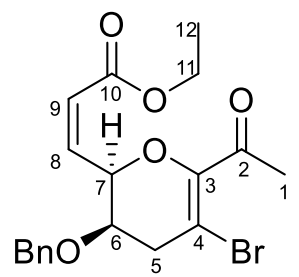

(Z)-91

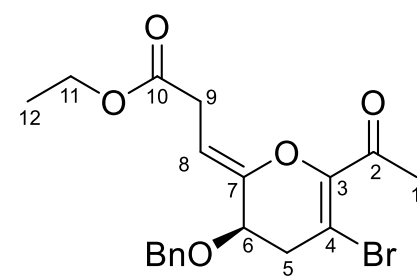

92

Figure 14: Proposed by-products isolated from reductive amination experiments on $(\boldsymbol{Z})$ - and $(\boldsymbol{E})$-72

(Z)-72 was again employed as the substrate for the second reductive amination (Entry 2, Table 4). N-propylamine and tetramethylammonium triacetoxyborohydride were used as the nucleophile and reductant, respectively. Magnesium sulfate was added as a dehydrating agent and acetic acid was used to create a $\mathrm{pH}$ environment of approximately neutral. After reacting overnight, a TLC of the crude reaction mixture showed the development of a more polar product ( $\mathrm{R}_{f} \approx 0.14$ in 9:1 petroleum ether:ethyl acetate) in addition to a product slightly less polar than the starting material $\left(\mathrm{R}_{f} \approx 0.33\right)$.

Following workup and purification, the more polar compound was assigned as $(\boldsymbol{E}) \mathbf{- 9 1}$, based on the obtained HRMS, ${ }^{1} \mathrm{H}-\mathrm{NMR}$ and COSY data. A double isomerisation had therefore occurred, wherein the pyran alkene shifted to the C-3-C-4 position, and the (Z)-alkene isomerised to the presumably more stable $(E)$-alkene. A comparison of the ${ }^{1} \mathrm{H}-\mathrm{NMR}$ spectra of $(\boldsymbol{E})-\mathbf{7 2}$ and by-product $(\boldsymbol{E})-\mathbf{9 1}$ are presented in Figure 15.

Prominent in the mass spectrum of $(\boldsymbol{E})-91$ were abundant peaks at $\mathrm{m} / \mathrm{z}=409.0641$ and 411.0631; 426.0921 and 428.0898; and 431.0467 and 433.0451. The mass separation of these peaks is indicative of a) a bromine-containing compound, and b) detection of the proton, ammonium and sodium adducts respectively of the specific compound. The $\mathrm{m} / \mathrm{z}$ of the proton adduct of the starting material $\left(\mathrm{C}_{19} \mathrm{H}_{21} \mathrm{BrO}_{5} \mathrm{H}^{+}\right)$was calculated as 409.0645 , which was within $0.98 \mathrm{ppm}$ of the observed peak. The significant differences in the ${ }^{1} \mathrm{H}-\mathrm{NMR}$ spectra, however, indicated that the compound was not the starting material $(\boldsymbol{Z})-\mathbf{7 2}$. This data suggested that the starting material had isomerised. 

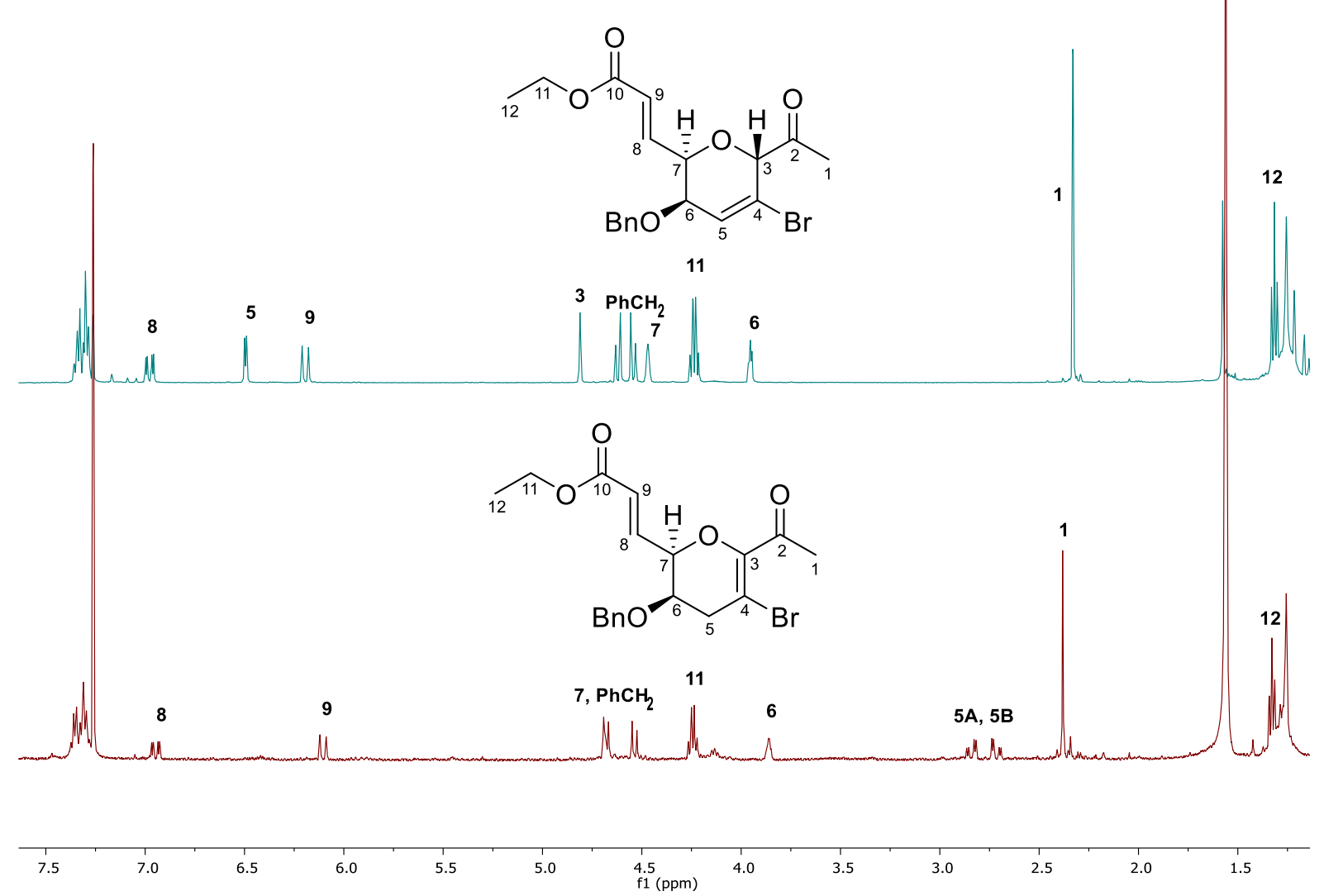

Figure 15: ${ }^{1} \mathrm{H}$ NMR spectra of ketone (E)-72 (top), and by-product (E)-91 (bottom).

The ${ }^{1} \mathrm{H}-\mathrm{NMR}$ spectrum of $(\boldsymbol{E})-91$ was highly congruent with that of the $(E)$-isomer of the starting material, viz. (E)-72. The chemical shifts, shapes and coupling constants of H-1, H-6, $\mathrm{H}-7, \mathrm{H}-8, \mathrm{H}-9, \mathrm{H}-11, \mathrm{H}-12$, and the benzylic and aromatic protons, were all comparable. The most notable difference was the absence of two key resonances: the bromoalkene proton $\mathrm{H}-5$ (which in (E)-72 appears as a doublet at $6.49 \mathrm{ppm}$ ) and the pseudo-anomeric H-3 (which in (E)-72 appears as a singlet at $4.81 \mathrm{ppm})$. Furthermore, two tenting double doublets had appeared at 2.84 and $2.72 \mathrm{ppm}$.

Isomerisation of the pyran alkene to the C-3-C-4 position has previously been observed in the Harvey group on several similar compounds, ${ }^{41,60}$ and is identifiable by the characteristic $\mathrm{H}-5 \mathrm{~A}$ and $\mathrm{H}-5 \mathrm{~B}$ proton resonances. These tend to occur as two double doublets at a similar chemical shift to the resonances observed in $(\boldsymbol{E})-91$. The primary coupling constant of $18.5 \mathrm{~Hz}$ was consistent with that expected for geminal coupling between $\mathrm{H}-5 \mathrm{~A}$ and $\mathrm{H}-5 \mathrm{~B}$. The COSY spectrum also indicated coupling of these resonances with the multiplet at $3.86 \mathrm{ppm}$, here assigned as H-6. It was therefore highly likely that the starting material ketone (Z)-72 had undergone isomerisation to the C-3-C-4 unsaturated compound. 
Additional isomerisation of the sidechain to the $(E)$-alkene was also apparent by analysis of the alkenyl H-8 and H-9 resonances. The ${ }^{1} \mathrm{H}-\mathrm{NMR}$ spectra of $(\boldsymbol{Z})-\mathbf{7 2}$ and $(\boldsymbol{E})-\mathbf{7 2}$ are easily distinguished by the chemical shift of these peaks. In (E)-72, H-8 and H-9 appear at 6.98 and 6.19 ppm, respectively, whereas in $(\boldsymbol{Z}) \mathbf{- 7 2}$ their resonances are shifted upfield to 6.36 and 5.94 ppm, respectively. Furthermore, the vicinal coupling between H-8 and H-9 is of a larger magnitude in $(\boldsymbol{E})-\mathbf{7 2}(15.8 \mathrm{~Hz})$ compared to $(\boldsymbol{Z})-\mathbf{7 2}(11.8 \mathrm{~Hz})$. The H-8-H-9 coupling constant observed in the isolated by-product was $15.8 \mathrm{~Hz}$, consistent with trans-alkene coupling. On the basis of these observations, the first by-product isolated from the attempted reductive amination was assigned as $(\boldsymbol{E})-\mathbf{9 1}$.

The less polar compound isolated from the same reaction $\left(\mathrm{R}_{f} \approx 0.33\right)$ was assigned as $(\boldsymbol{Z})-\mathbf{9 1}$. The mass spectrum of $(Z)-91$ was highly congruent with that of the starting material ketone $(Z)-72$ and the isolated by-product $(\boldsymbol{E})-\mathbf{9 1}$. Highly abundant peaks corresponding to the proton, ammonium and sodium adducts of a compound with the same mass as the starting material were observed $\left(\mathrm{C}_{19} \mathrm{H}_{21} \mathrm{BrO}_{5} \mathrm{H}^{+}\left[\mathrm{M}+\mathrm{H}^{+}\right]\right.$calc. 409.0645, found 409.0647, $\left.\Delta 0.49 \mathrm{ppm}\right)$.

The ${ }^{1} \mathrm{H}-\mathrm{NMR}$ spectra of the starting material $(\boldsymbol{Z})-\mathbf{7 2}$ and the proposed by-product $(\boldsymbol{Z}) \mathbf{- 9 1}$ are presented in Figure 16. While the H-1, H-6, H-11, H-12, and the benzylic and aromatic proton resonances were all comparable to those observed in the starting material, the distinguishing features observed in the spectrum of $(\boldsymbol{E})-\mathbf{9 1}$ were also evident here. These key differences included the absence of the bromoalkene H-5 and pseudo-anomeric H-3 signals, and the appearance of the two tenting doublets indicative of $\mathrm{H}-5 \mathrm{~A}$ and $\mathrm{H}-5 \mathrm{~B}$. The bromoalkene $\mathrm{H}-5$ doublet was observed at $6.49 \mathrm{ppm}$ in the ${ }^{1} \mathrm{H}-\mathrm{NMR}$ spectrum of starting material $(\boldsymbol{Z})-\mathbf{7 2}$. In the spectrum of (Z)-91, a multiplet was observed at $6.48 \mathrm{ppm}$. COSY indicated that this signal coupled to the doublet at $5.90 \mathrm{ppm}$, where $\mathrm{H}-9$ is expected to resonate. The coupling constant of $10.7 \mathrm{~Hz}$ was of a similar magnitude to that observed between $\mathrm{H}-8$ and $\mathrm{H}-9$ in the starting material, and is common for $c i s$-alkene proton coupling. Furthermore, the multiplet at $6.48 \mathrm{ppm}$ was observed to couple to the doublet at $5.44 \mathrm{ppm}$, which was assigned as H-7. The resonance at $6.48 \mathrm{ppm}$ was therefore assigned as $\mathrm{H}-8$, and the bromoalkene $\mathrm{H}-5$ resonance was not observed. 


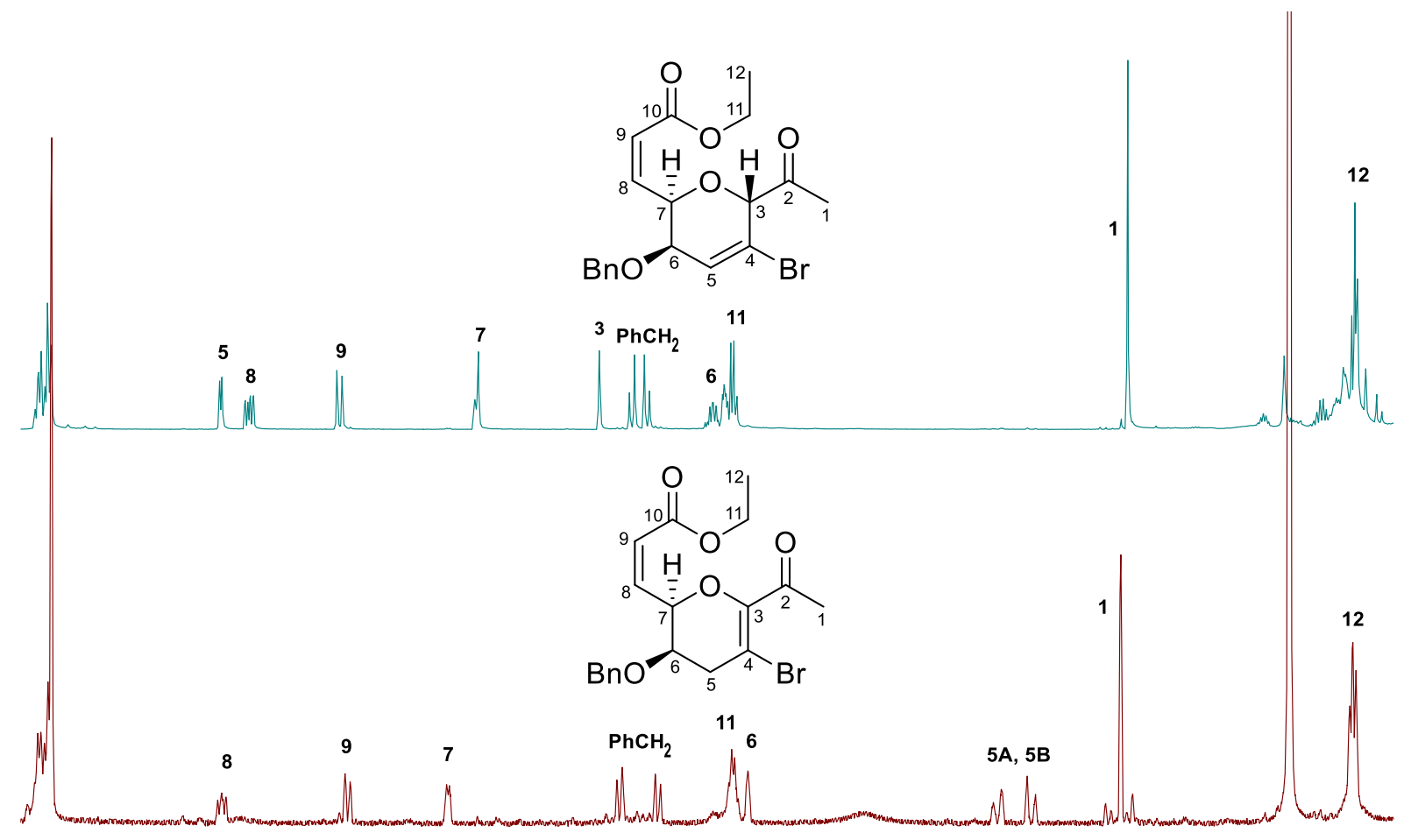

\begin{tabular}{llllllllllllllllllllllllllllllllllllllllllll}
\hline .4 & 7.2 & 7.0 & 6.8 & 6.6 & 6.4 & 6.2 & 6.0 & 5.8 & 5.6 & 5.4 & 5.2 & 5.0 & 4.8 & 4.6 & 4.4 & 4.2 & 4.0 & 3.8 & 3.6 & 3.4 & 3.2 & 3.0 & 2.8 & 2.6 & 2.4 & 2.2 & 2.0 & 1.8 & 1.6 & 1.4 & 1.2
\end{tabular}

Figure 16: ${ }^{1} \mathrm{H}$ NMR spectra of ketone (Z)-72 (top), and by-product (Z)-91 (bottom)

The appearance of two tenting doublets at 2.91 and $2.75 \mathrm{ppm}$ was analogous to the resonances observed in the ${ }^{1} \mathrm{H}-\mathrm{NMR}$ spectra of $(\boldsymbol{E})-\mathbf{9 1}$. As discussed above, these resonances correspond to protons $\mathrm{H}-5 \mathrm{~A}$ and $\mathrm{H}-5 \mathrm{~B}$. This assignment is supported by the upfield chemical shift of the signals, and their coupling constant of $18.7 \mathrm{~Hz}$ (indicative of geminal coupling).

The third reductive amination was carried out on $(\boldsymbol{E})$-72, again with $N$-propylamine as the nucleophile and tetramethylammonium triacetoxyborohydride as the reductant (Entry 3, Table 4). Magnesium sulfate and acetic acid were added. Reaction progress was monitored by TLC (5:1 petroleum ether:ethyl acetate). As little change was apparent in the TLC after reacting for 72 hours, further quantities of amine, magnesium sulfate, and reductant were added. Shortly thereafter, a TLC of the crude reaction mixture revealed the presence of a significantly polar compound $\left(\mathrm{R}_{f} \approx 0.05\right)$, in addition to two compounds of apparently very similar polarity to the starting material $\left(\mathrm{R}_{f} \approx 0.25\right)$. The reaction mixture was filtered and concentrated without further workup. Following purification by column chromatography, the by-product $(\boldsymbol{E})-\mathbf{9 1}$ was again obtained. The more polar compound was unable to be isolated. The third compound 92, which had a polarity similar to that of the starting material, was tentatively characterised by HRMS, 
${ }^{1} \mathrm{H}-\mathrm{NMR}$ and COSY spectroscopy. The proposed structure of 92 is presented in Figure 14, and is suggested to be the product of a double alkene isomerisation of the starting material $(\boldsymbol{E})-\mathbf{7 2}$. Significant conversion of $(\boldsymbol{E})-\mathbf{7 2}$ to $(\boldsymbol{E}) \mathbf{- 9 1}$ and $\mathbf{9 2}$ was observed, accounting for approximately $70 \%$ of the molar quantity of starting material.

The obtained mass spectrum of $\mathbf{9 2}$ was again comparable to that of the starting material $(\boldsymbol{E}) \mathbf{- 7 2}$ and the previously isolated by-products $(\boldsymbol{Z})$ - and $(\boldsymbol{E})-\mathbf{9 1}$. The most abundant peaks occurred at $\mathrm{m} / \mathrm{z}=409.0655$ and 411.0640; 426.0925 and 428.0905; and 431.0480 and 433.0460. The mass spectrum was therefore consistent with the detection of the proton, ammonium and sodium adducts of a rearranged compound possessing the same molecular formula as the aforementioned compounds $\left(\mathrm{C}_{19} \mathrm{H}_{21} \mathrm{BrO}_{5} \mathrm{H}^{+}[\mathrm{M}+\mathrm{H}]^{+}\right.$calc. 409.0645, found 409.0647, $\Delta 0.49$ ppm).

The ${ }^{1} \mathrm{H}-\mathrm{NMR}$ spectrum of $\mathbf{9 2}$ is displayed in Figure 17 with comparison to the starting material (E)-72. H-1, H-6, H-11, H-12, and the benzylic and aromatic protons all exhibited similar chemical shifts and coupling constants.
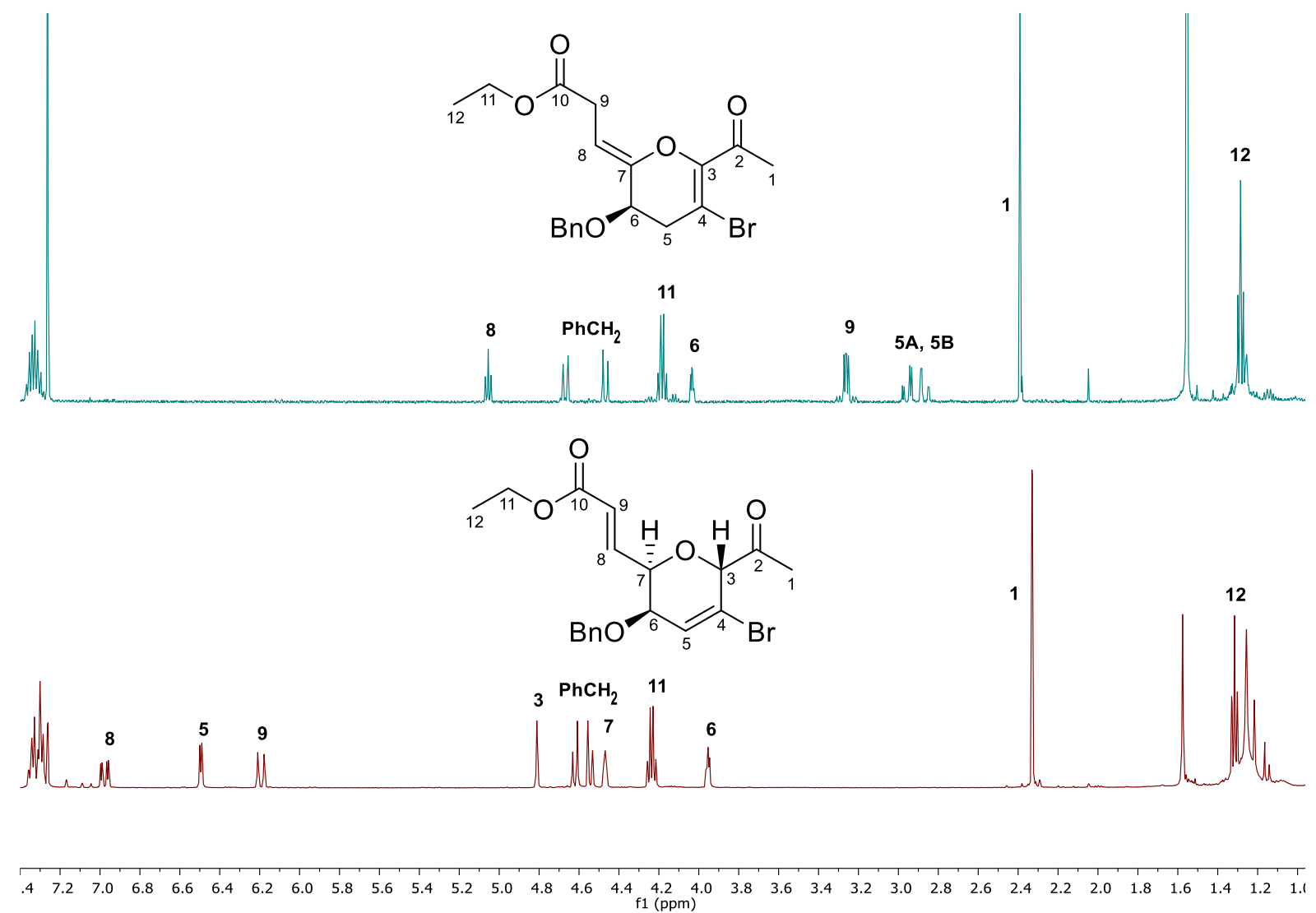

Figure 17: ${ }^{1} \mathrm{H}-\mathrm{NMR}$ spectra of by-product 92 (top), and ketone (E)-72 (bottom) 
Conspicuously absent, however, were the three resonances between 6.98 and $6.19 \mathrm{ppm}$ arising from the alkenyl protons H-5, H-8 and H-9. Instead, a triplet at $5.06 \mathrm{ppm}$, two heavily tenting overlapping double doublets at 3.28 and 3.24 ppm, and a further two tenting double doublets at 2.96 and 2.87 ppm were observed. The absence of apparent resonances for $\mathrm{H}-3$ and $\mathrm{H}-7$ was additionally noted.

The two double doublets between 2.96 and $2.87 \mathrm{ppm}$ were indicative of isomerisation to the C-3-C-4 unsaturated pyran evident in $(\boldsymbol{Z})$ - and $(\boldsymbol{E})-\mathbf{9 1}$. Indeed, the observed primary coupling constants of $18.5 \mathrm{~Hz}$ suggested geminal coupling between H-5A and H-5B. Coupling between both $\mathrm{H}-5 \mathrm{~A}$ and $\mathrm{H}-5 \mathrm{~B}$ with $\mathrm{H}-6$, the double doublet at $4.03 \mathrm{ppm}$, was also apparent from the COSY spectrum. The magnitude of this observed coupling -4.5 and $3.0 \mathrm{~Hz}$ - was consistent with vicinal coupling, and the different magnitudes reflect the different dihedral angles that would arise between H-6 and H-5A/B in the rigid pyran system. Finally, the loss of an H-3 signal was also suggestive of this alkene isomerisation.

It was then realised that the other differences in the ${ }^{1} \mathrm{H}-\mathrm{NMR}$ spectra of 92 could be explained if the C-8-C-9 alkene had shifted to the C-7-C-8 position. Such an isomerisation would account for a) the loss of the $\mathrm{H}-7$ resonance as C-7 becomes $\mathrm{sp}^{2}$-hybridised; b) the loss of the alkenyl $\mathrm{H}-9$ resonance (and the corresponding appearance of the tenting double doublets at 3.28 and 3.24 ppm, arising from $\mathrm{CH}_{2}$ group at C-9); and the conversion of the $\mathrm{H}-8$ resonance from a doublet of doublets to a triplet.

The presence of the H-6 resonance as a double doublet also supports the loss of H-7. The H-6 signal that appears in the intermediates of TAN-2483B analogues is typically a multiplet, often showing complex coupling patterns that cannot be readily elucidated. This complication is due to coupling of H-6 to H-5, H-7 and in some cases H-8. The signal may be further obscured by overlapping of the H-6 and H-7 resonances. In the proposed by-product 92, however, the double doublet of H-6 arises from the coupling of H-6 to H-5A and H-5B, as discussed above; but not, ostensibly, to $\mathrm{H}-7$.

More evidence for the isomerisation of the sidechain double bond to the C-7-C-8 position can be found by observing the H-8 and H-9 resonances. The COSY spectrum shows coupling between the triplet at $5.06 \mathrm{ppm}$ and the two tenting overlapping double doublets at 3.28 and $3.24 \mathrm{ppm}-$ at a chemical shift consistent with that of an allylic $\alpha$-centre. These signals were assigned $\mathrm{H}-8, \mathrm{H}-9 \mathrm{~A}$ and $\mathrm{H}-9 \mathrm{~B}$, respectively. The chemical shift of the triplet at $5.06 \mathrm{ppm}$ is 
indeed indicative of an alkenyl proton. Furthermore, the coupling constants of each of the resonances are consistent with the proposed structure.

The coupling constant of the $\mathrm{H}-8$ triplet was observed as $7.0 \mathrm{~Hz}$. The secondary coupling constants of the H-9A and H-9B double doublets were observed as 7.2 and $7.0 \mathrm{~Hz}$, respectively. The magnitude of these values suggests vicinal coupling between $\mathrm{H}-8$ and H-9A/9B. The primary coupling constants of the H-9A and H-9B resonances were both observed as $17.9 \mathrm{~Hz}$, consistent with geminal coupling.

Unfortunately, $(\boldsymbol{Z})-\mathbf{9 1},(\boldsymbol{E})-\mathbf{9 1}$ and 92 were not isolated in sufficient quantities for the collection of ${ }^{13} \mathrm{C}-\mathrm{NMR}$ spectra, including HSQC and HMBC, which would have enabled more definitive characterisation. Nevertheless, the spectral characterisation obtained from ${ }^{1} \mathrm{H}-\mathrm{NMR}$, COSY and HRMS data strongly support the assignment of the proposed structures.

Due to the disappointing results of the initial reductive amination experiments, alternative conditions were pursued. Benzylamine was tested as the amine nucleophile, and the reducing agent was changed to the more commonly used sodium cyanoborohydride. This nucleophilereductant combination has been shown to reductively aminate several chiral $\mathrm{N}, \mathrm{N}$ dibenzylamino ketones in good to excellent yields. ${ }^{106}$ The fourth reductive amination was conducted on (Z)-72 (Entry 4, Table 4). Unfortunately, as in Entry 2, (E)-91 was obtained following double isomerisation, with no trace of the desired amine. This result was replicated during the fifth reductive amination attempt (Entry 5, Table 4).

It was becoming apparent that the substrates $(\boldsymbol{Z})$ - and $(\boldsymbol{E})-\mathbf{7 2}$ were incompatible with the reductive amination conditions here-to-forth employed in this study. The substrates had a high propensity to undergo isomerisation at two positions: the pyran alkene to the $\mathrm{C}-3-\mathrm{C}-4$ position, and the sidechain $(Z)$-alkene to the $(E)$-alkene. These transformations are likely to be basecatalysed. Deprotonation of the acidic pseudo-anomeric proton appears to be more facile than nucleophilic attack of the amine at the ketone carbonyl (Scheme 41). 
<smiles>CCOC(=O)/C=C\[C@@]1(O)O[C@H](C(C)=O)C(Br)=C[C@H]1Br</smiles>

$(Z)-72$

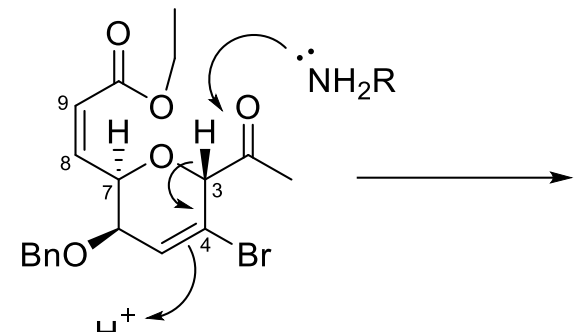

$\mathrm{H}^{+}$<smiles>CCOC(=O)C=CC1OC(C(C)=O)=C(Br)C[C@H]1OCc1ccccc1</smiles>

$(Z)-91$

Scheme 41: Proposed mechanism for pyran alkene isomerisation

Similarly, isomerisation from the $(Z)$ - to the $(E)$-alkene may be rationalised by deprotonation at the conjugated C-7 position, leading to an intermediate enolate; rotation around the $\mathrm{C}-8-\mathrm{C}-$ 9 bond may then afford the $(E)$-isomer after protonation at the $\gamma$-position (typically considered to be the thermodynamic product) (Scheme 42). Another plausible isomerisation mechanism could proceed via $N$-Michael addition whereby nucleophilic attack of the amine at the $\beta$ position is followed by similar rotation of the $\mathrm{C}-8-\mathrm{C}-9$ bond in the enolate intermediate. Subsequent elimination of the protonated amine would afford the $(E)$-isomer. The formation of 92 could be rationalised in a similar manner, whereby the enolate is quenched by protonation at the $\alpha$-position (Scheme 43).

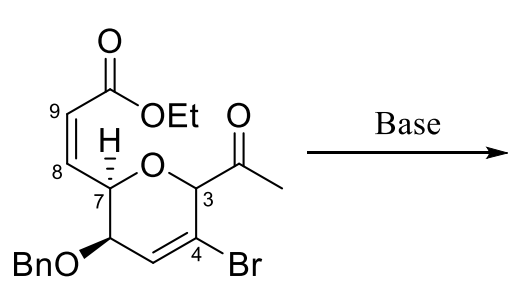

(Z)-72

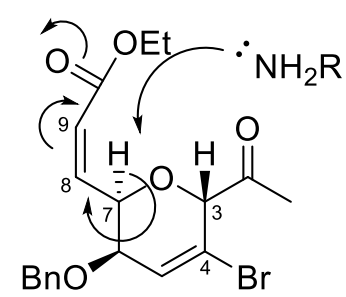<smiles>CCOC(=O)/C=C/[C@H]1O[C@@H](C(C)=O)C(Br)=C[C@H]1OCc1ccccc1</smiles>

$(E)-72$
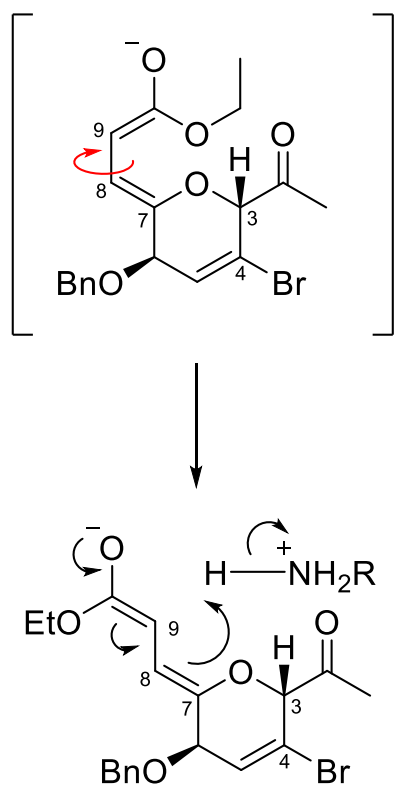

Scheme 42: Proposed mechanism for (Z)-72 to $(\boldsymbol{E})-\mathbf{7 2}$ isomerisation 


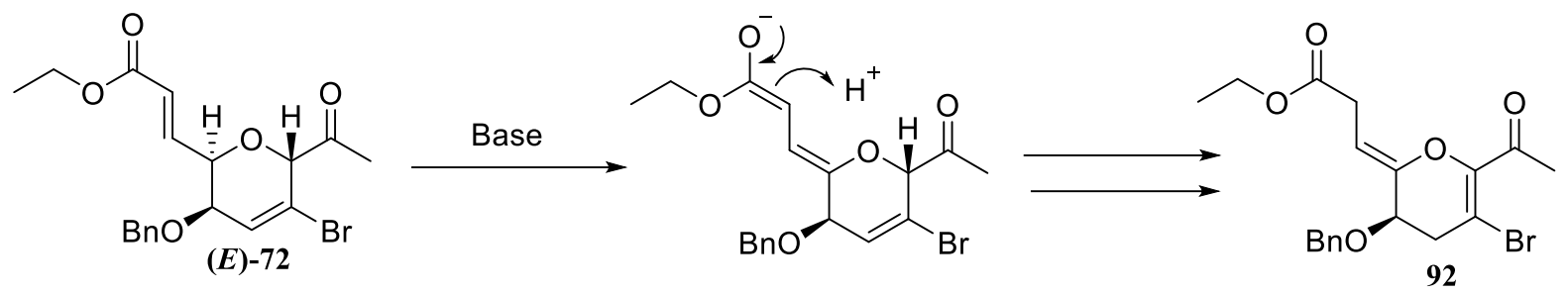

Scheme 43: Proposed mechanism for the formation of by-product 92

It was therefore reasoned that alkene isomerisation could be minimised by avoiding strongly basic conditions. Ammonium acetate was thus tested as the nucleophile (Entry 6, Table 4). Unfortunately, following workup and purification steps, a complex mixture was obtained with no isolable compounds.

\subsection{Alternative route to amines $\mathbf{8 2}$}

The sensitivity of the ketone substrates $\mathbf{7 2}$ toward basic conditions, presumed to be due to the presence of an acidic $\alpha$-proton, necessitated the exploration of an alternative route toward amines 82. It was reasoned that $\mathbf{8 2}$ could be accessed via nucleophilic substitution of a leaving group at C-2 (Scheme 44). One possibility is direct substitution with an amine nucleophile such as benzylamine. However, under the resulting basic conditions the elimination product may instead dominate, especially given the secondary substrate. Alternatively, a two-step sequence to the amine via azide $\mathbf{9 3}$ that is subsequently reduced under Staudinger conditions ${ }^{107}$ may be more compatible with the substrate. Possible leaving groups on intermediate 94 include mesylate, tosylate, or triflate. These derivatives could in turn be prepared by reaction of the known alcohols 53 with the appropriate activating agent. 
<smiles>CCOC(=O)/C=C/C1O[C@H]2C(=C[C@H]1O)C(=O)N[C@H]2C</smiles>

81<smiles>CCOC(=O)/C=C/C1O[C@H](C(C)=O)C(Br)=C[C@H]1OCc1ccccc1</smiles>

72<smiles>C=CC=CC1O[C@H](C=CC(=O)OCC)[C@@H](OCc2ccccc2)C=C1Br</smiles>

82

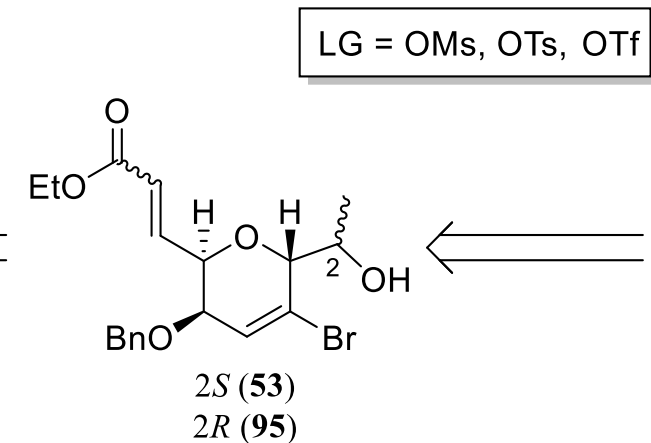<smiles>CCOC(=O)/C=C/[C@H]1O[C@H]([C@@H](C)N)C(Br)=C[C@H]1OC(=O)c1ccccc1</smiles>

93

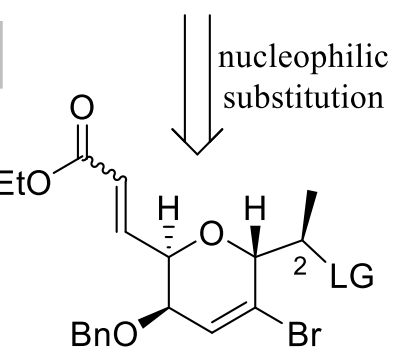

94

Scheme 44: Retrosynthetic analysis of alternative route toward lactam analogues $\mathbf{8 1}$

As discussed in section 1.4.2, the sodium borohydride-mediated reduction of ketones $\mathbf{7 2}$ employed previously in the Harvey group produces alcohols 53 with high stereoselectivity due to substrate control. The $S_{\mathrm{N}} 2$-like nucleophilic substitution of the corresponding mesylate by azide would then invert the chiral centre at $\mathrm{C}-2$. If the amine resulting from reduction was subjected to the palladium-catalysed carbonylation and deprotection of the benzyl group, the resulting lactam analogue of TAN-2483B would be diastereomeric to the natural product at the C-2 position. This could be avoided by the asymmetric reduction of ketones 72 to the diastereomeric alcohol 95, perhaps with the appropriate enantiomer of the CBS catalyst. However, due to time constraints, in this study the ketone would be reduced as usual with sodium borohydride. This would enable mesylation of alcohol $\mathbf{5 3}$ and the subsequent nucleophilic substitution with sodium azide to be explored as a proof-of-principle to assess substrate compatibility with the mesylation and substitution conditions (Scheme 45). If the mesylation, nucleophilic substitution and azide reduction reactions were facile, then a stereoselective ketone reduction to afford the correct configuration at C-2 could be explored in the future. 
<smiles>CCOC(=O)/C=C/C1O[C@H](C(C)N)C(Br)=CC1OCc1ccccc1</smiles>

96<smiles>CCOC(=O)/C=C/C1O[C@H](C(C)OC)C(Br)=C[C@H]1OCc1ccccc1</smiles>

94

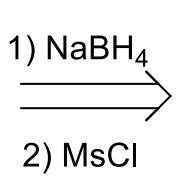

2) $\mathrm{MsCl}$<smiles>CCOC(=O)/C=C/C1O[C@H](C(C)=O)C(Br)=C[C@H]1OC(=O)c1ccccc1</smiles>

72

Scheme 45: Retrosynthetic analysis of the proposed proof-of-principle sequence

\subsubsection{Reduction of ketone $(Z)-72$}

Ketone (Z)-72 was reduced following the procedure utilised by Somarathne. ${ }^{41}$ The ketone was dissolved in dry methanol, cooled to $-78^{\circ} \mathrm{C}$ and treated with 1.6 equivalents of sodium borohydride. The resulting suspension was slowly warmed to $-10^{\circ} \mathrm{C}$ over the course of 90 minutes, whereupon the homogeneous mixture was quenched by the addition of acetone. The crude material was concentrated under reduced pressure, and purified via silica gel column chromatography to afford alcohol 53 in a 92\% yield (Scheme 46). The correct configuration at C-2 was confirmed by $J$ values, which matched those observed by Somarathne (who confirmed the stereochemistry by hydrogenation and nOe correlations of a later compound).<smiles>CCOC(=O)/C=C\[C@H]1O[C@H](C(C)=O)C(Br)=C[C@H]1OC(C)C</smiles>

(Z)-72

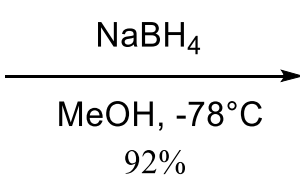<smiles>CCOC(=O)/C=C\[C@H]1O[C@H](OCc2ccccc2)[C@@H](C)C=C1Br</smiles>

53

Scheme 46: Reduction of ketone (Z)-72

\subsubsection{Mesylation of alcohol $\mathbf{5 3}$}

Several protocols for the facile mesylation of primary and secondary alcohols can be found in the literature. Secondary mesylates can be prepared by dissolving secondary alcohols in neat pyridine, treating with 1.2 equivalents of mesyl chloride, and reacting for two hours at room temperature to afford the corresponding mesylates in excellent yields. ${ }^{108}$ Alternatively, primary mesylates were prepared by treating primary alcohols in dichloromethane with 5 equivalents of triethylamine and 1.2 equivalents of mesyl chloride at $0^{\circ} \mathrm{C}$, and reacting for one hour. ${ }^{108}$ The corresponding mesylates were also obtained in excellent yields following purification via 
column chromatography. Another method involves the formation primary and secondary mesylates in quantitative yields by treating the corresponding alcohols in dichloromethane at $0^{\circ} \mathrm{C}$ with 2.3 equivalents of triethylamine followed by 1.2 equivalents of mesyl chloride. ${ }^{109}$ Some secondary alcohols may be converted more easily with a greater excess of mesyl chloride; 2.5 equivalents were required for the conversion of a hindered secondary alcohol to the corresponding mesylate as disclosed in a Pfizer patent. ${ }^{110}$

Here, the protocol of treating a solution of the alcohol in dichloromethane at $0^{\circ} \mathrm{C}$ with triethylamine and mesyl chloride was pursued. After cooling to $0^{\circ} \mathrm{C}$, alcohol $\mathbf{5 3}$ was treated with 2.3 equivalents of triethylamine dropwise followed by 2.5 equivalents of mesyl chloride. Monitoring the reaction progress by TLC proved difficult, as the mesylate and the alcohol had almost identical observed $\mathrm{R}_{f}$ values $\left(\mathrm{R}_{f} \approx 0.24\right.$ in 5:1 petroleum ether:ethyl acetate). After stirring at $0^{\circ} \mathrm{C}$ for one hour, the reaction mixture was allowed to warm to room temperature and left to react overnight. As the progress of reaction was not readily apparent from the TLC, a further 2.3 equivalents of triethylamine and 2.5 equivalents of mesyl chloride were then added, and the mixture was left to react for a further four hours before being quenched and worked up. Following purification by column chromatography, the mesylate $\mathbf{9 4}$ was obtained as a colourless oil in a $72 \%$ yield (Scheme 47$)$.

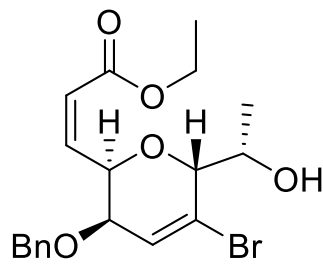

53

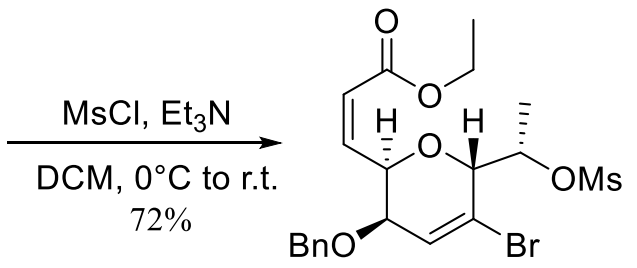

94

Scheme 47: Mesylation of alcohol 53

The mesylated product was identified by several significant changes in the ${ }^{1} \mathrm{H}-\mathrm{NMR}$ spectrum (Figure 18). The H-2 resonance had shifted downfield from 4.36 to $5.31 \mathrm{ppm}$, and was able to be resolved as a quartet of doublets. The appearance of a singlet peak integrating for three protons at $3.04 \mathrm{ppm}$ suggested the incorporation of the $\mathrm{SO}_{2} \mathrm{CH}_{3}$ group. (In mesyl chloride, the methyl signal appears as a singlet at 3.65 ppm in $\mathrm{D}_{2} \mathrm{O}$. $)^{111}$ The $\mathrm{H}-1 \mathrm{CH}_{3}$ doublet had also shifted downfield from 1.34 to 1.57 ppm. Finally, H-3 had shifted downfield from 4.05 to $4.22 \mathrm{ppm}$. Apart from these distinguishing characteristics, the ${ }^{1} \mathrm{H}-\mathrm{NMR}$ spectra of alcohol $\mathbf{5 3}$ and 
mesylate 94 were similar. HRMS data obtained for the isolated compound supported the proposed structure $\left(\mathrm{C}_{20} \mathrm{H}_{25} \mathrm{BrO}_{7} \mathrm{SH}^{+}\left[\mathrm{M}+\mathrm{H}^{+}\right]\right.$calc. 489.0577, found 489.0589, $\left.\Delta 2.25 \mathrm{ppm}\right)$.
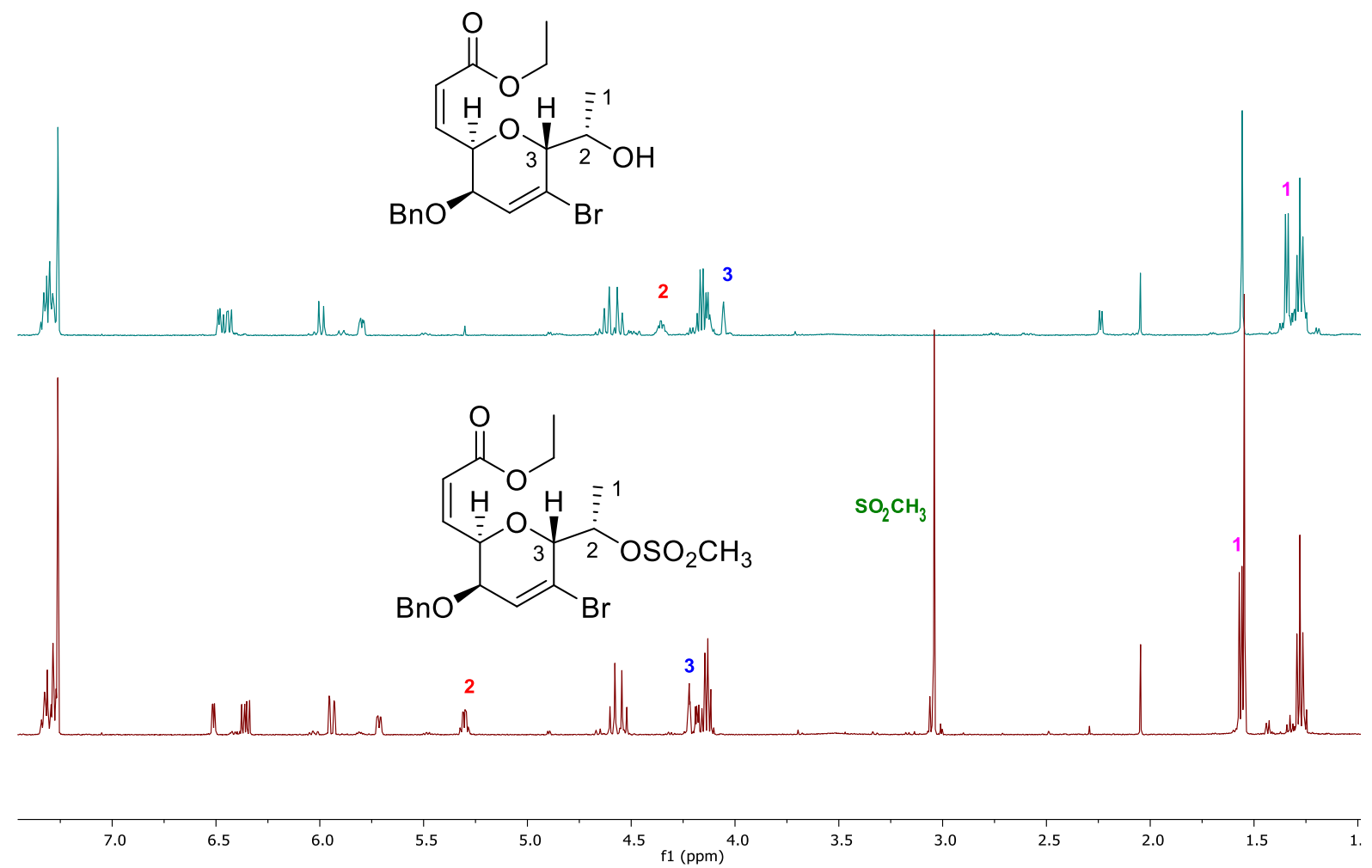

Figure 18: ${ }^{1} \mathrm{H}-\mathrm{NMR}$ spectra of alcohol 53 (top), and mesylate 94 (bottom)

Unfortunately, the nucleophilic substitution of mesylate 94 with sodium azide was unable to be investigated due to time constraints. There remain quantities of ketones $(\boldsymbol{Z})$ - and $(\boldsymbol{E})-\mathbf{7 2}$ which were synthesised in this project, and it is hoped that the proposed alternative synthetic route will be tested in the Harvey group in the near future. 


\section{Conclusion and future work}

Although the synthesis of lactam analogues of TAN-2483B was not achieved in this study, progress has been made toward their formation. Synthesis of advanced amine intermediates via a reductive amination was found to be incompatible with the ketone substrates, presumably due to base sensitivity. Ketones $\mathbf{7 2}$ displayed a high propensity to undergo isomerisation of the pyran alkene to the C-3-C-4 position, and from the sidechain $(Z)$ - to $(E)$-alkene.

However, there exist a number of alternative approaches toward the synthesis of advanced amine intermediates that could be explored in the future. A more thorough investigation of the reductive amination conditions, including the use of different solvents, reductants, and amine nucleophiles may be warranted. Generating a buffered solution at $\mathrm{pH} 6$ to avoid base-catalysed isomerisation is also recommended for future work. Non-conventional reductive amination protocols could also be investigated, including microwave-assisted reductive amination, or use of the mild reducing agent polymethylhydrosiloxane. Catalytic hydroamination of terminal acetylenes 90 and subsequent reduction is another potential route to amines $\mathbf{8 2}$ which avoids the highly toxic oxymercuration conditions used to generate ketones 72. Furthermore, the alternative route to amines via stereoselective reduction, mesylation, nucleophilic substitution and azide reduction that was briefly explored here could also prove viable. These alternatives are discussed in sections 3.2-3.4.

In addition to investigating amine-formation reactions, advances were made in the optimisation of the synthetic route toward sidechain analogues of TAN-2483B. Purification of benzylprotected glycal 45 was more easily carried out with dry-loading of the silica column and avoiding the initial use of pure petroleum ether to remove naphthalene. A more expedient transformation from the acetate 56 to the diol $\mathbf{6 3}$ was made by removing the intermediate purification step. The necessity of a large equivalent of potassium carbonate in the desilylation of 63 was also investigated.

\subsection{Alternative desilylation conditions}

Although previous work in the Harvey group found the desilylation of TMS-protected acetylene 63 proceeded with excellent yields, ${ }^{41,53,54}$ in this project these high yields were unable to be reliably replicated. Additionally, the desilylation of the analogous alkene $\mathbf{6 9}$ (containing the (1E)-propenyl sidechain found in the natural product) was previously shown to proceed 
only in moderate yields, with degradation to by-products a major concern. ${ }^{60}$ It may therefore be desirable to investigate milder means of desilylation in the future.

While the desilylation of TMS-protected acetylenes is commonly carried out using a weak base in a protic solvent, fluoride- and silver-promoted desilylations have also been widely reported. TBAF is commonly used to remove silyl groups, ${ }^{112}$ but is not usually used on silyl acetylenes or when the selective deprotection of TMS in the presence of other silyl groups is required. ${ }^{113}$ $\operatorname{Ag}(\mathrm{I})$-promoted desilylation, however, may be orthogonal to base-sensitive substrates and suitable when selective deprotection of TMS groups over other silyl groups is required. ${ }^{114}$ Schmidt and Arens first developed a two-step sequence using $\operatorname{Ag}(\mathrm{I})$ when their planned deprotection of a silyl acetylene with alcoholic $\mathrm{KOH}$ led to the formation of undesired allenic by-products. ${ }^{115}$ The silyl acetylene was first treated with alcoholic silver nitrate to generate the silver acetylide, and then aqueous potassium cyanide was added to uncover the terminal acetylene in good yields. Since then, the silver nitrate-potassium cyanide desilylation protocol has been used on a wide range of substrates including carbohydrates and polyenynes, ${ }^{114}$ and can, for example, selectively remove TMS in the presence of TIPS or other silyl groups. ${ }^{116}$ More recently, Kotora and co-workers reported the desilylation of a TMS-protected acetylene in the presence of acetate and pivaloyl protecting groups by alcoholic silver nitrate and sodium iodide, prior to Sonogashira coupling in the synthesis of the unsaturated fragment of the natural product callyspongiolide. ${ }^{117}$ It may be useful to explore some of these alternative deprotection conditions in future work, particularly on the advanced intermediate alkene 69 which undergoes significant degradation when treated with alcoholic potassium carbonate. ${ }^{60}$

\subsection{Alternative reductive amination conditions}

Although the reductive amination of advanced ketone intermediates $(\boldsymbol{Z})$ - and - $(\boldsymbol{E})-\mathbf{7 2}$ explored in this study was unsuccessful, a more thorough investigation may be warranted. While the ketone substrates appear to be unstable in basic conditions (and hence may be incompatible with nucleophiles such as benzylamine), the non-basic (but less nucleophilic) salt ammonium acetate may be more suitable. Conducting the reaction in a buffered solution with a $\mathrm{pH} 6$ may be explored. Furthermore, the reducing agent sodium triacetoxyborohydride, which was not tested here, could prove to be a milder alternative. Investigating other solvents for the reductive amination - such as the more commonly used 1,2-dichloroethane or acetonitrile - may also be appropriate. 
There also exist several protocols that differ to the traditional reductive amination conditions. The tin (II) chloride-catalysed reductive amination of a variety of aliphatic and aromatic ketones and aldehydes was recently demonstrated to proceed in excellent yields using the inexpensive reducing agent polymethylhydrosiloxane (PMHS). ${ }^{118}$ PMHS offers many advantages over the conventional reducing agents: it is non-toxic, easy to handle and stable to moisture and air. ${ }^{119}$

Microwave-assisted reductive aminations have also been reported. ${ }^{120}$ For example, Dong and co-workers described the synthesis of primary amines from aromatic ketones using ammonium acetate and sodium cyanoborohydride. Good to excellent yields were obtained in two minutes at $130^{\circ} \mathrm{C}$ in a microwave reactor ( 11 examples). ${ }^{121}$

\subsection{Direct catalytic hydroamination-reduction of alkynes}

In this study, the oxymercuration reaction to afford ketones $\mathbf{7 2}$ - promoted by the highly toxic mercury (II) sulfate - proceeded with variable yields between 16 to 70\%. However, hydroamination of the terminal acetylenes $(\boldsymbol{Z})$ - and $-(\boldsymbol{E})-\mathbf{7 1}$ followed by reduction of the intermediate imine would afford substituted amines directly, and avoid the use of mercury (II) sulfate.

The direct addition of primary or secondary amines to alkenes and alkynes represents a transformation of $100 \%$ atom economy, avoiding the production of by-products such as salts or water. While this approach was initially limited to alkenes and carried out in the presence of mercury or thallium salts, recent developments have expanded the applicability of this reaction to include alkynes and incorporate less toxic catalysts. ${ }^{122}$ Furthermore, the initially formed imine can be reduced with sodium cyanoborohydride to afford the corresponding amine without prior isolation (as in the direct reductive amination). For example, Beller and coworkers reported the facile formation of several secondary amines via the direct hydroamination-reduction of both terminal and internal alkynes in excellent yields (Scheme 48). ${ }^{123}$ The transformations were catalysed by the novel, stable aryloxotitanium complex 97 (Figure 19), with high regioselectivity for the Markovnikov product. (The synthesis of TAN2483B lactam analogues via terminal acetylenes $\mathbf{7 1}$ would require the preferential formation of the Markovnikov product.) 


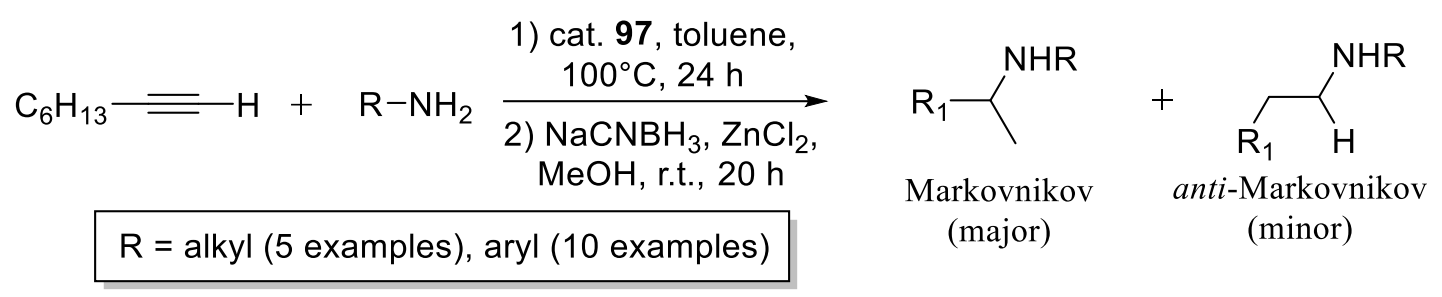

Scheme 48: Direct hydroamination-reduction of alkynes

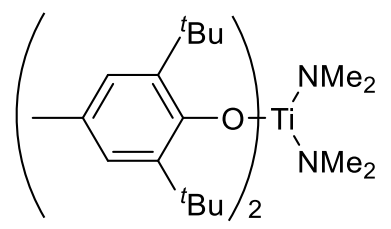

Figure 19: Aryloxotitanium catalyst 97

This approach would avoid the use of the highly toxic mercury (II) sulfate, and in doing so, produce secondary amines in fewer steps than the proposed route via the reductive amination of ketones 72. Furthermore, avoiding the base-sensitive ketone substrates is expected to reduce the amount of degradation occurring in the presence of basic amine nucleophiles.

\subsection{Amine formation via nucleophilic substitution}

The alternative route toward amines $\mathbf{8 2}$ briefly explored in this study may be more suitable than the conventional reductive amination, given the sensitivity of the ketones $\mathbf{7 2}$ in basic media. It could be worth investigating the direct nucleophilic substitution of mesylate 94 with an amine nucleophile such as benzylamine, despite the strong possibility of competing elimination. This direct substitution would avoid the required reduction of azide 93, and allow for the incorporation of further functionality at the nitrogen centre. Another alternative could be the substitution of alcohol 94 with a halogen under Appel ${ }^{124}$ conditions, followed by substitution and reduction to the primary amine as per the Gabriel ${ }^{125}$ synthesis. 


\section{Experimental}

\subsection{General experimental details}

Unless otherwise stated, the following conditions apply. All reactions were performed under argon in vacuum-dried glassware using dry solvents and standard syringe techniques. Tetrahydrofuran, dichloromethane and diethyl ether were taken from a solvent purification system (Innovative Technology's PureSolv apparatus). Methanol was distilled over calcium hydride. Bromoform was distilled immediately before use to remove small amounts of ethanol stabiliser. Anhydrous $\mathrm{N}, \mathrm{N}$-dimethylformamide was used as received. Sodium hydride was obtained as a $60 \%(\mathrm{w} / \mathrm{w})$ dispersion in paraffin oil and was used without purification. Water was distilled prior to use. All other reagents were of commercial quality and distilled prior to use if required.

Reaction progress was monitored using aluminium-backed thin layer chromatography plates pre-coated with silica UV254 and visualised by phosphomolybdic acid, $p$-anisaldehyde or potassium permanganate dips, and by UV fluorescence quenching $(254 \mathrm{~nm})$. Purification of products via flash chromatography was conducted using a column filled with Silica Zeoprep 60 (40-63 microns) as the matrix, obtained from Pure Science Ltd, with solvent system as indicated in the experimental details.

${ }^{1} \mathrm{H}$ - and ${ }^{13} \mathrm{C}$-NMR spectra were recorded on a Varian Unity Inova 500 spectrometer operating at $500 \mathrm{MHz}$ for ${ }^{1} \mathrm{H}$ and $125 \mathrm{MHz}$ for ${ }^{13} \mathrm{C}$. All chemical shifts $(\delta)$ were referenced to solvent peaks $\mathrm{CDCl}_{3}:{ }^{1} \mathrm{H}-7.26 \mathrm{ppm},{ }^{13} \mathrm{C}-77.16 \mathrm{ppm}$. High-resolution mass spectrometry was recorded on a 6530 Accurate Mass Q-TOF LC/MS instrument (Agilent Technologies).

The structure of each compound is presented with the corresponding method of preparation and spectroscopic data. Spectral data was consistent with that reported for all previously reported compounds. 


\subsection{Description of the experiments and analytical characterisation data}

(3aS,6R,6aS)-6-((R)-2,2-Dimethyl-1,3-dioxolan-4-yl)-2,2-dimethyltetrahydrofuro[3,4- $d]$ 1,3-dioxol-4-ol (57)

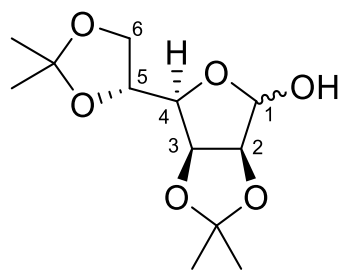

A solution of D-mannose $(9.10 \mathrm{~g}, 51 \mathrm{mmol})$ in acetone $(300 \mathrm{~mL})$ was treated with iodine $(2.58$ $\mathrm{g}, 10 \mathrm{mmol}, 0.2 \mathrm{eq}$.) and stirred under nitrogen at r.t. for $3 \mathrm{~h}$. The resulting dark brown solution was diluted with sat. aq. sodium thiosulfate solution $(150 \mathrm{~mL})$ and sat. aq. sodium bicarbonate solution $(150 \mathrm{~mL})$, and extracted with dichloromethane $(3 \times 150 \mathrm{~mL})$. The combined organic layers were dried over anhydrous magnesium sulfate, filtered and concentrated to afford the crude product as a pale-yellow solid. The crude material was recrystallized from boiling acetone to obtain the purified product $(10.75 \mathrm{~g}, 41 \mathrm{mmol}, 82 \%)$ as white crystals.

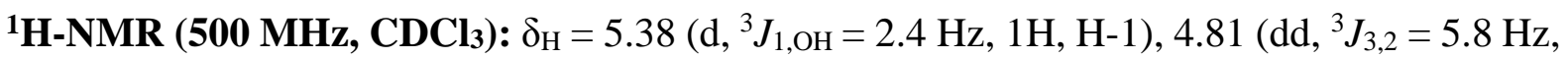
$\left.{ }^{3} J_{3,4}=3.8 \mathrm{~Hz}, 1 \mathrm{H}, \mathrm{H}-3\right), 4.62$ (d, $\left.{ }^{3} J_{2,3}=5.8 \mathrm{~Hz}, 1 \mathrm{H}, \mathrm{H}-2\right), 4.41$ (m, $\left.1 \mathrm{H}, \mathrm{H}-5\right), 4.19$ (dd, ${ }^{3} J_{4,5}=$ $\left.7.1 \mathrm{~Hz},{ }^{3} J_{4,3}=3.7 \mathrm{~Hz}, 1 \mathrm{H}, \mathrm{H}-4\right), 4.09\left(\mathrm{dd},{ }^{2} J_{6 \mathrm{a}, 6 \mathrm{~b}}=8.7 \mathrm{~Hz},{ }^{3} J_{6 \mathrm{a}, 5}=6.3 \mathrm{~Hz}, 1 \mathrm{H}, \mathrm{H}-6 \mathrm{a}\right), 4.05$ (dd, $\left.{ }^{2} J_{6 \mathrm{~b}, 6 \mathrm{a}}=8.7 \mathrm{~Hz},{ }^{3} J_{6 \mathrm{~b}, 5}=4.8 \mathrm{~Hz}, 1 \mathrm{H}, \mathrm{H}-6 \mathrm{~b}\right), 2.77$ (broad s, $\left.1 \mathrm{H}, \mathrm{OH}\right), 1.47$ (s, 3H, CH$)_{3}, 1.46(\mathrm{~s}$, $\left.3 \mathrm{H}, \mathrm{CH}_{3}\right), 1.38\left(\mathrm{~s}, 3 \mathrm{H}, \mathrm{CH}_{3}\right), 1.33\left(\mathrm{~s}, 3 \mathrm{H}, \mathrm{CH}_{3}\right) ;{ }^{\mathbf{1 3}} \mathbf{C}-\mathbf{N M R}\left(\mathbf{1 2 5} \mathbf{~ M H z}, \mathbf{C D C l}_{3}\right): \delta_{\mathrm{C}}=112.7(\mathrm{C}$, $\left.\left(\mathrm{CH}_{3}\right)_{2} \mathrm{C}\right), 109.1\left(\mathrm{C},\left(\mathrm{CH}_{3}\right)_{2} \mathrm{C}\right), 101.3(\mathrm{CH}, \mathrm{C}-1), 85.4(\mathrm{CH}, \mathrm{C}-2), 80.4(\mathrm{CH}, \mathrm{C}-4), 79.6(\mathrm{CH}, \mathrm{C}-$ 3), $73.2(\mathrm{CH}, \mathrm{C}-5), 66.6\left(\mathrm{CH}_{2}, \mathrm{C}-6\right), 26.9\left(\mathrm{CH}_{3},\left(\mathrm{CH}_{3}\right)_{2} \mathrm{C}\right), 25.8\left(\mathrm{CH}_{3},\left(\mathrm{CH}_{3}\right)_{2} \mathrm{C}\right), 25.2\left(\mathrm{CH}_{3}\right.$, $\left.\left(\mathrm{CH}_{3}\right)_{2} \mathrm{C}\right), 24.5\left(\mathrm{CH}_{3},\left(\mathrm{CH}_{3}\right)_{2} \mathrm{C}\right)$. 
(3aS,6R,6aS)-4-Chloro-6-((R)-2,2-dimethyl-1,3-dioxolan-4-yl)-2,2-

dimethyltetrahydrofuro $[3,4-d][1,3]$ dioxole $(58)$

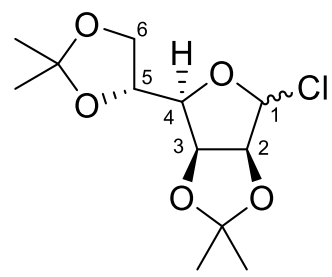

A solution of furanol $57(9.99 \mathrm{~g}, 38 \mathrm{mmol})$ in dichloromethane $(200 \mathrm{~mL})$ was treated sequentially with 4-dimethylaminopyridine (3.60 g, 29 mmol, 0.8 eq.), tosyl chloride ( $8.09 \mathrm{~g}$, $42 \mathrm{mmol}, 1.1 \mathrm{eq}$.$) , and triethylamine (5.3 \mathrm{~mL}, 38 \mathrm{mmol}, 1$ eq.) and stirred under nitrogen at r.t. for $4 \mathrm{~h}$. The resulting solution was washed with sat. aq. copper sulfate solution (200 mL), sat. aq. sodium bicarbonate solution $(200 \mathrm{~mL})$, and brine $(100 \mathrm{~mL})$. The organic layer was dried over anhydrous magnesium sulfate, filtered and concentrated to afford the crude product as a pale-yellow oil. The crude material was purified via flash column chromatography $(9: 1$ petroleum ether:ethyl acetate) to afford the chlorofuran $58(6.38 \mathrm{~g}, 23 \mathrm{mmol}, 60 \%)$ as a colourless oil.

${ }^{1}$ H-NMR (500 MHz, CDCl3): $\delta_{\mathrm{H}}=6.07(\mathrm{~s}, 1 \mathrm{H}, \mathrm{H}-1), 4.96\left(\mathrm{~d},{ }^{3} \mathrm{~J}_{2,3}=5.6 \mathrm{~Hz}, 1 \mathrm{H}, \mathrm{H}-2\right), 4.89$ $\left(\mathrm{dd},{ }^{3} J_{3,2}=5.7 \mathrm{~Hz},{ }^{3} J_{3,4}=3.7 \mathrm{~Hz}, 1 \mathrm{H}, \mathrm{H}-3\right), 4.44(\mathrm{~m}, 1 \mathrm{H}, \mathrm{H}-5), 4.21\left(\mathrm{dd},{ }^{3} J_{4,5}=7.8 \mathrm{~Hz},{ }^{3} J_{4,3}=\right.$ $3.4 \mathrm{~Hz}, 1 \mathrm{H}, \mathrm{H}-4), 4.10\left(\mathrm{dd},{ }^{2} J_{6 \mathrm{a}, 6 \mathrm{~b}}=8.9 \mathrm{~Hz},{ }^{3} J_{6 \mathrm{a}, 5}=6.2 \mathrm{~Hz}, 1 \mathrm{H}, \mathrm{H}-6 \mathrm{a}\right), 4.03\left(\mathrm{dd},{ }^{2} J_{6 \mathrm{~b}, 6 \mathrm{a}}=8.8\right.$ $\left.\mathrm{Hz},{ }^{3} J_{6 \mathrm{~b}, 5}=4.2 \mathrm{~Hz}, 1 \mathrm{H}, \mathrm{H}-6 \mathrm{~b}\right), 1.47$ (s, 6H, $\left.\mathrm{CH}_{3}\right), 1.39$ (s, 3H, $\left.\mathrm{CH}_{3}\right), 1.34$ (s, 3H. $\mathrm{CH}_{3}$ ).

\section{(R)-4-((2S,3R)-3-(Benzyloxy)-2,3-dihydrofuran-2-yl)-2,2-dimethyl-1,3-dioxolane (45)}

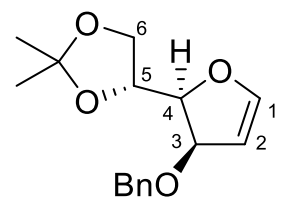

A solution of naphthalene (38.16 g, $297 \mathrm{mmol}, 8.0$ eq.) in tetrahydrofuran (150 mL) was treated with sodium ( $4.28 \mathrm{~g}, 186 \mathrm{mmol}, 5.0$ eq.) and stirred under nitrogen at r.t. for $2.5 \mathrm{~h}$. The dark green solution was then cooled to $0^{\circ} \mathrm{C}$, treated with a solution of chlorofuran $\mathbf{5 8}(10.32 \mathrm{~g}, 37.0$ mmol) in tetrahydrofuran $(40 \mathrm{~mL})$ via cannula and stirred at $0^{\circ} \mathrm{C}$ for $15 \mathrm{~min}$. The reaction was allowed to warm to r.t. and stirred for a further $20 \mathrm{~min}$, then quenched with sat. aq. ammonium chloride solution $(150 \mathrm{~mL})$ and water $(100 \mathrm{~mL})$. The layers were separated and the aqueous layer was extracted with diethyl ether $(2 \times 125 \mathrm{~mL})$, the combined organic fractions were 
washed with brine $(50 \mathrm{~mL})$, dried over anhydrous magnesium sulfate, filtered and concentrated to afford the crude intermediate as a yellow oil. Used without further purification, the crude intermediate was dissolved in tetrahydrofuran $(150 \mathrm{~mL})$, cooled to $0^{\circ} \mathrm{C}$ and treated with tetrabutylammonium iodide $(0.70 \mathrm{~g}, 1.89 \mathrm{mmol}, 0.05 \mathrm{eq}$.), sodium hydride (60\% in mineral oil, $1.94 \mathrm{~g}, 48.5 \mathrm{mmol}, 1.3 \mathrm{eq}$.) and benzyl bromide (5.8 mL, $48.8 \mathrm{mmol}, 1.3 \mathrm{eq}$.). The reaction was allowed to warm to r.t. and stirred under nitrogen for $24 \mathrm{~h}$ whereupon the yellow solution was quenched with brine $(150 \mathrm{~mL})$ and diluted with water $(100 \mathrm{~mL})$. The layers were separated and the aqueous layer was extracted with diethyl ether $(2 \times 150 \mathrm{~mL})$. The combined organic fractions were washed with brine $(150 \mathrm{~mL})$, dried over anhydrous magnesium sulfate, filtered and concentrated to afford a mixture of the crude product and naphthalene as a yellow solid. The crude product was separated into three batches and purified by dry-loaded column chromatography (9:1 petroleum ether:ethyl acetate) to afford the glycal 45 (7.11 g, $25.7 \mathrm{mmol}$, $69 \%)$ as a yellow oil.

${ }^{1}$ H-NMR (500 MHz, CDCl3): $\delta_{\mathrm{H}}=7.36-7.26$ (complex m, 5H, Ar-H), $6.63\left(\mathrm{~d},{ }^{3} J_{1,2}=2.7 \mathrm{~Hz}\right.$, $1 \mathrm{H}, \mathrm{H}-1), 5.29$ (apparent t, $J=2.6 \mathrm{~Hz}, 1 \mathrm{H}, \mathrm{H}-2), 4.66\left(\mathrm{dd},{ }^{3} J_{3,4}=7.1 \mathrm{~Hz},{ }^{3} J_{3,2}=2.1 \mathrm{~Hz}, 1 \mathrm{H}, \mathrm{H}-\right.$ 3), 4.59 (m, 1H, H-5), 4.57 (d, $\left.{ }^{2} J_{\mathrm{A}, \mathrm{B}}=11.9 \mathrm{~Hz}, 1 \mathrm{H}, \mathrm{Bn}-\mathrm{A}\right), 4.52\left(\mathrm{~d},{ }^{2} J_{\mathrm{B}, \mathrm{A}}=11.9 \mathrm{~Hz}, 1 \mathrm{H}, \mathrm{Bn}-\right.$ B), 4.44 (apparent t, $\left.{ }^{3} J_{4,5}={ }^{3} J_{4,3}=6.1 \mathrm{~Hz}, 1 \mathrm{H}, \mathrm{H}-4\right), 4.11\left(\mathrm{dd},{ }^{2} J_{6 \mathrm{a}, 6 \mathrm{~b}}=8.1 \mathrm{~Hz},{ }^{3} J_{6 \mathrm{a}, 5}=7.1 \mathrm{~Hz}\right.$, $1 \mathrm{H}, \mathrm{H}-6 \mathrm{a}), 4.00$ (dd, $\left.{ }^{2} J_{6 \mathrm{~b}, 6 \mathrm{a}}=8.0 \mathrm{~Hz},{ }^{3} J_{6 \mathrm{~b}, 5}=7.0 \mathrm{~Hz}, 1 \mathrm{H}, \mathrm{H}-6 \mathrm{~b}\right), 1.48$ (s, 3H, $\left.\mathrm{CH}_{3}\right), 1.40$ (s, 3H, $\left.\mathrm{CH}_{3}\right)$.

$(2 R, 5 R, 6 S)-5-($ benzyloxy)-3-bromo-6-((R)-2,2-dimethyl-1,3-dioxolan-4-yl)-5,6-

dihydro-2H-pyran-2-yl acetate $\alpha-(56)$ and $(2 S, 5 R, 6 S)-5$-(benzyloxy)-3-bromo-6-( $(R)-2,2-$ dimethyl-1,3-dioxolan-4-yl)-5,6-dihydro-2H-pyran-2-yl acetate $\beta$-(56)

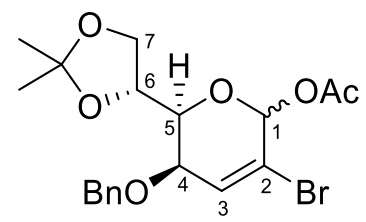

A solution of glycal $45(2.37 \mathrm{~g}, 8.58 \mathrm{mmol})$ in bromoform $(30 \mathrm{~mL}, 0.34 \mathrm{~mol} 40$ eq.) was treated with potassium carbonate $(7.76 \mathrm{~g}, 56 \mathrm{mmol}, 6.5 \mathrm{eq}$ ) $)$, sodium acetate $(2.70 \mathrm{~g}, 32.9 \mathrm{mmol}, 3.8$ eq.), 18-crown-6 (106 mg, $0.40 \mathrm{mmol}, 0.05$ eq.) and tetra-n-butylammonium bromide $(0.592$ g, $1.83 \mathrm{mmol}, 0.21$ eq.) and stirred under nitrogen at r.t. for $16 \mathrm{~h}$. The reaction vessel was then fitted with a water-cooled reflux condenser, heated to $82^{\circ} \mathrm{C}$ and left to react for $48 \mathrm{~h}$. At this 
point, the dark brown suspension was treated with a further amount of bromoform ( $4 \mathrm{~mL}, 45.7$ mmol, 5.3 eq.) and left to react for a further $24 \mathrm{~h}$. The reaction mixture was then diluted with dichloromethane $(30 \mathrm{~mL})$, filtered and concentrated. The crude material was purified by column chromatography (gradient elution 9:1 to 5:1 petroleum ether:ethyl acetate) to afford a mixture of $\alpha$ - and $\beta$-anomers of acetate $56(2.23 \mathrm{~g}, 5.22 \mathrm{mmol}, 61 \%)$ as a white solid.

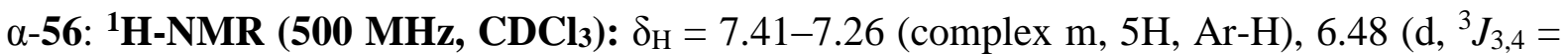
$5.8 \mathrm{~Hz}, 1 \mathrm{H}, \mathrm{H}-3), 6.25$ (apparent s, 1H, H-1), 4.71 (s, 2H, $\mathrm{PhCH}_{2}$ ), $4.41-4.38$ (m, 1H, H-6), $4.11\left(\mathrm{dd},{ }^{2} J_{7 \mathrm{a}, 7 \mathrm{~b}}=8.9 \mathrm{~Hz},{ }^{3} J_{7 \mathrm{a}, 6}=6.2 \mathrm{~Hz}, 1 \mathrm{H}, \mathrm{H}-7 \mathrm{a}\right), 4.03\left(\mathrm{dd},{ }^{2} J_{7 \mathrm{~b}, 7 \mathrm{a}}=8.9 \mathrm{~Hz},{ }^{3} J_{7 \mathrm{~b}, 6}=4.5 \mathrm{~Hz}\right.$, $1 \mathrm{H}, \mathrm{H}-7 \mathrm{~b}), 3.95$ (dt, $\left.{ }^{3} J_{4,3}=5.9 \mathrm{~Hz},{ }^{3} J_{4,5}=1.9 \mathrm{~Hz}, 1 \mathrm{H}, \mathrm{H}-4\right), 3.69\left(\mathrm{dd},{ }^{3} J_{5,6}=8.5 \mathrm{~Hz},{ }^{3} J_{5,4}=2.2\right.$ $\mathrm{Hz}, 1 \mathrm{H}, \mathrm{H}-5), 2.16$ (s, 3H, Ac), 1.40 (s, 3H, $\left.\left(\mathrm{CH}_{3}\right)_{2} \mathrm{C}\right), 1.37$ (s, 3H, $\left.\left(\mathrm{CH}_{3}\right)_{2} \mathrm{C}\right) ;{ }^{13} \mathbf{C}-\mathbf{N M R}(\mathbf{1 2 5}$ MHz, CDCl 3$): \delta_{\mathrm{C}}=169.1\left(\mathrm{C}, \mathrm{CH}_{3} \mathrm{CO}\right), 138.0(\mathrm{C}, \mathrm{Ar}), 131.6(\mathrm{CH}, \mathrm{C}-3), 128.4(\mathrm{CH}, \mathrm{Ar}), 128.0$ (CH, Ar), 127.9 (CH, Ar), 124.5 (C, C-2), $109.4\left(\mathrm{C},\left(\mathrm{CH}_{3}\right)_{2} \mathrm{C}\right), 90.6(\mathrm{CH}, \mathrm{C}-1), 76.8(\mathrm{CH}, \mathrm{C}-$ 5), $73.0(\mathrm{CH}, \mathrm{C}-6), 71.9\left(\mathrm{CH}_{2}, \mathrm{PhCH}_{2}\right), 69.5(\mathrm{CH}, \mathrm{C}-4), 67.0\left(\mathrm{CH}_{2}, \mathrm{C}-7\right), 27.0\left(\mathrm{CH}_{3},\left(\mathrm{CH}_{3}\right)_{2} \mathrm{C}\right)$, $25.3\left(\mathrm{CH}_{3},\left(\mathrm{CH}_{3}\right)_{2} \mathrm{C}\right), 20.9\left(\mathrm{CH}_{3}, \mathrm{Ac}\right)$.

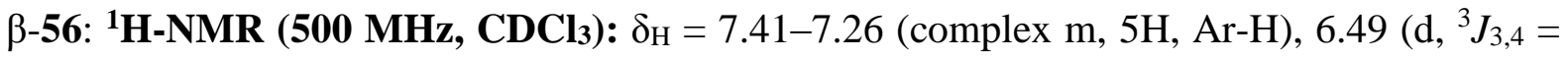
$5.9 \mathrm{~Hz}, 1 \mathrm{H}, \mathrm{H}-3), 6.34$ (s, 1H, H-1), 4.69 (s, 2H, $\mathrm{PhCH}_{2}$ ), 4.41 - 4.36 (m, 1H, H-6), 4.12 (dd, $\left.{ }^{2} J_{7 \mathrm{a}, 7 \mathrm{~b}}=8.9 \mathrm{~Hz},{ }^{3} J_{7 \mathrm{a}, 6}=6.4 \mathrm{~Hz}, 1 \mathrm{H}, \mathrm{H}-7 \mathrm{a}\right), 3.92\left(\mathrm{dd},{ }^{3} J_{4,3}=6.0 \mathrm{~Hz},{ }^{3} J_{4,5}=2.5 \mathrm{~Hz}, 1 \mathrm{H}, \mathrm{H}-4\right)$, $3.88\left(\mathrm{dd},{ }^{2} J_{7 \mathrm{~b}, 7 \mathrm{a}}=8.9 \mathrm{~Hz},{ }^{3} J_{7 \mathrm{~b}, 6}=4.5 \mathrm{~Hz}, 1 \mathrm{H}, \mathrm{H}-7 \mathrm{~b}\right), 3.85\left(\mathrm{dd},{ }^{3} J_{5,6}=8.2 \mathrm{~Hz},{ }^{3} J_{5,4}=2.4 \mathrm{~Hz}, 1 \mathrm{H}\right.$, H-5), 2.14 (s, 3H, Ac), 1.41 (s, 3H, $\left.\left(\mathrm{CH}_{3}\right)_{2} \mathrm{C}\right), 1.38$ (s, 3H, $\left.\left(\mathrm{CH}_{3}\right)_{2} \mathrm{C}\right) ;{ }^{13} \mathrm{C}-\mathrm{NMR}(\mathbf{1 2 5} \mathbf{M H z}$, CDCl 3$): \delta_{\mathrm{C}}=169.5\left(\mathrm{C}, \mathrm{CH}_{3} \mathrm{CO}\right), 137.8(\mathrm{C}, \mathrm{Ar}), 130.2(\mathrm{CH}, \mathrm{C}-3), 128.4(\mathrm{CH}, \mathrm{Ar}), 127.99(\mathrm{CH}$, Ar), 127.96 (CH, Ar), 122.6 (C, C-2), 109.4 (C, $\left.\left(\mathrm{CH}_{3}\right)_{2} \mathrm{C}\right), 90.0$ (CH, C-1), 76.8 (CH, C-5), $72.9(\mathrm{CH}, \mathrm{C}-6), 72.1\left(\mathrm{CH}_{2}, \mathrm{PhCH}_{2}\right), 69.1(\mathrm{CH}, \mathrm{C}-4), 67.1\left(\mathrm{CH}_{2}, \mathrm{C}-7\right), 26.9\left(\mathrm{CH}_{3},\left(\mathrm{CH}_{3}\right)_{2} \mathrm{C}\right)$, $25.2\left(\mathrm{CH}_{3},\left(\mathrm{CH}_{3}\right)_{2} \mathrm{C}\right), 20.9\left(\mathrm{CH}_{3}, \mathrm{Ac}\right)$. 


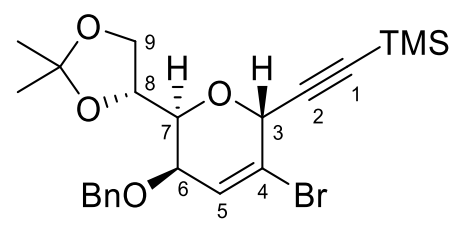

The acetate 56 (380 mg, $0.89 \mathrm{mmol})$ was dissolved in dichloromethane ( $3 \mathrm{~mL}$ ) and added to bis(trimethylsilyl)acetylene ( $0.68 \mathrm{~g}, 3.7 \mathrm{mmol}, 4 \mathrm{eq}$.). The reaction mixture was cooled to -78 ${ }^{\circ} \mathrm{C}$ and treated with tin tetrachloride ( $1 \mathrm{~mL}, 1 \mathrm{mmol}, 1.1 \mathrm{eq}$.), and left to react for $1.5 \mathrm{~h}$. After further stirring at r.t. for $1 \mathrm{~h}$, the reaction was quenched with sat. aq. sodium bicarbonate solution $(20 \mathrm{~mL})$, extracted with dichloromethane $(3 \times 30 \mathrm{~mL})$, dried over anhydrous magnesium sulfate, filtered and concentrated. The crude material was purified by column chromatography (gradient elution 20:1 to $2: 1$ petroleum ether:ethyl acetate) to afford the acetonide 64 (85 mg, $0.18 \mathrm{mmol}, 21 \%$ ) as a pale yellow oil and the diol 63 (160 mg, $0.38 \mathrm{mmol}$, $41 \%)$ as a colourless oil.

64: ${ }^{1} \mathrm{H}-\mathrm{NMR}\left(500 \mathrm{MHz}, \mathbf{C D C l}_{3}\right): \delta_{\mathrm{H}}=7.38-7.29$ (complex m, 5H, Ar-H), $6.27\left(\mathrm{dd},{ }^{3} J_{5,6}=5.5\right.$ $\left.\mathrm{Hz},{ }^{4} J_{5,3}=1.3 \mathrm{~Hz}, 1 \mathrm{H}, \mathrm{H}-5\right), 4.92$ (d, $\left.{ }^{4} J_{3,5}=1.2 \mathrm{~Hz}, 1 \mathrm{H}, \mathrm{H}-3\right), 4.69$ (apparent s, 2H, $\mathrm{PhCH}_{2}$ ), $4.39(\mathrm{~m}, 1 \mathrm{H}, \mathrm{H}-8), 4.16\left(\mathrm{dd},{ }^{2} J_{9 \mathrm{a}, 9 \mathrm{~b}}=8.5 \mathrm{~Hz},{ }^{3} J_{9 \mathrm{a}, 8}=6.3 \mathrm{~Hz}, 1 \mathrm{H}, \mathrm{H}-9 \mathrm{a}\right), 3.97$ (dd, ${ }^{2} J_{9 \mathrm{~b}, 9 \mathrm{a}}=8.6$ $\mathrm{Hz},{ }^{3} J_{9 \mathrm{~b}, 8}=5.3 \mathrm{~Hz}, 1 \mathrm{H}, \mathrm{H}-9 \mathrm{~b}$ ), 3.91 (complex m, 2H, H-6 \& H-7), 1.42 (s, 3H, CH ), 1.40 (s, $\left.3 \mathrm{H}, \mathrm{CH}_{3}\right), 0.19\left(\mathrm{~s}, 9 \mathrm{H},\left(\mathrm{CH}_{3}\right)_{3} \mathrm{Si}\right) ;{ }^{13} \mathbf{C}-\mathbf{N M R}\left(\mathbf{1 2 5} \mathbf{M H z}, \mathbf{C D C l}_{3}\right): \delta_{\mathrm{C}}=138.0(\mathrm{C}, \mathrm{Ar}), 128.4$ (CH, Ar), 128.1 (CH, Ar), 127.8 (CH, Ar), 126.9 (CH, C-5), 124.9 (CH, C-4), 109.4 (C, $\left.\left(\mathrm{CH}_{3}\right)_{2} \mathrm{C}\right), 99.4$ (C, C-2), 92.3 (C, C-1), 74.2 (CH, C-6), $72.9(\mathrm{CH}, \mathrm{C}-8), 72.1\left(\mathrm{CH}_{2}, \mathrm{PhCH}_{2}\right)$, $\left.66.90(\mathrm{CH}, \mathrm{C}-3), 69.89(\mathrm{CH}, \mathrm{C}-7), 67.6\left(\mathrm{CH}_{2}, \mathrm{C}-9\right), 26.9\left(\mathrm{CH}_{3},\left(\mathrm{CH}_{3}\right)_{2} \mathrm{C}\right), 25.5\left(\mathrm{CH}_{3}\right)_{2} \mathrm{C}\right),-0.33$ $\left(\mathrm{CH}_{3},\left(\mathrm{CH}_{3}\right)_{3} \mathrm{Si}\right)$.

63: ${ }^{1} \mathbf{H}-N M R\left(500 ~ M H z, \mathbf{C D C l}_{3}\right)$ : $\delta_{\mathrm{H}}=7.37-7.32\left(\right.$ complex m, 5H, Ar-H), $6.38\left(\mathrm{dd},{ }^{3} J_{5,6}=5.6\right.$ $\left.\mathrm{Hz},{ }^{4} J_{5,3}=1.4 \mathrm{~Hz}, 1 \mathrm{H}, \mathrm{H}-5\right), 4.96\left(\mathrm{~d},{ }^{4} J_{3,5}=1.5 \mathrm{~Hz}, 1 \mathrm{H}, \mathrm{H}-3\right), 4.74\left(\mathrm{~d},{ }^{2} J_{\mathrm{A}, \mathrm{B}}=11.7 \mathrm{~Hz}, 1 \mathrm{H}\right.$, $\left.\mathrm{PhCH}_{2}-\mathrm{A}\right), 4.60\left(\mathrm{~d},{ }^{2} J_{\mathrm{B}, \mathrm{A}}=11.7 \mathrm{~Hz}, 1 \mathrm{H}, \mathrm{PhCH}_{2}-\mathrm{B}\right), 4.04-3.95$ (complex m, 3H, H-6, H-7 \& $\mathrm{H}-8), 3.84\left(\mathrm{dd},{ }^{2} J_{9 \mathrm{a}, 9 \mathrm{~b}}=11.6 \mathrm{~Hz},{ }^{3} J_{9 \mathrm{a}, 8}=3.1 \mathrm{~Hz}, 1 \mathrm{H}, \mathrm{H}-9 \mathrm{a}\right), 3.79\left(\mathrm{dd},{ }^{2} J_{9 \mathrm{~b}, 9 \mathrm{a}}=11.6 \mathrm{~Hz},{ }^{3} J_{9 \mathrm{~b}, 8}=\right.$ $5 \mathrm{~Hz}, 1 \mathrm{H}, \mathrm{H}-9 \mathrm{~b}), 0.18$ (s, 9H, $\left.\left(\mathrm{CH}_{3}\right)_{3} \mathrm{Si}\right) ;{ }^{13} \mathbf{C}-\mathbf{N M R}\left(125 \mathbf{M H z}, \mathbf{C D C l}_{3}\right): \delta_{\mathrm{C}}=137.7(\mathrm{C}, \mathrm{Ar})$, 128.7 (CH, Ar), 128.2 (CH, Ar), 128.1 (CH, Ar), 126.4 (CH, C-5), 125.5 (CH, C-4), 99.3 (C, C-2), 92.4 (C, C-1), 72.5 (CH, C-7), $71.2\left(\mathrm{CH}_{2}, \mathrm{PhCH}_{2}\right), 69.9$ (CH, C-3), 69.8 (CH, C-8), 69.4 $(\mathrm{CH}, \mathrm{C}-6), 64.0\left(\mathrm{CH}_{2}, \mathrm{C}-9\right),-0.36\left(\mathrm{CH}_{3},\left(\mathrm{CH}_{3}\right)_{3} \mathrm{Si}\right)$. 
$(R)-1-((2 R, 3 R, 6 R)-3-(B e n z y l o x y)-5-b r o m o-$

6-((trimethylsilyl)ethynyl)-3,6-dihydro-2H-pyran-2-yl)ethane-1,2-diol (63)

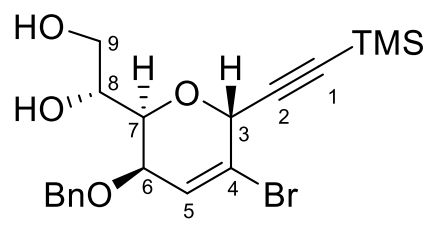

A) The TMS-protected acetonide $64(66 \mathrm{mg}, 0.14 \mathrm{mmol})$ was dissolved in acetonitrile $(5 \mathrm{~mL})$, cooled to $0^{\circ} \mathrm{C}$ and treated with trifluoroacetic acid $(0.1 \mathrm{~mL}, 1.3 \mathrm{mmol}, 9.3$ eq.). After $90 \mathrm{~min}$., a further $0.1 \mathrm{~mL}$ trifluoroacetic acid was added, the reaction mixture was allowed to warm to r.t., and left to react for $16 \mathrm{~h}$. The reaction was quenched with powdered sodium bicarbonate (2.7 g) until $\mathrm{pH} 7$ was reached, diluted with water $(10 \mathrm{~mL})$, extracted with dichloromethane (3 x $20 \mathrm{~mL}$ ), dried over anhydrous sodium sulfate, filtered and concentrated. The crude material was purified by column chromatography (gradient elution 20:1 to 3:1 petroleum ether:ethyl acetate) to afford the diol $\mathbf{6 3}(45 \mathrm{mg}, 0.11 \mathrm{mmol}, 74 \%)$ as a colourless oil.

B) The acetate 56 (1.14 g, $2.67 \mathrm{mmol})$ dissolved in dichloromethane (27 mL) was treated with bis(trimethylsilyl)acetylene ( $2.4 \mathrm{~mL}, 11 \mathrm{mmol}, 4.0 \mathrm{eq}$.). The reaction mixture was cooled to $78^{\circ} \mathrm{C}$, treated dropwise with tin tetrachloride $(2.9 \mathrm{~mL}, 1 \mathrm{M}$ solution in dichloromethane, 2.9 mmol, 1.1 eq.) and left to react for $2.25 \mathrm{~h}$. The reaction mixture was then allowed to warm to room temperature, and left to react for a further $2 \mathrm{~h}$, whereupon it was quenched with sat. aq. sodium bicarbonate $(35 \mathrm{~mL})$. The layers were separated, and the aqueous layer was extracted with dichloromethane $(3 \times 30 \mathrm{~mL})$, the combined organic fractions were washed with distilled water $(50 \mathrm{~mL})$, dried over anhydrous magnesium sulfate, filtered and concentrated. The crude residue, a yellow oil, was redissolved in acetonitrile $(50 \mathrm{~mL})$, cooled to $0^{\circ} \mathrm{C}$, and treated dropwise with trifluoroacetic acid $(5.1 \mathrm{~mL}, 67 \mathrm{mmol}, 25 \mathrm{eq}$.). The reaction mixture was allowed to warm to room temperature and left to react for $16 \mathrm{~h}$. The reaction mixture was then quenched with powdered sodium bicarbonate until $\mathrm{pH} 7$ was reached, diluted with distilled water (30 $\mathrm{mL})$, and extracted with dichloromethane $(3 \times 30 \mathrm{~mL})$. The combined organic fractions were dried over anhydrous magnesium sulfate, filtered and concentrated. The crude material was purified by column chromatography (gradient elution 3:1 to 2:1 petroleum ether:ethyl acetate) to afford the diol 63 (712 $\mathrm{mg}, 1.67 \mathrm{mmol}, 62 \%)$ as a colourless oil. 
yl)ethane-1,2-diol (90)

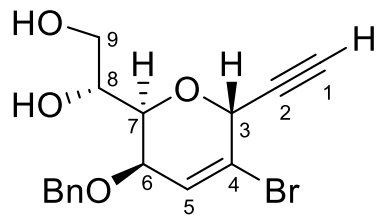

The TMS-protected acetylene diol $63(197 \mathrm{mg}, 0.46 \mathrm{mmol})$ was dissolved in dichloromethane $(5.8 \mathrm{~mL})$ and methanol $(1.2 \mathrm{~mL}, 21 \% \mathrm{v} / \mathrm{v})$, treated with potassium carbonate $(198 \mathrm{mg}, 1.43$ mmol, 3.1 eq.) and stirred at r.t. for 2.5 h. The resulting suspension was diluted with dichloromethane $(10 \mathrm{~mL})$, filtered into brine $(15 \mathrm{~mL})$ and the aqueous layer was extracted with dichloromethane $(3 \times 10 \mathrm{~mL})$. The combined organic fractions were dried over anhydrous sodium sulfate, filtered and concentrated at r.t. to afford the deprotected acetylene diol 90 (110 $\mathrm{mg}, 0.31 \mathrm{mmol}, 67 \%$ crude yield) as a white solid which was used without further purification.

${ }^{1}$ H-NMR (500 MHz, CDCl $): \delta_{H}=7.38-7.36$ (complex m, 5H, Ar-H), $6.42\left(\mathrm{dd},{ }^{3} J_{5,6}=5.5 \mathrm{~Hz}\right.$, $\left.{ }^{4} J_{5,3}=1.3 \mathrm{~Hz}, 1 \mathrm{H}, \mathrm{H}-5\right), 5.00($ broad s, $1 \mathrm{H}, \mathrm{H}-3), 4.75\left(\mathrm{~d},{ }^{2} J_{\mathrm{A}, \mathrm{B}}=11.7 \mathrm{~Hz}, 1 \mathrm{H}, \mathrm{PhCH}_{2}-\mathrm{A}\right), 4.60$ $\left(\mathrm{d},{ }^{2} J_{\mathrm{B}, \mathrm{A}}=11.4 \mathrm{~Hz}, 1 \mathrm{H}, \mathrm{PhCH}_{2}-\mathrm{B}\right), 4.03\left(\mathrm{dd},{ }^{3} J_{6,5}=5.6 \mathrm{~Hz},{ }^{3} J_{6,7}=2.0 \mathrm{~Hz}, 1 \mathrm{H}, \mathrm{H}-6\right), 4.00-$ 3.98 (complex m, 2H, H-7 \& H-8), 3.86 (dd, $\left.{ }^{2} J_{9 a}, 9 \mathrm{~b}=11.5 \mathrm{~Hz},{ }^{3} J_{9 \mathrm{a}, 8}=2.9 \mathrm{~Hz}, 1 \mathrm{H}, \mathrm{H}-9 \mathrm{a}\right), 3.78$ $\left(\mathrm{dd},{ }^{2} J_{9 \mathrm{~b}, 9 \mathrm{a}}=11.5 \mathrm{~Hz},{ }^{3} J_{9 \mathrm{~b}, 8}=4.7 \mathrm{~Hz}, 1 \mathrm{H}, \mathrm{H}-9 \mathrm{~b}\right), 2.53\left(\mathrm{~d},{ }^{4} J_{1,3}=2.2 \mathrm{~Hz}, 1 \mathrm{H}, \mathrm{H}-1\right) ;{ }^{13} \mathbf{C}-\mathbf{N M R}$ $(125 \mathrm{MHz}, \mathbf{C D C l} 3): \delta_{\mathrm{C}}=137.6(\mathrm{C}, \mathrm{Ar}), 128.7(\mathrm{CH}, \mathrm{Ar}), 128.2(\mathrm{CH}, \mathrm{Ar}), 128.0(\mathrm{CH}, \mathrm{Ar}), 126.7$ $\mathrm{CH}, \mathrm{C}-5), 125.1$ (C, C-4), 78.2 (C, C-2), 75.0 (CH, C-1), 72.5 (CH, C-7), $71.3\left(\mathrm{CH}_{2}, \mathrm{PhCH}_{2}\right)$, $69.8(\mathrm{CH}, \mathrm{C}-8), 69.4(\mathrm{CH}, \mathrm{C}-6), 69.2(\mathrm{CH}, \mathrm{C}-3), 63.8\left(\mathrm{CH}_{2}, \mathrm{C}-9\right)$.

\section{(2S,3R,6R)-3-(Benzyloxy)-5-bromo-6-ethynyl-3,6-dihydro-2H-pyran-2-carbaldehyde} (70)

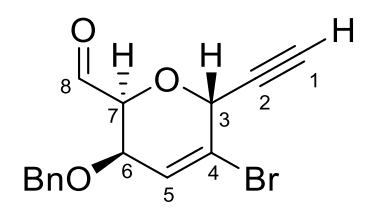

A solution of diol 90 (13 mg, $0.04 \mathrm{mmol})$ in tetrahydrofuran $(0.64 \mathrm{~mL})$ was treated with $\mathrm{pH} 7$ sodium phosphate buffer $(0.2 \mathrm{~mL})$ followed by sodium periodate $(47 \mathrm{mg}, 0.22 \mathrm{mmol}, 6.1 \mathrm{eq}$.) and stirred at r.t. for $1.5 \mathrm{~h}$. The reaction mixture was then diluted with brine $(5 \mathrm{~mL})$ and extracted with diethyl ether $(3 \times 5 \mathrm{~mL})$. The combined organic fractions were then washed with 
brine $(2 \times 10 \mathrm{~mL})$, dried over anhydrous magnesium sulfate, filtered and concentrated to afford aldehyde 70 (12 mg, $0.04 \mathrm{mmol}, 100 \%)$ as a white solid which was used without further purification.

${ }^{1}$ H-NMR (500 MHz, CDCl3): $\delta_{\mathrm{H}}=9.67$ (s, 1H, H-8), 7.37-7.28 (complex m, 5H, Ar-H), 6.32 $\left(\mathrm{dd},{ }^{3} J_{5,6}=5.4 \mathrm{~Hz},{ }^{4} J_{5,3}=1.4 \mathrm{~Hz}, 1 \mathrm{H}, \mathrm{H}-5\right), 5.15$ (apparent t, $\left.J=1.9 \mathrm{~Hz}, 1 \mathrm{H}, \mathrm{H}-3\right), 4.59$ (d, $\left.{ }^{2} J_{\mathrm{A}, \mathrm{B}}=11.7 \mathrm{~Hz}, 1 \mathrm{H}, \mathrm{PhCH}_{2}-\mathrm{A}\right), 4.53\left(\mathrm{~d},{ }^{2} J_{\mathrm{B}, \mathrm{A}}=11.4 \mathrm{~Hz}, 1 \mathrm{H}, \mathrm{PhCH}_{2}-\mathrm{B}\right), 4.48\left(\mathrm{~d},{ }^{3} J_{7,6}=3.0 \mathrm{~Hz}\right.$, $1 \mathrm{H}, \mathrm{H}-7$ ), 4.22 (dd, $\left.{ }^{3} J_{6,5}=5.5 \mathrm{~Hz},{ }^{4} J_{6,7}=3.0 \mathrm{~Hz}, 1 \mathrm{H}, \mathrm{H}-6\right), 2.56$ (d, $\left.{ }^{4} J_{1,3}=2.3 \mathrm{~Hz}, 1 \mathrm{H}, \mathrm{H}-1\right)$. ${ }^{13} \mathrm{C}-N M R(125$ MHz, CDCl 3$): \delta_{\mathrm{C}}=199.1(\mathrm{CH}, \mathrm{C}-8), 137.0(\mathrm{C}, \mathrm{Ar}), 128.5(\mathrm{CH}, \mathrm{Ar}), 128.2$ (CH, Ar), 128.1 (CH, Ar), 125.7 (CH, C-5), 125.0 (C, C-4), 77.3 (C, C-2), 77.0 (CH, C-7), 75.9 (CH, C-1), $71.8\left(\mathrm{CH}_{2}, \mathrm{PhCH}_{2}\right), 70.2(\mathrm{CH}, \mathrm{C}-6), 68.9(\mathrm{CH}, \mathrm{C}-3)$.

Ethyl (E/Z)-3-((2R,3R,6R)-3-(benzyloxy)-5-bromo-6-ethynyl-3,6-dihydro-2H-pyran-2yl)acrylate $(Z-71)$ and $(E-71)$

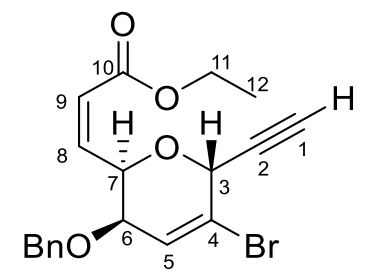

The aldehyde 70 (25 mg, $0.078 \mathrm{mmol})$ was dissolved in tetrahydrofuran (1.6 mL), treated with ethyl (triphenylphosphoranylidene)acetate (58 mg, $0.17 \mathrm{mmol}, 2.1$ eq.) and stirred at r.t. for 17 $\mathrm{h}$. The resulting pale yellow solution was concentrated under reduced pressure and purified by column chromatography (14:1 petroleum ether:ethyl acetate) to afford (Z)-71 as a colourless oil (14 mg, $0.037 \mathrm{mmol}, 47 \%)$ and (E)-71 as a white solid (10 mg, $0.026 \mathrm{mmol}, 33 \%)$.

(Z)-71 ${ }^{1} \mathrm{H}-\mathrm{NMR}\left(\mathbf{5 0 0} \mathbf{M H z}, \mathbf{C D C l}_{3}\right): \delta_{\mathrm{H}}=7.33-7.26\left(\right.$ complex m, 5H, Ar-H), $6.35\left(\mathrm{dd},{ }^{3} J_{8,9}=\right.$ $\left.11.8 \mathrm{~Hz},{ }^{3} J_{8,7}=6.7 \mathrm{~Hz}, 1 \mathrm{H}, \mathrm{H}-8\right), 6.33\left(\mathrm{dd},{ }^{3} J_{5,6}=5.6 \mathrm{~Hz},{ }^{4} J_{5,3}=1.1 \mathrm{~Hz}, 1 \mathrm{H}, \mathrm{H}-5\right), 5.94$ (dd, $\left.{ }^{3} J_{9,8}=11.8 \mathrm{~Hz},{ }^{4} J_{9,7}=1.6 \mathrm{~Hz}, 1 \mathrm{H}, \mathrm{H}-9\right), 5.56\left(\mathrm{ddd},{ }^{3} J_{7,8}=6.7 \mathrm{~Hz},{ }^{3} J_{7,6}=2.6 \mathrm{~Hz},{ }^{4} J_{7,9}=1.7 \mathrm{~Hz}\right.$, 1H, H-7), 5.03 (apparent t, $1.9 \mathrm{~Hz}, 1 \mathrm{H}, \mathrm{H}-3), 4.59$ (d, $\left.{ }^{2} J_{\mathrm{A}, \mathrm{B}}=11.8 \mathrm{~Hz}, 1 \mathrm{H}, \mathrm{PhCH}_{2}-\mathrm{A}\right), 4.51$ (d, $\left.{ }^{2} J_{\mathrm{B}, \mathrm{A}}=11.8 \mathrm{~Hz}, 1 \mathrm{H}, \mathrm{PhCH}_{2}-\mathrm{B}\right), 4.21\left(\mathrm{dd},{ }^{3} J_{6,5}=5.6 \mathrm{~Hz},{ }^{3} J_{6,7}=2.7 \mathrm{~Hz}, 1 \mathrm{H}, \mathrm{H}-6\right), 4.15\left(\mathrm{q},{ }^{3} J_{11,12}\right.$ $=7.1 \mathrm{~Hz}, 2 \mathrm{H}, \mathrm{H}-11), 2.51\left(\mathrm{~d},{ }^{4} J_{1,3}=2.3 \mathrm{~Hz}, 1 \mathrm{H}, \mathrm{H}-1\right), 1.29\left(\mathrm{t},{ }^{3} J_{12,11}=7.1 \mathrm{~Hz}, 3 \mathrm{H}, \mathrm{H}-12\right)$; ${ }^{13} \mathrm{C}-$ NMR (125 MHz, CDCl3): $\delta_{\mathrm{C}}=165.6(\mathrm{C}, \mathrm{C}-10), 145.8(\mathrm{CH}, \mathrm{C}-8), 137.6(\mathrm{C}, \mathrm{Ar}), 128.4(\mathrm{CH}$, Ar), 128.0 (CH, Ar), 127.9 (CH, Ar), 127.1 (CH, C-5), 124.4 (C, C-4), 120.5 (CH, C-9), 78.1 
(C, C-2), $75.1(\mathrm{CH}, \mathrm{C}-1), 71.9\left(\mathrm{CH}_{2}, \mathrm{PhCH}_{2}\right), 71.3(\mathrm{CH}, \mathrm{C}-6), 71.0,(\mathrm{CH}, \mathrm{C}-7), 68.8$ (CH, C3), $60.4\left(\mathrm{CH}_{2}, \mathrm{C}-11\right), 14.2\left(\mathrm{CH}_{3}, \mathrm{C}-12\right)$.

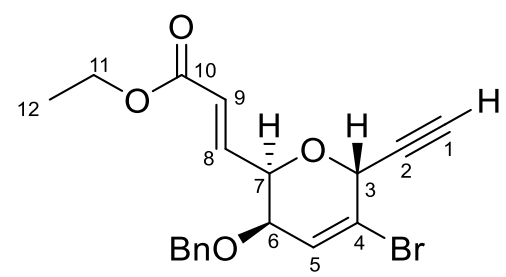

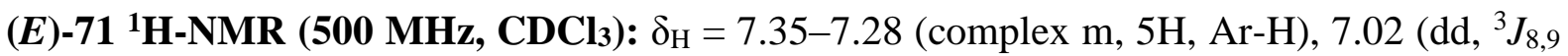
$\left.=15.8 \mathrm{~Hz},{ }^{3} J_{8,7}=4.2 \mathrm{~Hz}, 1 \mathrm{H}, \mathrm{H}-8\right), 6.35\left(\mathrm{dd},{ }^{3} J_{5,6}=5.5 \mathrm{~Hz},{ }^{3} J_{5,3}=1.4 \mathrm{~Hz}, 1 \mathrm{H}, \mathrm{H}-5\right), 6.22(\mathrm{dd}$, ${ }^{3} J_{9,8}=15.8 \mathrm{~Hz},{ }^{3} J_{9,7}=2.0 \mathrm{~Hz}, 1 \mathrm{H}, \mathrm{H}-9$ ), 5.09 (apparent t, $1.6 \mathrm{~Hz}, 1 \mathrm{H}, \mathrm{H}-3$ ), 4.73 (m, 1H, H-7), $4.61\left(\mathrm{~d},{ }^{2} J_{\mathrm{A}, \mathrm{B}}=11.8 \mathrm{~Hz}, 1 \mathrm{H}, \mathrm{PhCH}_{2}-\mathrm{A}\right), 4.53\left(\mathrm{~d},{ }^{2} J_{\mathrm{B}, \mathrm{A}}=11.8 \mathrm{~Hz}, 1 \mathrm{H}, \mathrm{PhCH}_{2}-\mathrm{B}\right), 4.24\left(\mathrm{q},{ }^{3} J_{11,12}\right.$ $=7.1 \mathrm{~Hz}, 2 \mathrm{H}, \mathrm{H}-11), 3.92\left(\mathrm{dd},{ }^{3} J_{6,5}=5.4 \mathrm{~Hz},{ }^{3} J_{6,7}=2.8 \mathrm{~Hz}, 1 \mathrm{H}, \mathrm{H}-6\right), 2.53\left(\mathrm{~d},{ }^{4} J_{1,3}=2.3 \mathrm{~Hz}\right.$, 1H, H-1), 1.31 (t, $\left.{ }^{3} J_{12,10}=7.1 \mathrm{~Hz}, 3 \mathrm{H}, \mathrm{H}-12\right) ;{ }^{13} \mathbf{C}-\mathbf{N M R}(125$ MHz, CDCl$): \delta_{\mathrm{C}}=166.0(\mathrm{C}$, C-10), 142.4 (CH, C-8), 137.4 (C, Ar), 128.5 (CH, Ar), 128.0 (CH, Ar), 127.98 (CH, Ar), 126.6 (CH, C-5), 124.9 (C, C-4), 122.7 (CH, C-9), 77.9 (C, C-2), 75.3 (CH, C-1), 72.2 (CH, C-7), $71.1\left(\mathrm{CH}_{2}, \mathrm{PhCH}_{2}\right), 71.0(\mathrm{CH}, \mathrm{C}-6), 69.0(\mathrm{CH}, \mathrm{C}-3), 60.5\left(\mathrm{CH}_{2}, \mathrm{C}-11\right), 14.3\left(\mathrm{CH}_{3}, \mathrm{C}-12\right)$.

\section{Ethyl (Z)-3-((2R,3R,6R)-6-acetyl-3-(benzyloxy)-5-bromo-3,6-dihydro-2H-pyran-2-} yl)acrylate (Z-72)

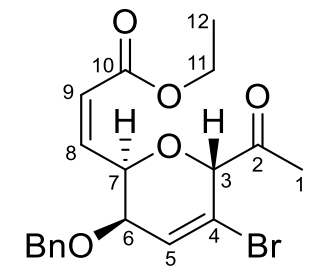

A solution of the ethyl ester $(Z)-71(19 \mathrm{mg}, 0.05 \mathrm{mmol})$ in tetrahydrofuran $(0.25 \mathrm{~mL})$ was treated with mercury sulfate $(3.2 \mathrm{mg}, 0.01 \mathrm{mmol}, 0.2 \mathrm{eq}$.) and sulfuric acid $(0.23 \mathrm{~mL}, 10 \% \mathrm{v} / \mathrm{v}$ aqueous) and stirred at r.t. for $24 \mathrm{~h}$. The reaction mixture was diluted with diethyl ether $(3 \mathrm{~mL})$, treated with powdered sodium bicarbonate until $\mathrm{pH} 7$ was reached, and the organic layer was isolated, dried over anhydrous magnesium sulfate, filtered and concentrated. The crude material was purified by column chromatography ( $9: 1$ petroleum ether:ethyl acetate) to afford the ketone (Z)-72 (14 $\mathrm{mg}, 0.03 \mathrm{mmol}, 70 \%)$ as a colourless oil. 
(Z)-72 ${ }^{1} \mathrm{H}-\mathrm{NMR}\left(\mathbf{5 0 0} \mathbf{M H z}, \mathbf{C D C l}_{3}\right): \delta_{\mathrm{H}}=7.34-7.26$ (complex m, 5H, Ar-H), 6.49 (broad d, $\left.{ }^{3} J_{5,6}=5.2 \mathrm{~Hz}, 1 \mathrm{H}, \mathrm{H}-5\right), 6.36\left(\mathrm{ddd},{ }^{3} J_{8,9}=11.8 \mathrm{~Hz},{ }^{3} J_{8,7}=7.1 \mathrm{~Hz},{ }^{4} J_{8,6}=1.3 \mathrm{~Hz}, 1 \mathrm{H}, \mathrm{H}-8\right), 5.94$ (broad d, $\left.{ }^{3} J_{9,8}=11.8 \mathrm{~Hz}, 1 \mathrm{H}, \mathrm{H}-9\right), 5.31$ (broad d, $\left.{ }^{3} J_{7,8}=7.1 \mathrm{~Hz}, 1 \mathrm{H}, \mathrm{H}-7\right), 4.74$ (s, 1H, H-3), $4.59\left(\mathrm{~d},{ }^{2} J_{\mathrm{A}, \mathrm{B}}=11.8 \mathrm{~Hz}, \mathrm{PhCH}_{2}-\mathrm{A}\right), 4.52\left(\mathrm{~d},{ }^{2} J_{\mathrm{B}, \mathrm{A}}=11.8 \mathrm{~Hz}, \mathrm{PhCH}_{2}-\mathrm{B}\right), 4.17\left(\mathrm{dd},{ }^{3} J_{6,5}=5.2\right.$ $\left.\mathrm{Hz},{ }^{3} J_{6,7}=3.0 \mathrm{~Hz}, 1 \mathrm{H}, \mathrm{H}-6\right), 4.13$ (q, $\left.{ }^{3} J_{11,12}=7.1 \mathrm{~Hz}, 2 \mathrm{H}, \mathrm{H}-11\right), 2.31$ (s, 3H, H-1), 1.27 (t, $\left.{ }^{3} J_{12,11}=7.1 \mathrm{~Hz}, 3 \mathrm{H}, \mathrm{H}-12\right)$; ${ }^{13} \mathrm{C}-\mathbf{N M R}(\mathbf{1 2 5} \mathbf{M H z}, \mathbf{C D C l}): \delta_{\mathrm{C}}=202.8(\mathrm{C}, \mathrm{C}-2), 165.3(\mathrm{C}, \mathrm{C}-$ 10), 144.6 (CH, C-8), 137.6 (C, Ar), 128.7 (CH, C-5), 128.4 (CH, Ar), 128.0 (CH, Ar), 127.9 (CH, Ar), 121.5 (CH, C-9), 121.3 (C, C-4), 81.2 (CH, C-3), $71.8\left(\mathrm{CH}_{2}, \mathrm{PhCH}_{2}\right), 71.4$ (CH, C6), 71.2 (CH, C-7), $60.5\left(\mathrm{CH}_{2}, \mathrm{C}-11\right), 28.1\left(\mathrm{CH}_{3}, \mathrm{C}-1\right), 14.1\left(\mathrm{CH}_{3}, \mathrm{C}-12\right)$.

\section{Ethyl $(E)-3-((2 R, 3 R, 6 R)-6$-acetyl-3-(benzyloxy)-5-bromo-3,6-dihydro-2H-pyran-2-} yl)acrylate $(E-72)$

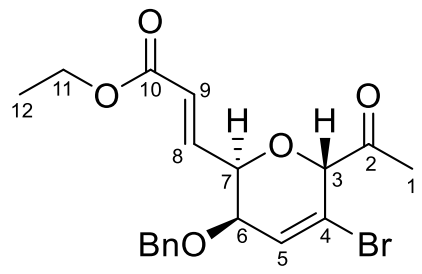

A solution of the ethyl ester $71(24 \mathrm{mg}, 0.06 \mathrm{mmol}, 1.4: 1 \mathrm{Z:E})$ in tetrahydrofuran $(0.31 \mathrm{~mL})$ was treated with mercury sulfate $(3.8 \mathrm{mg}, 0.01 \mathrm{mmol}, 0.17$ eq. $)$ and sulfuric acid $(0.29 \mathrm{~mL}$, $10 \% \mathrm{v} / \mathrm{v}$ aqueous) and stirred at r.t. for $20 \mathrm{~h}$. The reaction mixture was diluted with diethyl ether $(3 \mathrm{~mL})$, treated with powdered sodium bicarbonate until $\mathrm{pH} 7$ was reached, and the organic layer was isolated, dried over anhydrous magnesium sulfate, filtered and concentrated. The crude material was purified by column chromatography (gradient elution 9:1 to 5:1 petroleum ether:ethyl acetate) to afford the $Z$-alkene $(Z)-72(11 \mathrm{mg}, 0.03 \mathrm{mmol}, 71 \%)$ as a colourless oil and the $E$-alkene $(\boldsymbol{E})-72)(7.2 \mathrm{mg}, 0.02 \mathrm{mmol}, 69 \%)$ as a white solid.

(E)-72 ${ }^{1}$ H-NMR (500 MHz, CDCl $)$ ): $\delta_{\mathrm{H}}=7.36-7.28$ (complex m, 5H, Ar-H), 6.98 (ddd, ${ }^{3} J_{8,9}$ $\left.=15.8 \mathrm{~Hz},{ }^{3} J_{8,7}=4.3 \mathrm{~Hz},{ }^{4} J_{8,6}=0.9 \mathrm{~Hz}, 1 \mathrm{H}, \mathrm{H}-8\right), 6.49\left(\operatorname{broad~d},{ }^{3} J_{5,6}=5.0 \mathrm{~Hz}, 1 \mathrm{H}, \mathrm{H}-5\right), 6.19$ (broad d, $\left.{ }^{3} J_{9,8}=15.8 \mathrm{~Hz}, 1 \mathrm{H}, \mathrm{H}-9\right), 4.81$ (s, 1H, H-3), $4.62\left(\mathrm{~d},{ }^{2} J_{\mathrm{A}, \mathrm{B}}=11.8 \mathrm{~Hz}, 1 \mathrm{H}, \mathrm{PhCH}_{2}-\mathrm{A}\right.$ ), $4.54\left(\mathrm{~d},{ }^{2} J_{\mathrm{B}, \mathrm{A}}=11.8 \mathrm{~Hz}, 1 \mathrm{H}, \mathrm{PhCH}_{2}-\mathrm{B}\right), 4.47$ (m, $\left.1 \mathrm{H}, \mathrm{H}-7\right), 4.23\left(\mathrm{q},{ }^{3} J_{11,12}=7.1 \mathrm{~Hz}, 2 \mathrm{H}, \mathrm{H}-\right.$ 11), 3.95 (apparent t, $J=4.0 \mathrm{~Hz}, 1 \mathrm{H}, \mathrm{H}-6), 2.33$ (d, $\left.{ }^{4} J_{1,3}=1.0 \mathrm{~Hz}, 3 \mathrm{H}, \mathrm{H}-1\right), 1.32$ (t, ${ }^{3} J_{12,11}=$ 7.1 Hz, 3H, H-12); ${ }^{13} \mathbf{C}-\mathbf{N M R}\left(\mathbf{1 2 5}\right.$ MHz, CDCl3): $\delta_{\mathrm{C}}=202.6$ (C, C-2), 165.8 (C, C-10), 142.1 (CH, C-8), $137.3(\mathrm{C}, \mathrm{Ar}), 128.5(\mathrm{CH}, \mathrm{Ar}$ and $\mathrm{CH}, \mathrm{C}-5), 128.1(\mathrm{CH}, \mathrm{Ar}), 127.9(\mathrm{CH}, \mathrm{Ar}), 123.1$ 
(CH, C-9), 121.2 (C, C-4), 80.8 (CH, C-3), $72.9(\mathrm{CH}, \mathrm{C}-7), 71.3\left(\mathrm{CH}, \mathrm{C}-6\right.$ and $\left.\mathrm{CH}_{2}, \mathrm{PhCH}_{2}\right)$, $60.6\left(\mathrm{CH}_{2}, \mathrm{C}-11\right), 28.1\left(\mathrm{CH}_{3}, \mathrm{C}-1\right), 14.2\left(\mathrm{CH}_{3}, \mathrm{C}-12\right)$.

Ethyl (Z)-3-((2R,3R,6R)-3-(benzyloxy)-5-bromo-6-((S)-1-hydroxyethyl)-3,6-dihydro-2Hpyran-2-yl)acrylate (53)

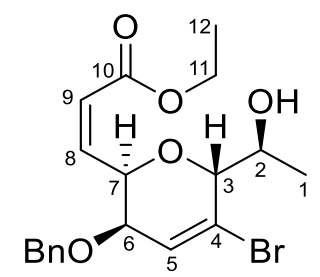

A solution of the ketone $(Z)-72(75 \mathrm{mg}, 0.18 \mathrm{mmol})$ in methanol $(1.9 \mathrm{~mL})$ was cooled to $-78^{\circ} \mathrm{C}$ and treated with sodium borohydride $(11 \mathrm{mg}, 1.6$ eq.). The reaction mixture was allowed to warm to $-10^{\circ} \mathrm{C}$ over the course of 90 minutes, whereupon it was quenched by the addition of acetone $(0.8 \mathrm{~mL})$. The crude material was concentrated, then purified via column chromatography (5:1 petroleum ether:ethyl acetate) to afford the alcohol $\mathbf{5 3}$ (69 $\mathrm{mg}, 0.17$ mmol, 92\%) as a colourless oil.

${ }^{1}$ H-NMR (500 MHz, CDCl 3 ): $\delta_{\mathrm{H}}=7.35-7.29$ (complex m, 5H, Ar-H), 6.49 (dd, ${ }^{3} J_{5,6}=4.9 \mathrm{~Hz}$, $\left.{ }^{4} J_{5,7}=1.7 \mathrm{~Hz}, 1 \mathrm{H}, \mathrm{H}-5\right), 6.45\left(\mathrm{dd},{ }^{3} J_{8,9}=11.7 \mathrm{~Hz},{ }^{3} J_{8,7}=7.7 \mathrm{~Hz}, 1 \mathrm{H}, \mathrm{H}-8\right), 5.99\left(\mathrm{dd},{ }^{3} J_{9,8}=11.7\right.$ $\left.\mathrm{Hz},{ }^{4} J_{9,7}=1.3 \mathrm{~Hz}, 1 \mathrm{H}, \mathrm{H}-9\right), 5.80$ (ddd, ${ }^{3} J_{7,8}=7.7 \mathrm{~Hz},{ }^{3} J_{7,6}=3.2 \mathrm{~Hz},{ }^{4} J_{7,9}=1.2 \mathrm{~Hz}, 1 \mathrm{H}, \mathrm{H}-7$ ), $4.62\left(\mathrm{~d},{ }^{2} J_{\mathrm{A}, \mathrm{B}}=11.9 \mathrm{~Hz}, 1 \mathrm{H}, \mathrm{PhCH}_{2}-\mathrm{A}\right), 4.55\left(\mathrm{~d},{ }^{2} J_{\mathrm{B}, \mathrm{A}}=11.9 \mathrm{~Hz}, 1 \mathrm{H}, \mathrm{PhCH}_{2}-\mathrm{B}\right), 4.36(\mathrm{~m}, 1 \mathrm{H}$, H-2), 4.16 (q, ${ }^{3} J_{11,12}=7.1 \mathrm{~Hz}, 2 \mathrm{H}, \mathrm{H}-11$ ), 4.12 (m, 1H, H-6), 4.06 (apparent s, 1H, H-3), 1.34 $\left(\mathrm{d},{ }^{3} J_{1,2}=6.5 \mathrm{~Hz}, 3 \mathrm{H}, \mathrm{H}-1\right), 1.28\left(\mathrm{t},{ }^{3} J_{12,11}=7.1 \mathrm{~Hz}, 3 \mathrm{H}, \mathrm{H}-12\right)$; ${ }^{13} \mathbf{C}-\mathbf{N M R}\left(\mathbf{1 2 5} \mathbf{M H z}, \mathbf{C D C l}_{3}\right)$ : $\delta_{\mathrm{C}}=165.7(\mathrm{C}, \mathrm{C}-10), 144.3(\mathrm{CH}, \mathrm{C}-8), 137.8(\mathrm{C}, \mathrm{Ar}), 129.2(\mathrm{CH}, \mathrm{C}-5), 128.4(\mathrm{CH}, \mathrm{Ar}), 127.9$ (CH, Ar), 127.8 (CH, Ar), 125.2 (C, C-4), 122.6 (CH, C-9), 79.5 (CH, C-3), 71.8 (CH, C-6), $71.4\left(\mathrm{CH}_{2}, \mathrm{PhCH}_{2}\right), 69.9(\mathrm{CH}, \mathrm{C}-7), 68.0(\mathrm{CH}, \mathrm{C}-2), 60.5\left(\mathrm{CH}_{2}, \mathrm{C}-11\right), 19.6\left(\mathrm{CH}_{3}, \mathrm{C}-1\right), 14.2$ $\left(\mathrm{CH}_{3}, \mathrm{C}-12\right)$. 
Ethyl (Z)-3-((2R,3R,6R)-3-(benzyloxy)-5-bromo-6-((S)-1-((methylsulfonyl)oxy)ethyl)-3,6dihydro-2H-pyran-2-yl)acrylate (94)

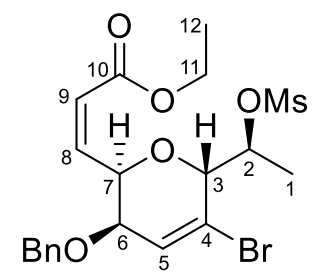

A solution of the alcohol $53(69 \mathrm{mg}, 0.17 \mathrm{mmol})$ in dichloromethane $(0.20 \mathrm{~mL})$ was cooled to $0^{\circ} \mathrm{C}$ and treated with triethylamine $(0.05 \mathrm{~mL}, 0.36 \mathrm{mmol}, 2.1$ eq. $)$ followed by mesyl chloride (0.04 mL, $0.41 \mathrm{mmol}, 2.4$ eq.). The reaction mixture was stirred for $1 \mathrm{~h}$ at $0^{\circ} \mathrm{C}$, then warmed to r.t. and stirred for $22 \mathrm{~h}$. The reaction mixture was then cooled to $0^{\circ} \mathrm{C}$ and treated with further quantities of triethylamine $(0.05 \mathrm{~mL}, 0.36 \mathrm{mmol}, 2.1 \mathrm{eq}$.$) and mesyl chloride (0.04 \mathrm{~mL}, 0.41$ mmol, 2.4 eq.), warmed to r.t. and left to react for a further $4 \mathrm{~h}$. The crude material was purified by column chromatography (5:1 petroleum ether:ethyl acetate) to afford the mesylate 94 (62 $\mathrm{mg}, 12 \mathrm{mmol}, 72 \%$ ) as a colourless oil.

${ }^{1}$ H-NMR (500 MHz, CDCl3): $\delta_{\mathrm{H}}=7.34-7.27$ (complex m, 5H, Ar-H), 6.51 (dd, ${ }^{3} J_{5,6}=5.3 \mathrm{~Hz}$, $\left.{ }^{3} J_{5,3}=1.8 \mathrm{~Hz}, 1 \mathrm{H}, \mathrm{H}-5\right), 6.36\left(\mathrm{dd},{ }^{3} J_{8,9}=11.8 \mathrm{~Hz},{ }^{3} J_{8,7}=7.2 \mathrm{~Hz}, 1 \mathrm{H}, \mathrm{H}-8\right), 5.94\left(\mathrm{dd},{ }^{3} J_{9,8}=\right.$ $\left.11.8 \mathrm{~Hz},{ }^{4} J_{9,7}=1.4 \mathrm{~Hz}, 1 \mathrm{H}, \mathrm{H}-9\right), 5.72\left(\mathrm{ddd},{ }^{3} J_{7,8}=7.2 \mathrm{~Hz},{ }^{3} J_{7,6}=2.8 \mathrm{~Hz},{ }^{4} J_{7,9}=1.4 \mathrm{~Hz}, 1 \mathrm{H}\right.$, $\mathrm{H}-7), 5.31\left(\mathrm{qd},{ }^{3} J_{2,1}=6.6 \mathrm{~Hz},{ }^{3} J_{2,3}=2.3 \mathrm{~Hz}, 1 \mathrm{H}, \mathrm{H}-2\right), 4.59\left(\mathrm{~d},{ }^{2} J_{\mathrm{A}, \mathrm{B}}=11.8 \mathrm{~Hz}, 1 \mathrm{H}, \mathrm{PhCH}_{2}-\right.$ A), $4.53\left(\mathrm{~d},{ }^{2} J_{\mathrm{B}, \mathrm{A}}=11.9 \mathrm{~Hz}, 1 \mathrm{H}, \mathrm{PhCH}_{2}-\mathrm{B}\right), 4.22(\mathrm{~m}, 1 \mathrm{H}, \mathrm{H}-3), 4.18\left(\mathrm{dd},{ }^{3} J_{6,5}=5.2 \mathrm{~Hz},{ }^{3} J_{6,7}=\right.$ $3.0 \mathrm{~Hz}, 1 \mathrm{H}, \mathrm{H}-6), 4.14$ (q, $\left.{ }^{3} J_{11,12}=7.1 \mathrm{~Hz}, 2 \mathrm{H}, \mathrm{H}-11\right), 3.04$ (s, 3H, $\left.\mathrm{SO}_{2} \mathrm{CH}_{3}\right), 1.57$ (d, ${ }^{3} J_{1,2}=6.5$ $\mathrm{Hz}, 3 \mathrm{H}, \mathrm{H}-1), 1.28$ (t, $\left.{ }^{3} J_{12,11}=7.1 \mathrm{~Hz}, 3 \mathrm{H}, \mathrm{H}-12\right)$; ${ }^{13} \mathbf{C}-\mathbf{N M R}(125$ MHz, CDCl 3$): \delta_{\mathrm{C}}=165.5$ (C, C-10), 145.3 (CH, C-8), 137.6 (C, Ar), 129.7 (CH, C-5), 128.4 (C, Ar), 128.0 (C, Ar), 127.9 (C, Ar), 123.5 (C, C-4), $121.3(\mathrm{CH}, \mathrm{C}-9), 78.4(\mathrm{CH}, \mathrm{C}-3), 78.2(\mathrm{CH}, \mathrm{C}-2), 71.8\left(\mathrm{CH}_{2}, \mathrm{PhCH}_{2}\right)$, $71.6(\mathrm{CH}, \mathrm{C}-6), 71.3$ (CH, C-7), $60.5\left(\mathrm{CH}_{2}, \mathrm{C}-11\right), 38.9\left(\mathrm{CH}_{3}, \mathrm{SO}_{2} \mathrm{CH}_{3}\right), 18.3\left(\mathrm{CH}_{3}, \mathrm{C}-1\right), 14.1$ $\left(\mathrm{CH}_{3}, \mathrm{C}-12\right)$; HRMS: m/z C $20 \mathrm{H}_{25} \mathrm{BrO}_{7} \mathrm{SH}^{+}\left[\mathrm{M}+\mathrm{H}^{+}\right]$calc. 489.0577, found 489.0589, $\Delta 2.25$ ppm. 


\subsection{Characterisation data for described by-products}

$(1 R, 4 R, 5 R, 6 R)-6$-(benzyloxy)-8-bromo-2,9-dioxabicyclo[3.3.1]non-7-en-4-ol (89)

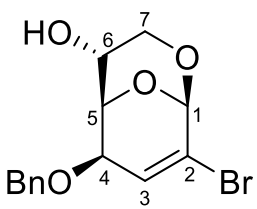

${ }^{1}$ H-NMR (500 MHz, CDCl$)$ ): $\delta_{\mathrm{H}}=7.39-7.30$ (complex m, 5H, Ar-H), $6.53\left(\mathrm{~d},{ }^{3} J_{3,4}=2.4 \mathrm{~Hz}\right.$, $1 \mathrm{H}, \mathrm{H}-3), 5.21$ (s, 1H, H-1), $4.65\left(\mathrm{~d},{ }^{2} J_{\mathrm{A}, \mathrm{B}}=11.7 \mathrm{~Hz}, 1 \mathrm{H}, \mathrm{PhCH}_{2}-\mathrm{A}\right), 4.57\left(\mathrm{~d},{ }^{2} J_{\mathrm{B}, \mathrm{A}}=11.7 \mathrm{~Hz}\right.$, $\left.1 \mathrm{H}, \mathrm{PhCH}_{2}-\mathrm{B}\right), 4.48\left(\mathrm{dd},{ }^{3} J_{4,5}=6.9 \mathrm{~Hz},{ }^{3} J_{4,3}=2.5 \mathrm{~Hz}, 1 \mathrm{H}, \mathrm{H}-4\right), 4.23\left(\mathrm{dd},{ }^{2} J_{7 \mathrm{~A}, 7 \mathrm{~B}}=12.9 \mathrm{~Hz}\right.$, $\left.{ }^{3} J_{7,6}=1.8 \mathrm{~Hz}, 1 \mathrm{H}, \mathrm{H}-7 \mathrm{~A}\right), 4.19(\mathrm{~m}, 1 \mathrm{H}, \mathrm{H}-5), 3.86\left(\mathrm{~d},{ }^{2} J_{7 \mathrm{~B}, 7 \mathrm{~A}}=12.7 \mathrm{~Hz}, 1 \mathrm{H}, \mathrm{H}-7 \mathrm{~B}\right), 3.84(\mathrm{~m}$, 1H, H-6); ${ }^{13}$ C-NMR (125 MHz, CDCl 3 ): $\delta_{\mathrm{C}}=136.9$ (C, Ar), 131.4 (CH, C-3), 128.7 (CH, Ar), 128.3 (CH, Ar), 127.8 (CH, Ar), 117.4 (C, C-2), 93.7 (CH, C-1), 72.9 (CH, C-5), 72.6 (CH, C4), $71.8\left(\mathrm{CH}_{2}, \mathrm{PhCH}_{2}\right), 63.7\left(\mathrm{CH}_{2}, \mathrm{C}-7\right), 63.1(\mathrm{CH}, \mathrm{C}-6)$; HRMS: $\left(\mathrm{C}_{14} \mathrm{H}_{15} \mathrm{BrO}_{4} \mathrm{NH}_{4}^{+}\left[\mathrm{M}+\mathrm{NH}_{4}{ }^{+}\right]\right.$ calc. 344.0492 , found $344.0480, \Delta 3.49 \mathrm{ppm}$ ).

Ethyl $(E)-3-((2 R, 3 R)-6-a c e t y l-3-(b e n z y l o x y)-5-b r o m o-3,4-d i h y d r o-2 H-p y r a n-2-$ yl)acrylate $(E-91)$

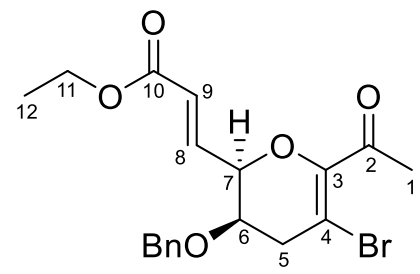

${ }^{1} \mathbf{H}-N M R(500$ MHz, CDCl 3$): \delta_{H}=7.36-7.30$ (complex m, 5H, Ar-H), $6.95\left(\mathrm{dd},{ }^{3} J_{8,9}=15.8\right.$ $\left.\mathrm{Hz},{ }^{3} J_{8,7}=4.1 \mathrm{~Hz}, 1 \mathrm{H}, \mathrm{H}-8\right), 6.11$ (d, $\left.{ }^{3} J_{9,8}=15.7 \mathrm{~Hz}, 1 \mathrm{H}, \mathrm{H}-9\right), 4.68$ (complex m, 2H, $\mathrm{PhCH}_{2}-$ A, H-7), $4.54\left(\mathrm{~d},{ }^{2} J_{\mathrm{B}, \mathrm{A}}=12.4 \mathrm{~Hz}, 1 \mathrm{H}, \mathrm{PhCH}_{2}-\mathrm{B}\right), 4.25$ (q, $\left.{ }^{3} J_{11,12}=7.1 \mathrm{~Hz}, 2 \mathrm{H}, \mathrm{H}-11\right), 3.86$ (m, $1 \mathrm{H}, \mathrm{H}-6), 2.84\left(\mathrm{dd},{ }^{2} J_{5 \mathrm{~A}, 5 \mathrm{~B}}=18.5 \mathrm{~Hz},{ }^{3} J_{5 \mathrm{~A}, 6}=5.1 \mathrm{~Hz}, 1 \mathrm{H}, \mathrm{H}-5 \mathrm{~A}\right), 2.72\left(\mathrm{dd},{ }^{2} J_{5 \mathrm{~B}, 5 \mathrm{~A}}=18.6 \mathrm{~Hz}\right.$, $\left.{ }^{3} J_{5 \mathrm{~B}, 6}=4.8 \mathrm{~Hz}, 1 \mathrm{H}, \mathrm{H}-5 \mathrm{~B}\right), 2.38(\mathrm{~s}, 3 \mathrm{H}, \mathrm{H}-1), 1.33\left(\mathrm{t},{ }^{3} J_{12,11}=7.1 \mathrm{~Hz}, 3 \mathrm{H}, \mathrm{H}-12\right) ; \mathrm{HRMS}: \mathrm{m} / \mathrm{z}$ $\mathrm{C}_{19} \mathrm{H}_{21} \mathrm{BrO}_{5} \mathrm{H}^{+}\left[\mathrm{M}+\mathrm{H}^{+}\right]$calc. 409.0645, found 409.0641, $\Delta 0.98 \mathrm{ppm}$. 
Ethyl (Z)-3-((2R,3R)-6-acetyl-3-(benzyloxy)-5-bromo-3,4-dihydro-2H-pyran-2yl)acrylate (Z-91)

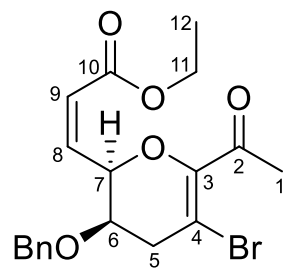

${ }^{1} \mathbf{H}-\mathbf{N M R}\left(500 \mathrm{MHz}, \mathbf{C D C l}_{3}\right): \delta_{\mathrm{H}}=7.34-7.28$ (complex m, 5H, Ar-H), 6.48 (m, 1H, H-8), 5.90 $\left(\mathrm{d},{ }^{3} J_{9,8}=10.7 \mathrm{~Hz}, 1 \mathrm{H}, \mathrm{H}-9\right), 5.44\left(\mathrm{~d},{ }^{3} J_{7,8}=7.7 \mathrm{~Hz}, 1 \mathrm{H}, \mathrm{H}-7\right), 4.65\left(\mathrm{~d},{ }^{2} J_{\mathrm{A}, \mathrm{B}}=14.2 \mathrm{~Hz}, 1 \mathrm{H}\right.$, $\left.\mathrm{PhCH}_{2}-\mathrm{A}\right), 4.47\left(\mathrm{~d},{ }^{2} J_{\mathrm{B}, \mathrm{A}}=14.1 \mathrm{~Hz}, 1 \mathrm{H}, \mathrm{PhCH}_{2}-\mathrm{B}\right), 4.13\left(\mathrm{q},{ }^{3} J_{11,12}=7.1 \mathrm{~Hz}, 2 \mathrm{H}, \mathrm{H}-11\right), 4.06$ (apparent s, 1H, H-6), $2.91\left(\mathrm{~d},{ }^{2} J_{5 \mathrm{~A}, 5 \mathrm{~B}}=18.7 \mathrm{~Hz}, 1 \mathrm{H}, \mathrm{H}-5 \mathrm{~A}\right), 2.75\left(\mathrm{~d},{ }^{2} J_{5 \mathrm{~B}, 5 \mathrm{~A}}=18.8 \mathrm{~Hz}, 1 \mathrm{H}, \mathrm{H}-\right.$ 5B), 1.27 (t, $\left.{ }^{3} J_{12,11}=7.1 \mathrm{~Hz}, 3 \mathrm{H}, \mathrm{H}-12\right)$; HRMS: m/z C ${ }_{19} \mathrm{H}_{21} \mathrm{BrO}_{5} \mathrm{H}^{+}\left[\mathrm{M}+\mathrm{H}^{+}\right]$calc. 409.0645 , found $409.0647, \Delta 0.49 \mathrm{ppm}$.

Ethyl (R,Z)-3-(6-acetyl-3-(benzyloxy)-5-bromo-3,4-dihydro-2H-pyran-2ylidene)propanoate (92)

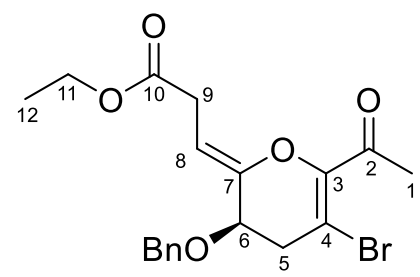

${ }^{1}$ H-NMR (500 MHz, CDCl 3$): \delta_{\mathrm{H}}=7.37-7.30$ (complex m, 5H, Ar-H), $5.06\left(\mathrm{t},{ }^{3} J_{8,9}=7.0 \mathrm{~Hz}\right.$, $1 \mathrm{H}, \mathrm{H}-8), 4.67\left(\mathrm{~d},{ }^{2} J_{\mathrm{A}, \mathrm{B}}=12.4 \mathrm{~Hz}, 1 \mathrm{H}, \mathrm{PhCH}_{2}-\mathrm{A}\right), 4.47\left(\mathrm{~d},{ }^{2} J_{\mathrm{B}, \mathrm{A}}=12.4 \mathrm{~Hz}, 1 \mathrm{H}, \mathrm{PhCH}_{2}-\mathrm{B}\right)$, $4.19\left(\mathrm{q},{ }^{3} J_{11,12}=7.1 \mathrm{~Hz}, 2 \mathrm{H}, \mathrm{H}-11\right), 4.03\left(\mathrm{dd},{ }^{3} J_{6,5 \mathrm{~A}}=4.4 \mathrm{~Hz},{ }^{3} J_{6,5 \mathrm{~B}}=3.1 \mathrm{~Hz}, 1 \mathrm{H}, \mathrm{H}-6\right), 3.28$ $\left(\mathrm{dd},{ }^{2} J_{9 \mathrm{~A}, 9 \mathrm{~B}}=17.9 \mathrm{~Hz},{ }^{3} J_{9 \mathrm{~A}, 8}=7.0 \mathrm{~Hz}, 1 \mathrm{H}, \mathrm{H}-9 \mathrm{~A}\right), 3.24\left(\mathrm{dd},{ }^{2} J_{9 \mathrm{~B}, 9 \mathrm{~A}}=17.9 \mathrm{~Hz},{ }^{3} J_{9 \mathrm{~B}, 8}=7.2 \mathrm{~Hz}\right.$, $1 \mathrm{H}, \mathrm{H}-9 \mathrm{~B}), 2.96\left(\mathrm{dd},{ }^{2} J_{5 \mathrm{~A}, 5 \mathrm{~B}}=18.6 \mathrm{~Hz},{ }^{3} J_{5 \mathrm{~A}, 6}=4.5 \mathrm{~Hz}, 1 \mathrm{H}, \mathrm{H}-5 \mathrm{~A}\right), 2.87\left(\mathrm{dd},{ }^{2} J_{5 \mathrm{~B}, 5 \mathrm{~A}}=18.4 \mathrm{~Hz}\right.$, $\left.{ }^{3} J_{5 \mathrm{~B}, 6}=3.0 \mathrm{~Hz}, 1 \mathrm{H}, \mathrm{H}-5 \mathrm{~B}\right), 2.39$ (s, 3H, H-1), 1.29 (t, ${ }^{3} J_{12,11}=7.2$ ppm, 3H, H-12); HRMS: m/z $\mathrm{C}_{19} \mathrm{H}_{21} \mathrm{BrO}_{5} \mathrm{H}^{+}\left[\mathrm{M}+\mathrm{H}^{+}\right]$calc. 409.0645, found 409.0655, $\Delta$ 0.2.44 ppm. 


\section{Appendix}

$5.1{ }^{1} \mathrm{H}-\mathrm{NMR}$ and ${ }^{13} \mathrm{C}-\mathrm{NMR}$ spectra for described compounds 


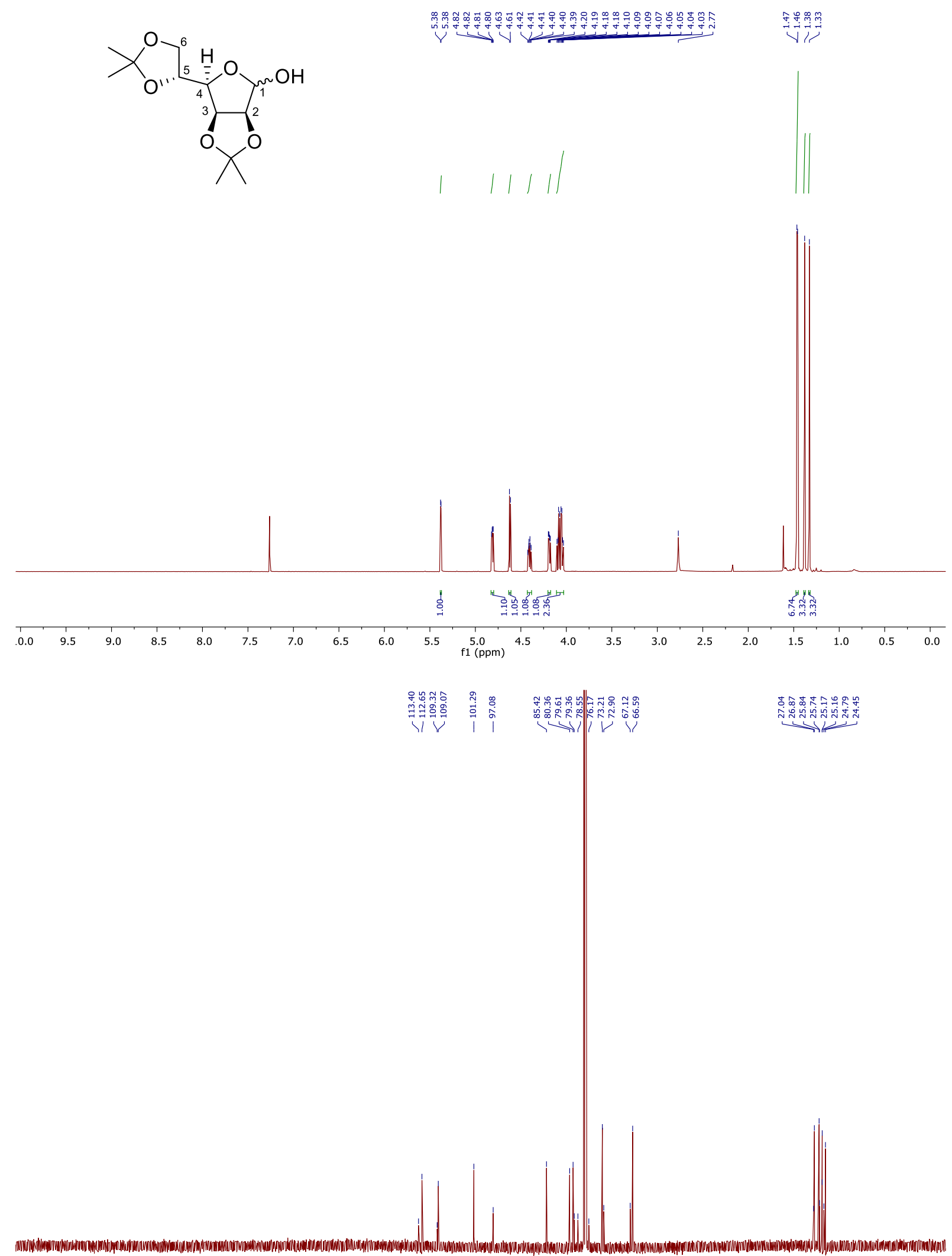

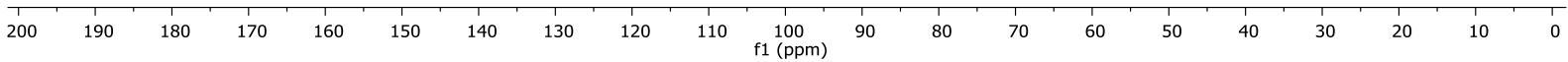

${ }^{1} \mathrm{H}-\mathrm{NMR}$ and ${ }^{13} \mathrm{C}-\mathrm{NMR}$ spectra of compound $\mathbf{5 7}$ 


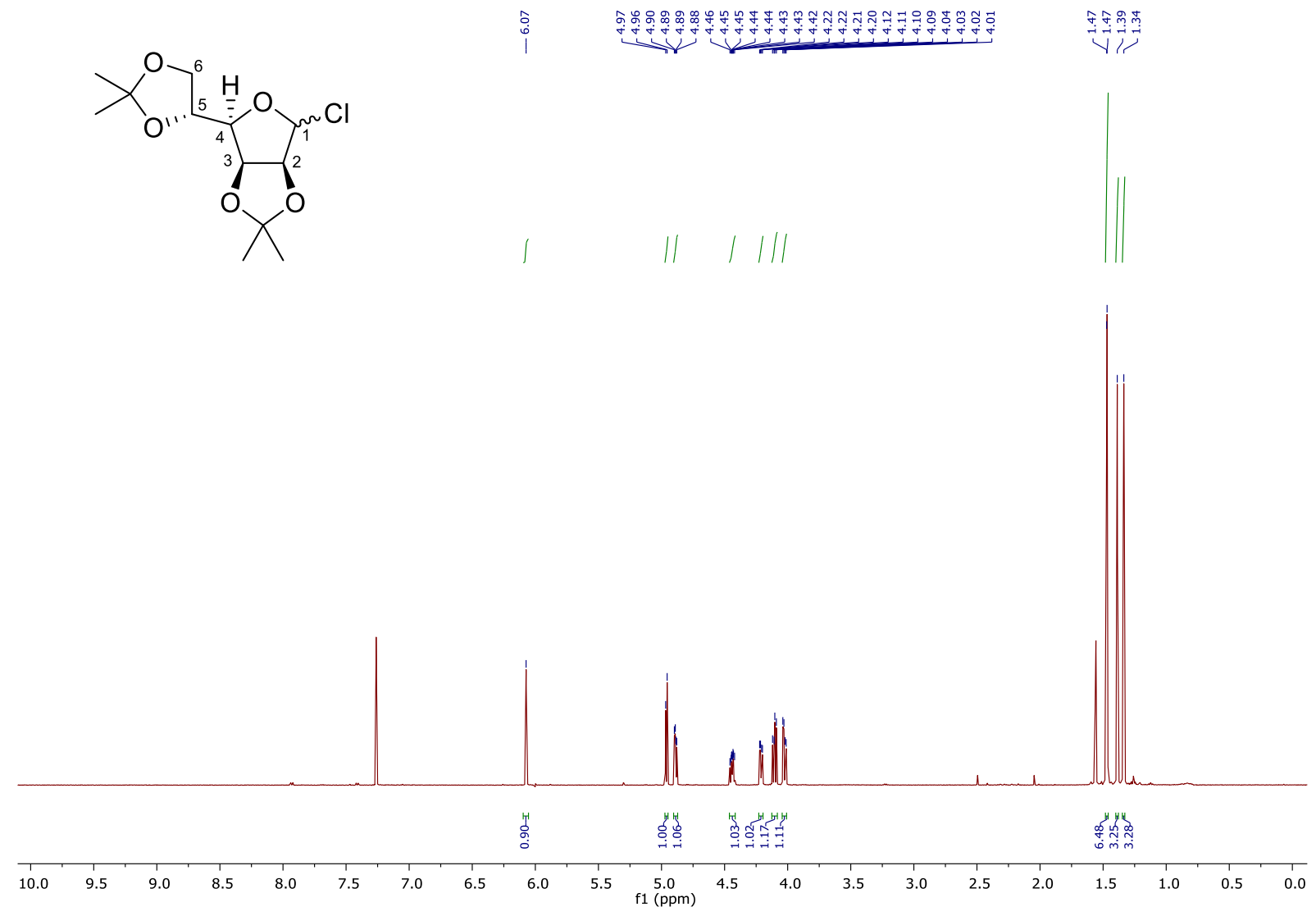

${ }^{1} \mathrm{H}-\mathrm{NMR}$ spectrum of compound $\mathbf{5 8}$ 


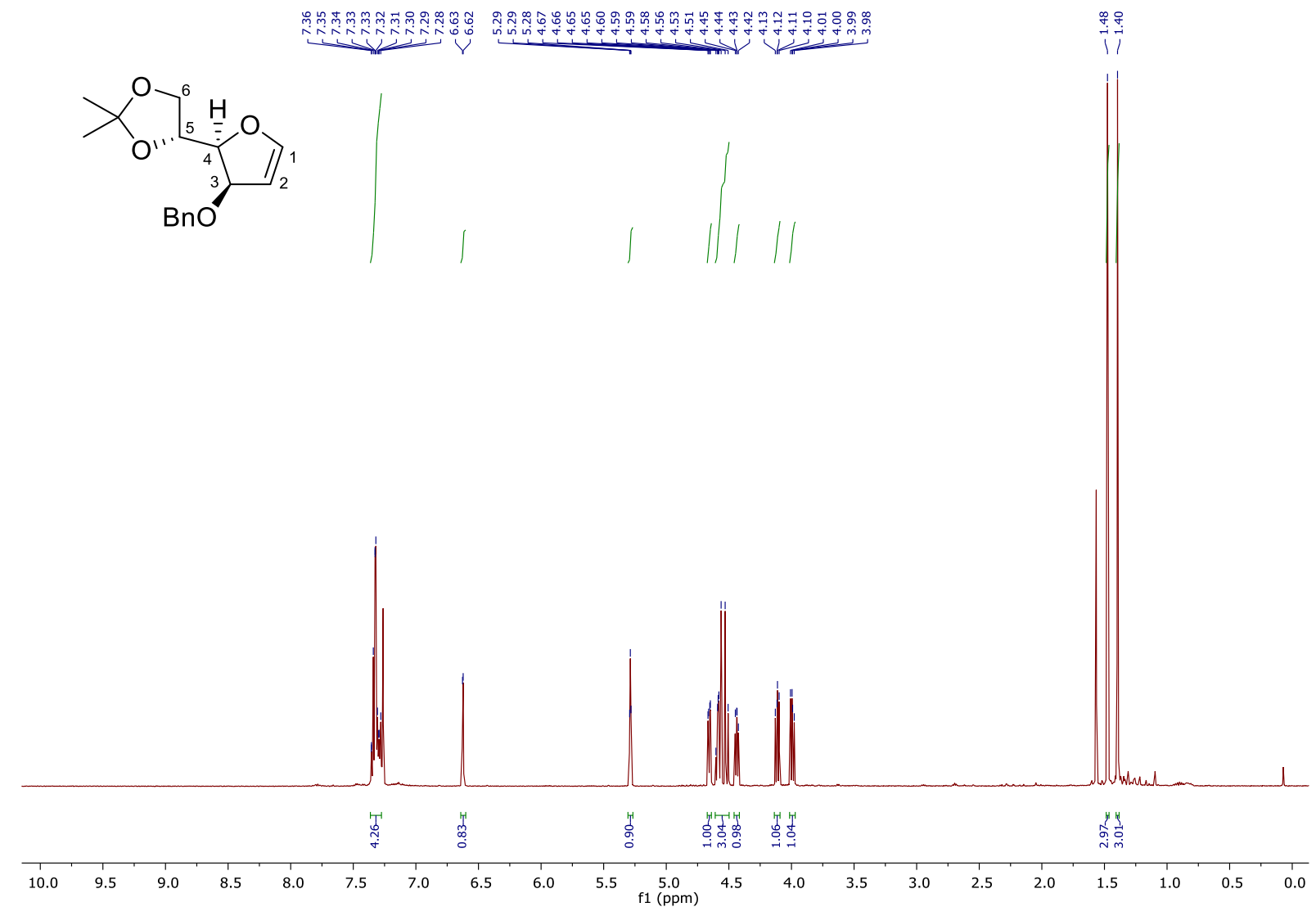

${ }^{1} \mathrm{H}-\mathrm{NMR}$ spectrum of compound $\mathbf{4 5}$ 
<smiles>CC(=O)O[C@H]1O[C@H]([C@H]2COC(C)(C)O2)[C@H](O)C[C@H]1Br</smiles>
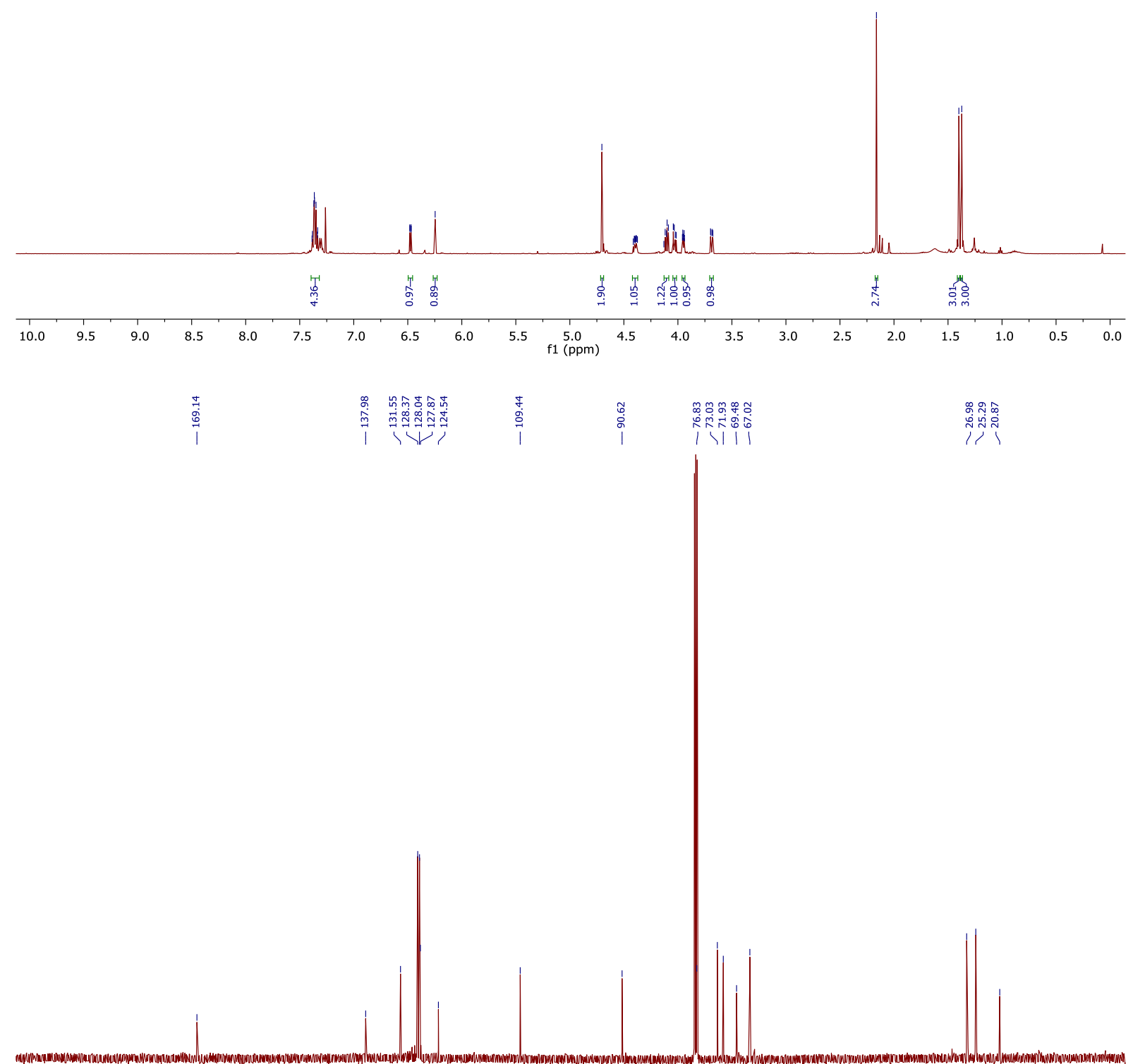

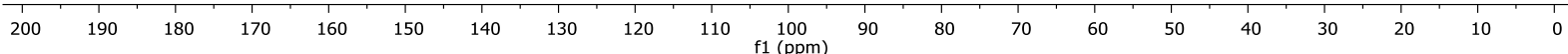

${ }^{1} \mathrm{H}-\mathrm{NMR}$ and ${ }^{13} \mathrm{C}-\mathrm{NMR}$ spectra of compound $\alpha-56$ 


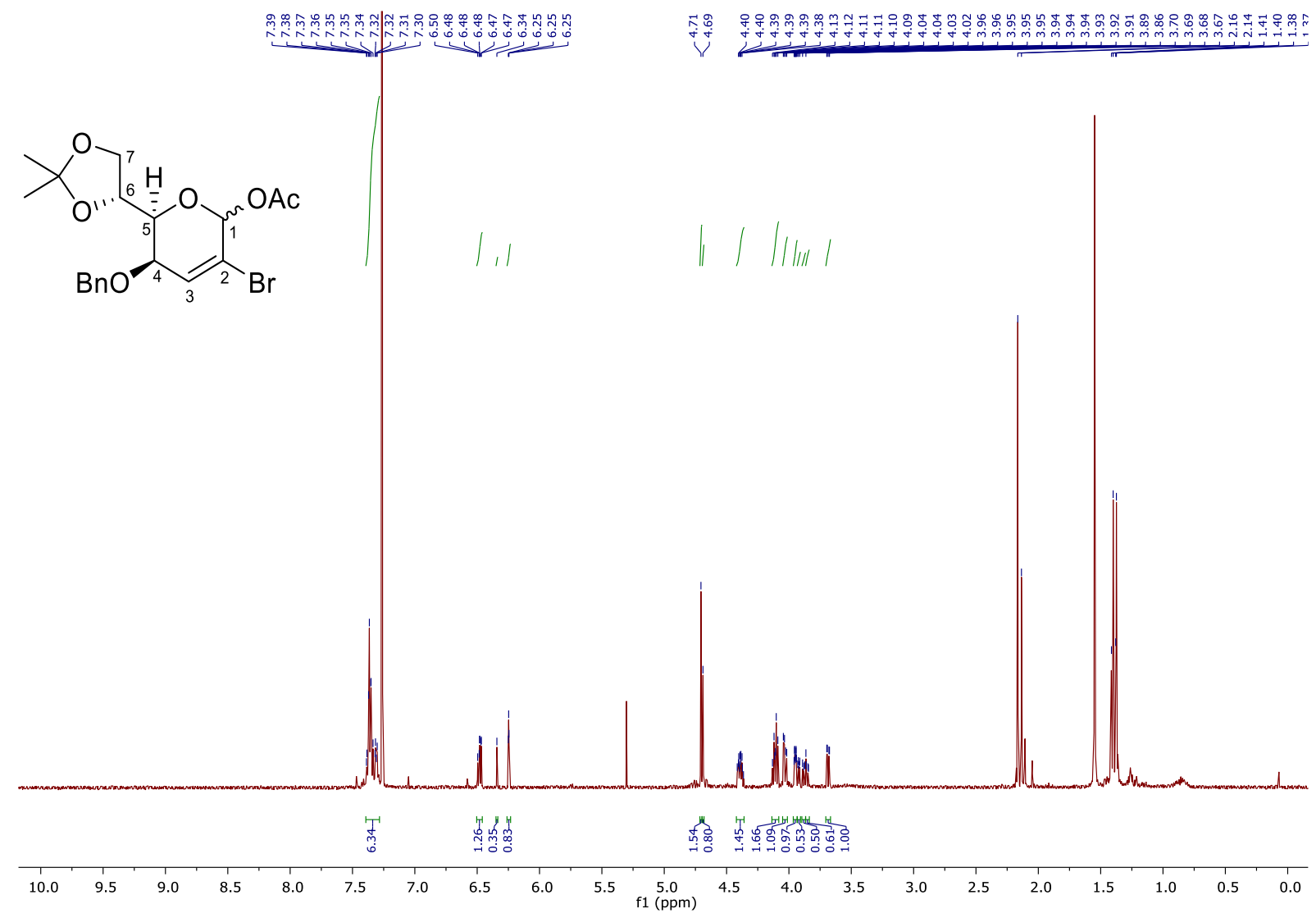

V
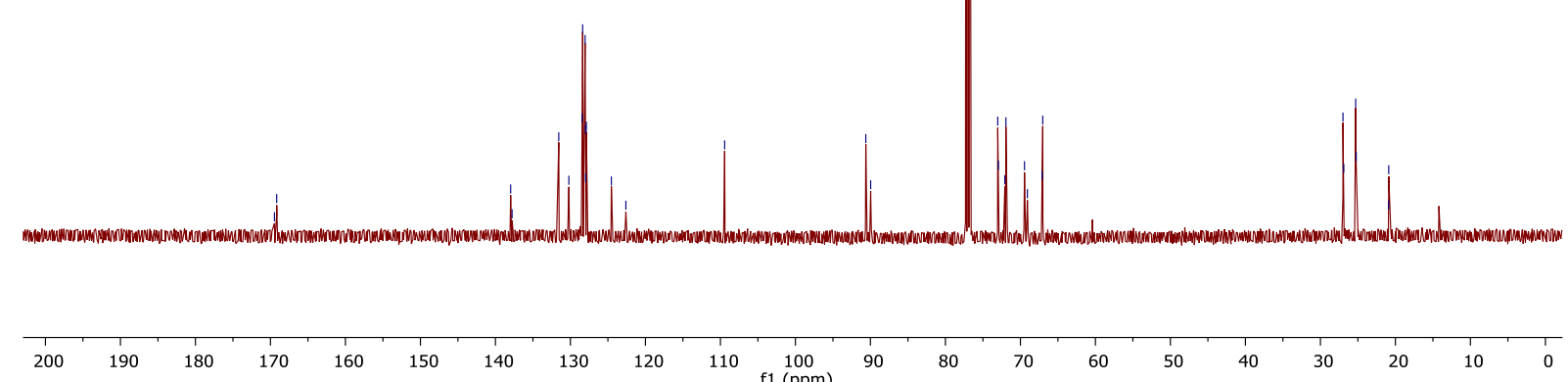

${ }^{1} \mathrm{H}-\mathrm{NMR}$ and ${ }^{13} \mathrm{C}-\mathrm{NMR}$ spectra of mixture of $\alpha$ - and $\beta-56$ 


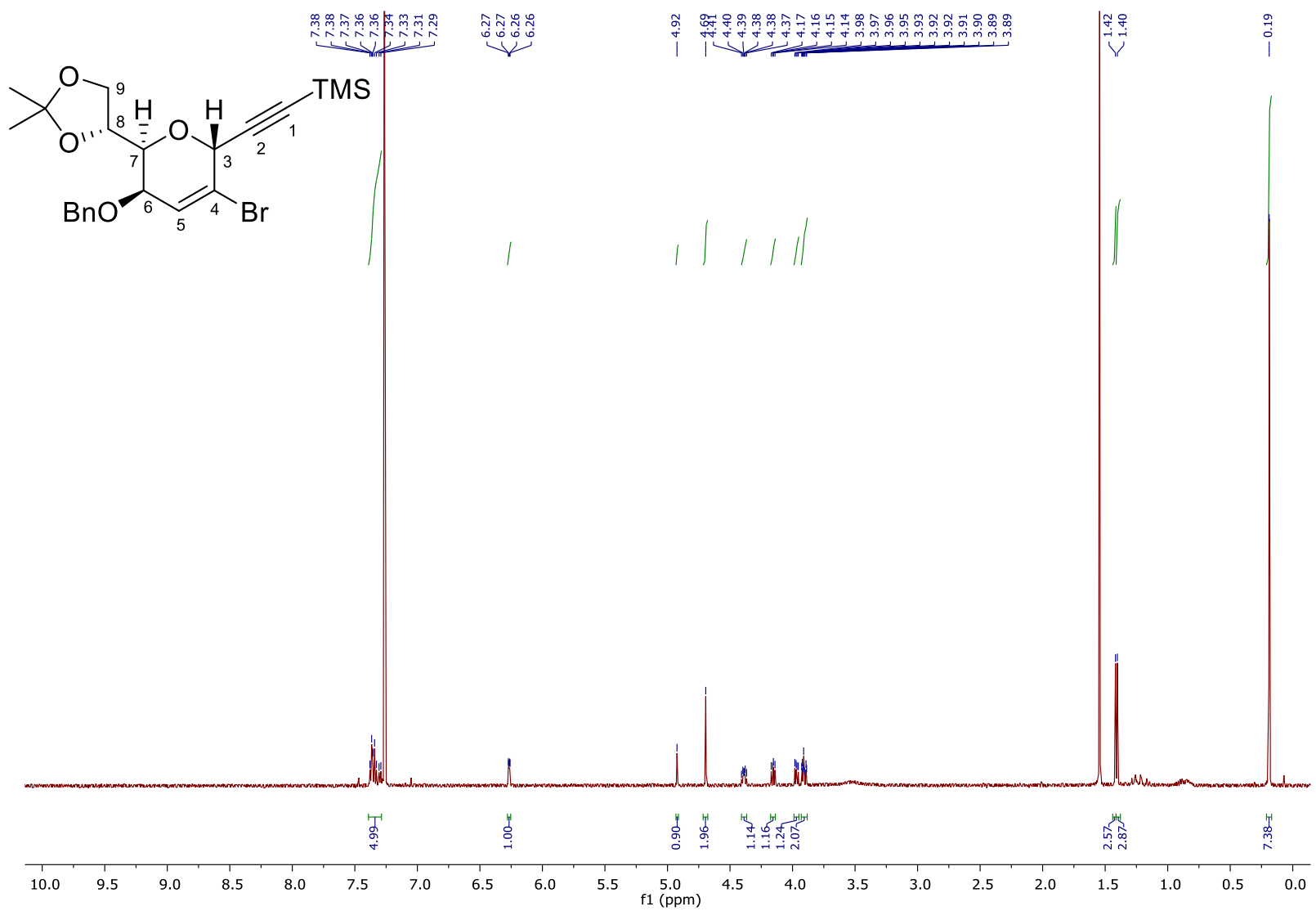

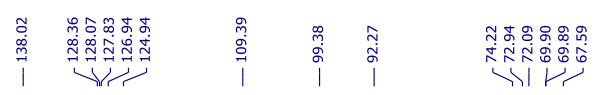

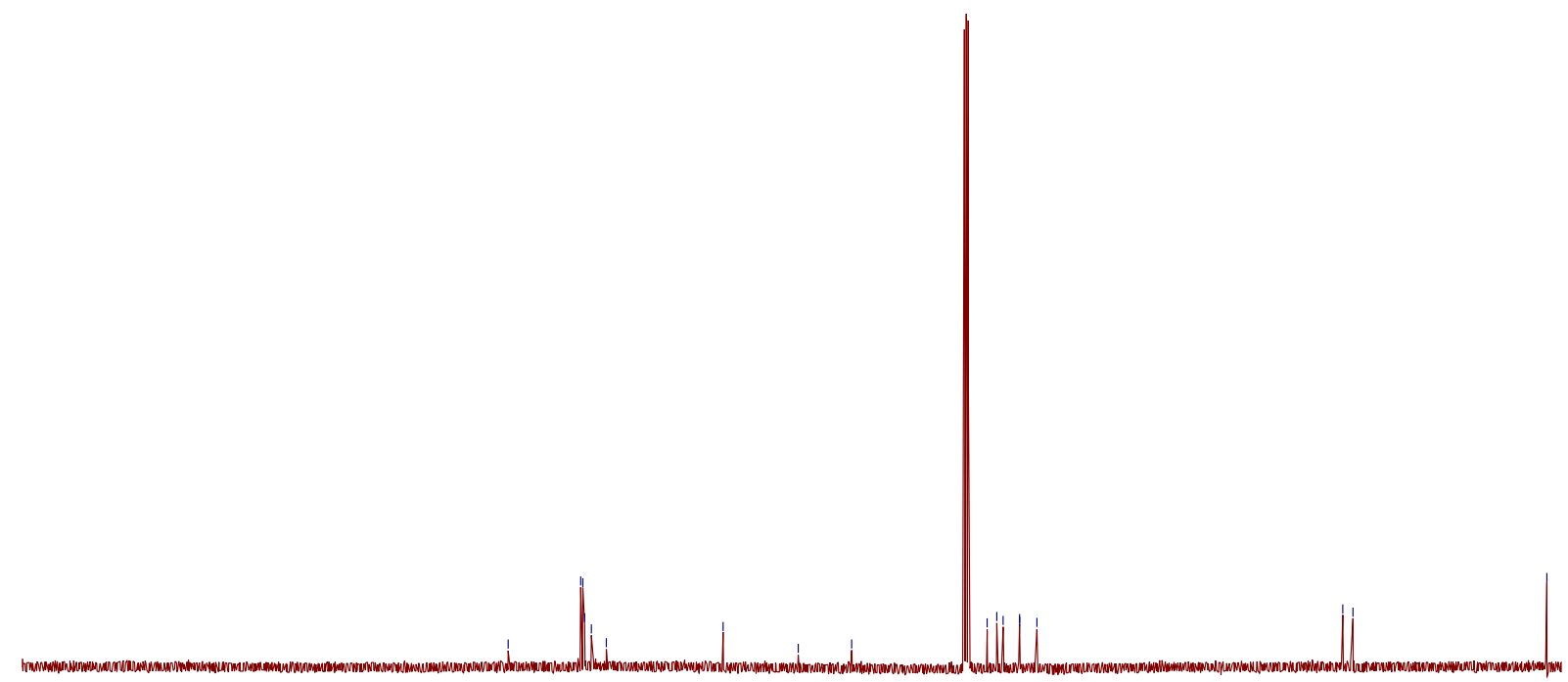

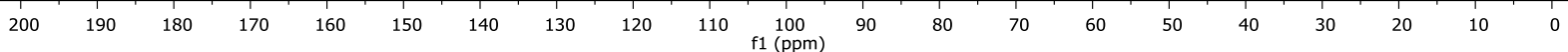

${ }^{1} \mathrm{H}-\mathrm{NMR}$ and ${ }^{13} \mathrm{C}$-NMR spectra of compound 64 

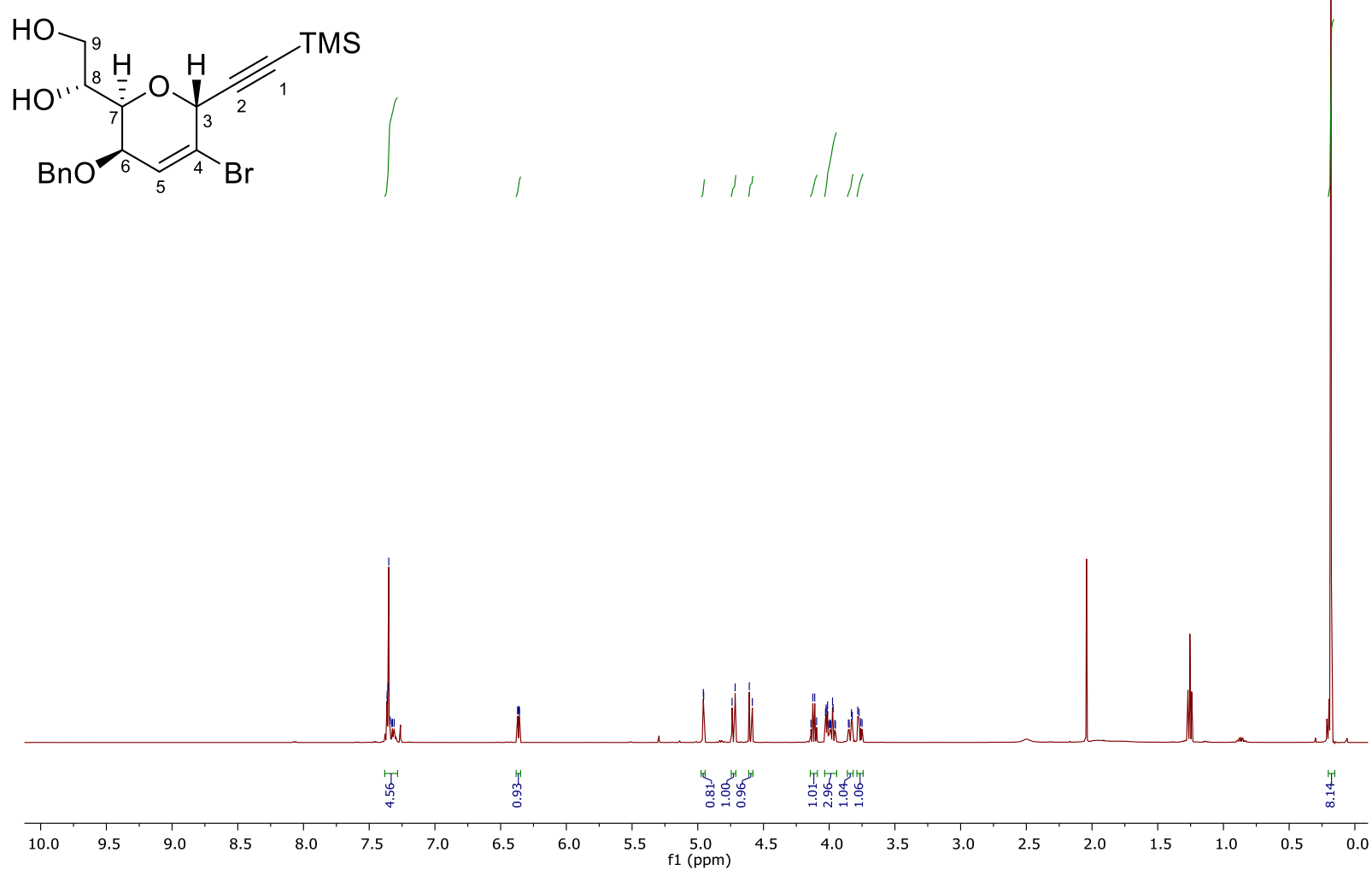

|
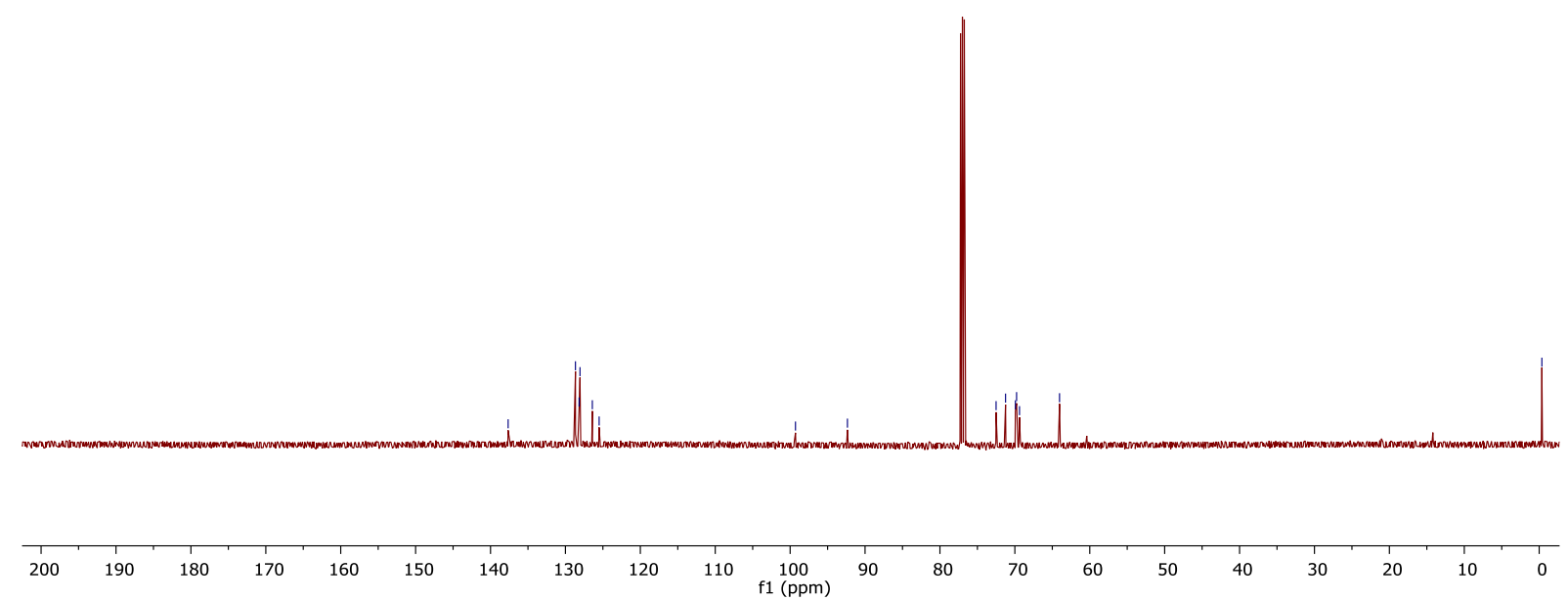

${ }^{1} \mathrm{H}-\mathrm{NMR}$ and ${ }^{13} \mathrm{C}$-NMR spectra of compound 63 

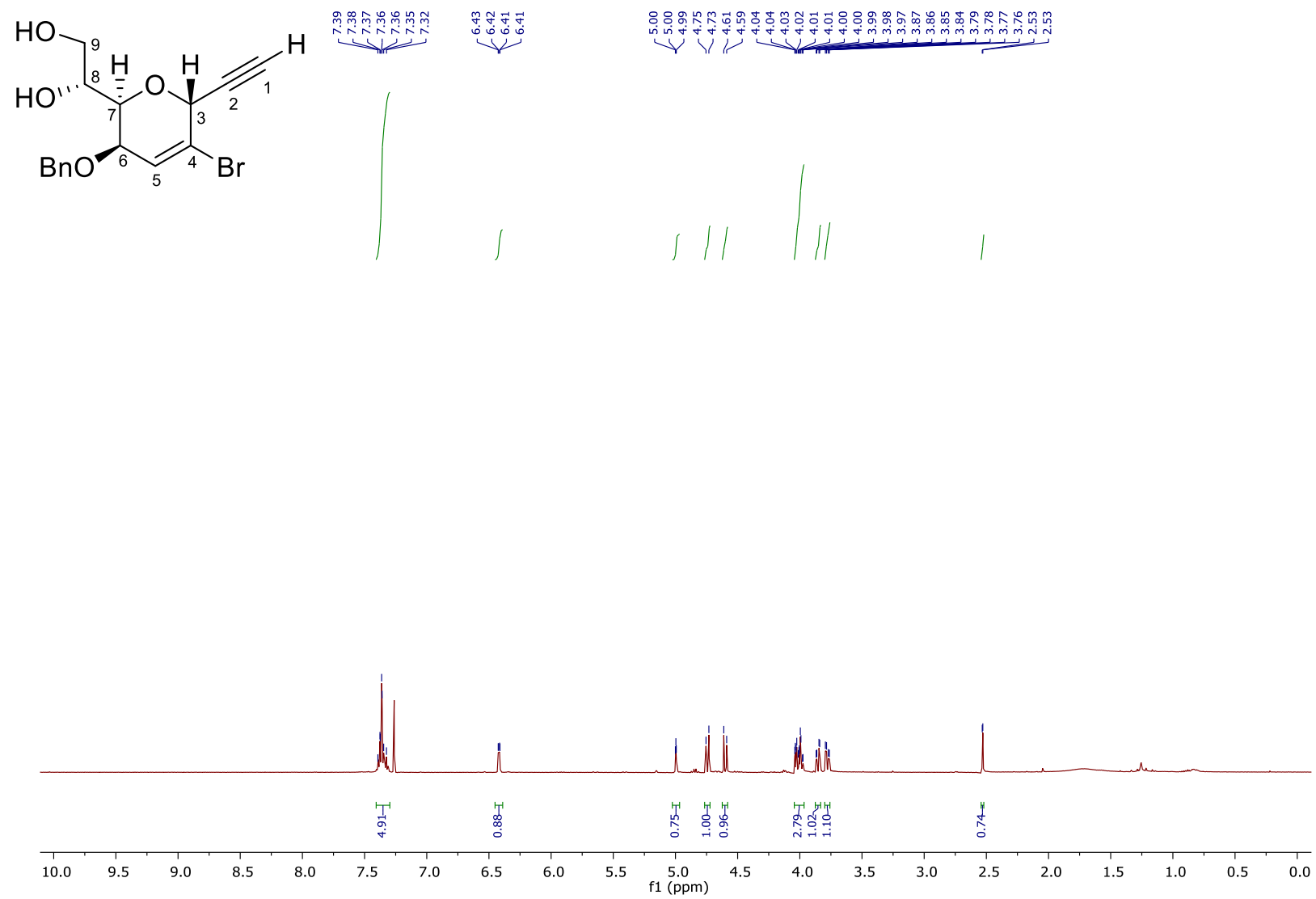

\begin{tabular}{|c|c|}
\hline 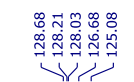 & 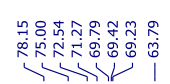 \\
\hline
\end{tabular}

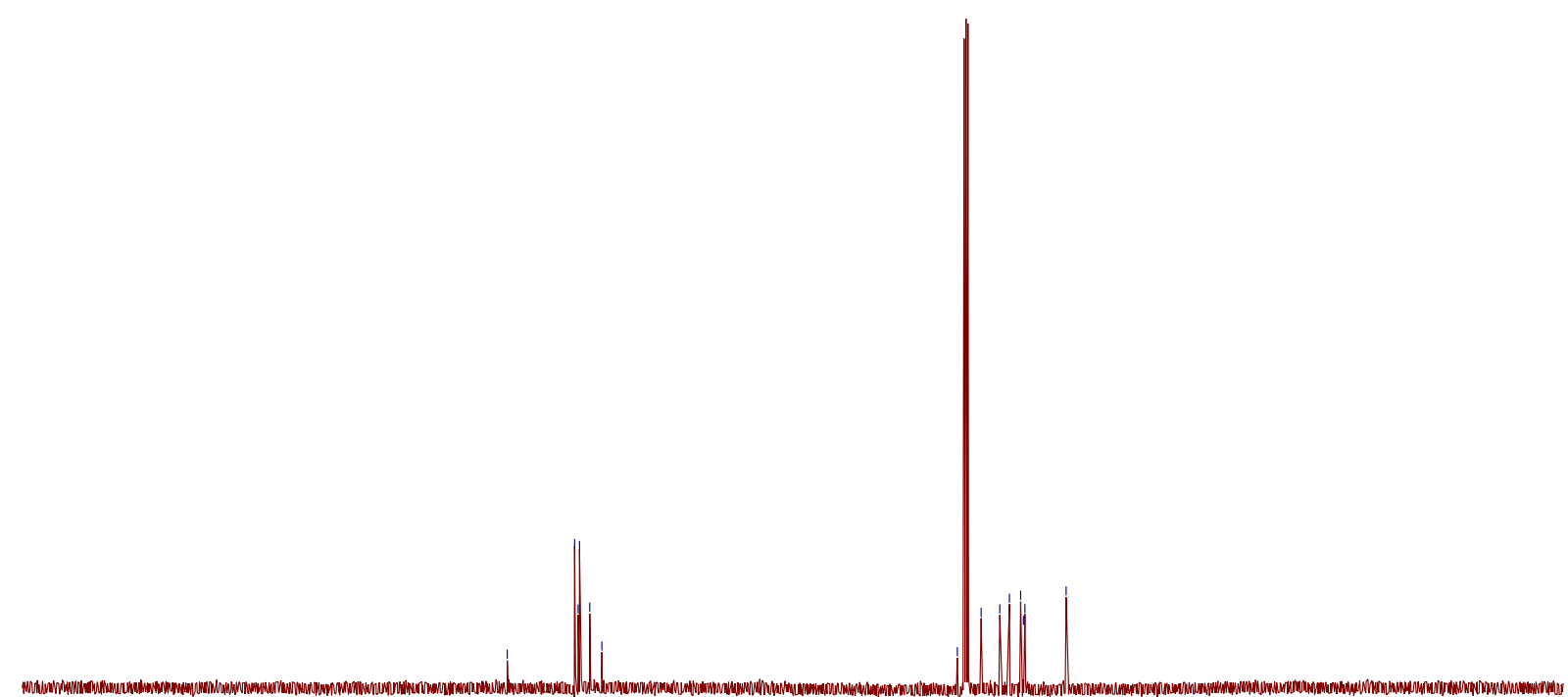

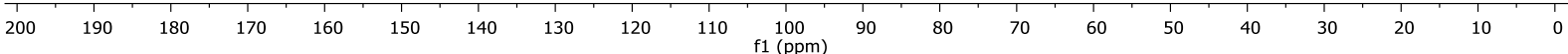

${ }^{1} \mathrm{H}-\mathrm{NMR}$ and ${ }^{13} \mathrm{C}-\mathrm{NMR}$ spectra of compound 90 

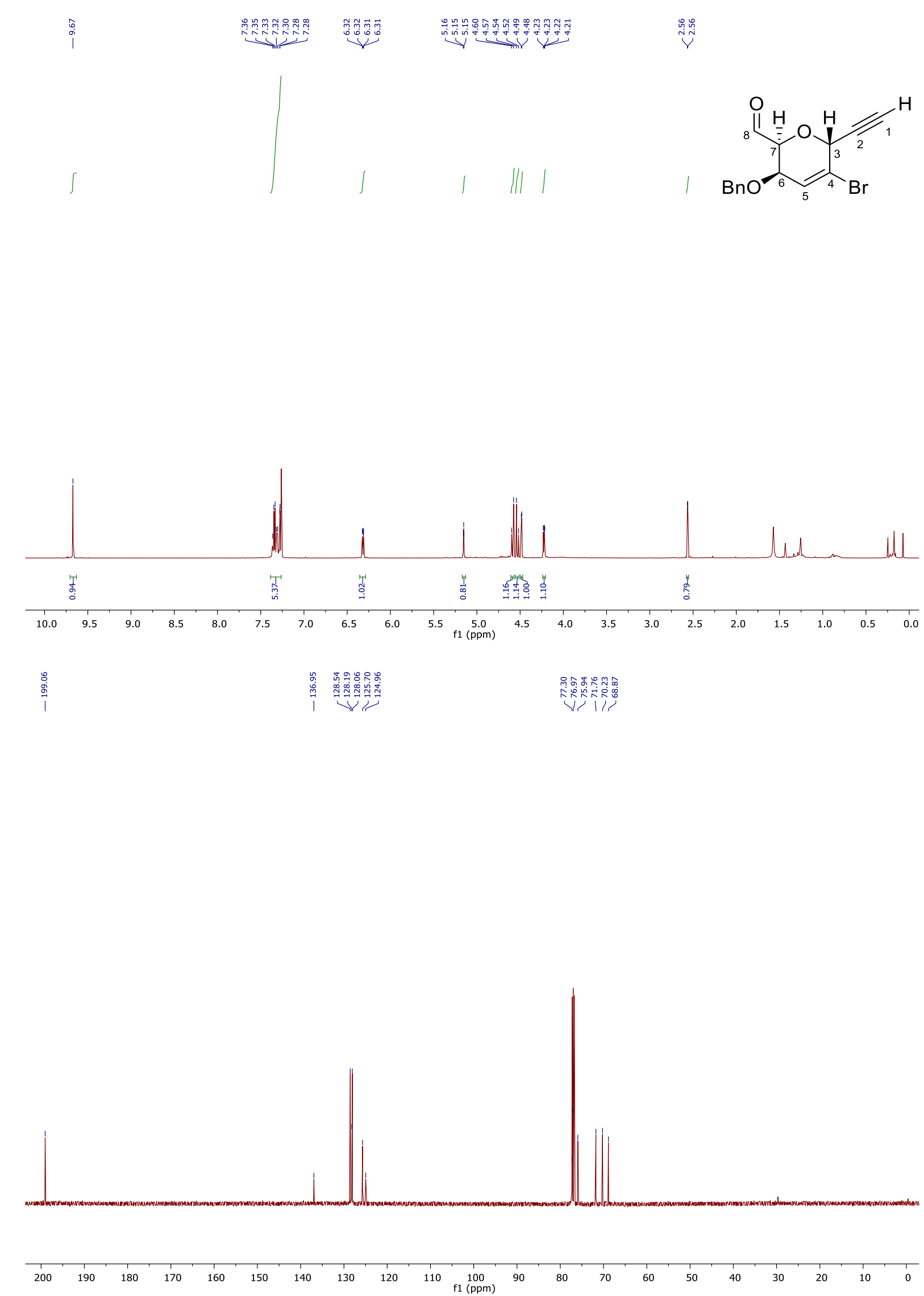

${ }^{1} \mathrm{H}-\mathrm{NMR}$ and ${ }^{13} \mathrm{C}-\mathrm{NMR}$ spectra of compound $\mathbf{7 0}$ 
<smiles>CC#CC1OC(/C=C\C(=O)OC=[V])C(Br)C=C1Br</smiles>
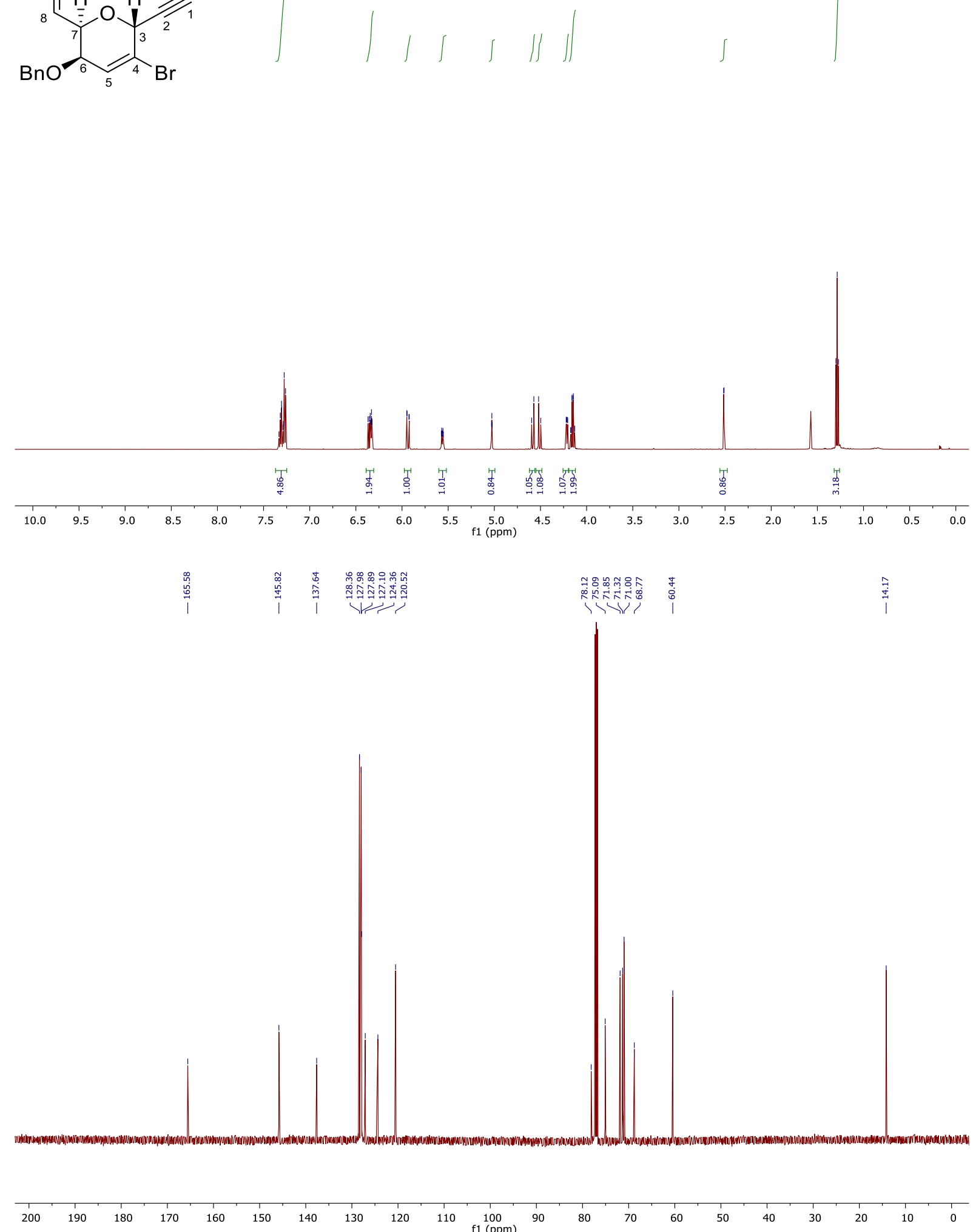


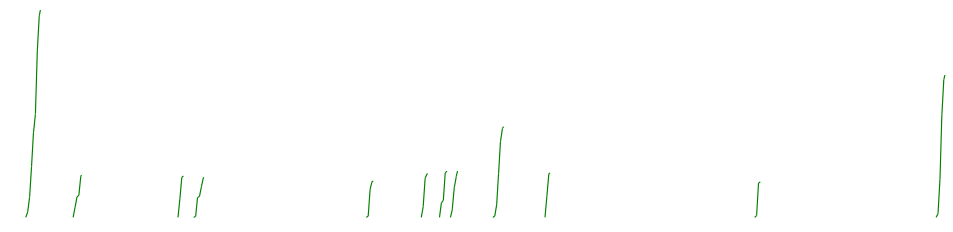<smiles>CC#CC1OC(C=CC(=O)OCC)C(Br)C=C1Br</smiles>

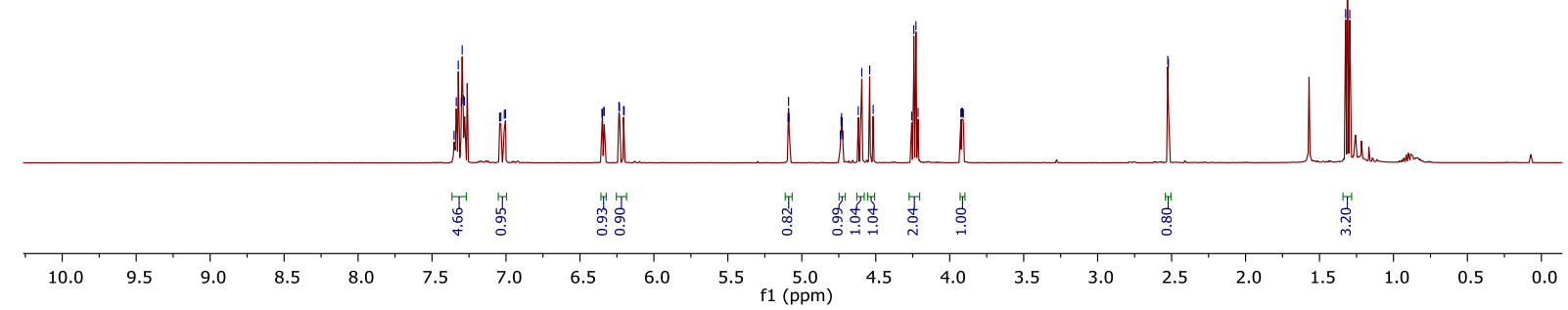

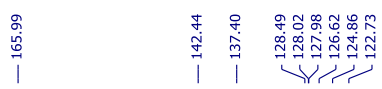

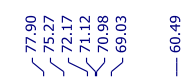

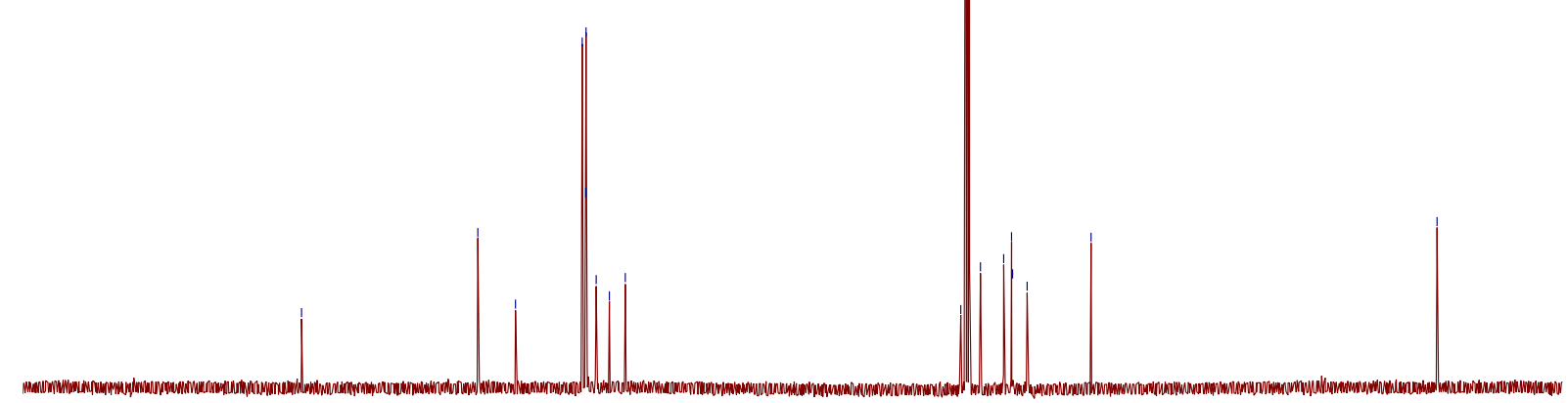

${ }^{1} \mathrm{H}$-NMR and ${ }^{13} \mathrm{C}-\mathrm{NMR}$ spectra of compound (E)-71 


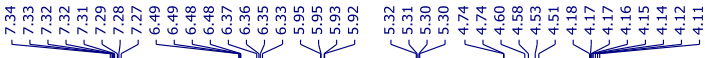
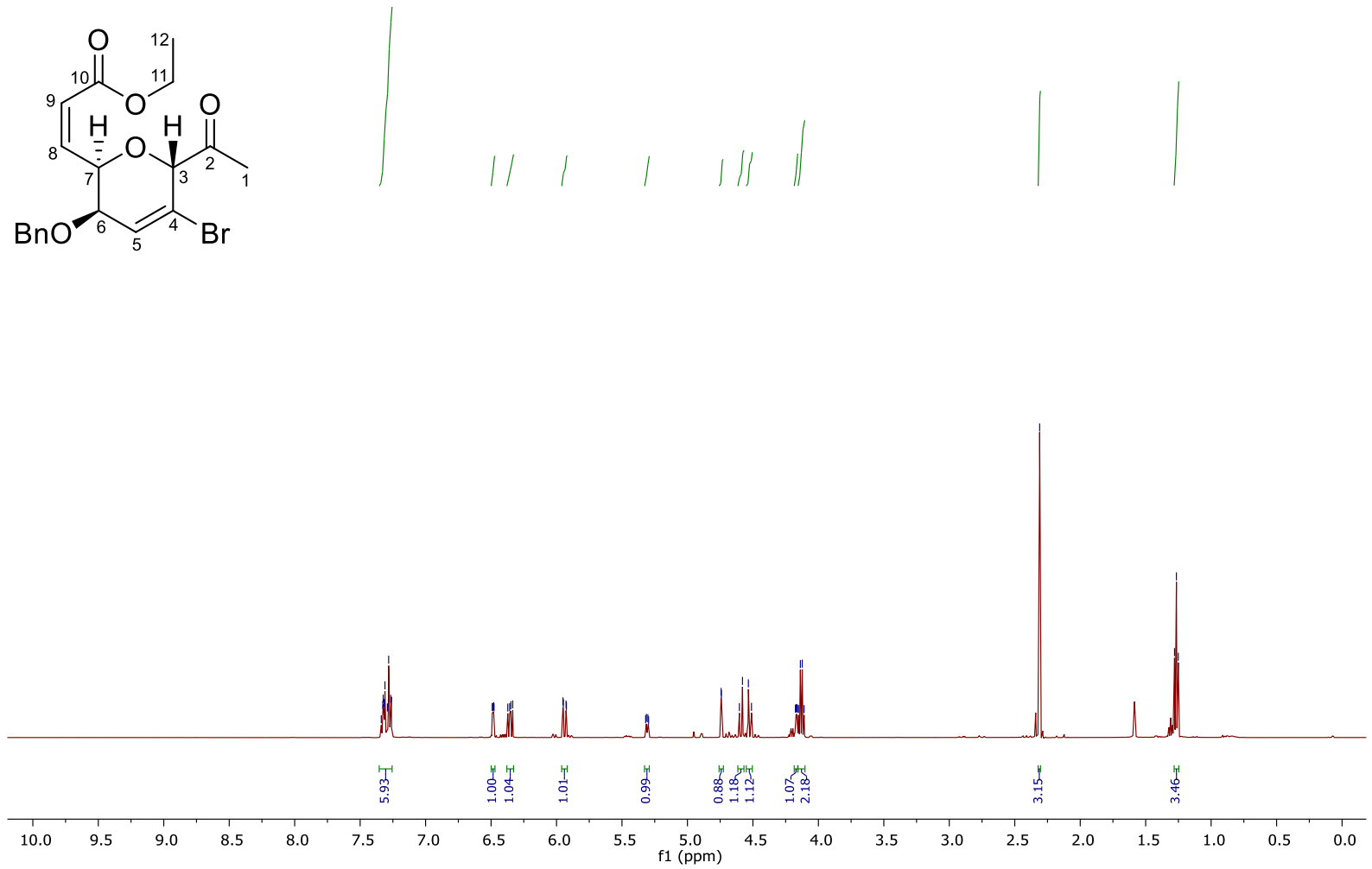

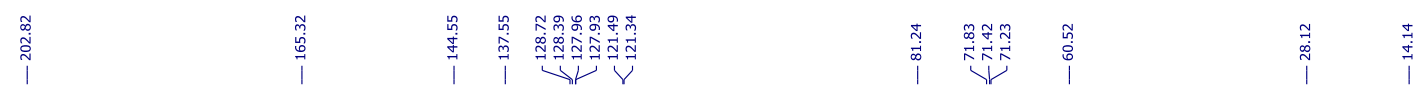

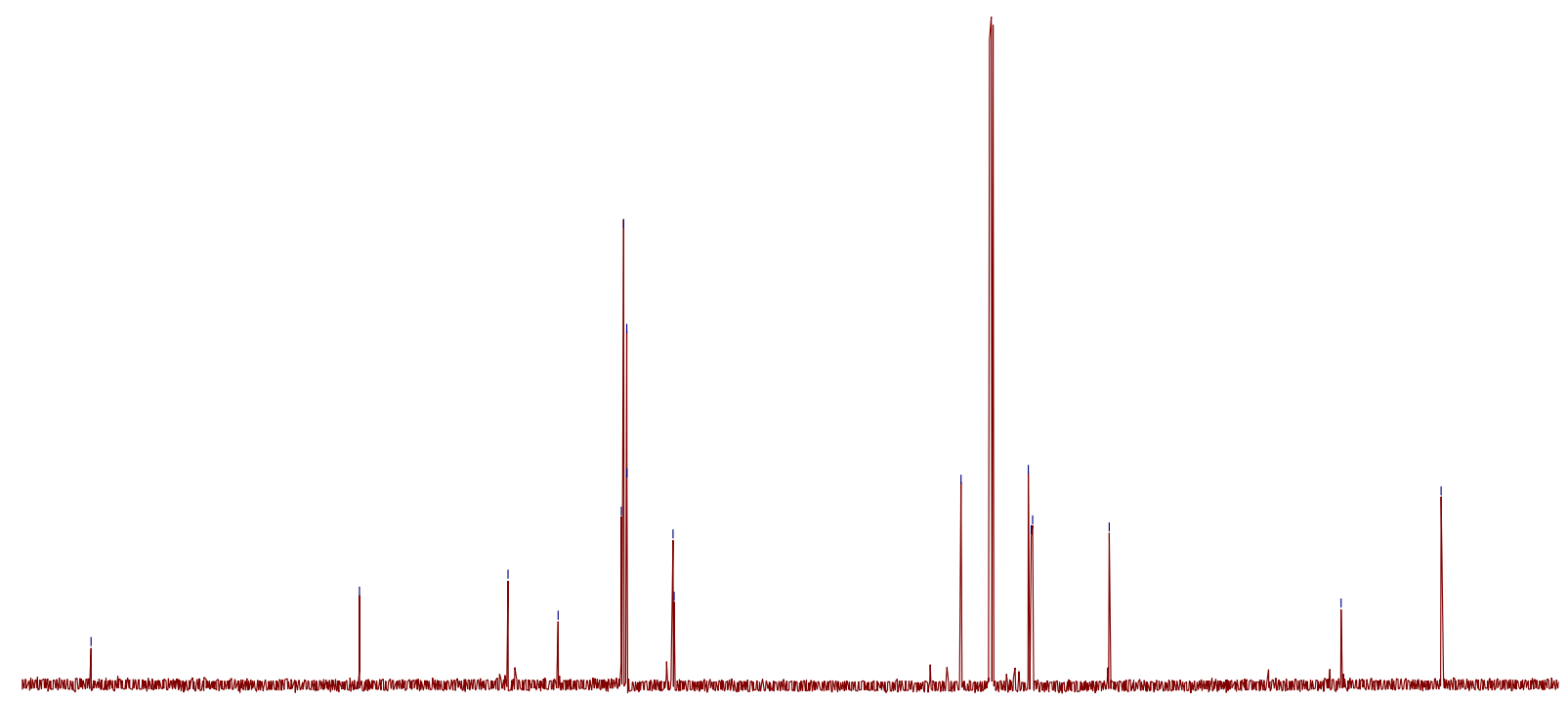

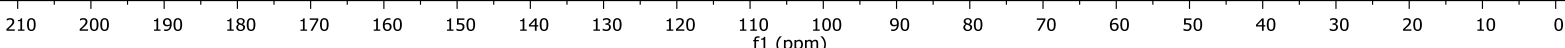

${ }^{1} \mathrm{H}-\mathrm{NMR}$ and ${ }^{13} \mathrm{C}-\mathrm{NMR}$ spectra of compound $(\boldsymbol{Z})-\mathbf{7 2}$ 


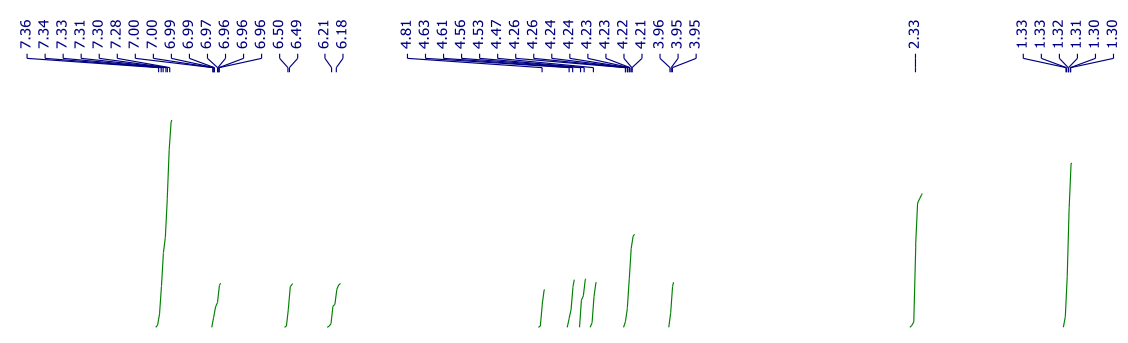<smiles>CCOC(=O)/C=C/C1O[C@H](C(C)=O)C(Br)=C[C@H]1OCc1ccccc1</smiles>
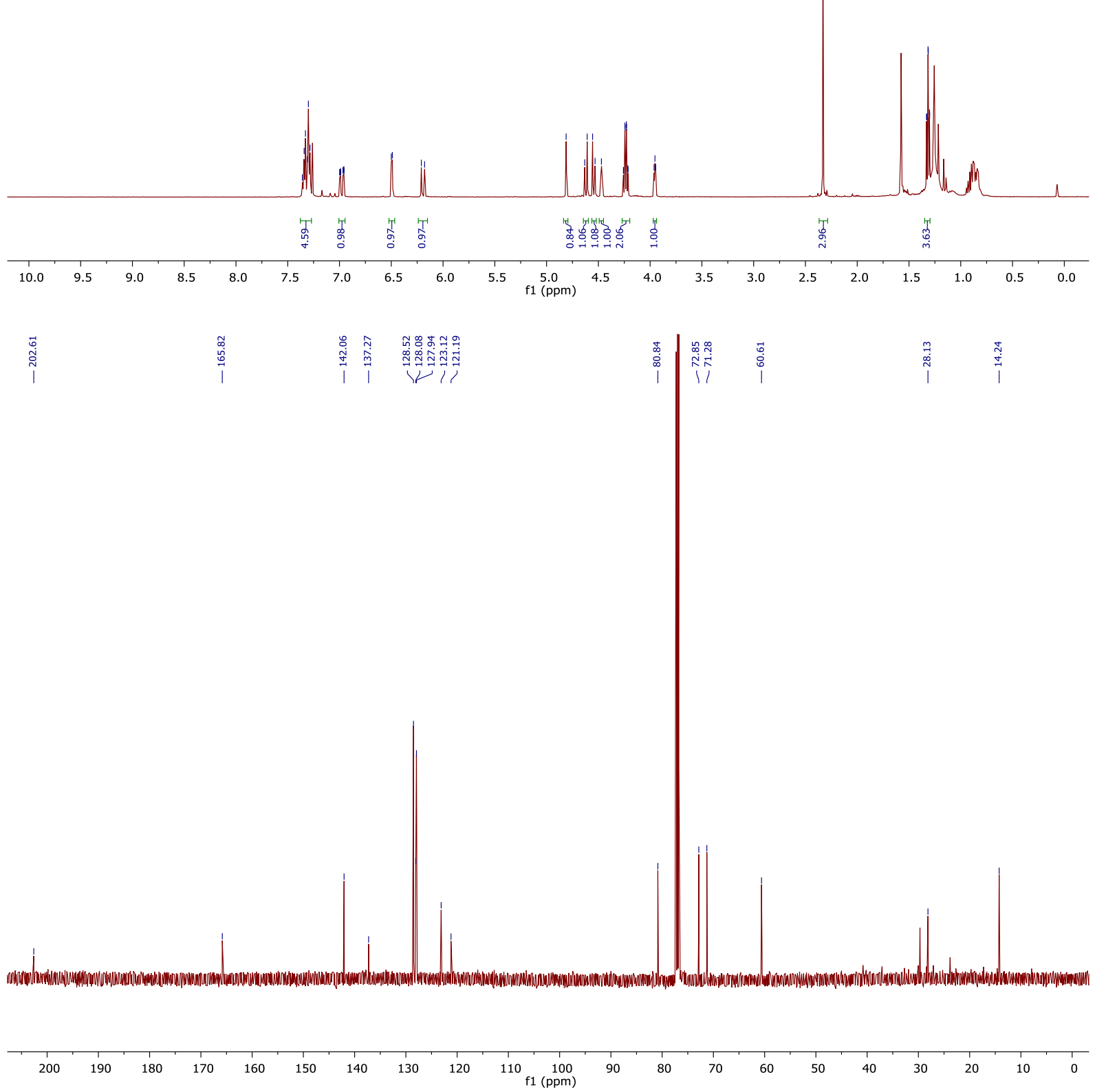

${ }^{1} \mathrm{H}-\mathrm{NMR}$ and ${ }^{13} \mathrm{C}-\mathrm{NMR}$ spectra of compound $(\boldsymbol{E})-72$ 

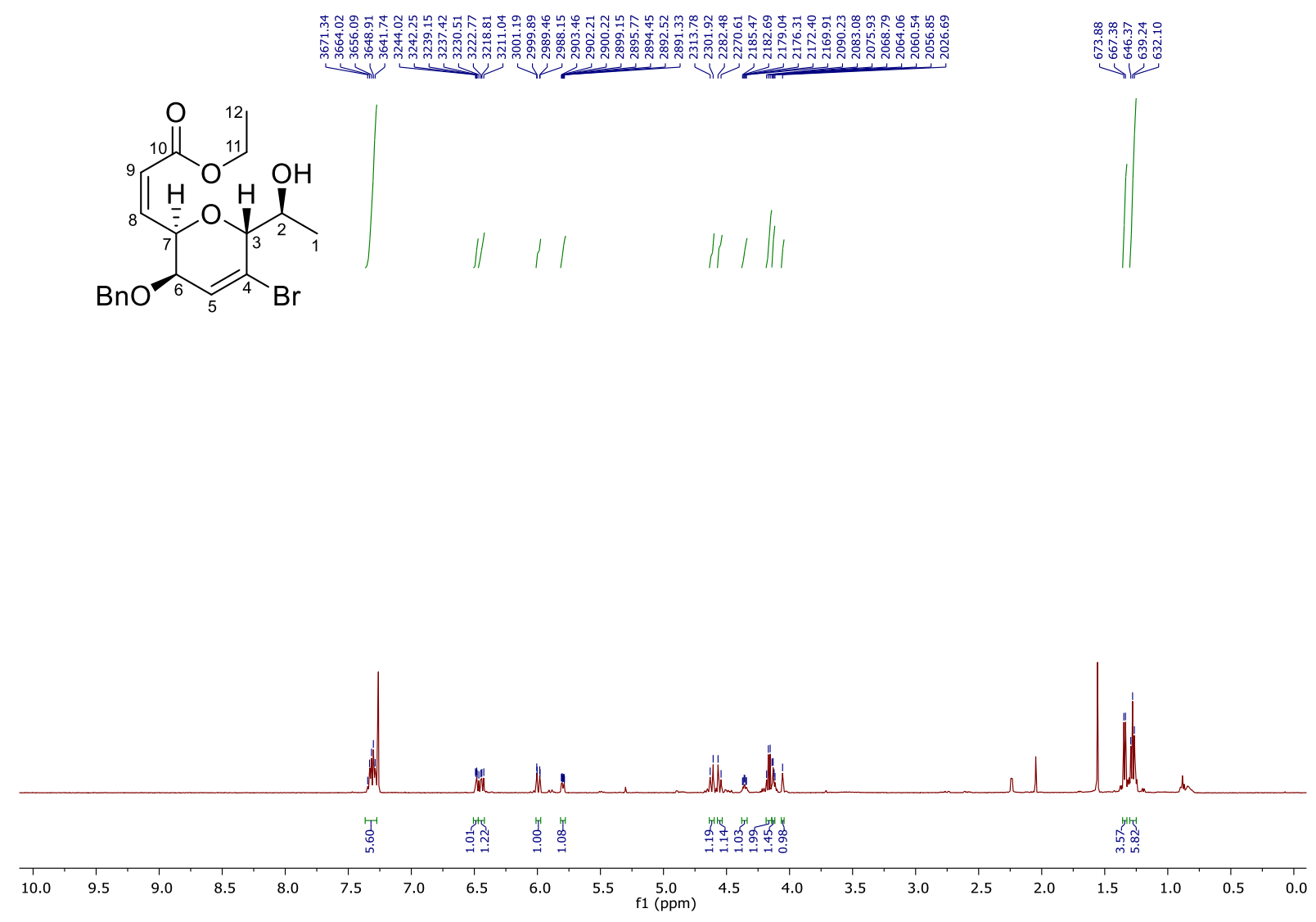

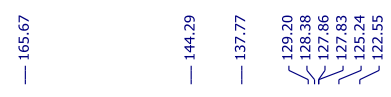

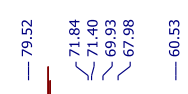

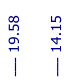

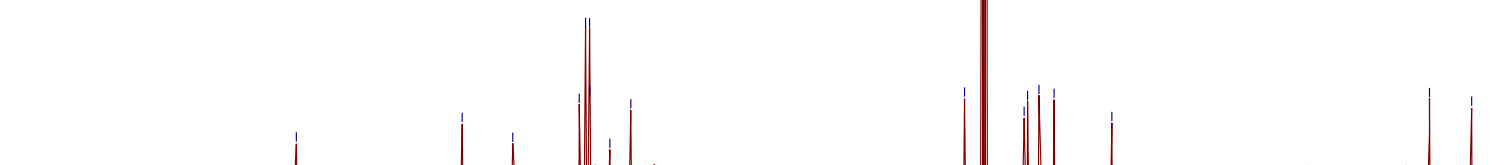

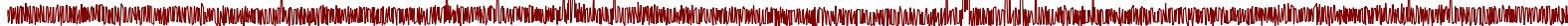

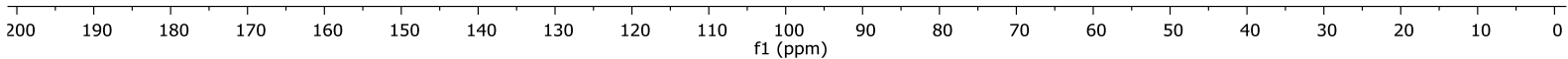

${ }^{1} \mathrm{H}-\mathrm{NMR}$ and ${ }^{13} \mathrm{C}-\mathrm{NMR}$ spectra of compound $\mathbf{5 3}$ 


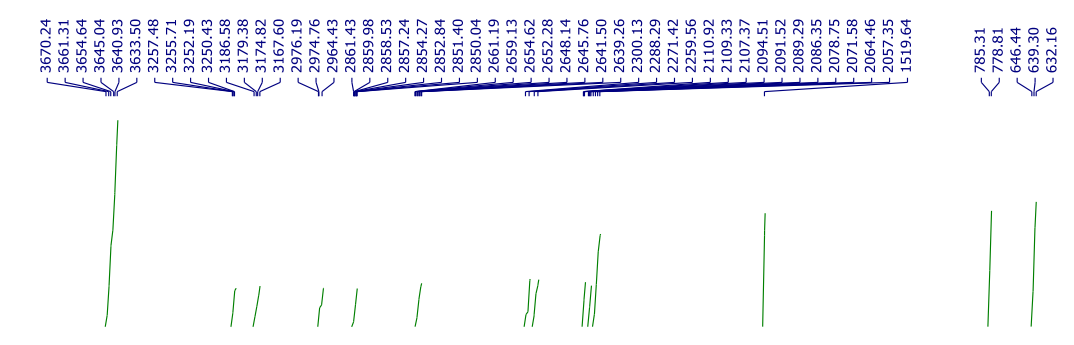<smiles>CCOC(=O)/C=C\C1OC(C(C)C)C(Br)=C[C@H]1OCc1ccccc1</smiles>
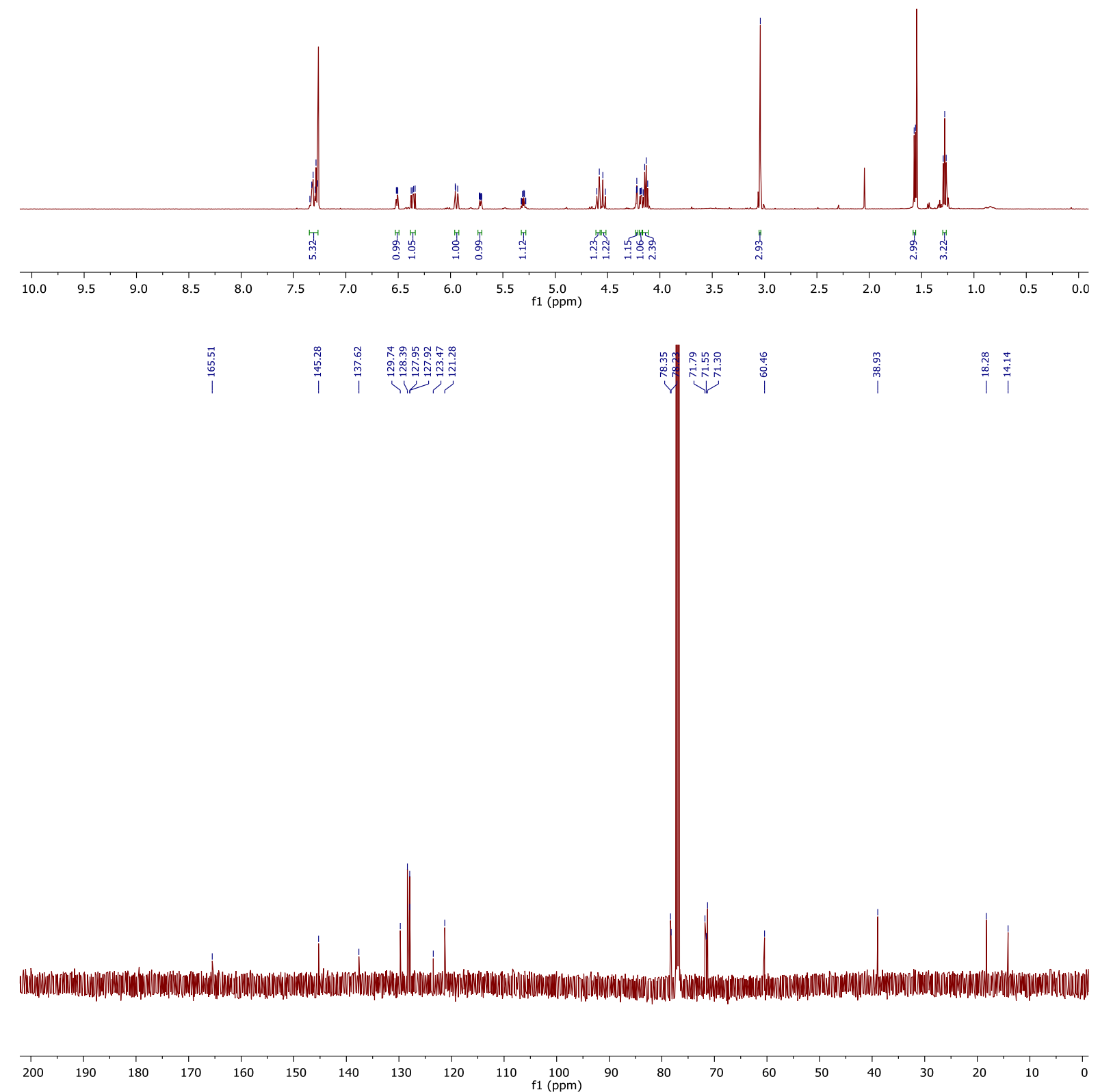

${ }^{1} \mathrm{H}-\mathrm{NMR}$ and ${ }^{13} \mathrm{C}-\mathrm{NMR}$ spectra of compound 94 

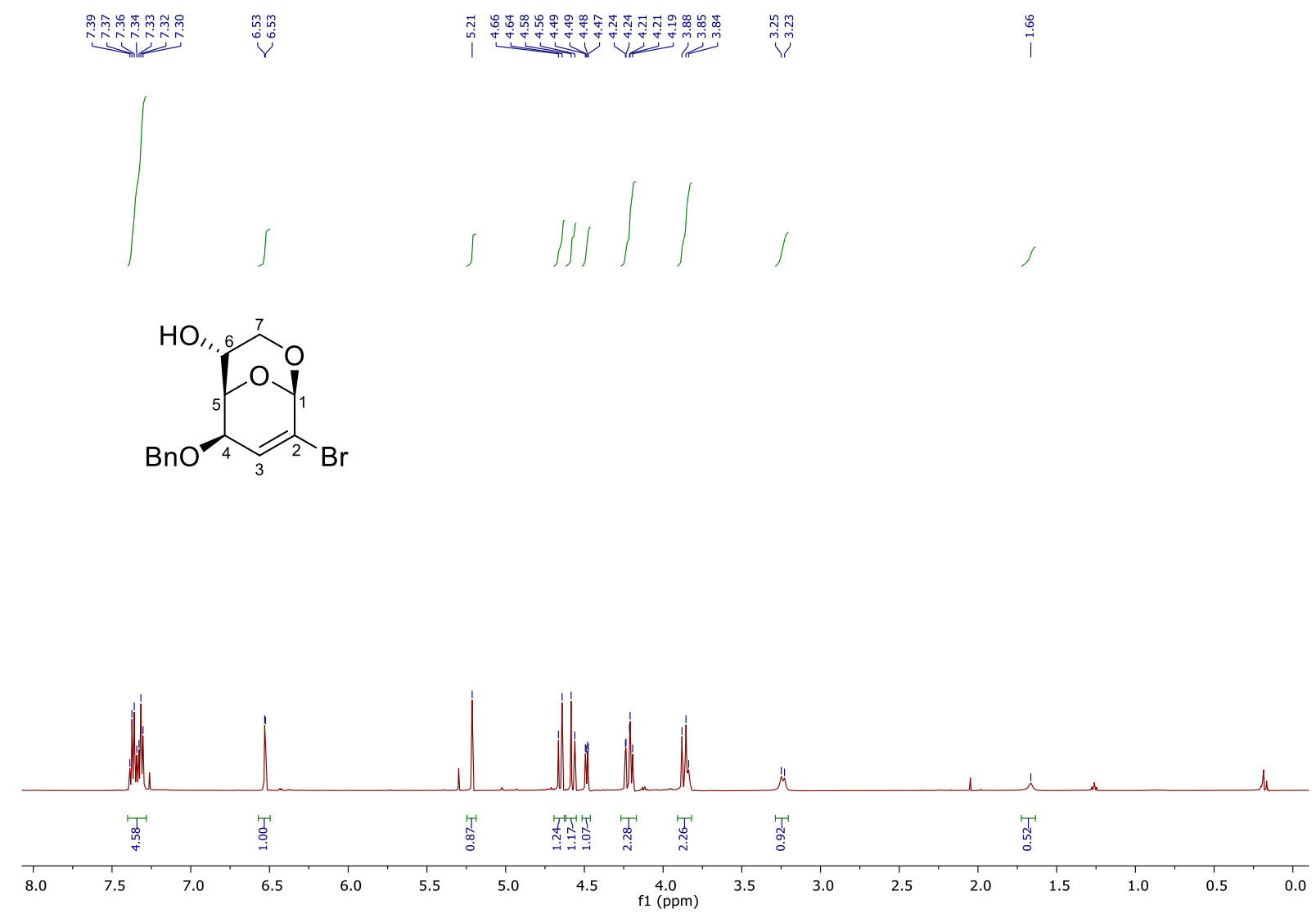

|
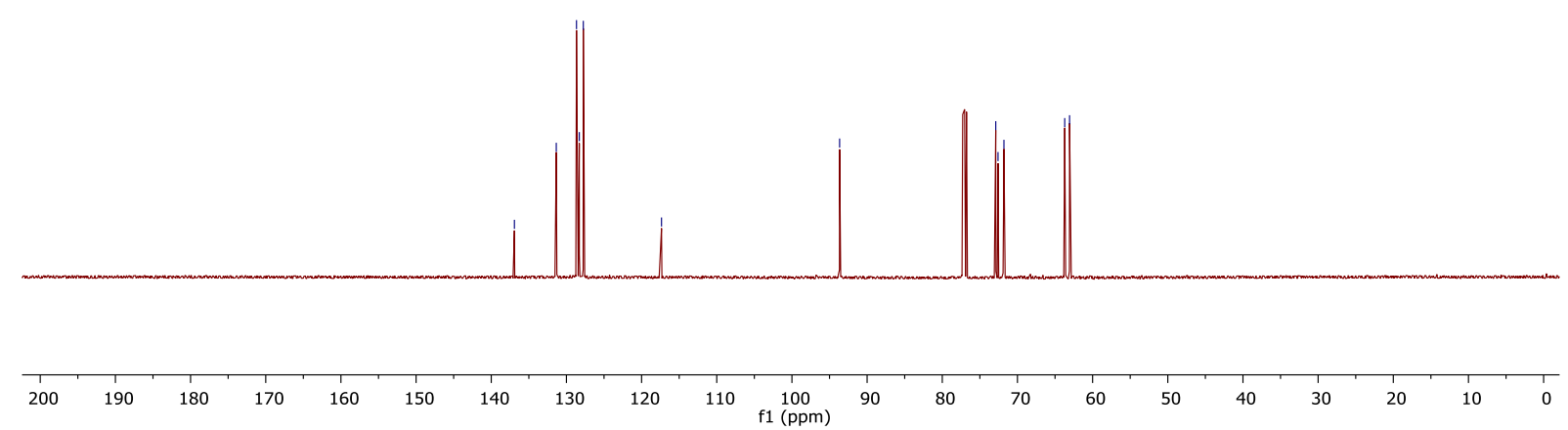

${ }^{1} \mathrm{H}-\mathrm{NMR}$ and ${ }^{13} \mathrm{C}-\mathrm{NMR}$ spectra of compound $\mathbf{8 9}$ 

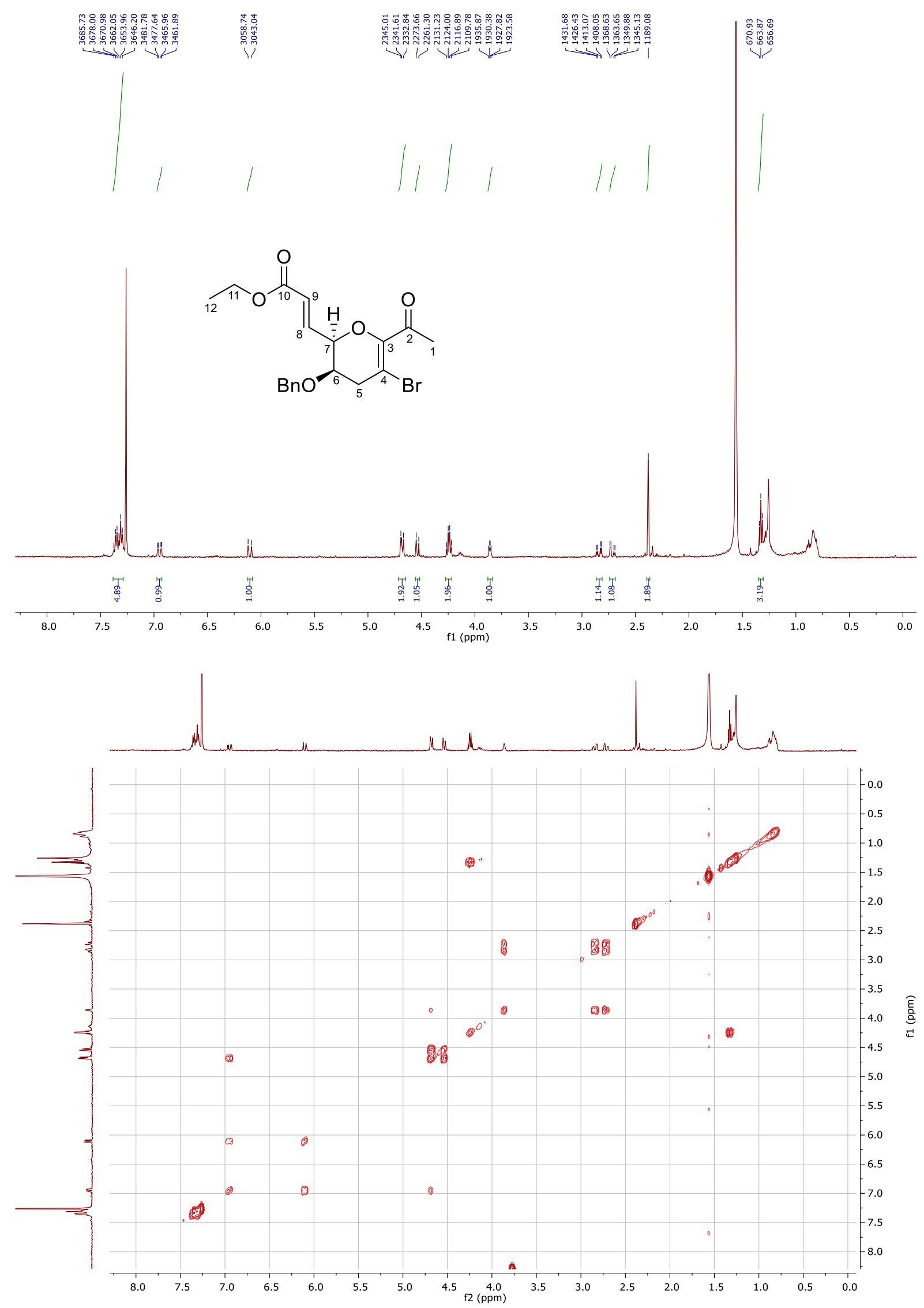

${ }^{1} \mathrm{H}-\mathrm{NMR}$ and COSY spectra of compound $(\boldsymbol{E})-\mathbf{9 1}$ 


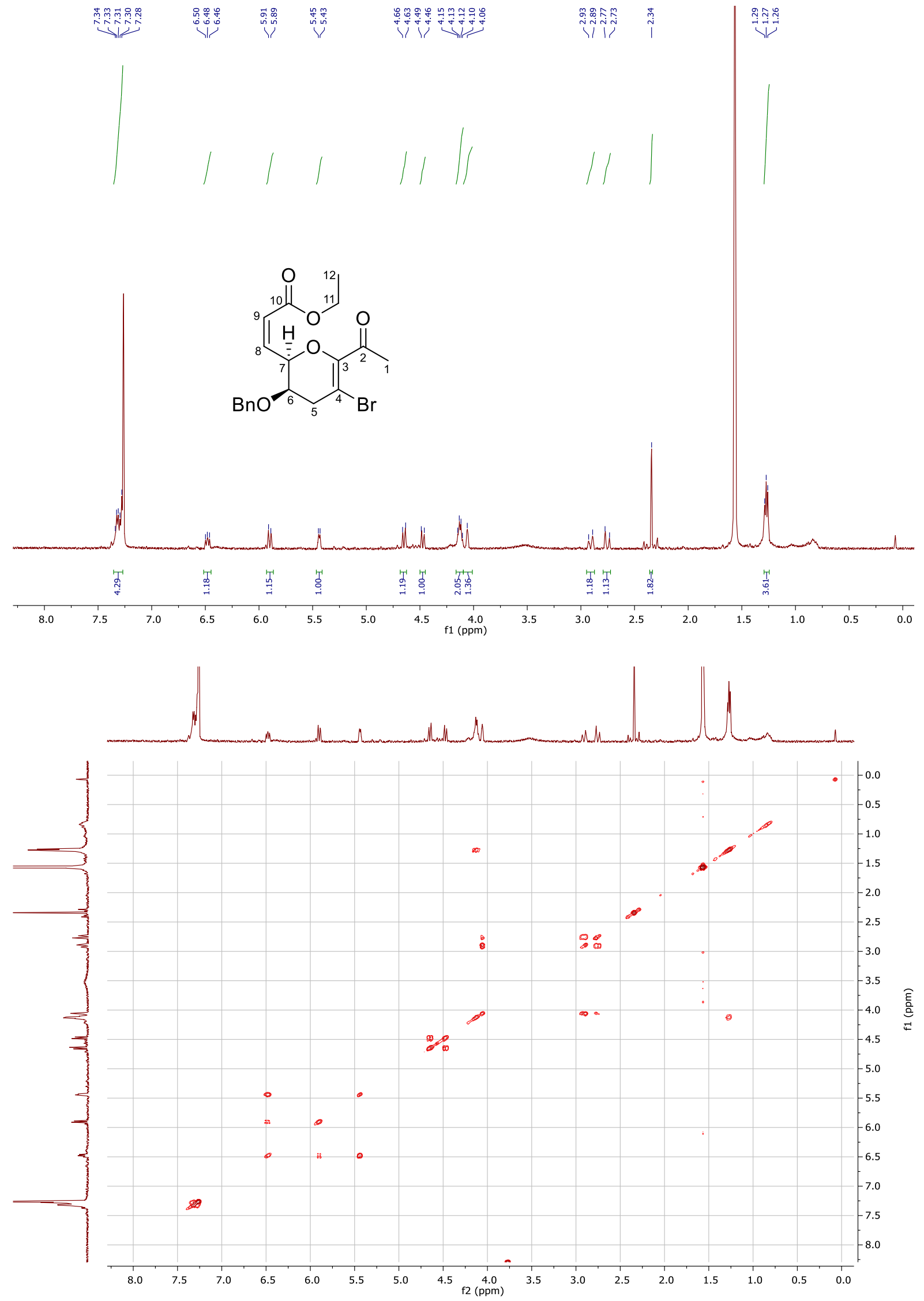

${ }^{1} \mathrm{H}-\mathrm{NMR}$ and COSY spectra of compound (Z)-91 


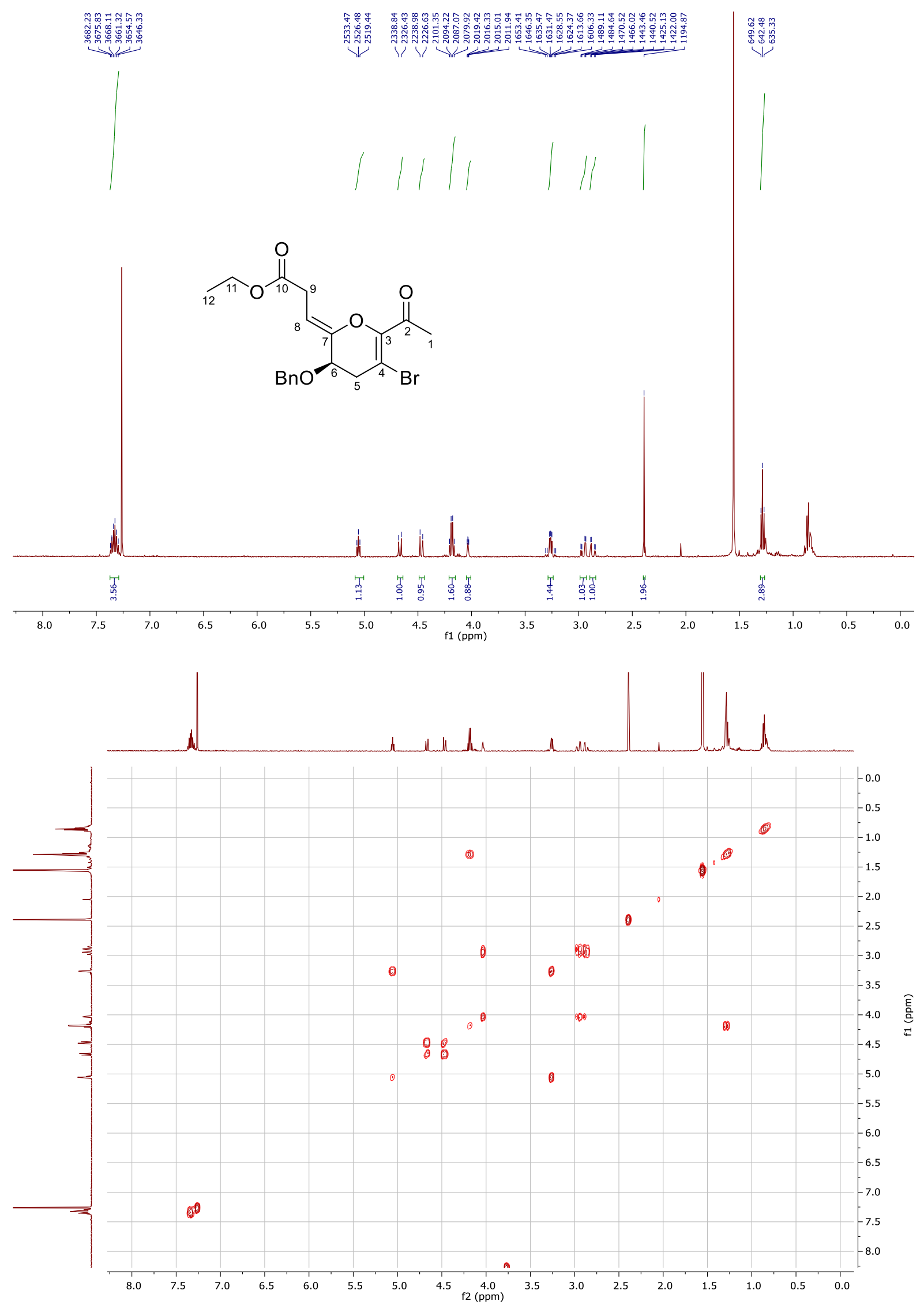

${ }^{1} \mathrm{H}-\mathrm{NMR}$ and COSY spectra of compound $\mathbf{9 2}$ 


\subsection{HRMS of selected compounds}
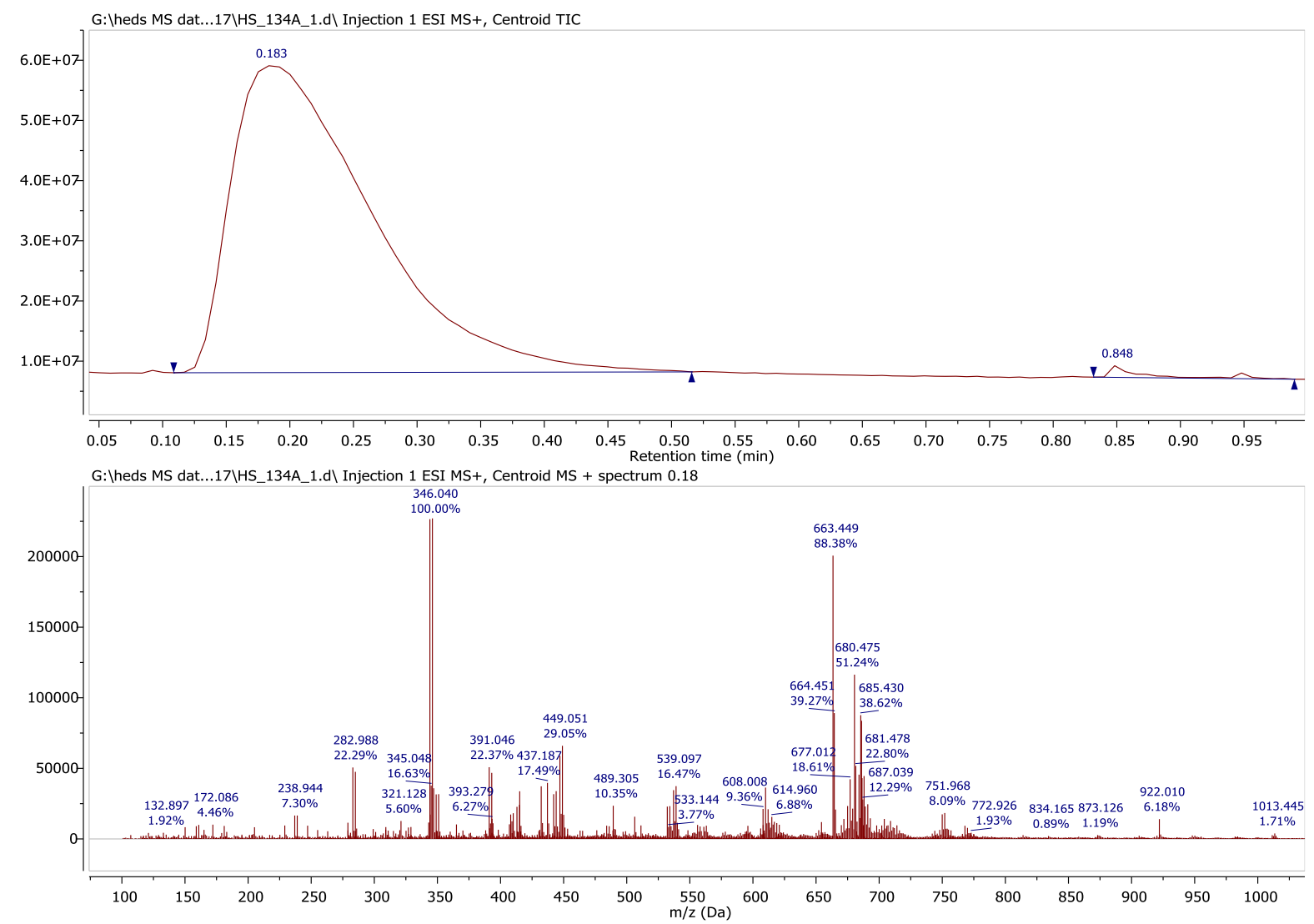

HRMS spectrum and chromatogram of compound $\mathbf{8 9}$ 

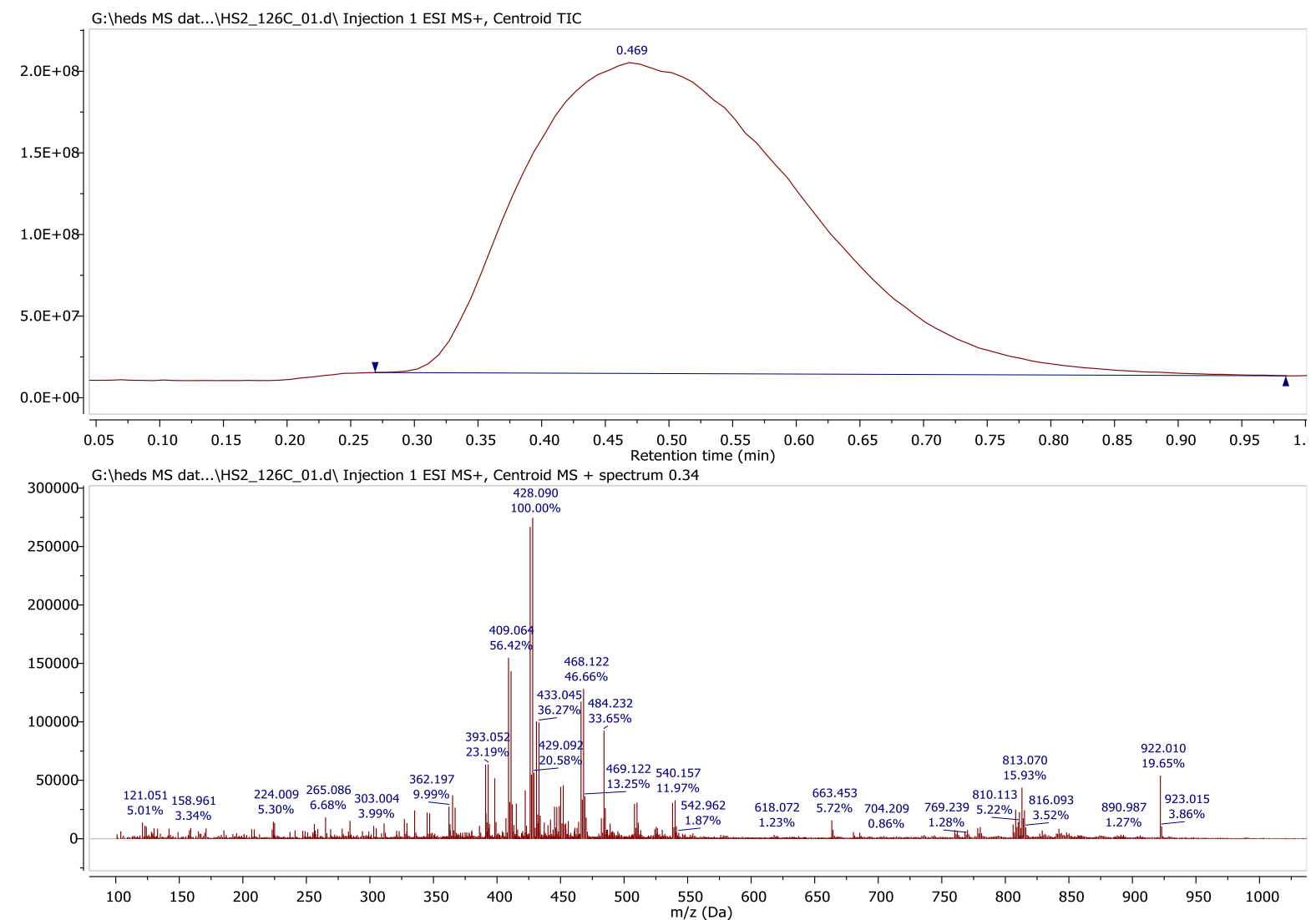

HRMS spectrum and chromatogram of compound $(\boldsymbol{E})-\mathbf{9 1}$ 

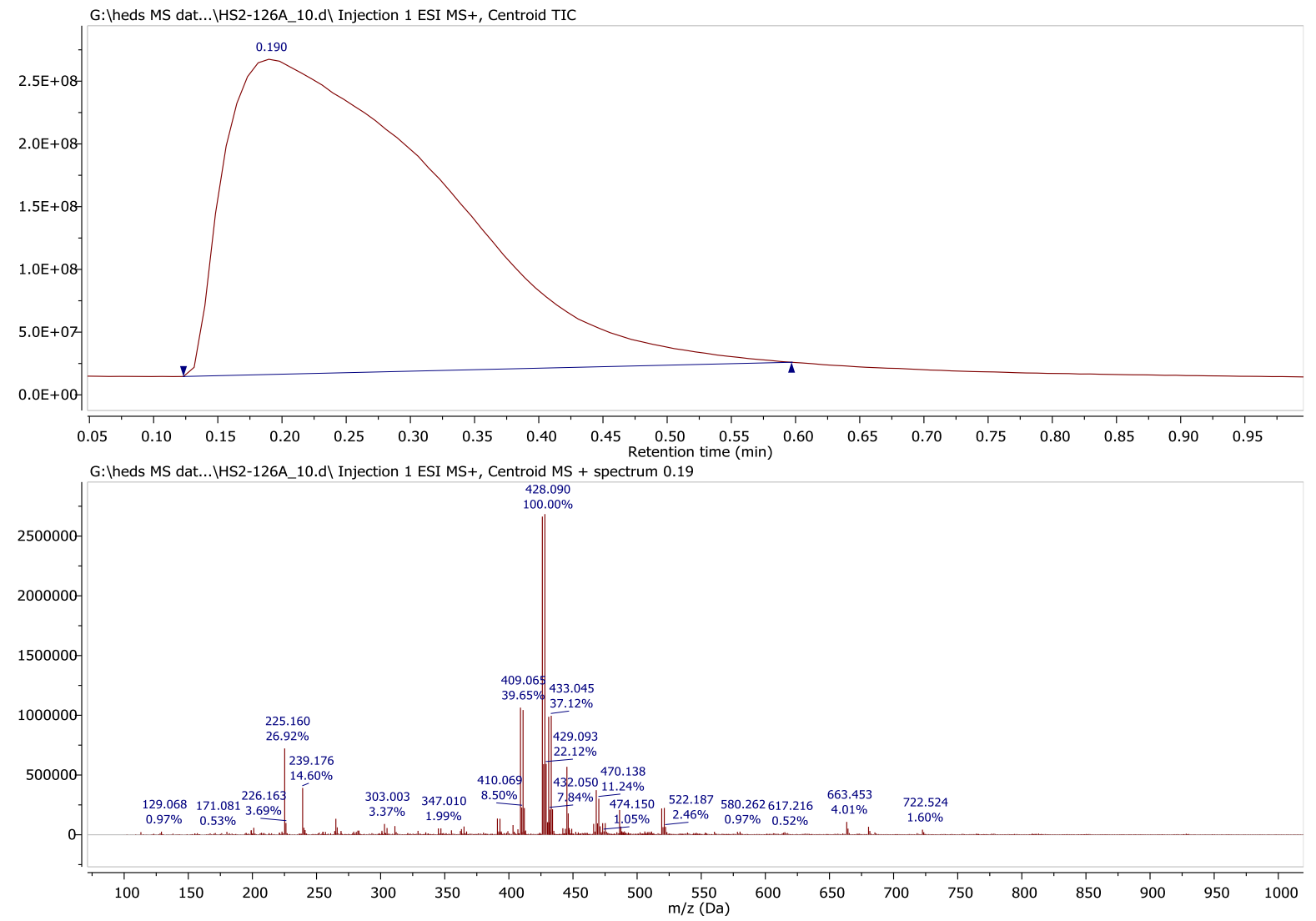

HRMS spectrum and chromatogram of compound (Z)-91 

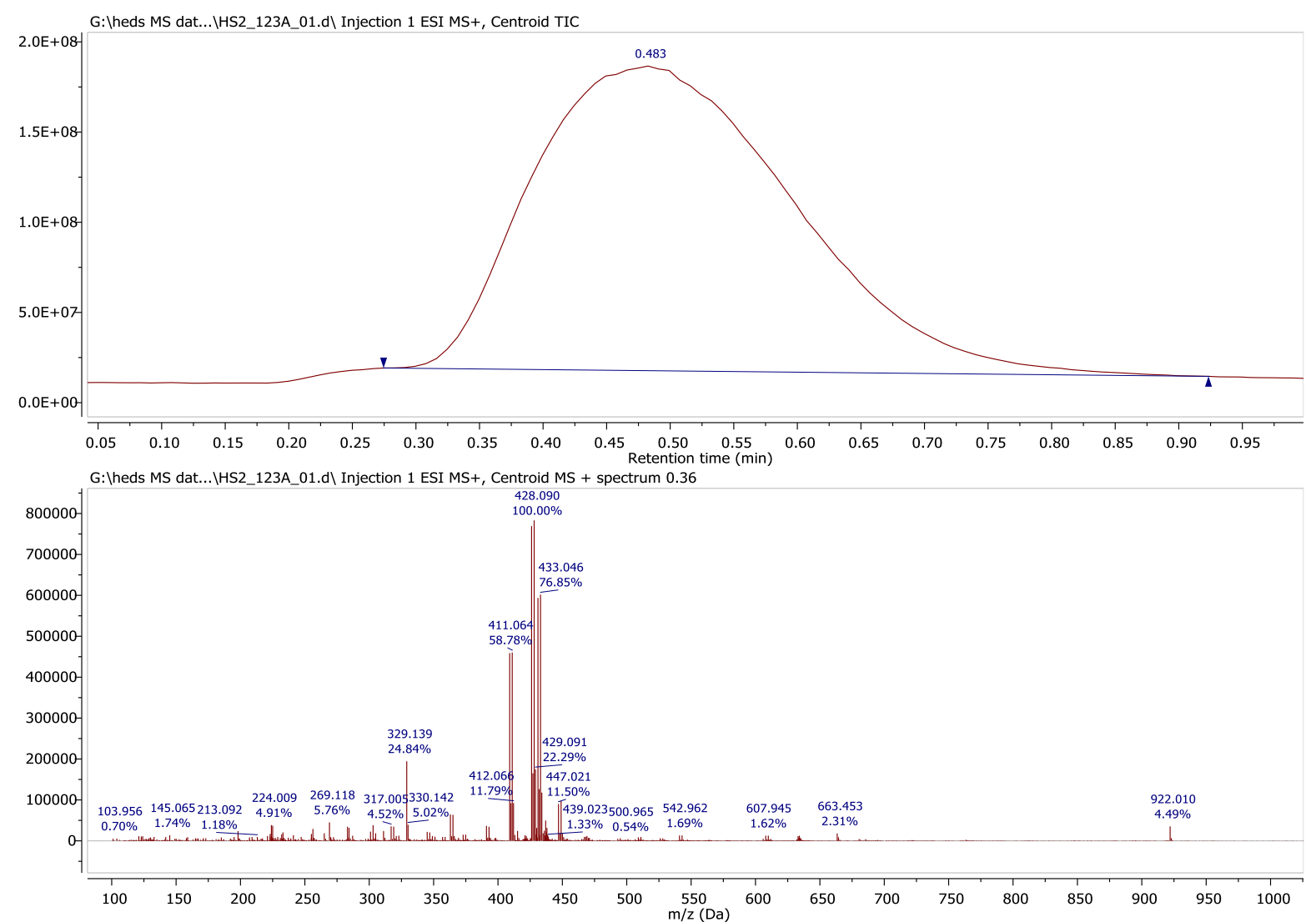

HRMS spectrum and chromatogram of compound $\mathbf{9 2}$ 


\section{References}

(1) Newman, D. J.; Cragg, G. M. Natural Products as Sources of New Drugs Over the 30 Years from 1981 to 2010. J. Nat. Prod. 2012, 75 (3), 311.

(2) Goldman , J. M.; Melo, J. V. Chronic Myeloid Leukemia - Advances in Biology and New Approaches to Treatment. N. Engl. J. Med. 2003, 349 (15), 1451.

(3) Maplestone, R. A.; Stone, M. J.; Williams, D. H. The Evolutionary Role of Secondary Metabolites - a Review. Gene 1992, 115 (1-2), 151.

(4) Harvey, A. L.; Edrada-Ebel, R.; Quinn, R. J. The Re-Emergence of Natural Products for Drug Discovery in the Genomics Era. Nat. Rev. Drug Discov. 2015, 14 (2), 111.

(5) Firn, R. D.; Jones, C. G. The Evolution of Secondary Metabolism - a Unifying Model. Mol. Microbiol. 2000, 37 (5), 989.

(6) Battersby, B. J.; Trau, M. Novel Miniaturized Systems in High-Throughput Screening. Trends Biotechnol. 2002, 20 (4), 167.

(7) Davies, J. W.; Glick, M.; Jenkins, J. L. Streamlining Lead Discovery by Aligning in Silico and High-Throughput Screening. Curr. Opin. Chem. Biol. 2006, 10 (4), 343.

(8) Lipinski, C. A.; Lombardo, F.; Dominy, B. W.; Feeney, P. J. Experimental and Computational Approaches to Estimate Solubility and Permeability in Drug Discovery and Development Settings. Adv. Drug Deliv. Rev. 2012, 64, Supplement, 4.

(9) Sukuru, S. C. K.; Jenkins, J. L.; Beckwith, R. E. J.; Scheiber, J.; Bender, A.; Mikhailov, D.; Davies, J. W.; Glick, M. Plate-Based Diversity Selection Based on Empirical HTS Data to Enhance the Number of Hits and Their Chemical Diversity. J. Biomol. Screen. 2009, 14 (6), 690.

(10) Wall, M. E.; Wani, M. C.; Brown, D. M.; Fullas, F.; Olwald, J. B.; Josephson, F. F.; Thornton, N. M.; Pezzuto, J. M.; Beecher, C. W. W.; Farnsworth, N. R.et al. Effect of Tannins on Screening of Plant Extracts for Enzyme Inhibitory Activity and Techniques for their Removal. Phytomedicine 1996, 3 (3), 281.

(11) Appleton, D. R.; Buss, A. D.; Butler, M. S. A Simple Method for High-Throughput Extract Prefractionation for Biological Screening. CHIMIA 2007, 61 (6), 327.

(12) Tu, Y.; Jeffries, C.; Ruan, H.; Nelson, C.; Smithson, D.; Shelat, A. A.; Brown, K. M.; Li, X.-C.; Hester, J. P.; Smillie, T. Automated High-Throughput System to Fractionate Plant Natural Products for Drug Discovery. J. Nat. Prod. 2010, 73 (4), 751.

(13) Bugni, T. S.; Richards, B.; Bhoite, L.; Cimbora, D.; Harper, M. K.; Ireland, C. M. Marine Natural Product Libraries for High-Throughput Screening and Rapid Drug Discovery. J. Nat. Prod. 2008, 71 (6), 1095.

(14) Schueffler, A.; Anke, T. Fungal Natural Products in Research and Development. Nat. Prod. Rep. 2014, 31 (10), 1425.

(15) Wiemann, P.; Keller, N. P. Strategies for Mining Fungal Natural Products. J. Ind. Microbiol. Biotechnol. 2014, 41 (2), 301.

(16) Hayashi, K.; Takizawa, M.; Noguchi, K. Japan Patent 10,287,679, 1998.

(17) Krohn, K.; Biele, C.; Drogies, K.-H.; Steingröver, K.; Aust, H.-J.; Draeger, S.; Schulz, B. Fusidilactones, a New Group of Polycyclic Lactones from an Endophyte, Fusidium sp. Eur. J. Org. Chem. 2002, 2002 (14), 2331.

(18) Qin, S.; Krohn, K.; Flörke, U.; Schulz, B.; Draeger, S.; Pescitelli, G.; Salvadori, P.; Antus, S.; Kurtán, T. Two New Fusidilactones from the Fungal Endophyte Fusidium sp. Eur. J. Org. Chem. 2009, 2009 (19), 3279.

(19) Oh, H.; Swenson, D. C.; Gloer, J. B.; Shearer, C. A. Massarilactones A and B: Novel Secondary Metabolites from the Freshwater Aquatic Fungus Massarina tunicata. Tetrahedron Lett. 2001, 42 (6), 975. 
(20) Kock, I.; Krohn, K.; Egold, H.; Draeger, S.; Schulz, B.; Rheinheimer, J. New Massarilactones, Massarigenin E, and Coniothyrenol, Isolated from the Endophytic Fungus Coniothyrium sp. from Carpobrotus edulis. Eur. J. Org. Chem. 2007, 2007 (13), 2186.

(21) Krohn, K.; Zia, U.; Hussain, H.; Flörke, U.; Schulz, B.; Draeger, S.; Pescitelli, G.; Salvadori, P.; Antus, S.; Kurtán, T. Massarilactones E-G, New Metabolites from the Endophytic Fungus Coniothyrium sp., Associated with the Plant Artimisia maritima. Chirality 2007, 19 (6), 464.

(22) Zhang, G. F.; Han, W. B.; Cui, J. T.; Ng, S. W.; Guo, Z. K.; Tan, R. X.; Ge, H. M. Neuraminidase Inhibitory Polyketides from the Marine-Derived Fungus Phoma herbarum. Planta Med. 2012, 78 (1), 76.

(23) Nozawa, O.; Okazaki, T.; Sakai, N.; Komurasaki, T.; Hanada, K.; Morimoto, S.; Chen, Z.-X.; He, B.-M.; Mizoue, K. A Novel Bioactive. Delta Lactone FD-211. Taxonomy, Isolation and Characterization. J. Antibiot. 1995, 48 (2), 113.

(24) Gao, X.; Nakadai, M.; Snider, B. B. Synthesis of (-)-TAN-2483A. Revision of the Structures and Syntheses of ( \pm )-FD-211 (Waol A) and ( \pm )-FD-212 (Waol B). Org. Lett. 2003, 5 (4), 451.

(25) Nozawa, O.; Okazaki, T.; Morimoto, S.; Chen, Z.-X.; He, B.-M.; Mizoue, K. Waol B, a New Trihydrofuran Derivative with Cytocidal Activity, Isolated from Myceliophthora lutea. J. Antibiot. 2000, 53 (11), 1296.

(26) Chang, Y.-C.; Deng, T.-S.; Pang, K.-L.; Hsiao, C.-J.; Chen, Y.-Y.; Tang, S.-J.; Lee, T.H. Polyketides from the Littoral Plant Associated Fungus Pseudallescheria boydii. $J$. Nat. Prod. 2013, 76 (9), 1796.

(27) Wang, J.; Hsung, R. P.; Ghosh, S. K. Stereoselective Ketal-Tethered Intramolecular Diels-Alder Cycloadditions. An Approach to the 2-Oxadecalin Spiroketal Core of Antifungal Agent Fusidilactone C. Org. Lett. 2004, 6 (12), 1939.

(28) Ghosh, S. K.; Wei, Y.; Gerasyuto, A. I.; Wang, J.; Feltenberger, J. B.; Hsung, R. P. A Cyclic Acetal Tethered Intramolecular Diels-Alder Cycloaddition: Studies Directed Toward a Total Synthesis of ( \pm )-fusidilactone C. Heterocycles 2011, 82 (2), 1379.

(29) Gao, X.; Snider, B. B. Syntheses of (-)-TAN-2483A, (-)-Massarilactone B, and the Fusidilactone B Ring System. Revision of the Structures of and Syntheses of $( \pm)$-Waol A (FD-211) and ( \pm )-Waol B (FD-212). J. Org. Chem. 2004, 69 (17), 5517.

(30) Li, J.; Wu, X.; Ding, G.; Feng, Y.; Jiang, X.; Guo, L.; Che, Y. $\alpha$-Pyrones and Pyranes from the Plant Pathogenic Fungus Pestalotiopsis scirpina. Eur. J. Org. Chem. 2012, 2012 (12), 2445.

(31) Shao, M.-W.; Kong, L.-C.; Jiang, D.-H.; Zhang, Y.-L. Phytotoxic and Antimicrobial Metabolites from Paraphaeosphaeria sp. QTYC11 Isolated from the Gut of Pantala flavescens Larvae. Rec. Nat. Prod. 2016, 10 (3).

(32) Chen, S.; Ren, F.; Niu, S.; Liu, X.; Che, Y. Dioxatricyclic and Oxabicyclic Polyketides from Trichocladium opacum. J. Nat. Prod. 2014, 77 (1), 9.

(33) Su, M.; Chen, S.; Liu, X.; Pei, Y. Trichocladinols IK, Oxatricyclic and Oxabicyclic Polyketides from Trichocladium opacum. Nat. Prod. Commun. 2014, 9 (5), 695.

(34) Suzuki, E.; Takao, K.-I.; Tadano, K. I. Synthesis of an Enantiomeric 2, 5-di-(E)propenyltetrahydrofuran-3, 4-diol Derivative. Heterocycles 2000, 52 (2), 519.

(35) Hugelshofer, C. L.; Magauer, T. Bioinspired Total Syntheses of Terpenoids. Org. Biomol. Chem. 2017, 15 (1), 12.

(36) Boll, P.; Sorensen, E.; Balieu, E. Naturally Occurring Lactones and Lactames. 2. The Absolute Configuration of Gamma-Methyltetronic Acid, Carolinic Acid and Carolic Acid. Acta Chem. Scand. 1968, 22 (10), 3251. 
(37) Bomann, G. "Furo[3,4-b]pyran Fungal Metabolites: Isolation to Synthetic Production," Report prepared in fulfilment of the requirements of CHEM441, Victoria University of Wellington, 2015.

(38) Ayer, W. A.; Craw, P. A. Biosynthesis and Biogenetic Interrelationships of Metabolites of the Fungus Arthropsistruncata. Can. J. Chem. 1992, 70 (5), 1348.

(39) Sandmeier, P.; Tamm, C. New Spirostaphylotrichins from Staphylotrichum coccosporum. Helv. Chim. Acta 1989, 72 (4), 784.

(40) Oh, H.; Swenson, D. C.; Gloer, J. B.; Shearer, C. A. New Bioactive Rosigenin Analogues and Aromatic Polyketide Metabolites from the Freshwater Aquatic Fungus Massarina tunicata. J. Nat. Prod. 2003, 66 (1), 73.

(41) Somarathne, R. M. K. K. Synthesis of Highly Functionalized Furo[3,4-b]pyrans: Towards the Fungal Metabolite (-)-TAN-2483B. Ph.D. Thesis, Victoria University of Wellington, Wellington, New Zealand, 2014.

(42) Hewitt, R. J.; Harvey, J. E. Synthesis of the (-)-TAN-2483B Ring System via a Dmannose-derived Cyclopropane. Org. Biomol. Chem. 2011, 9 (4), 998.

(43) Kim, C.; Hoang, R.; Theodorakis, E. A. Synthetic Studies on Norrisolide: Enantioselective Synthesis of the Norrisane Side Chain. Org. Lett. 1999, 1 (8), 1295.

(44) Mạkosza, M.; Wawrzyniewicz, M. Reactions of Organic Anions. XXIV. Catalytic Method for Preparation of Dichlorocyclopropane Derivatives in Aqueous Medium. Tetrahedron Lett. 1969, 10 (53), 4659.

(45) Schoenberg, A.; Heck, R. Palladium-Catalyzed Formylation of Aryl, Heterocyclic, and Vinylic Halides. J. Am. Chem. Soc. 1974, 96 (25), 7761.

(46) Schoenberg, A.; Heck, R. Palladium-Catalyzed Amidation of Aryl, Heterocyclic, and Vinylic Halides. J. Org. Chem. 1974, 39 (23), 3327.

(47) Brennführer, A.; Neumann, H.; Beller, M. Palladium-Catalyzed Carbonylation Reactions of Aryl Halides and Related Compounds. Angew. Chem. Int. Ed. 2009, 48 (23), 4114.

(48) Barnard, C. F. J. Palladium-Catalyzed Carbonylation-A Reaction Come of Age. Organometallics 2008, 27 (21), 5402.

(49) Barnard, C. F. J. Carbonylation of Aryl Halides: Extending the Scope of the Reaction. Org. Proc. Res. Dev. 2008, 12 (4), 566.

(50) Garst, J. F. Electron Transfer, Naphthalene Radical Anion, and Alkyl Halides. Acc. Chem. Res. 1971, 4 (12), 400.

(51) Hewitt, R. J. Investigations of Ring-Opening Reactions of Cyclopropanated Carbohydrates: Towards the Synthesis of the Natural Product (-)-TAN-2483B. Ph.D. Thesis, Victoria University of Wellington, Wellington, New Zealand, 2010.

(52) Kasradze, V.; Gilyazetdinova, I.; Kukovinets, O.; Salimova, E.; Naleukhin, I.; Zainullin, R.; Lobov, A.; Spirikhin, L.; Galin, F. Synthesis of Dicyclopropanes from 4,7,7-Trimethyl-3-oxabicyclo[4.1.0]hept-4-en-2-one. Russ. J. Org. Chem. 2007, 43 (6), 834.

(53) Riesterer, J. Synthesis of a New Long Chain Ester-Based Analogue of (-)-TAN-2483B. Master's Thesis, Victoria University of Wellington, Wellington, New Zealand, 2015.

(54) Rivera, J. L. P. Synthetic Development of TAN-2483B, a Fungal Metabolite with Anticancer and Anti-Osteoporosis Activity. Master's Thesis, Victoria University of Wellington, Wellington, New Zealand, 2015.

(55) Isobe, M.; Nishizawa, R.; Hosokawa, S.; Nishikawa, T. Stereocontrolled Synthesis and Reactivity of Sugar Acetylenes. Chem. Commun. 1998, (24), 2665.

(56) Caddick, S.; Delisser, V. M.; Doyle, V. E.; Khan, S.; Avent, A. G.; Vile, S. Studies Toward the Synthesis of Natural and Unnatural Dienediynes 1. Approaches to a Functionalised Bicyclic Ring System. Tetrahedron 1999, 55 (9), 2737. 
(57) Jung, M. E.; Hagenah, J. A. Synthetic Approach to Aklavinone using 2-oxo-2H-pyran5-carboxylate (coumalate) Intermediates. J. Org. Chem. 1987, 52 (10), 1889.

(58) Blakemore, P. R. The Modified Julia Olefination: Alkene Synthesis via the Condensation of Metallated Heteroarylalkylsulfones with Carbonyl Compounds. $J$. Chem. Soc., Perkin Trans. 1 2002, (23), 2563.

(59) Bartlett, M. (Triphenylphosphoranylidene) Ketene: The Bestmann Ylide. Synlett 2013, 24 (06), 773.

(60) Orme, C. "Synthetic Approaches Towards the Total Synthesis of (-)-TAN-2483B; a Lead as a Novel Kinase Inhibitor," Victoria University of Wellington, 2016.

(61) Whitesides, G. M.; San Filippo, J. Mechanism of Reduction of Alkylmercuric Halides by Metal Hydrides. J. Am. Chem. Soc. 1970, 92 (22), 6611.

(62) Anh, N. T.; Eisenstein, O.; Lefour, J.; Tran Huu Dau, M. Orbital Factors and Asymmetric Induction. J. Am. Chem. Soc. 1973, 95 (18), 6146.

(63) Dunitz, J.; Lehn, J.; Wipff, G. Stereochemistry of Reaction Paths at Carbonyl Centres. Tetrahedron 1974, 30 (12), 1563.

(64) Cohen, P. Protein Kinases - the Major Drug Targets of the Twenty-First Century? Nat. Rev. Drug Discov. 2002, 1 (4), 309.

(65) Manning, G.; Whyte, D. B.; Martinez, R.; Hunter, T.; Sudarsanam, S. The Protein Kinase Complement of the Human Genome. Science 2002, 298 (5600), 1912.

(66) Druker, B. J. Molecularly Targeted Therapy: Have the Floodgates Opened? The Oncologist 2004, 9 (4), 357.

(67) Martin, G. S. The Hunting of the Src. Nat, Rev. Mol. Cell Bio. 2001, 2 (6), 467.

(68) Xu, W.; Doshi, A.; Lei, M.; Eck, M. J.; Harrison, S. C. Crystal Structures of c-Src Reveal Features of its Autoinhibitory Mechanism. Mol. Cell 1999, 3 (5), 629.

(69) Wheeler, D. L.; Iida, M.; Dunn, E. F. The Role of Src in Solid Tumors. The Oncologist 2009, 14 (7), 667.

(70) Knight, Z. A.; Shokat, K. M. Features of Selective Kinase Inhibitors. Chem. Biol. 2005, $12(6), 621$.

(71) Brandvold, K. R.; Steffey, M. E.; Fox, C. C.; Soellner, M. B. Development of a Highly Selective c-Src Kinase Inhibitor. ACS Chem. Biol. 2012, 7 (8), 1393.

(72) Rho, J.; Takami, M.; Choi, Y. Osteoimmunology: Interactions of the Immune and Skeletal Systems. Mol. Cells 2004, 17 (1), 1.

(73) Mensah, K. A.; Schwarz, E. M.; Ritchlin, C. T. Altered Bone Remodeling in Psoriatic Arthritis. Curr. Rheumatol. Rep. 2008, 10 (4), 311.

(74) Potts, J. T. Parathyroid Hormone: Past and Present. J. Endocrinol. 2005, 187 (3), 311.

(75) Harvey, J. E.; Hewitt, R. J.; Somarathne, R. M. K. K. Furo[3,4-b]pyran Compounds and Pharmaceutical Uses. New Zealand Patent WO2015084181 A1, 2015.

(76) Birnie, G. D. The HL60 Cell Line: a Model System for Studying Human Myeloid Cell Differentiation. Br. J. Cancer. Suppl. 1988, 9, 41.

(77) Schwartzberg, P. L.; Finkelstein, L. D.; Readinger, J. A. TEC-family Kinases: Regulators of T-helper-cell Differentiation. Nat Rev Immunol 2005, 5 (4), 284.

(78) Hendriks, R. W.; Yuvaraj, S.; Kil, L. P. Targeting Bruton's Tyrosine Kinase in B Cell Malignancies. Nat Rev Cancer 2014, 14 (4), 219.

(79) Burger, J. A. Bruton's Tyrosine Kinase (BTK) Inhibitors in Clinical Trials. Curr. Hematol. Malig. R. 2014, 9 (1), 44.

(80) Qiu, L.; Wang, F.; Liu, S.; Chen, X.-L. Current Understanding of Tyrosine Kinase BMX in Inflammation and its Inhibitors. Burns \& Trauma 2014, 2 (3), 121.

(81) Nilsson, J.; Gidlöf, R.; Johansson, M.; Sterner, O. Lactam Analogues of Galiellalactone. Tetrahedron 2012, 68 (16), 3336. 
(82) Long, J.; Ding, Y.-H.; Wang, P.-P.; Zhang, Q.; Chen, Y. Total Syntheses and Structureactivity Relationship Study of Parthenolide Analogues. Tetrahedron Lett. 2016, 57 (8), 874.

(83) Borzilleri, R. M.; Zheng, X.; Schmidt, R. J.; Johnson, J. A.; Kim, S.-H.; DiMarco, J. D.; Fairchild, C. R.; Gougoutas, J. Z.; Lee, F. Y.; Long, B. H. A Novel Application of a Pd (0)-catalyzed Nucleophilic Substitution Reaction to the Regio-and Stereoselective Synthesis of Lactam Analogues of the Epothilone Natural Products. J. Am. Chem. Soc. 2000, 122 (37), 8890.

(84) Micovic, I. V.; Roglic, G. M.; Ivanovic, M. D.; Dosen-Micovic, L.; Kiricojevic, V. D.; Popovic, J. B. The Synthesis of Lactam Analogues of Fentanyl. J. Chem. Soc., Perkin Trans. 1 1996, (16), 2041.

(85) Hargittai, B.; Solé, N. A.; Groebe, D. R.; Abramson, S. N.; Barany, G. Chemical Syntheses and Biological Activities of Lactam Analogues of $\alpha$-Conotoxin SI. J. Med. Chem. 2000, 43 (25), 4787.

(86) Don-Doncow, N.; Escobar, Z.; Johansson, M.; Kjellström, S.; Garcia, V.; Munoz, E.; Sterner, O.; Bjartell, A.; Hellsten, R. Galiellalactone is a Direct Inhibitor of the Transcription Factor STAT3 in Prostate Cancer Cells. J. Biol. Chem. 2014, 289 (23), 15969.

(87) Kowalski, R. J.; Giannakakou, P.; Hamel, E. Activities of the Microtubule-stabilizing Agents Epothilones A and B with Purified Tubulin and in Cells Resistant to Paclitaxel (Taxol®). J. Biol. Chem. 1997, 272 (4), 2534.

(88) Bollag, D. M.; McQueney, P. A.; Zhu, J.; Hensens, O.; Koupal, L.; Liesch, J.; Goetz, M.; Lazarides, E.; Woods, C. M. Epothilones, a New Class of Microtubule-stabilizing Agents with a Taxol-like Mechanism of Action. Cancer Res. 1995, 55 (11), 2325.

(89) Tararov, V. I.; Boerner, A. Approaching Highly Enantioselective Reductive Amination. Synlett 2005, (2), 203.

(90) Storer, R. I.; Carrera, D. E.; Ni, Y.; MacMillan, D. W. C. Enantioselective Organocatalytic Reductive Amination. J. Am. Chem. Soc. 2006, 128 (1), 84.

(91) Nugent, T. C.; El-Shazly, M. Chiral Amine Synthesis - Recent Developments and Trends for Enamide Reduction, Reductive Amination, and Imine Reduction. Adv. Synth. Catal. 2010, 352 (5), 753.

(92) Dangerfield, E. M.; Plunkett, C. H.; Win-Mason, A. L.; Stocker, B. L.; Timmer, M. S. M. Protecting-Group-Free Synthesis of Amines: Synthesis of Primary Amines from Aldehydes via Reductive Amination. J. Org. Chem. 2010, 75 (16), 5470.

(93) Abdel-Magid, A. F.; Carson, K. G.; Harris, B. D.; Maryanoff, C. A.; Shah, R. D. Reductive Amination of Aldehydes and Ketones with Sodium Triacetoxyborohydride. Studies on Direct and Indirect Reductive Amination Procedures. J. Org. Chem. 1996, 61 (11), 3849.

(94) Borch, R. F.; Hassid, A. I. New Method for the Methylation of Amines. J. Org. Chem. 1972, 37 (10), 1673.

(95) Abdel-Magid, A. F.; Mehrman, S. J. A Review on the Use of Sodium Triacetoxyborohydride in the Reductive Amination of Ketones and Aldehydes. Org. Proc. Res. Dev. 2006, 10 (5), 971.

(96) Borch, R. F.; Bernstein, M. D.; Durst, H. D. Cyanohydridoborate Anion as a Selective Reducing Agent. J. Am. Chem. Soc. 1971, 93 (12), 2897.

(97) Gribble, G. W.; Nutaitis, C. F. Sodium Borohydride in Carboxylic Acid Media. A Review of the Synthetic Utility of Acyloxyborohydrides. Org. Prep. Proc. Int. 1985, 17 (4-5), 317. 
(98) Abdel-Magid, A. F.; Maryanoff, C. A.; Carson, K. G. Reductive Amination of Aldehydes and Ketones by Using Sodium Triacetoxyborohydride. Tetrahedron Lett. 1990, 31 (39), 5595.

(99) Evans, D.; Chapman, K.; Carreira, E. Directed Reduction of Beta-hydroxy Ketones Employing Tetramethylammonium Triacetoxyborohydride. J. Am. Chem. Soc. 1988, 110 (11), 3560.

(100) Pegorier, L.; Petit, Y.; Larcheveque, M. A Synthetic Route to Anti Aminoalkyl Epoxides by Stereocontrolled Reductive Amination of Ketoepoxides. J. Chem. Soc., Chem. Commun. 1994, (5), 633.

(101) Nugent, T. C.; Wakchaure, V. N.; Ghosh, A. K.; Mohanty, R. R. Evolution of Titanium(IV) Alkoxides and Raney Nickel for Asymmetric Reductive Amination of Prochiral Aliphatic Ketones. Org. Lett. 2005, 7 (22), 4967.

(102) Boggs, S. D.; Cobb, J. D.; Gudmundsson, K. S.; Jones, L. A.; Matsuoka, R. T.; Millar, A.; Patterson, D. E.; Samano, V.; Trone, M. D.; Xie, S.et al. Efficient Asymmetric Synthesis of N-[(1R)-6-Chloro-2,3,4,9-tetrahydro-1H-carbazol-1-yl]-2pyridinecarboxamide for Treatment of Human Papillomavirus Infections. Org. Proc. Res. Dev. 2007, 11 (3), 539.

(103) Whitaker, D. T.; Whitaker, K. S.; Johnson, C. R. In Encyclopedia of Reagents for Organic Synthesis; John Wiley \& Sons, Ltd, 2001.

(104) Zhao, Y.; Slepkov, A. D.; Akoto, C. O.; McDonald, R.; Hegmann, F. A.; Tykwinski, R. R. Synthesis, Structure, and Nonlinear Optical Properties of Cross-Conjugated Perphenylated iso-Polydiacetylenes. Chem. Eur. J. 2005, 11 (1), 321.

(105) Still, W. C.; Gennari, C. Direct Synthesis of Z-Unsaturated Esters. A Useful Modification of the Horner-Emmons Olefination. Tetrahedron Lett. 1983, 24 (41), 4405.

(106) Reetz, M. T.; Schmitz, A. Stereoselective Reductive Amination of Chiral N,NDibenzylamino Ketones. Tetrahedron Lett. 1999, 40 (14), 2741.

(107) Nyffeler, P. T.; Liang, C.-H.; Koeller, K. M.; Wong, C.-H. The Chemistry of Amine-Azide Interconversion: Catalytic Diazotransfer and Regioselective Azide Reduction. J. Am. Chem. Soc. 2002, 124 (36), 10773.

(108) Marcotullio, M. C.; Campagna, V.; Sternativo, S.; Costantino, F.; Curini, M. A New, Simple Synthesis of N-tosyl Pyrrolidines and Piperidines. Synthesis 2006, 2006 (16), 2760.

(109) Albrecht, S.; Defoin, A.; Tarnus, C. Simple Preparation of O-substituted Hydroxylamines from Alcohols. Synthesis 2006, 2006 (10), 1635.

(110) Ninkovic, S.; Braganza, J. F.; Collins, M. R.; Kath, J. C.; Li, H.; Richter, D. T. 6 Substituted 2-heterocyclylamino Pyrazine Compounds as Chk-1 Inhibitors. US Patent WO2010016005 A1, 2010.

(111) Mukhopadhyay, S.; Zerella, M.; Bell, A. T.; Vijay Srinivas, R.; Smith, G. S. Synthesis of Methanesulfonyl Chloride (MSC) from Methane and Sulfuryl Chloride. Chem. Commun. 2004, (4), 472.

(112) Gung, B. W.; Kumi, G. Total Synthesis of (S)-(-)-(E)-15,16-Dihydrominquartynoic Acid: A Highly Potent Anticancer Agent. J. Org. Chem. 2004, 69 (10), 3488.

(113) Nelson, T. D.; Crouch, R. D. Selective Deprotection of Silyl Ethers. Synthesis 1996, (9), 1031.

(114) Yamamoto, Y. Silver-Catalyzed Csp- H and Csp- Si Bond Transformations and Related Processes. Chem. Rev. 2008, 108 (8), 3199.

(115) Schmidt, H.; Arens, J. Cleavage of the Carbon-Silicon Bond in 1-Alkynylsilanes by Silver Nitrate: Protection of a Terminal Triple Bond in Hydrogenation Reactions with the Trimethylsilyl Group. Recl. Trav. Chim. Pays-Bas 1967, 86 (10), 1138. 
(116) Alzeer, J.; Vasella, A. Oligosaccharide Analogues of Polysaccharides. Part 2. Regioselective Deprotection of Monosaccharide-derived Monomers and Dimers. Helv. Chim. Acta 1995, 78 (1), 177.

(117) Matoušová, E.; Koukal, P.; Formánek, B.; Kotora, M. Enantioselective Synthesis of the Unsaturated Fragment of Callyspongiolide. Org. Lett. 2016, 18 (21), 5656.

(118) Nayal, O. S.; Bhatt, V.; Sharma, S.; Kumar, N. Chemoselective Reductive Amination of Carbonyl Compounds for the Synthesis of Tertiary Amines Using SnCl2. 2H2O/PMHS/MeOH. J. Org. Chem. 2015, 80 (11), 5912.

(119) Lavis, J. M.; Maleczka, R. E. In Encyclopedia of Reagents for Organic Synthesis; John Wiley \& Sons, Ltd, 2001.

(120) Kangasmetsä, J. J.; Johnson, T. Microwave-accelerated Methodology for the Direct Reductive Amination of Aldehydes. Org. Lett. 2005, 7 (25), 5653.

(121) Dong, L.; Aleem, S.; Fink, C. A. Microwave-accelerated Reductive Amination Between Ketones and Ammonium Acetate. Tetrahedron Lett. 2010, 51 (39), 5210.

(122) Pohlki, F.; Doye, S. The Catalytic Hydroamination of Alkynes. Chem. Soc. Rev. 2003, 32 (2), 104.

(123) Khedkar, V.; Tillack, A.; Beller, M. A Dramatic Effect of Aryloxo Ligands on the Titanium-catalyzed Hydroamination of Alkynes. Org. Lett. 2003, 5 (25), 4767.

(124) SC de Andrade, V.; CS de Mattos, M. New Reagents and Synthetic Approaches to the Appel Reaction. Curr. Org. Synth. 2015, 12 (3), 309.

(125) Gibson, M.; Bradshaw, R. The Gabriel Synthesis of Primary Amines. Angew. Chem. Int. Ed. 1968, 7 (12), 919. 